MAURICIO DE CASTRO NAVARRETE

MODELO DE PREVISÃO DE POSIÇÃO DE AERONAVES PARA USO EM SISTEMAS DE VIGILÂNCIA DO ESPAÇO AÉREO

SÃo PAULO

2006 


\title{
MODELO DE PREVISÃO DE POSIÇÃO DE AERONAVES PARA USO EM SISTEMAS DE VIGILÂNCIA DO ESPAÇO AÉREO
}

\author{
Dissertação apresentada à Escola Politécnica da \\ Universidade de São Paulo para a obtenção do título \\ de Mestre em Engenharia. \\ Área de Concentração: Sistemas Digitais \\ Orientador: Prof. Dr. Paulo Sérgio Cugnasca
}

SÃO PAULO 
Este exemplar foi revisado e alterado em relação à versão original, sob responsabilidade única do autor e com a anuência de seu orientador.

São Paulo, 23 de agosto de 2006.

Assinatura do autor

Assinatura do orientador

FICHA CATALOGRÁFICA

Navarrete, Mauricio de Castro

Modelo de previsão de posição de aeronaves para uso em sistemas de vigilância do espaço aéreo. / Mauricio de Castro Navarrete; orient. Prof. Dr. Paulo Sérgio Cugnasca -- São Paulo, 2006.

$135 \mathrm{p}$.

Dissertação (Mestrado) - Escola Politécnica da Universidade de São Paulo. Departamento de Engenharia de Computação e Sistemas Digitais.

1. Disponibilidade e segurança de sistemas computacionais 2. Transporte aéreo I. Universidade de São Paulo. Escola Politécnica. Departamento de Engenharia de Computação e Sistemas Digitais II. $t$ 


\section{DEDICATÓRIA}

Dedico este trabalho a meus pais, pela paciência que tiveram e pelo apoio nos momentos difíceis. À minha namorada, Sabrina, que soube entender a minha ausência em alguns momentos. 


\section{AGRADECIMENTOS}

Agradeço a Deus pela saúde e pela coragem, que nunca me faltaram para perseverar em busca da conclusão deste trabalho.

Ao Prof. Dr. Paulo Sérgio Cugnasca, pelo incentivo e auxílio prestado durante todo o período do Mestrado.

Um agradecimento especial ao Ítalo, que esteve sempre disponível para esclarecer as dúvidas aeronáuticas.

Ao Major Eno, pelo auxílio, idéias, sugestões, e também por ajudar a obter os dados necessários para a realização das simulações.

Agradeço à Elisa, da Atech, que me auxiliou a interpretar os dados recebidos, possibilitando utilizá-los nas simulações.

Agradeço ao meu amigo Antonio Carlos, que me ajudou a encontrar material sobre regressão linear e estatística.

Agradeço pelo apoio que os órgãos aeronáuticos têm proporcionado aos trabalhos de pesquisa dentro das Universidades, em particular pelo incentivo do CINDACTA I, comandado pelo Coronel Rivera.

A todos os colegas do GAS que, de algumas maneira, auxiliaram com a troca de conhecimentos. 


\section{RESUMO}

Esta pesquisa apresenta uma contribuição para a avaliação do problema de previsão de posição futura de aeronaves dentro da aviação brasileira. $\mathrm{O}$ uso dessas previsões é muito importante para os sistemas de vigilância do espaço aéreo, sobretudo para a detecção de conflitos entre aeronaves. O problema é estudado para vôos em rota, considerando previsões de posição para instantes de 1 a 20 minutos. Primeiramente, o problema é apresentado, de forma que fique claro o contexto de sua aplicação dentro dos sistemas automatizados para a gestão do tráfego aéreo. Em seguida, são mostrados os métodos matemáticos necessários para o estudo da previsão de posição futura de aeronaves em rota. O modelo proposto para se realizar a previsão utiliza a regressão linear das posições conhecidas da aeronave, extrapolando suas possíveis posições futuras. As condições de um vôo em rota permitem a utilização deste método. Os resultados obtidos são comparados com as informações de posições reais das aeronaves, permitindo avaliar a qualidade das posições estimadas. Por fim, são apresentadas formas de se aplicar o modelo proposto dentro de sistemas computacionais utilizados para a previsão de posição futura de aeronaves, permitindo que os sistemas de vigilância do espaço aéreo façam uso das previsões. 


\begin{abstract}
This research presents a contribution to the evaluation of the predicting aircraft future positions problem considering the Brazilian airspace. These predictions are very important for airspace surveillance systems, mainly to the detection of conflict among aircraft. The problem is studied for en route flights, considering position predictions from 1 to 20 minutes. Firstly, the problem is proposed, so that its application context to air traffic management automation can be clear. Then, the necessary mathematical methods used to study en route aircraft future position prediction are shown. The proposed model employed to find the predictions makes use of linear regression of known aircraft positions, extrapolating its future positions. En route flight conditions permit this approach. Prediction results are then compared with real aircraft positions, so that position estimates quality can be evaluated. Finally, ways of practical application of the proposed model inside computational systems used for aircraft future position prediction are presented. This allows surveillance airspace systems to make use of the predictions.
\end{abstract}




\section{SUMÁRIO}

1. INTRODUÇÃO .................................................................................................................14

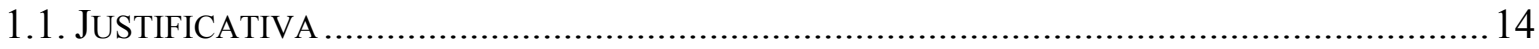

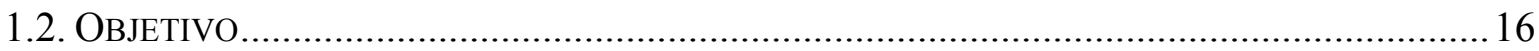

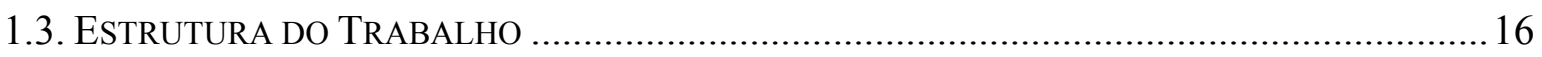

2. ASPECTOS GERAIS DO CNS/ATM E VIGILÂNCIA.................................................18

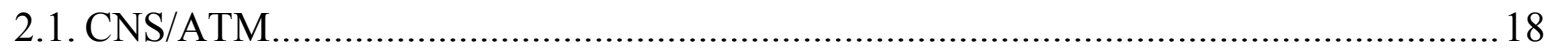

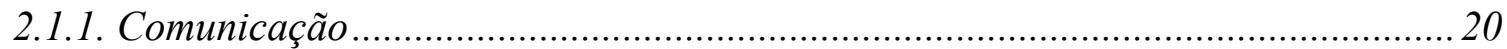

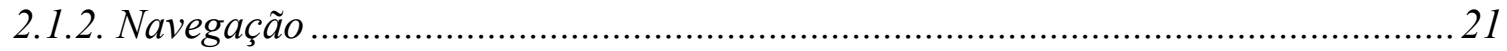

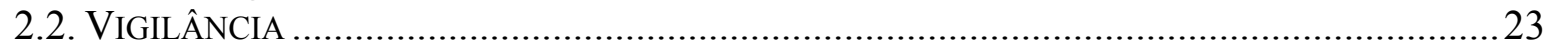

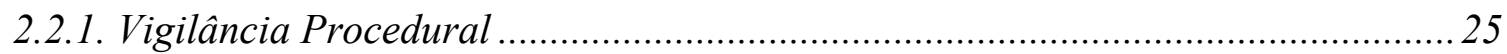

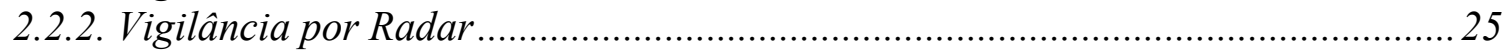

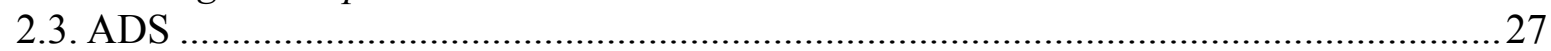

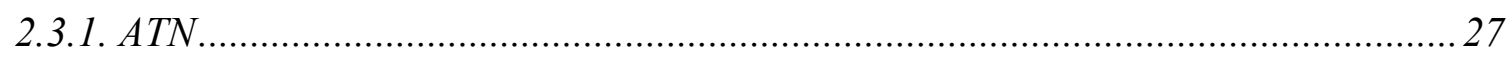

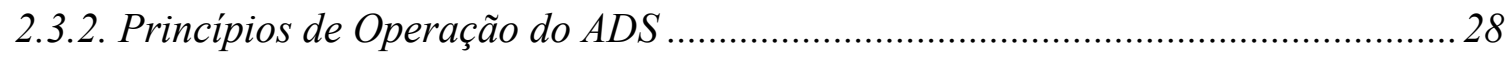

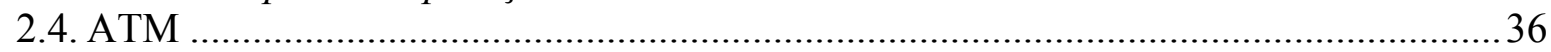

2.5. CONSIDERAÇÕES FINAIS DO CAPÍTULO..........................................................................

3. A PREVISÃO DA POSIÇÃO FUTURA DE AERONAVES DENTRO DOS SISTEMAS DE NAVEGAÇÃO ....................................................................................38

3.1. MotivaÇões Para o Estudo da Previsão de Posição Futura de Aeronaves .......38

3.2. Sistemas de APoio À DeCis̃̃o PARA DeteCÇão e ReSoluÇão de CoNFlitos .............40

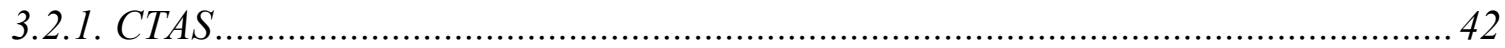

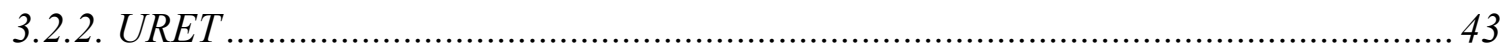

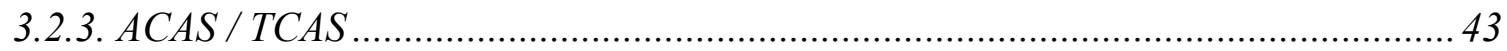

3.2.4. CE-6 - Negociação de Trajetória Em Rota ………………...................................43

3.3. Aspectos Conceituais da Previsão de Posição Futura de Aeronaves ................. 43

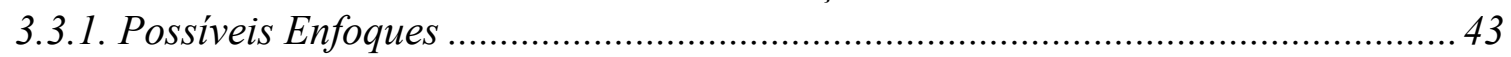

3.4. ReQuisitos da PREVISÃo de TRAJETÓRIA ................................................................. 45

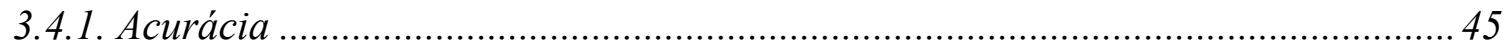

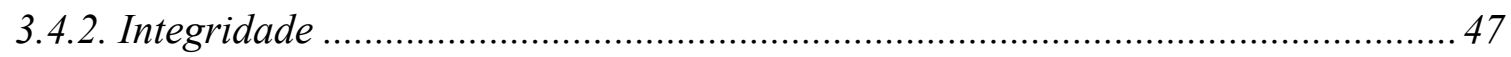

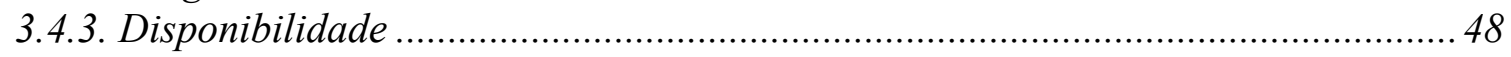

3.5. FONTES DE DADOS E FATORES DE INCERTEZA …………...............................................4 48

3.5.1. Roteamento e Intenção de Trajetória (Trajectory Routing and Intent)...................51

3.5.2. Incertezas do Vetor do Vento e da Velocidade da Aeronave em Relação ao Ar....51

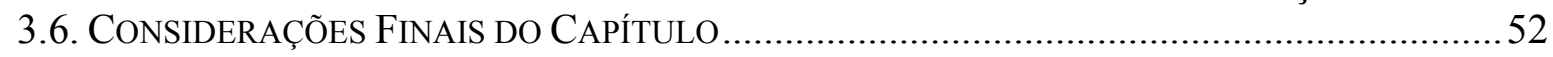

4. MÉTODOS ESTATÍSTICOS E REGRESSÃO LINEAR ..............................................54

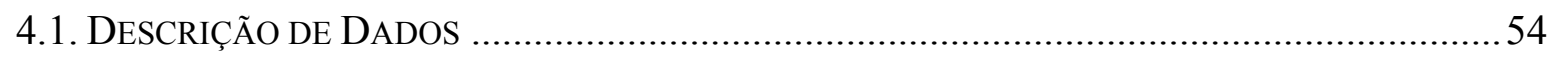

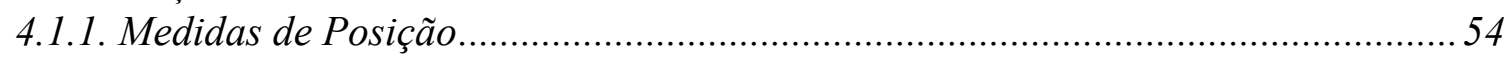

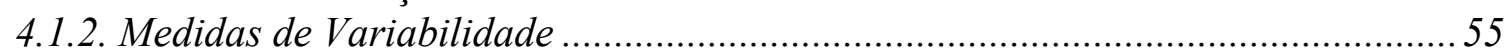

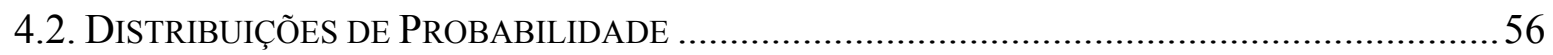

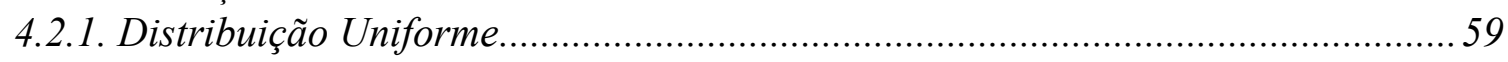

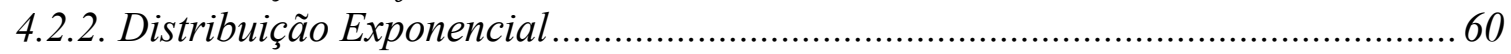

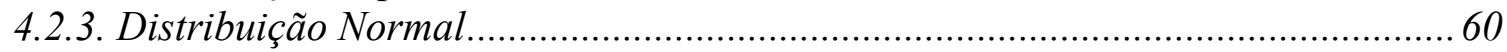

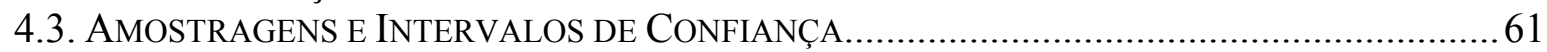




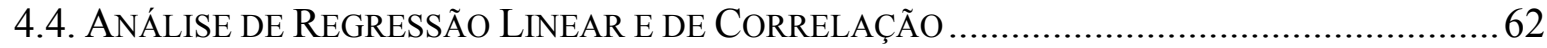

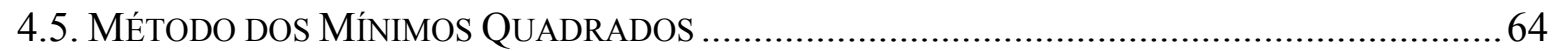

4.5.1. Método dos Mínimos Quadrados para Retas em Duas Dimensões ........................67 67

4.5.2. Método dos Mínimos Quadrados para Retas em Três Dimensões...........................69 69

4.5.3. Noções sobre Erros de Estimação ........................................................................... 70

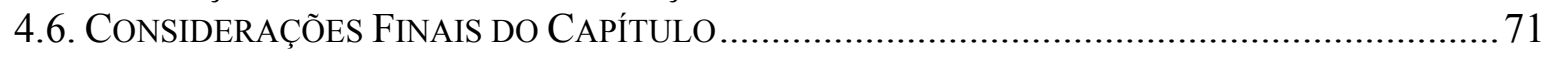

5. MODELO PARA PREVISÃO DE POSIÇÃO FUTURA DE AERONAVES ............... 72

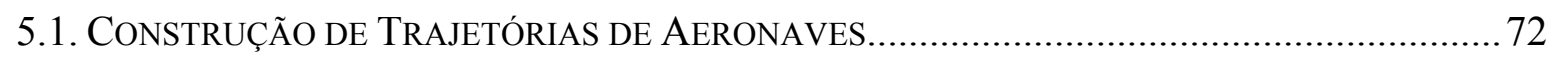

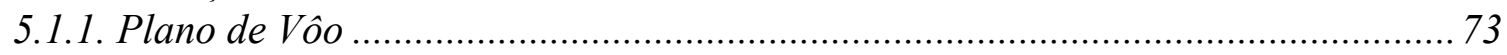

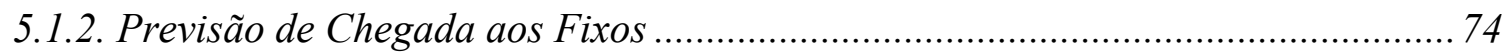

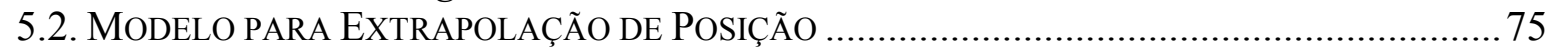

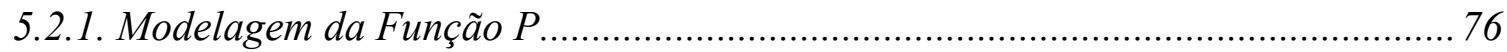

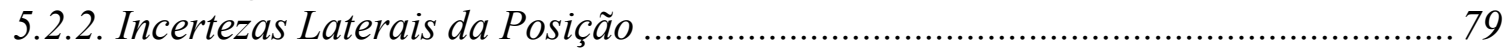

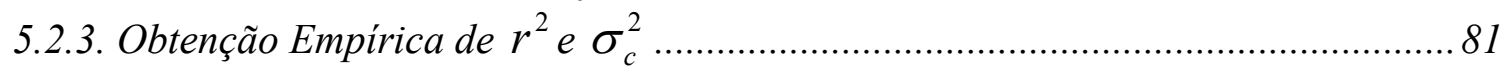

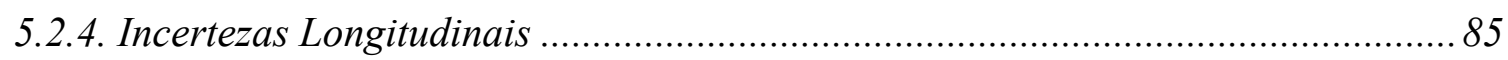

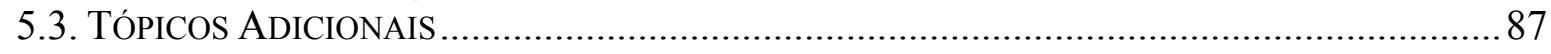

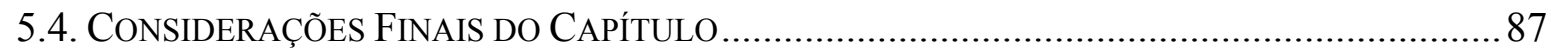

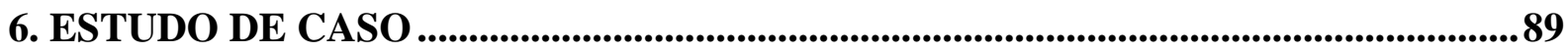

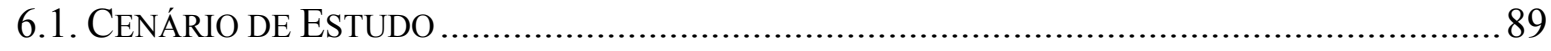

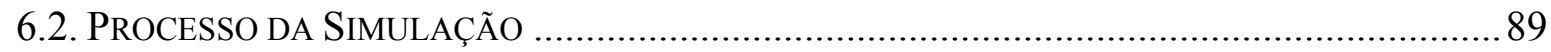

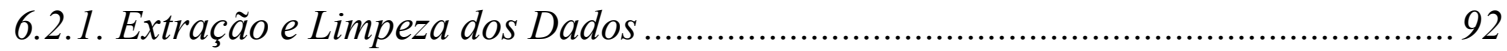

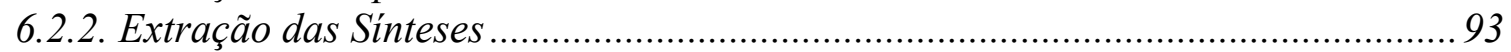

6.2.3. Extração de Erros na Contagem do Tempo ........................................................... 94

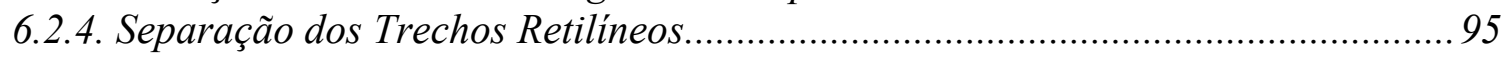

6.2.5. Análise Estatística dos Erros................................................................................... 95

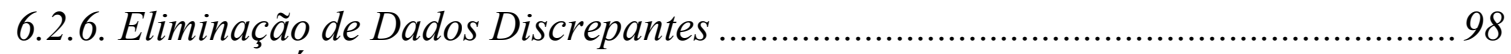

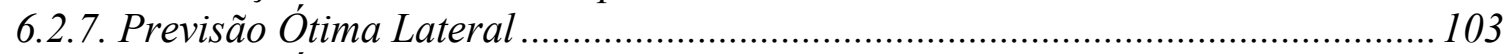

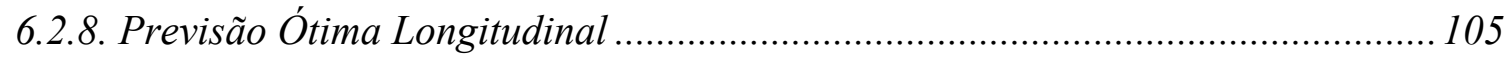

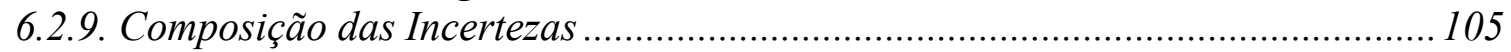

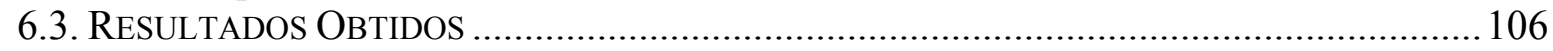

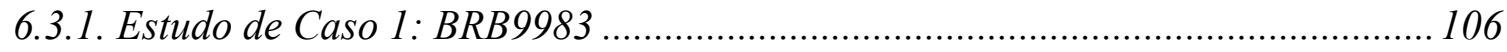

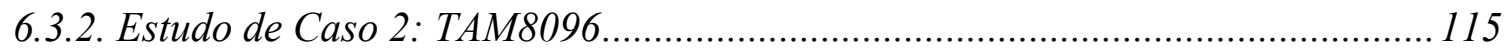

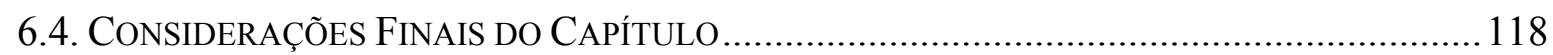

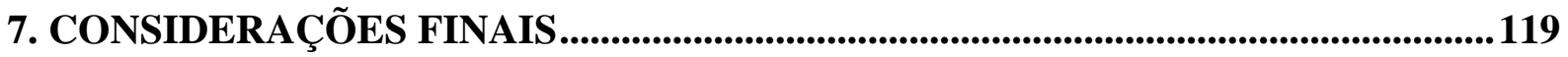

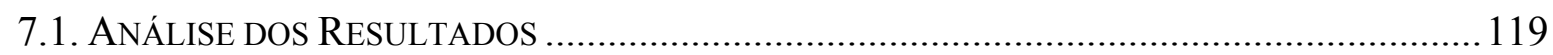

7.2. APLICAÇÕES PRÁTICAS RELACIONADAS À PESQUISA ................................................. 120

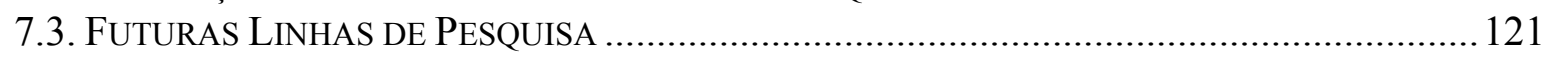

7.3.1. Análise da Magnitude do Erro Associado a uma Previsão................................... 122

7.3.2. Sistema Inteligente para Melhorar os Niveis de Acerto....................................... 122

7.3.3. Análises Utilizando Amostras Maiores ................................................................ 123

7.3.4. Consideração das Incertezas Associadas às Medidas dos Radares ou Satélites. 123

7.3.5. Detecção Automática de Problemas de Integridade ......................................... 123

7.3.6. Inclusão de Outras Variáveis de Incerteza ....................................................... 124

7.3.7. Análise do Impacto da Utilização de Previsão de Posições Futuras de Aeronaves no Risco Geral do Controle do Tráfego Aéreo ............................................................... 124

7.3.8. Previsões de Posição Considerando Variação de Altitude .................................... 125

7.3.9. Outras Possibilidade de Simulações ..................................................................... 125 
7.4. CONCLUSÕES

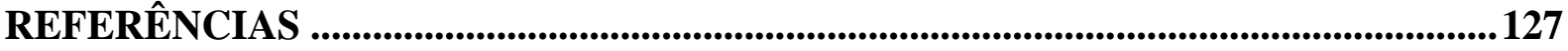




\section{LISTA DE FIGURAS}

Figura 1: Crescimento anual projetado para o tráfego aéreo (GALOTTI, 1998)....................18

Figura 2: Visão geral do CNS/ATM (OLIVEIRA, 2003) .......................................................20

Figura 3: Ambiente de comunicação da rede ATN (ICAO, 1999) ..........................................28

Figura 4: Ilustração do funcionamento e fronteiras do ADS (EUROCONTROL, 2002). .......29

Figura 5: Fases de operação no espaço aéreo (OGATA, 2003) ................................................34

Figura 6: Ilustração do funcionamento do ADS-B (EUROCONTROL, 2001). .......................35

Figura 7: Processo de detecção e resolução de conflitos (KUCHAR; YANG, 2000). ............41

Figura 8: Enfoques para a propagação de erro (KUCHAR; YANG, 2000)..............................44

Figura 9: Propagação da incerteza ao longo do tempo.......................................................... 46

Figura 10: Cálculo da velocidade vetorial da aeronave em relação ao solo $\left(\mathrm{V}_{\mathrm{g}}\right)$....................52

Figura 11: Ilustração da definição de uma variável aleatória discreta. ....................................57

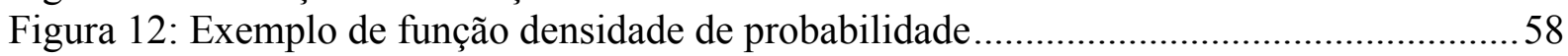

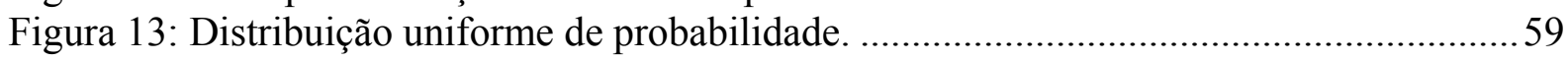

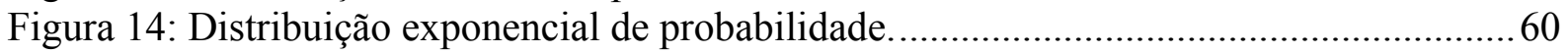

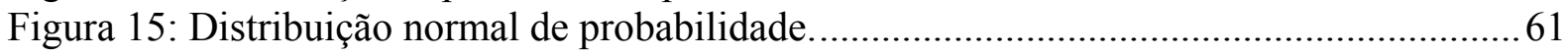

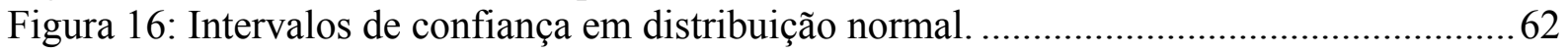

Figura 17: Pontos da amostra dos carregamentos de caminhão. ..........................................63

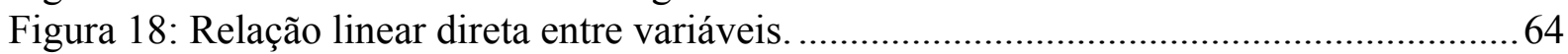

Figura 19: Função exponencial de relação curvilínea entre variáveis.....................................65

Figura 20: Exemplo de aproximação não adequada por curva de soma de erro mínima.........66

Figura 21: Processo de construção de trajetórias de aeronaves............................................... 73

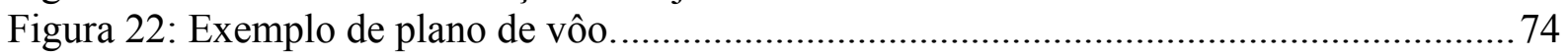

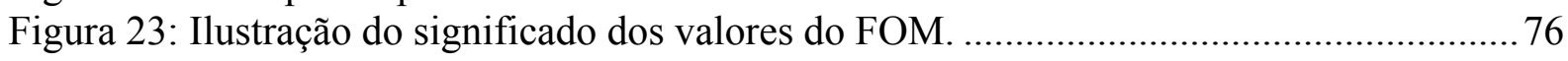

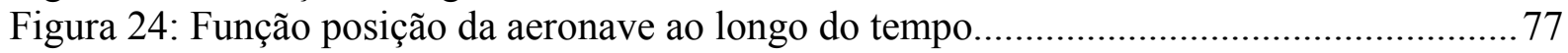

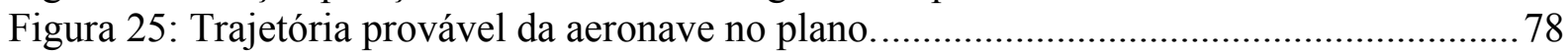

Figura 26: Incerteza da posição da aeronave para um determinado instante $t_{i}$......................79

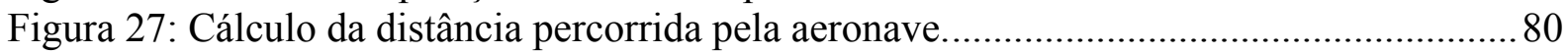

Figura 28: Comportamento da incerteza lateral de posição da aeronave. ................................ 81

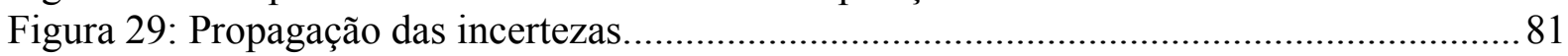

Figura 30: Cálculo do erro lateral para a previsão da posição futura de uma aeronave........... 83

Figura 31: Previsões de posição futura para um trecho de vôo.............................................. 84

Figura 32: Crescimento da variância do erro lateral de forma quadrática............................... 84

Figura 33: Cálculo do erro longitudinal para a previsão da posição futura de uma aeronave.. 86

Figura 34: Crescimento da variância do erro longitudinal de forma quadrática. ..................... 87

Figura 35: Etapas do processo de simulação para determinação de posição futura de uma

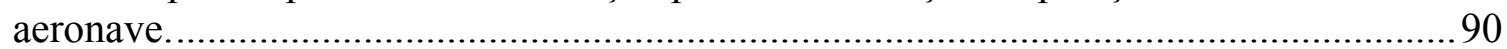

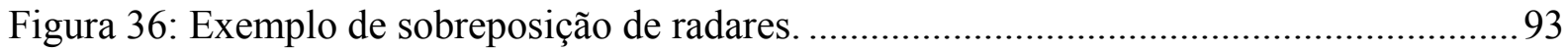

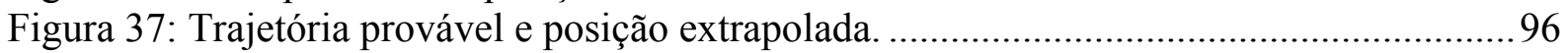

Figura 38: Previsões de posição baseadas em um trecho retilíneo de vôo................................98

Figura 39: Ilustração dos dados considerados na análise. ....................................................99

Figura 40: Ilustração da composição das incertezas para a determinação da posição futura de

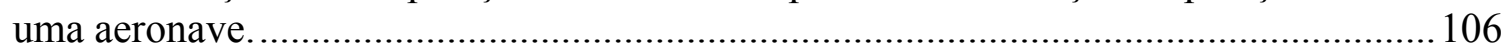

Figura 41: Taxa de acerto para as previsões laterais, considerando incertezas constantes. ... 108

Figura 42: Taxa de acerto para as previsões longitudinais, considerando incertezas constantes.

Figura 43: Taxa de acerto geral para as previsões, considerando incertezas constantes........ 110

Figura 44: Taxa de acerto para as previsões laterais, considerando as incertezas crescentes.111 
Figura 45: Taxa de acerto para as previsões longitudinais, considerando as incertezas crescentes

Figura 46: Taxa de acerto geral para as previsões, considerando as incertezas crescentes.... 114 Figura 47: Trechos retilínios para a análise das previsões do vôo TAM8096...................... 115 Figura 48: Taxas de acerto para as previsões do vôo TAM8096, considerando incertezas constantes.

Figura 49: Taxas de acerto para as previsões do vôo TAM8096, considerando incertezas crescentes 


\section{LISTA DE TABELAS}

Tabela 1: Fontes de dados para melhoria nas previsões de posição futura (WARREN,2000) 50

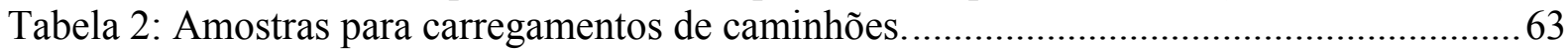

Tabela 3: Valores de FOM (Figure of Merit) (KODO; NAGAOKA; AMAI, 2002). .............76

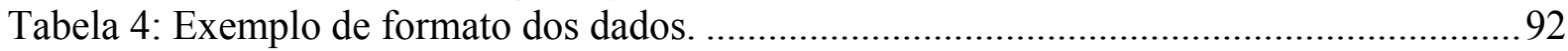

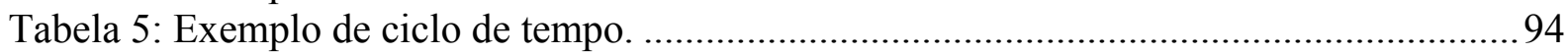

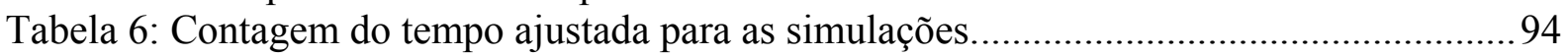

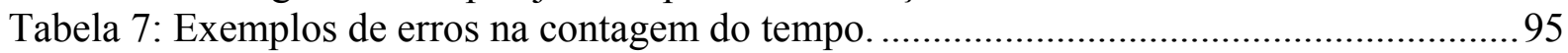

Tabela 8: Quantidades de posições conhecidas consideradas nas simulações.........................96

Tabela 9: Média e variância do erro lateral e distância média percorrida............................... 100

Tabela 10: Média e variância do erro lateral e distância média percorrida, após eliminação dos dados discrepantes, considerando 30 pontos passados (5 minutos)............................. 101

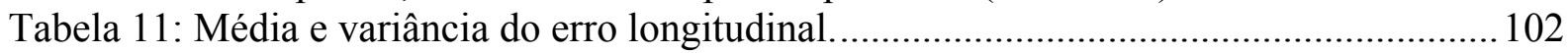

Tabela 12: Média e variância do erro longitudinal, após eliminação dos dados discrepantes, considerando 18 posições passadas (3 minutos)........................................................... 103

Tabela 13: Taxa de acerto para as previsões laterais, considerando incertezas constantes.... 107

Tabela 14: Taxa de acerto para as previsões longitudinais, considerando incertezas constantes.

Tabela 15: Taxa de acerto geral para as previsões, considerando incertezas constantes. ...... 110

Tabela 16: Taxa de acerto para as previsões laterais, considerando as incertezas crescentes 111

Tabela 17: Taxa de acerto para as previsões longitudinais, considerando as incertezas

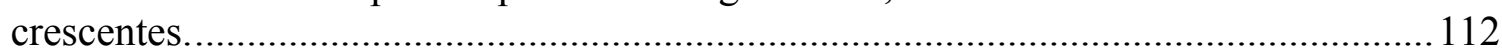

Tabela 18: Taxa de acerto geral para as previsões, considerando as incertezas crescentes. .. 114

Tabela 19: Taxas de acerto para as previsões do vôo TAM8096, considerando incertezas

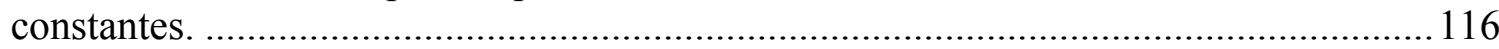

Tabela 20: Taxas de acerto para as previsões do vôo TAM8096, considerando incertezas

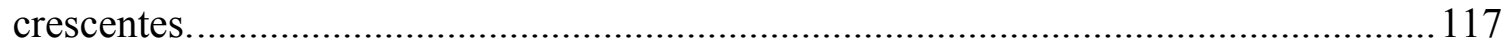

Tabela 21: Resultados sintetizados das previsões de posições............................................. 119 


\section{LISTA DE ABREVIATURAS}

AAF

AATT

ABAS

ACC

ACAS

ADS

ADS-B

ADS-C

ASAS

ASM

APP

ATC

ATFM

ATM

ATN

ATS

BADA

CAS

CD\&R

$\mathrm{CE}$

CNS

CTAS

ECAC

EDA

EUR

EUROCONTROL

FAA

FANS

FIR

FMS

FOM

FTE

GAF

GBAS
ADS na aeronave

Advanced Air Traffic Technologies

Aircraft Based Augmentation System

Area Control Center

Air Collision Avoidance System

Automatic Dependent Surveillance

ADS-Broadcast

ADS-Contract

Airborne Separation Assistance System

Airspace Management

Approach Control

Air Traffic Control

Air Traffic Flow Management

Air Traffic Management

Aeronautical Telecommunications Network

Air Traffic Services

Base of Aircraft Data

Calibrated Airspeed

Conflict Detection and Resolution

Concept Elements

Communications, Navigation, Surveillance

Center TRACON Automation System

European Civil Aviation Conference

En-route Descent Advisor

European Organization for the Safety of Air Navigation

Federal Aviation Administration

Future Air Navigation System

Flight Information Region

Flight Management Systems

Figure of Merit

Flight Technical Error

ADS no solo

Ground-Based Augmentation Systems 


\begin{tabular}{|c|c|}
\hline GLONASS & Global Orbiting Navigation Satellite System \\
\hline GNSS & Global Navigation Satellite Systems \\
\hline GPS & Global Positioning System \\
\hline GVAT & ADS em veículo de solo \\
\hline ICAO & International Civil Aviation Organization \\
\hline INMARSAT & International Maritime Satellite Organization \\
\hline ISO & International Standards Organization \\
\hline NASA & National Aeronautics and Space Administration \\
\hline ND & Navigation Display \\
\hline NM & Nautical Mile ou Milha Náutica, corresponde a 1.852 metros \\
\hline OSI & Open System Interconnect \\
\hline PSR & Primary Surveillance Radar \\
\hline RNAV & aRea NAVigation \\
\hline RNP & Required Navigation Performance \\
\hline RSP & Required Surveillance Performance \\
\hline RVSM & Reduced Vertical Separation Minimum \\
\hline SATCOM & Satellite Communications \\
\hline SDPD & Surveillance Data Processing and Distribution \\
\hline SSR & Secondary Surveillance Radar \\
\hline SWAP & Severe Weather Avoidance Plan \\
\hline TCAS & Traffic Collision Avoidance System \\
\hline TRACON & Terminal Radar Approach Control \\
\hline URET & User Request Evaluation Tool \\
\hline VNAV & Vertical Navigation \\
\hline VDL & VHF Data Link \\
\hline VHF & Very High Frequency \\
\hline VOR & VHF Omnidirectional Radio Range \\
\hline
\end{tabular}




\section{INTRODUÇÃO}

O transporte aéreo constitui-se em um dos meios de locomoção mais importantes no mundo moderno. Cada vez mais as pessoas buscam esse tipo de transporte, inclusive aquelas de menor poder aquisitivo, impulsionadas pelas companhias que operam no conceito de baixas tarifas. Há uma expectativa de um considerável crescimento no tráfego aéreo para os próximos anos (GALOTTI, 1998).

Essa maior busca das pessoas por viagens aéreas leva a um crescimento do tráfego mundial de aeronaves. Se esse crescimento ocorrer de forma desordenada, as conseqüências podem ser desastrosas, já que o aumento do tráfego aéreo poderá resultar em um maior número de acidentes, caso políticas de segurança não sejam adotadas. Por esse motivo, a International Civil Aviation Organization (ICAO) criou um projeto intitulado Future Air Navigation System (FANS). Posteriormente, o conceito envolvido neste projeto passou a ser chamado de Communications, Navigation, Surveillance / Air Traffic Management (CNS/ATM). O objetivo do CNS/ATM é permitir a expansão do tráfego aéreo por meio do uso de novas tecnologias, tais como as utilizadas em satélites.

O projeto completo é longo, sendo dividido e implantado em várias etapas. De forma geral, espera-se poder reduzir a separação mínima entre as aeronaves, possibilitando aumentar a capacidade do sistema. Haverá também uma maior flexibilização no uso do espaço aéreo, com a existência de um maior dinamismo no planejamento dos vôos. O mais importante é que os níveis de segurança também deverão aumentar, já que a quantidade absoluta de acidentes não pode subir, pois a sociedade espera encontrar na aviação um meio eficiente e altamente seguro de transporte.

\subsection{Justificativa}

O conhecimento da utilização do espaço aéreo é fundamental para que objetivos dos sistemas futuros de navegação aérea sejam atingidos, tais como maior segurança, redução da separação das aeronaves e flexibilidade no uso do espaço aéreo, pois uma quantidade maior de aeronaves poderá voar simultaneamente em uma mesma região. 
Portanto, os sistemas de gestão do tráfego aéreo, sobretudo os sistemas envolvidos direta ou indiretamente na detecção e resolução de conflitos, deverão ser remodelados. Muitos dos procedimentos executados pelo ser humano, considerando tanto pilotos como controladores de tráfego aéreo, exigirão automação. A capacidade humana para resolver conflitos ou problemas não será suficiente para analisar todas as situações de perigo que possam surgir, dificultando a tomada da decisão adequada em tempo hábil. A necessidade de automação torna-se fundamental, sobretudo em situações críticas, tais como nas situações de pousos e decolagens, em que decisões rápidas e precisas devem ser tomadas e, dificilmente, há tempo suficiente para se corrigir um erro.

Para realizar esse processo de automação será essencial que se possa conhecer, em tempo real, a utilização do espaço aéreo. Por outro lado, não bastará ter esse conhecimento apenas para um momento presente, sendo também necessário conhecer a previsão de utilização do espaço aéreo em momentos futuros. Isso possibilitará a utilização de sistemas de apoio à decisão que saibam avaliar situações de congestionamento e identificar possíveis soluções para as condições adversas encontradas.

Conhecer a utilização do espaço aéreo presente e futuro requer avanços nos sistemas de controle, envolvendo comunicação, navegação e vigilância. Uma necessidade que surge é conseguir obter a previsão de trajetórias que serão seguidas pelas aeronaves. De modo particular, torna-se necessário conhecer também as previsões de posições futuras de curto (até 5 minutos) e médio (de 5 a 20 minutos) prazos para uma determinada aeronave. Essas informações podem ser utilizadas em diversos sistemas de apoio a decisão, como por exemplo, sistemas de detecção e resolução de conflitos e sistemas de gerenciamento de carga do espaço aéreo.

Estudos mostram que as incertezas associadas às previsões de posição são maiores que o desejado, o que exigiria novas pesquisas nesta área. Um desses estudos foi realizado na região do Pacífico Norte (KODO; NAGAOKA; AMAI, 2002). Nessa região, um sistema ADS foi implantado de maneira experimental. Então, realizou-se uma análise para investigar o comportamento das previsões de posição futura das aeronaves. Como conclusão, ficou clara a necessidade de realizar novas análises para se investigar os mecanismos de previsão de posição, além de se entender os motivos que levaram a alguns grandes erros de previsão.

Em virtude da grande importância que a previsão de posição tem no contexto da vigilância do espaço aéreo, ela torna-se também um fator de motivação para se estudar o problema. Além disso, faltam trabalhos nesta linha dentro do contexto da aviação brasileira. A realização de um trabalho neste sentido contribui para a melhoria da utilização do espaço 
aéreo brasileiro, antecipando a solução de problemas que podem ocorrer se houver um crescimento acelerado do tráfego aéreo nacional.

\subsection{Objetivo}

Este trabalho tem como objetivo investigar o problema de previsão de trajetórias e o problema de previsão da posição futura de uma aeronave no médio prazo, inserindo-o no contexto dos sistemas de controle de tráfego aéreo. Os sistemas de vigilância devem acompanhar toda a movimentação de uma aeronave ao longo do seu vôo, mantendo um controle da rota seguida, o que corresponde a se saber as posições passadas da aeronave, sua posição presente e, também, as previsões para suas posições futuras em função do tempo. Com esse acompanhamento é possível ter um melhor controle da utilização do espaço aéreo, otimizando sua ocupação e buscando-se manter ou melhorar seus níveis de segurança.

Informações reais referentes às movimentações das aeronaves são avaliadas, dentro do cenário brasileiro. Com base nisso, propõe-se nesse trabalho de pesquisa um modelo que utiliza regressão linear para extrapolar as posições futuras de uma aeronave. $\mathrm{O}$ algoritmo utilizado pelo modelo pode ser ajustado, de acordo com características do vôo sendo analisado, a fim de tornar-se funcional. As variáveis, fatores e requisitos ligados às previsões de posição são apresentados e estudados, mostrando como eles influenciam nos resultados obtidos. Dentre os fatores que causam maior influência no resultado da previsão de uma posição, destacam-se: as incertezas meteorológicas, como a previsão do comportamento dos ventos; as incertezas associadas ao desempenho da aeronave (empuxo, arrasto, massa, velocidade permitida, coeficientes aerodinâmicos, etc); variações de velocidade e direção em relação ao plano de vôo original.

\subsection{Estrutura do Trabalho}

No capítulo 2 apresentam-se os principais conceitos relacionados ao CNS/ATM. Uma maior ênfase é atribuída aos aspectos de vigilância, que constituem o elemento do CNS/ATM mais diretamente ligado a essa pesquisa.

O capítulo 3 mostra como o problema da previsão da posição das aeronaves se insere dentro das exigências dos sistemas futuros. Descrevem-se os principais sistemas de apoio à decisão existentes, destacando a importância de se prever as posições futuras das aeronaves. Também são mostrados os detalhes sobre os requisitos exigidos para as previsões de posição futura. Estes requisitos tornam-se referências para a avaliação da qualidade dos sistemas, no que diz respeito à segurança. Dentro do contexto deste estudo, toda vez que houver referência 
ao termo segurança, será assumido o significado do termo safety ${ }^{l}$. Há também uma descrição das fontes de dados e principais fatores de incerteza relacionados ao problema de determinação da previsão de posição de uma aeronave.

No capítulo 4, são destacados os métodos matemáticos utilizados na modelagem do algoritmo que será proposto no capítulo 5. De forma geral, o ponto mais importante do capítulo é a descrição de algumas propriedades estatísticas essenciais para o modelo proposto. Há também uma breve explicação de algumas distribuições estatísticas, de forma que seja possível entender as escolhas feitas para modelar a solução proposta. Finalmente, algumas propriedades do tratamento de erros e incertezas são apresentadas.

O capítulo 5 apresenta um modelo geral para a previsão da posição futura de uma aeronave e descreve o processo de construção de trajetórias. Posteriormente, o escopo do problema tratado neste trabalho é formalmente delimitado, sendo apresentado, com maiores detalhes, o algoritmo de previsão das posições de uma aeronave.

O capítulo 6 apresenta o estudo de caso elaborado, destacando os resultados obtidos. Finalmente, no capítulo 7, são expostas as conclusões, considerações finais e propostas para continuidade deste trabalho de pesquisa.

\footnotetext{
${ }^{1} \mathrm{O}$ termo safety, expresso por $S(t)$, é uma função do tempo definida como a probabilidade condicional de que o sistema executará corretamente suas funções no intervalo de tempo $\left[t_{0}, t\right]$, dado que o sistema estava funcionando corretamente em $t_{0}$, ou descontinuará suas funções de maneira a não interromper a operação de outros sistemas, sem comprometer a segurança das pessoas nem do meio ambiente a ele relacionados (JOHNSON, 1989).

O termo security é a habilidade de um sistema resistir a atentados que possam influenciar sua operação e, em geral, está associado à segurança de sistemas de informação (TRIBBLE, 2002).
} 


\section{ASPECTOS GERAIS DO CNS/ATM E VIGILÂNCIA}

Neste capítulo destaca-se a situação atual do projeto do CNS/ATM. Os principais conceitos relacionados ao projeto são descritos, já que a pesquisa realizada neste trabalho está inserida no contexto do CNS/ATM. A maior ênfase é atribuída aos aspectos da vigilância, seus diversos tipos, as vantagens e desvantagens de cada tipo, de forma que o problema da previsão da posição futura possa ser inserido e visualizado no contexto da vigilância.

\subsection{CNS/ATM}

Em 1991, teve início uma série de discussões sobre alguns problemas enfrentados pela aviação mundial, com uma reunião organizada pela International Civil Aviation Organization (ICAO), onde estavam presentes comissões de vários países, para discutirem os aspectos futuros da aviação. Um grande crescimento estava sendo previsto no tráfego aéreo mundial, exigindo avanços nos sistemas existentes, de forma a atender essa demanda em expansão.

A Figura 1 ilustra a taxa de crescimento anual esperada para o tráfego aéreo mundial na época. Além disso, aspectos de confiabilidade e segurança ${ }^{2}$ dos sistemas de controle de tráfego aéreo também foram considerados, tendo em vista que constituem requisitos fundamentais para um sistema que apresenta uma grande criticidade. A partir dessas constatações, nasceu o conceito de Future Air Navigation System (FANS) ou Sistemas Futuros de Navegação Aérea (GALOTTI, 1998).

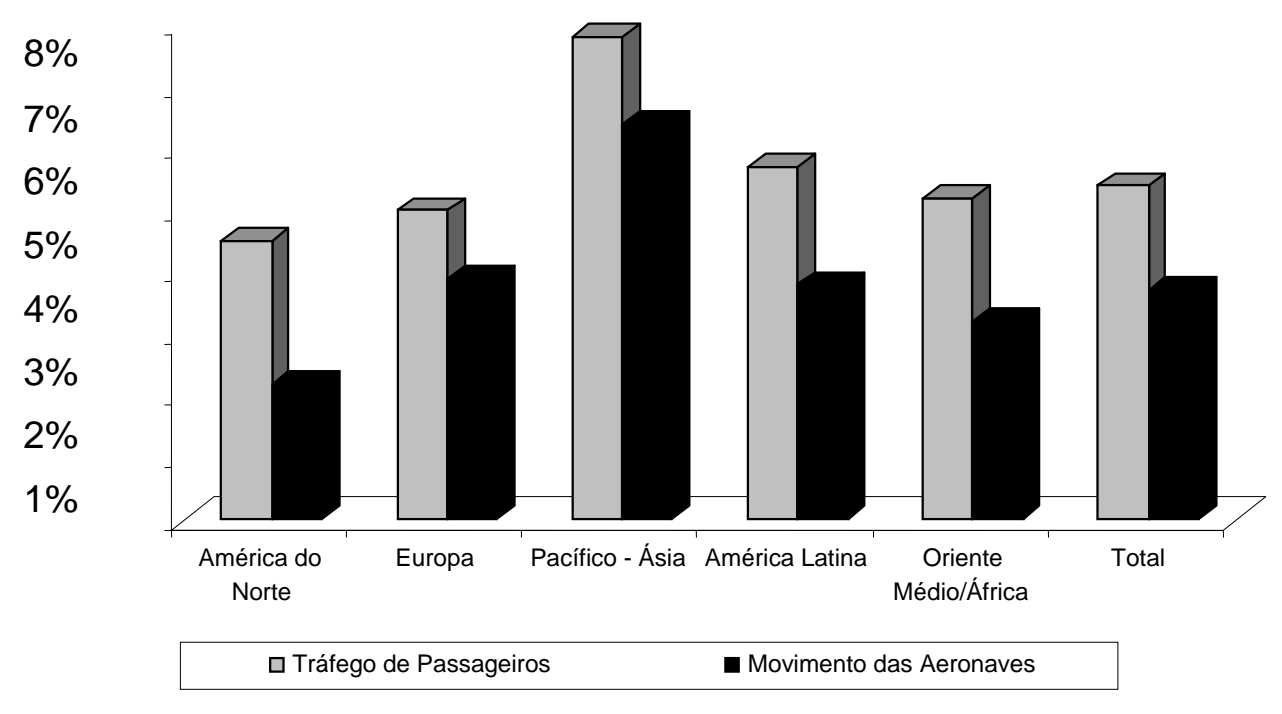

Figura 1: Crescimento anual projetado para o tráfego aéreo (GALOTTI, 1998).

\footnotetext{
${ }^{2}$ A confiabilidade de um sistema, expressa por $R(t)$, é uma função do tempo definida como a probabilidade condicional de que o sistema executará corretamente suas funções no intervalo de tempo $\left[\mathrm{t}_{0}, \mathrm{t}\right]$, dado que o sistema estava funcionando corretamente no instante inicial $t_{0}$ (JOHNSON, 1989).
} 
Esse sistema futuro apresentava a necessidade de avanços nas áreas de Comunicação, Navegação e Vigilância (CNS - Communication, Navigation, Surveillance) como um meio de atingir os requisitos desejados para a Gestão do Tráfego Aéreo (ATM - Air Traffic Management). Dessa maneira, o FANS passou a ser designado por CNS/ATM (GALOTTI, 1998).

Os avanços do CNS estão muito relacionados à utilização de satélites, que se mostrou uma saída viável para solucionar os problemas apontados pela comunidade internacional de aviação civil. Dentre esses problemas, destaca-se a limitação para o crescimento seguro do tráfego aéreo. A utilização de satélites permite que mais informações possam ser utilizadas, levando a um maior nível de automação, o que é essencial para que os objetivos do CNS/ATM, tais como permitir um crescimento seguro do tráfego aéreo, possam ser atingidos. Além dos aspectos de segurança, questões econômicas também estão envolvidas no projeto. Idealmente, uma aeronave deve voar do seu ponto de partida ao seu destino da maneira mais eficiente possível em termos de tempo e gasto de combustível. Ao mesmo tempo, a demanda para que diversas aeronaves possam compartilhar os mesmos recursos exige um trabalho de gestão do tráfego aéreo. Todas essas questões devem ser consideradas na implantação do CNS/ATM.

Aliado aos conceitos do CNS/ATM, os novos sistemas de Gestão de Tráfego Aéreo propõem um conceito conhecido por Free Flight, cujo objetivo é prover maneiras pelas quais a eficiência no fluxo do tráfego aéreo aumente. De acordo com os conceitos de Free Flight (KIRK; BOLCZAK, 2003), muita da rigidez existente nos métodos atuais de separação diminuiria. Como conseqüência, as aeronaves teriam maior flexibilidade para alterar rotas, de acordo com mudanças que ocorram nas condições do tráfego aéreo (YANG; KUCHAR, 1997).

A Figura 2 traz uma visão geral do CNS/ATM (OLIVEIRA, 2003). Os elementos presentes na figura encontram-se descritos nas seções seguintes, as quais também trazem maiores detalhes sobre os aspectos de comunicação e navegação. Em particular, a seção 2.2 apresenta informações mais detalhadas sobre vigilância, pois trata-se do elemento do CNS em que se insere o estudo da previsão de posição futura de aeronaves. 


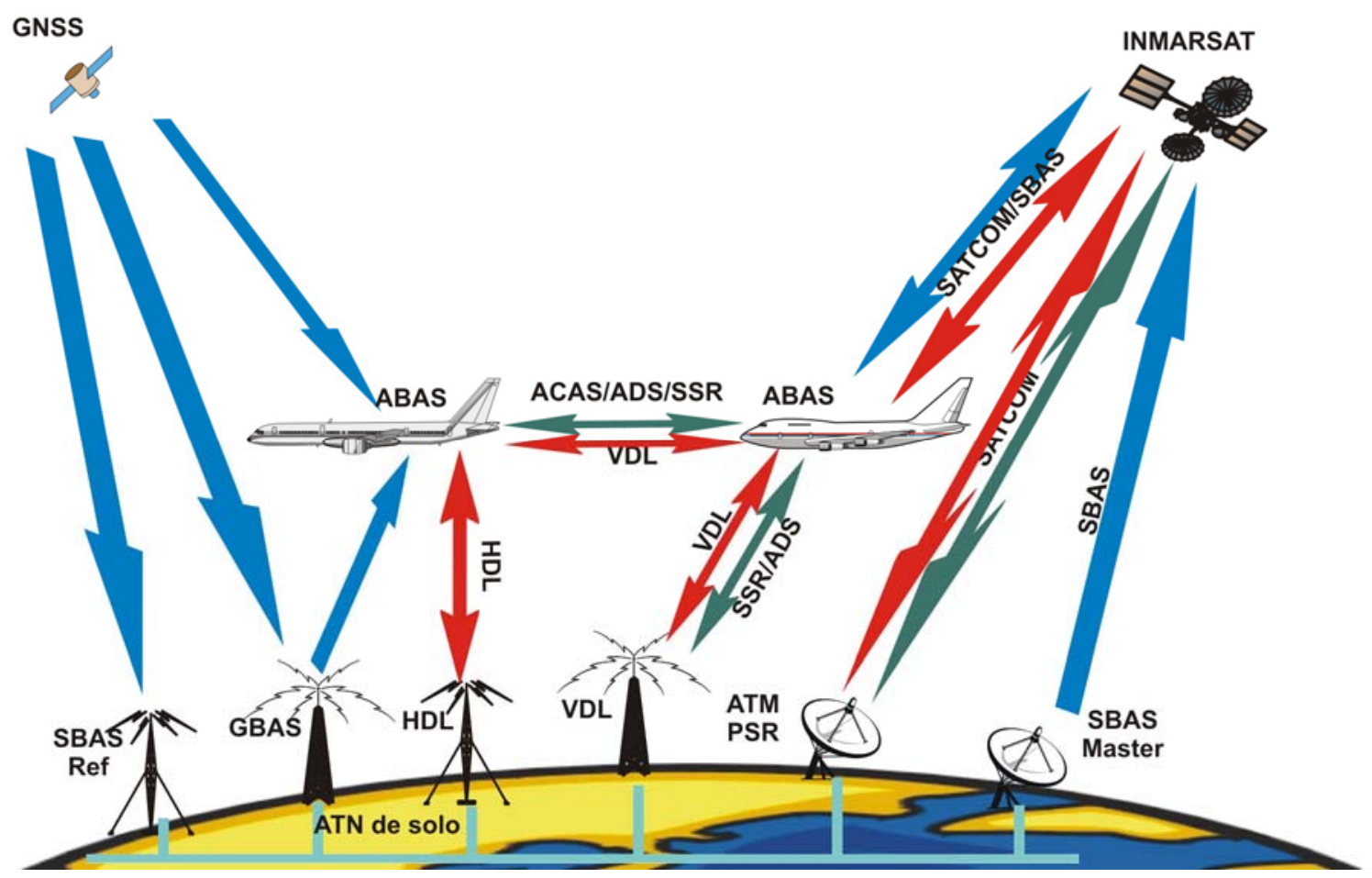

Figura 2: Visão geral do CNS/ATM (OLIVEIRA, 2003).

\subsubsection{Comunicação}

A comunicação é um elemento essencial para o bom funcionamento de praticamente tudo o que existe no mundo atual e não poderia ser diferente em sistemas de tráfego aéreo. Os avanços na comunicação decorrem, principalmente, de uma maior utilização de canais digitais de dados, sobretudo em substituição a transmissões de voz, que é o canal utilizado tradicionalmente no meio aeronáutico. Inclusive, há muita discussão em relação à possibilidade da total extinção ou não da comunicação por voz. O mais importante é que a comunicação, inclusive por voz, tenha uma cobertura global. A introdução de uma rede chamada Aeronautical Telecommunications Network (ATN) proverá um intercâmbio de dados digitais entre os diversos usuários do sistema e a tecnologia de satélites terá um papel fundamental para os avanços de comunicação (GALOTTI, 1998).

A ATN integrará vários serviços de comunicação e navegação, como o SATCOM (Satellite Communications), que é um serviço global de telecomunicações via satélite, fornecido por empresas privadas. O SATCOM utiliza uma rede de alcance global, composta de satélites geoestacionários da organização INMARSAT (International Maritime Satellite Organization) (OLIVEIRA, 2003). 
Os canais digitais de comunicação são os data links ou enlaces de dados, que correspondem a um dos elementos críticos da tecnologia, já que permitirão a transmissão de dados digitais. Informações não prioritárias, geralmente transmitidas por voz, passarão a utilizar os canais digitais, destacando-se dados meteorológicos e informações sobre a situação do tráfego aéreo. Serviços de voz ficarão reservados para comunicações prioritárias e casos de emergência, ou serão uma opção em caso de falha nos canais digitais.

A comunicação pode envolver diferentes usuários dos sistemas de tráfego aéreo, incluindo unidades de controle em solo, denominados Air Traffic Control (ATC). Além disso, há a comunicação móvel, que ocorre entre aeronaves ou entre uma unidade de solo e uma aeronave.

Para a comunicação ar-ar, utiliza-se o VDL (VHF Data Links), através do qual as aeronaves podem trocar informações sobre a navegação e o tráfego aéreo (OLIVEIRA, 2003).

\subsubsection{Navegação}

Os sistemas atuais de navegação, introduzidos na década de 40, requerem milhares de unidades ATC espalhadas em solo pelo planeta, além de serem incapazes de atender o crescente congestionamento ao redor dos aeroportos. Avanços na navegação incluem a introdução progressiva de navegação por área (RNAV - Area Navegation) juntamente com a utilização de constelações de satélites denominadas Global Navigation Satellite Systems (GNSS) (GALOTTI, 1998).

Idealmente, uma aeronave espera voar da maneira mais econômica em termos de consumo de combustível. Por algumas razões, que incluem garantir a organização e segurança na ocupação do espaço aéreo, rotas precisam ser estabelecidas. Dentro do CNS/ATM, existe um conceito de navegação denominado RNAV, segundo o qual uma maior quantidade de rotas pode existir dentro de um determinado espaço aéreo. De acordo com o RNAV, as aeronaves não dependem dos auxílios à navegação em terra, pois a navegação por satélite fornece a previsão requerida em qualquer parte do globo. Enquanto os auxílios em terra limitam as rotas que podem ser criadas, com o RNAV qualquer rota pode ser tratada e executada. Isso pode trazer uma maior possibilidade de caminhos a serem percorridos, permitindo que as aeronaves voem de uma forma mais econômica. Por exemplo, no momento em que um vôo é planejado, pode-se utilizar um menor caminho a ser percorrido pela aeronave entre a origem e o destino. 
Para que um ambiente como esse possa ser desenvolvido, surge o conceito de Required Navigation Performance (RNP). Este conceito determina que o desempenho necessário para a navegação seja atingido. De forma simplificada, RNP é definido com o máximo desvio que uma aeronave pode ter do caminho previamente estabelecido, considerando uma determinada probabilidade. Operações RNAV dentro do conceito de RNP permitirão vôos em qualquer espaço aéreo, obedecendo aos requisitos desejados e sem a necessidade dos dispositivos de navegação baseados em solo. A aplicação das técnicas RNAV em várias partes do mundo já mostrou alguns benefícios que podem ser alcançados, tais como: rotas mais diretas, diminuição da distância percorrida em um vôo, rotas paralelas e vôos em rotas alternativas (GALOTTI, 1998).

A base para o desenvolvimento dos novos métodos de navegação corresponde aos sistemas de navegação por satélites desenvolvidos pelos Estados Unidos e pela antiga União Soviética durante a Guerra Fria. O sistema desenvolvido pelos Estados Unidos é chamado de Global Positioning System (GPS), enquanto o sistema da antiga União Soviética é conhecido como Global Orbiting Navigation Satellite System (GLONASS). Esses sistemas oferecem acurácia de posição ainda insuficiente para garantir condições seguras, caso sejam utilizados somente os sinais dos satélites de navegação. Por isso, são previstos sistemas que aumentem a acurácia do valor computado, baseados em solo (GBAS), nas aeronaves (ABAS) ou por uma constelação de satélites (SBAS) (OLIVEIRA, 2003).

A ICAO acabou utilizando um termo genérico para o conceito de navegação por satélite, chamado de Global Navigation Satellite Systems (GNSS). Esse sistema engloba constelações de satélites, receptores nas aeronaves e um sistema de monitoração de integridade das informações fornecidas. Sendo assim, o GNSS inclui os dois sistemas já existentes, acrescidos de outros serviços. A preferência da ICAO é pelo GNSS, de forma que ele se torne um meio único para a navegação, já que se trata de um sistema independente e será peça chave nos futuros sistemas CNS/ATM. Maiores detalhes sobre o funcionamento do GNSS encontram-se em (GALOTTI, 1998).

Tudo isso proverá uma maior cobertura global para a navegação. O GNSS proverá uma alta integridade e precisão nos serviços de navegação do mundo inteiro, permitindo que aeronaves naveguem em todos os tipos de espaços aéreos em qualquer lugar do mundo, apenas utilizando equipamentos a bordo que recebam e interpretem informações dos satélites. Com os avanços esperados, a navegação será diferente do que ela é hoje. Aliada ao uso de satélites, a tecnologia dos computadores também estará presente para permitir a automação necessária. 
$\mathrm{O}$ comitê do CNS/ATM definiu dois conceitos relacionados à navegação por satélite. $\mathrm{O}$ primeiro deles é a navegação independente, onde a posição da aeronave é determinada a bordo, a partir de informações recebidas por transmissões de satélites. O segundo conceito é o da navegação dependente, que utiliza serviços de satélite, mas a posição da aeronave é determinada no solo e então transmitida à mesma. Os sistemas independentes são potencialmente dotados de maior confiabilidade, precisão e maior cobertura global, atendendo aos requisitos buscados pela aviação civil (GALOTTI, 1998).

\subsection{Vigilância}

As pessoas, tais como os controladores de vôo, e os sistemas no solo, necessitam saber a posição de uma aeronave continuamente e também saber estimar suas posições futuras, visando garantir a segurança no controle do tráfego aéreo. De forma geral, a idéia de acompanhar as mudanças de posição de uma aeronave é conhecida como vigilância. Há uma outra definição de vigilância que ajuda a elucidar este conceito e o seu objetivo: "Vigilância consiste na disponibilização e uso de informações de forma a permitir a separação ${ }^{3}$ segura e o seqüenciamento ${ }^{4}$ do tráfego, de forma a permitir a gestão do tráfego aéreo (ATM) tanto no ambiente de solo como no ar" (EUROCONTROL, 2001).

O método mais antigo para se saber a posição de uma aeronave e para se determinar sua posição futura é por meio da comunicação direta com a aeronave. Esse tipo de controle de tráfego aéreo é conhecido como controle procedural. Uma forma mais avançada de vigilância é encontrada com o uso de radares, que permitem a visualização da posição da aeronave em um monitor utilizado pelo controlador de tráfego aéreo.

O grande avanço na área de vigilância aeronáutica corresponde ao surgimento do ADS (Automatic Dependent Surveillance). Com a utilização de tecnologia de satélites é possível que a própria aeronave calcule sua posição e retransmita esta informação aos outros elementos participantes do ambiente de tráfego aéreo. Nesse caso, a cobertura será maior que aquela fornecida pela tecnologia baseada em radares, além de outras vantagens descritas posteriormente.

\footnotetext{
${ }^{3}$ Separação entre aeronaves corresponde a uma região no espaço dentro da qual apenas uma aeronave está voando. As definições dos requisitos de separação influenciam na forma como ocorre a gestão de conflito (ICAO, 2003c).

${ }^{4}$ Seqüenciamento de aeronaves corresponde a uma ordem em que as aeronaves estão voando, como ocorre em uma fila.
} 
Os sistemas de vigilância mais utilizados atualmente incluem uma parte de aquisição de dados baseado em radares clássicos. Neste caso os dados são tratados por sistemas de processamento e distribuição de dados. Esses sistemas foram desenvolvidos por diversos países, de forma a atender suas necessidades particulares, o que dificulta a integração e uma eventual troca de informações sobre vigilância. De forma geral, os sistemas atuais de vigilância trazem diversas limitações, como a cobertura limitada dos radares, e isso obriga que vôos operando fora da área de cobertura tenham de ser controlados com base no plano de vôo. Há pouca automação nesse processo, causando uma grande dependência do operador humano, em geral um controlador de tráfego aéreo. As próprias limitações na forma de funcionamento de alguns radares impedem que o sistema fique mais eficiente. Com isso, o custo operacional para as companhias acaba se elevando, já que as operações de vôo não ocorrem de uma forma completamente eficiente. Como resultado dessas restrições, as necessidades de aumento da capacidade, flexibilidade e eficiência na gestão do tráfego aéreo não podem ser totalmente atingidas (EUROCONTROL, 2001; GALOTTI, 1998).

As limitações dos sistemas atuais levam à pesquisa e desenvolvimento de novos sistemas de vigilância. O mais importante dos novos sistemas é o ADS, pois seu uso possibilita a automação de vários serviços no controle do tráfego aéreo. Entre os chamados benefícios operacionais, destacam-se: a automação na detecção e resolução de conflitos entre aeronaves, a facilidade para serviços de organização do tráfego e a possibilidade de uma aeronave voar dentro do conceito de Free Flight. Operações de aeronaves segundo o Free Flight são almejadas pela FAA (Federal Aviation Administration), tratando-se de um conceito que permitirá caminhos de vôos ótimos para a maioria das aeronaves, com a aplicação das tecnologias CNS/ATM. A gestão de tráfego aéreo, segundo o conceito do Free Flight, deverá permitir que se maximize a flexibilidade de utilização do espaço aéreo, ao mesmo tempo garantindo uma separação mínima segura entre as aeronaves (GALOTTI, 1998; YANG; KUCHAR, 1997). 
Um dos pontos de grande importância do ADS corresponde à possibilidade de ele proporcionar a divulgação de informações futuras do comportamento da aeronave. Dentro do escopo deste trabalho de pesquisa, insere-se a investigação do problema da previsão de trajetórias e previsão de posições futuras das aeronaves que estiverem sob vigilância. Convém também destacar outros benefícios, tais como: aumento na segurança dos vôos, cobertura em áreas oceânicas, bem como em outras áreas não cobertas por radar (como por exemplo, desertos, florestas e oceanos), e redução nas separações mínimas entre as aeronaves, proporcionando aumento da capacidade geral do sistema. Outros detalhes sobre os sistemas futuros, em particular o ADS, são explicados no decorrer deste trabalho (EUROCONTROL, 2001; GALOTTI, 1998).

A evolução dos sistemas de vigilância deve garantir a interoperação com o sistema atual, de forma que dois princípios devem ser mantidos (OLIVEIRA, 2003):

- A compatibilidade com os sistemas secundários de radar atuais; e

- A interoperabilidade com os sistemas anticolisão atuais (ACAS).

Em seguida, os diferentes tipos de vigilância são descritos, sendo possível verificar as diferenças existentes entre esses tipos, a evolução de cada um deles, além de se destacar as vantagens e desvantagens de cada um.

\subsubsection{Vigilância Procedural}

A vigilância procedural utiliza uma comunicação direta entre o controlador de vôo e a aeronave, utilizando rádio. O vôo é controlado por meio do plano de vôo de cada aeronave, sendo que o processo de atualização do caminho percorrido pela mesma utiliza as informações recebidas sobre as posições da aeronave. Regiões que adotam o controle procedural, como por exemplo as regiões oceânicas, ficam com pouco suporte automatizado. Considerando os avanços necessários à gestão de tráfego aéreo, este tipo de vigilância apenas deve ficar restrito a áreas cuja densidade de fluxo de tráfego aéreo não seja crítica e que, portanto, não justificam pesados investimentos em melhorias tecnológicas.

\subsubsection{Vigilância por Radar}

A utilização de radares permite uma forma mais avançada de vigilância. A posição de cada aeronave é exibida em um monitor do centro de controle de tráfego aéreo, possibilitando um melhor trabalho ao controlador de tráfego aéreo. Há dois tipos de radar que são utilizados: Primary Surveillance Radar (PSR) e Secondary Survaillance Radar (SSR), descritos a seguir (GALOTTI, 1998). 


\subsubsection{Radar de Vigilância Primária (PSR)}

O radar primário corresponde à forma mais simples de comunicação por radar que existe. Esta forma de comunicação via radar não exige nenhum tipo de equipamento na aeronave e não exige nenhuma ação do piloto ou da própria aeronave. Por isso, a vigilância proporcionada pelo radar primário é conhecida como vigilância independente.

O princípio de funcionamento é simples. Os sinais emitidos pelo radar são refletidos pelas aeronaves, assim como por outros possíveis objetos que estejam voando na região. Então, o controlador de tráfego aéreo pode visualizar a posição dos objetos na tela de um monitor. Não há informações sobre altitude, nem informações sobre a identificação das aeronaves. Se for necessário saber maiores informações sobre a aeronave, deve ocorrer uma comunicação direta entre o controlador e o piloto (GALOTTI, 1998).

\subsubsection{Radar de Vigilância Secundário (SSR)}

Radares secundários são mais evolú́dos tecnologicamente em relação aos radares primários. Eles são compostos de um equipamento denominado transponder, que é colocado na aeronave, e também de um equipamento chamado de interrogador, o qual é localizado em solo.

O radar secundário funciona da seguinte forma: um sinal é enviado para a aeronave pelo equipamento de solo e uma resposta é gerada pelo transponder existente na aeronave. Então esta resposta é enviada por meio de um sinal para o equipamento de solo. Diferente do radar primário, é necessária uma ação por parte da aeronave, ou seja, o transponder deve gerar uma resposta e, por esta razão, a vigilância proporcionada pelo radar secundário é considerada como vigilância dependente.

Em locais onde funcionam radares secundários, o interrogador costuma ser colocado junto com um radar primário, de forma que objetos identificados pelo radar primário sejam exibidos no mesmo monitor, juntamente com as aeronaves identificadas pelo radar secundário.

O uso do SSR provê diversos ganhos para o controle de tráfego, pois são exibidas aos controladores informações como: identificação e tipo da aeronave, altitude e velocidade da aeronave em relação ao solo. Essas informações aliviam muito a carga de trabalho dos controladores, auxiliando na correta compreensão da situação do tráfego e possibilitando melhores tomadas de decisão. 
Os radares secundários podem ter uma característica própria, determinada pelo modo no qual funcionam. O termo modo se refere ao tipo de transmissão de dados que é utilizada. $\mathrm{O}$ tipo mais avançado de radar corresponde ao SSR Modo S, o qual oferece vantagens, sobretudo o fato de que nele cada aeronave terá um código único de identificação. No SSR Modo A, utilizado em muitas regiões, o número de códigos existente é limitado a 4096; porém, há regiões em que essa quantidade de códigos não é suficiente para lidar com as necessidades operacionais do controle de tráfego aéreo. Já no SSR Modo S esse problema não ocorre, pois é considerada a mesma identificação da aeronave usada no plano de vôo (GALOTTI, 1998).

\subsection{ADS}

Dentro do contexto do CNS/ATM é proposto pela ICAO um método mais recente de vigilância, conhecido como Vigilância Dependente Automática ou Automatic Dependent Surveillance (ADS). Com o uso do ADS, a aeronave transmite automaticamente aos sistemas de solo ou a outras aeronaves algumas informações geradas à bordo. A introdução e a utilização do ADS possibilitará estender a automação da vigilância para áreas que não têm cobertura de radares, tais como oceanos, desertos, florestas e regiões montanhosas. A implantação do ADS também proporcionará benefícios para áreas continentais em rota, áreas terminais e superfícies de aeroportos (ICAO, 1999).

De forma geral, os componentes de comunicação e navegação são combinados de forma a prover os avanços necessários já citados na área de vigilância. Os três componentes do CNS devem sempre ser vistos em conjunto, já que nenhum deles funciona isoladamente e, assim, como todos os elementos do CNS/ATM, o ADS também é amplamente baseado no uso de comunicação via satélite. É importante destacar que o ADS faz parte da camada de aplicação dentro da rede ATN (Aeronautical Telecommunications Network).

\subsubsection{ATN}

ATN é uma rede que interliga todos os usuários do CNS/ATM, abrangendo os sistemas de solo e as aeronaves, e funciona de uma forma análoga à Internet. A Figura 3 ilustra um ambiente de comunicação ponta-a-ponta para uma aplicação ATN, sendo que neste modelo se insere a comunicação envolvida na troca de mensagens do ADS, já que o ADS é uma das aplicações da ATN (ICAO, 1999). Esta troca ocorre entre os sistemas que utilizam o ADS, identificados na figura por Processo da Aplicação. A topologia descrita segue os conceitos das camadas OSI (Open System Interconnect) da ISO (International Standards Organization) (TANENBAUM, 2003). 


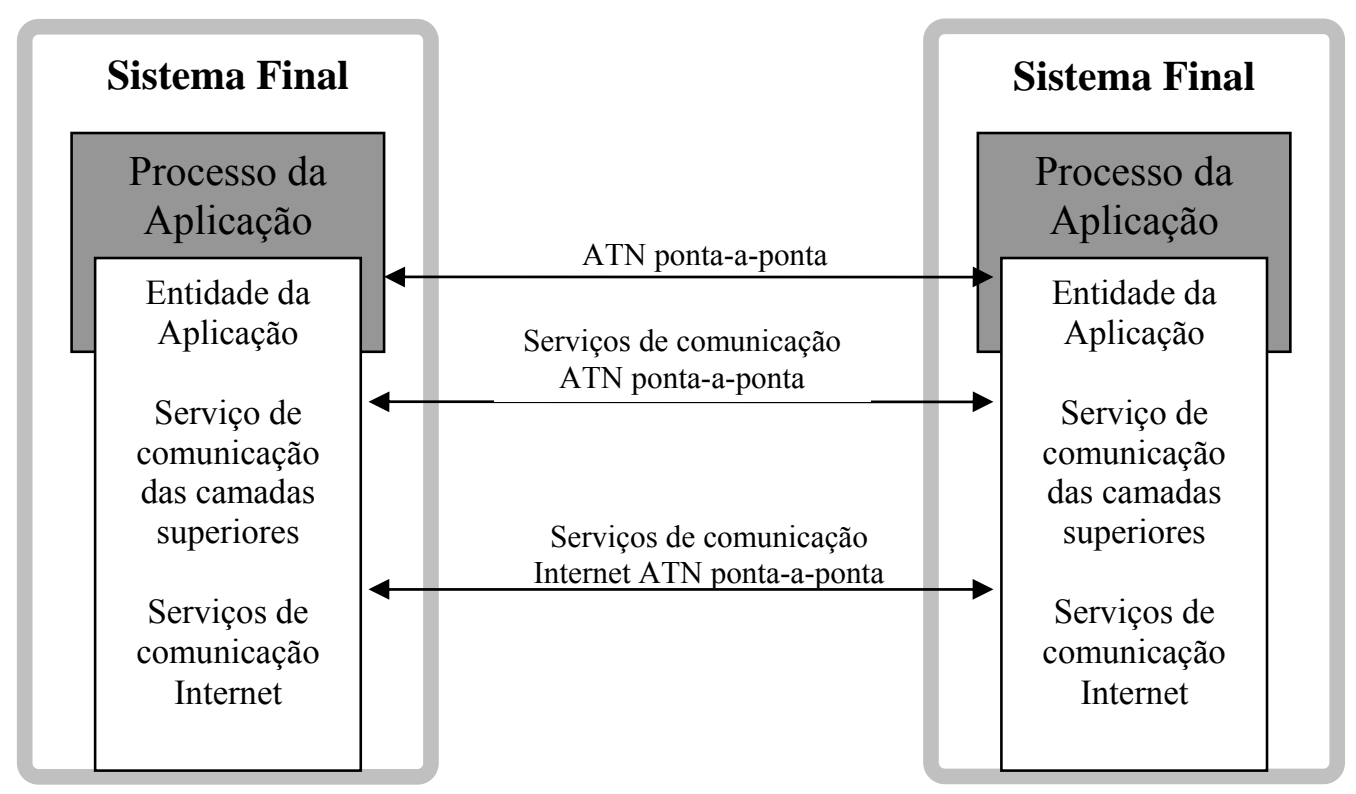

Figura 3: Ambiente de comunicação da rede ATN (ICAO, 1999).

\subsubsection{Princípios de Operação do ADS}

O princípio de operação é simples: por meio dos enlaces de comunicação digitais (data links), as informações sobre posição geradas na aeronave são transmitidas para centros de controle ou outras aeronaves quase em tempo real, havendo apenas um pequeno atraso (delay) causado pelo tempo de transmissão dos dados.. O processo ocorre de forma automática sem a necessidade de ação direta do piloto ou controlador de vôo. As informações proporcionadas pelo ADS são:

- Posição da aeronave, proveniente do sistema sendo utilizado para navegar a aeronave;

- Rota utilizada para navegar a aeronave, que pode ser utilizada para verificar se o plano de vôo está sendo seguido; e

- Informações meteorológicas.

A Figura 4 ilustra o funcionamento e as fronteiras do ADS com os outros sistemas. A parte cinza da figura mostra o fluxo dos dados dentro da aeronave, onde os dados provenientes dos sistemas de navegação são transmitidos ao sistema ADS e ficam disponíveis aos usuários do sistema a bordo: piloto e co-piloto. Por meio do sistema ADS, os dados referentes à vigilância da aeronave são transmitidos a outras aeronaves e aos sistemas de solo. 


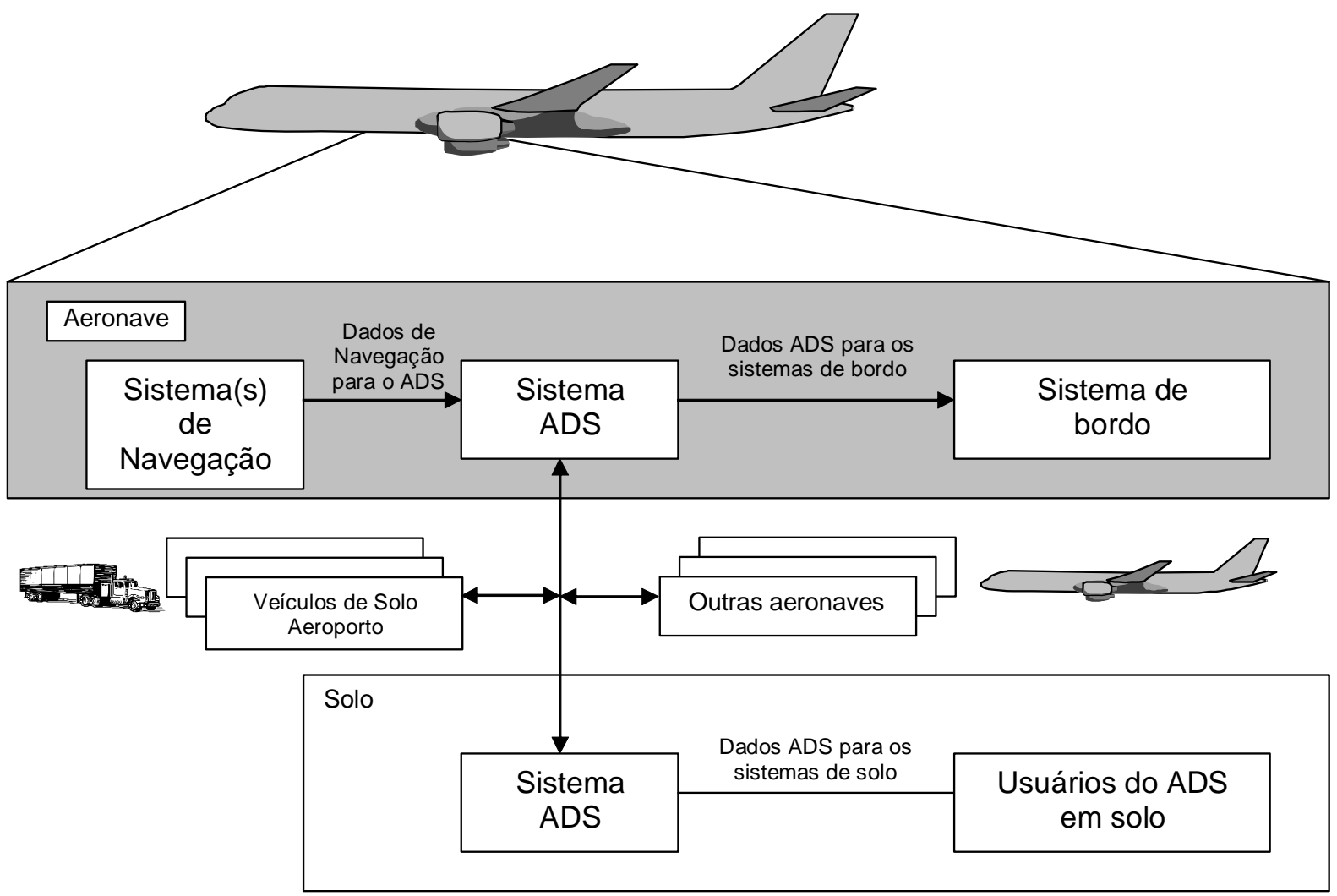

Figura 4: Ilustração do funcionamento e fronteiras do ADS (EUROCONTROL, 2002).

O funcionamento do ADS depende dos equipamentos chamados aviônicos, os quais devem estar presentes nas aeronaves. Eles são responsáveis por obter as informações dos sensores e do painel de controle, processar, formatar e enviar os dados aos usuários do sistema, conforme ilustrado também na Figura 4. Os equipamentos de bordo também devem ter a capacidade de receber mensagens enviadas pelos centros de controle em solo.

De acordo com a ICAO e o EUROCONTROL (European Organization for the Safety of Air Navigation), o ADS é visto como altamente estratégico e o início do seu uso operacional na Europa é apontado para ocorrer a partir de 2007, conforme definido na ECAC (European Civil Aviation Conference) (EUROCONTROL, 2001).

Há algumas funcionalidades genéricas do ADS, que são: aquisição, processamento e distribuição de dados de vigilância. Essas funcionalidades correspondem a um processo de fusão de dados vindos do ADS com aqueles oriundos de outras possíveis fontes, tais como radares. Então, esses dados podem ser processados, gerando informações importantes a serem distribuídas para as outras aeronaves ou para os sistemas de solo. Informações sobre previsão de posição futura da aeronave também podem ser encontradas em (EUROCONTROL, 2001). 
Outras características devem ser consideradas no ADS, entre elas: interfaces com outros sistemas, requisitos funcionais, requisitos de desempenho, integridade, disponibilidade, continuidade, segurança, etc. Tais fatores estão fora do escopo desse trabalho. Para maiores detalhes, verificar (ICAO, 1999) e (EUROCONTROL, 2001). Em seguida, há uma explicação dos diferentes tipos de ADS existentes.

\subsubsection{ADS-C}

O ADS-C corresponde ao ADS por Contrato. Nessa seção está contida a descrição dos tipos de contrato, mostrando que as previsões de posição futuras de aeronaves são importantes para o período entre um contrato e outro.

No ADS-C, é necessária a existência de uma comunicação ponto-a-ponto entre as aplicações no solo e nas aeronaves. Com o uso do ADS-C, é possível a implementação de um report agreement, que é estabelecido exclusivamente pelos sistemas de solo, a não ser que a aeronave esteja em modo de emergência. Esse agreement é um plano que estabelece as condições em que as mensagens serão trocadas entre a aeronave e os sistemas de solo. Essas condições são determinadas por meio de um ou mais contratos estabelecidos entre as partes, sendo que um contrato do ADS estabelece as condições em que relatórios ADS serão transmitidos e também quais informações farão parte de cada relatório. Existem quatro tipos de contrato: sob demanda, periódico, por evento e de emergência. Os aviônicos são capazes de suportar cada um dos quatro tipos de contrato com um sistema de solo simultaneamente.

\section{Contrato sob Demanda}

Em um contrato sob demanda, o sistema de solo faz a requisição dos dados e um único relatório é gerado e enviado ao requisitante. Um número qualquer de contratos sob demanda pode ser estabelecido, seqüencialmente, com uma aeronave. Quando o sistema de solo faz uma requisição à aeronave, os aviônicos verificam a possibilidade de responder à requisição. Então, havendo a possibilidade de atender a requisição, o relatório é enviado assim que possível. Caso os aviônicos não possam atender, eles enviam uma resposta negativa ao sistema requisitante, explicando as razões pelas quais não é possível o envio das informações solicitadas. 


\section{Contrato Periódico}

Quando um contrato periódico é estabelecido, relatórios são gerados e enviados periodicamente, de acordo com um intervalo de tempo estabelecido pelo sistema de solo. Os sistemas de solo especificam quais informações estarão disponíveis além das informações básicas (por exemplo, posição da aeronave, identificação da aeronave, etc). A taxa de envio das mensagens também é definida pelo sistema de solo. Apenas um contrato periódico pode existir por vez entre um sistema de solo e uma aeronave. Cada vez que um contrato periódico é estabelecido, ele substitui algum eventual contrato periódico que esteja em vigor.

Contratos periódicos são os mais utilizados para operações em rota. Nessa fase do vôo, os fatores de incerteza são menores e o percurso estabelecido pelo plano de vôo da aeronave não deverá sofrer grandes modificações. Por essa razão, há uma menor periodicidade de envio de mensagens. O uso de relatórios periódicos contendo informações básicas, mais o vetor de solo (enhanced surveillance), explicado na seção 2.3.2.2, que contém a previsão de posição futura da aeronave, permite uma redução ainda maior na taxa de mensagens que devem ser transmitidas. Isso ocorre porque os sistemas de controle podem utilizar as informações das previsões de posição futura ao invés de exigir que um novo relatório de posição seja gerado. Há estudos que mostram como obter valores ideais para a periodicidade de envio das mensagens (ATKINS; HANSMAN, 1999).

Contratos periódicos também são muito utilizados nas operações em áreas terminais, porém com uma periodicidade maior do que em outras áreas, já que isso é necessário para manter a aeronave sob vigilância constante.

\section{Contrato por Evento}

Um contrato por evento estabelece o envio de um relatório quando um evento específico ocorre. Nesse caso, os relatórios contêm informações básicas, além de informações adicionais solicitadas pelo sistema que disparou o evento. Os principais eventos que podem indicar mudança nas suas respectivas variáveis associadas a um vôo são:

- Desvio lateral - a aeronave, que está supostamente voando em linha reta, sofre um desvio de trajetória maior que o esperado;

- Mudança de Altitude - a aeronave, que está supostamente voando a uma altitude constante, sofre uma mudança inesperada de altitude;

- Mudança na razão vertical - modificação, para um nível acima do esperado, na razão de subida ou descida da aeronave; 
- Mudança na Velocidade em relação ao $\operatorname{solo}^{5}$ - a aeronave sofre uma mudança inesperada na sua velocidade em relação ao solo;

- Mudança na velocidade em relação ao $\operatorname{ar}^{6}$ - a aeronave sofre uma mudança inesperada na sua velocidade em relação ao ar;

- Mudança do fixo seguinte - em um plano de vôo, há uma série de pontos, chamados de fixos, pelos quais a aeronave deve passar. Entre um fixo e outro, a aeronave deve percorrer um caminho em um grande círculo (considerando a curvatura terrestre) ou um rumo constante. $\mathrm{O}$ alerta de mudança do fixo seguinte ocorre quando há alguma modificação no plano de vôo que leva a aeronave a se encaminhar para um fixo diferente do previsto;

- Mudança no perfil projetado - este evento é disparado por uma mudança em qualquer um dos futuros fixos definidos para o vôo;

- FOM (Figure of Merit) - FOM indica a acurácia do sistema de navegação ao determinar a posição de uma aeronave. Este evento indica que houve alteração no FOM atual da aeronave; e

- Mudança de direção - ocorre quando a aeronave sofre uma mudança na direção que está seguindo.

Em operações em rota, contratos por evento são utilizados para identificar o início de alguma manobra.

\section{Contrato de Emergência}

Trata-se de um tipo especial de contrato, utilizado em situações de emergência. Diante dessas situações, a aeronave fornece informações regularmente, sem que ocorra uma solicitação pelos sistemas de solo. Um contrato por evento ou periódico já deve existir para que o contrato de emergência possa ser estabelecido (ICAO, 1999)

\subsubsection{ADS-B}

ADS-B significa ADS-Broadcast e corresponde ao estado da arte em termos de vigilância. O princípio de funcionamento do ADS-B é o mesmo aplicado ao conceito geral do ADS. No entanto, informações tais como identificação e posição das aeronaves, são transmitidas via broadcast. Além de aeronaves, outros elementos também podem ser equipados com o ADS-B, incluindo obstáculos (por exemplo, edifícios, montanhas), sistemas de solo, torres de controle, etc. Assim, qualquer elemento, seja aeronave ou sistemas de solo,

\footnotetext{
${ }^{5}$ Velocidade em relação ao solo: velocidade da aeronave tendo como referências as coordenadas de solo.

${ }^{6}$ Velocidade em relação ao ar: velocidade da aeronave medida através da pressão do deslocamento do ar.
} 
que estejam adequadamente e dentro de uma certa área de cobertura, poderão receber e transmitir informações. Do ponto de vista das aeronaves, isto permitirá que se tenha um maior controle sobre a situação do tráfego ao seu redor, auxiliando na detecção e resolução de conflitos, os quais poderão ser feitas por sistemas no solo ou no ar. Os equipamentos do ADSB devem funcionar independentemente da localidade das aeronaves, o que possibilita evitar conflitos também nas superfícies dos aeroportos.

Dependendo de sua implementação, o ADS-B poderá englobar vigilância ar-ar, ar-solo e incluir também a vigilância entre aeronaves no solo e outros veículos no solo. A vigilância incluindo o solo poderá aumentar os níveis de segurança do tráfego aéreo, de forma a permitir aumento de operações simultâneas, o que é muito importante já que grande parte dos congestionamentos na aviação ocorre no próprio aeroporto, e não apenas no ar.

A operação do ADS-B envolve a transmissão de mensagens em intervalos regulares. Todo o protocolo do sistema deve ser construído de forma que haja sincronia na transmissão, ou seja, as mensagens devem ser recebidas na mesma ordem em que forem transmitidas. Além disso, há requisitos mínimos relativos à integridade e tempo para se receber as mensagens. De nada adianta o recebimento de uma mensagem muito atrasada, já que provavelmente esta informação não terá mais utilidade. A arquitetura com que o ADS-B é construído deve ser capaz de proporcionar todos os requisitos desejados (EUROCONTROL, 2003). Todas essas normas de funcionamento são estabelecidas pelos painéis ${ }^{7}$ da ICAO. Um bom exemplo de avaliação operacional do ADS-B é encontrado em (CIEPLAK; HAHN; OLMOS, 2000).

Conforme já descrito no conceito de ADS, o ADS-B está totalmente integrado aos elementos de comunicação e navegação do CNS/ATM. Os sistemas de comunicação e navegação (GNSS) deverão ser capazes de disponibilizar as informações necessárias ao ADSB. Assim, os requisitos de segurança exigidos pelo ADS-B devem ser considerados pelos outros elementos do sistema (ICAO, 2003a).

Sabendo-se que o ADS-B poderá trabalhar de forma automática, ele poderá ser útil na identificação de diversos obstáculos, bastando que esses obstáculos sejam devidamente equipados. Igualmente, é possível que diversos tipos de equipamentos de solo, tais como veículos, estejam preparados para trabalhar com o ADS-B, de maneira que se tenha vigilância no ar e no solo. As aplicações que utilizam o ADS-B estão presentes em todas as fases do vôo. Em um cenário como esse, obtém-se um ambiente com controle gate-to-gate, com a

\footnotetext{
${ }^{7}$ Painéis são constituídos de pequenos grupos de especialistas na área de aviação, nomeados para estudar um determinado assunto dentro da ICAO.
} 
vigilância ocorrendo durante todo o vôo, desde o portão de embarque origem até o portão de embarque destino. A Figura 5 mostra todas as fases de um vôo, sendo que um controle gateto-gate abrange todas essas fases. É conveniente salientar que este trabalho de pesquisa de mestrado concentra-se no estudo de previsões de posição de aeronaves que estejam em rota, o que corresponde à fase 6 do vôo.
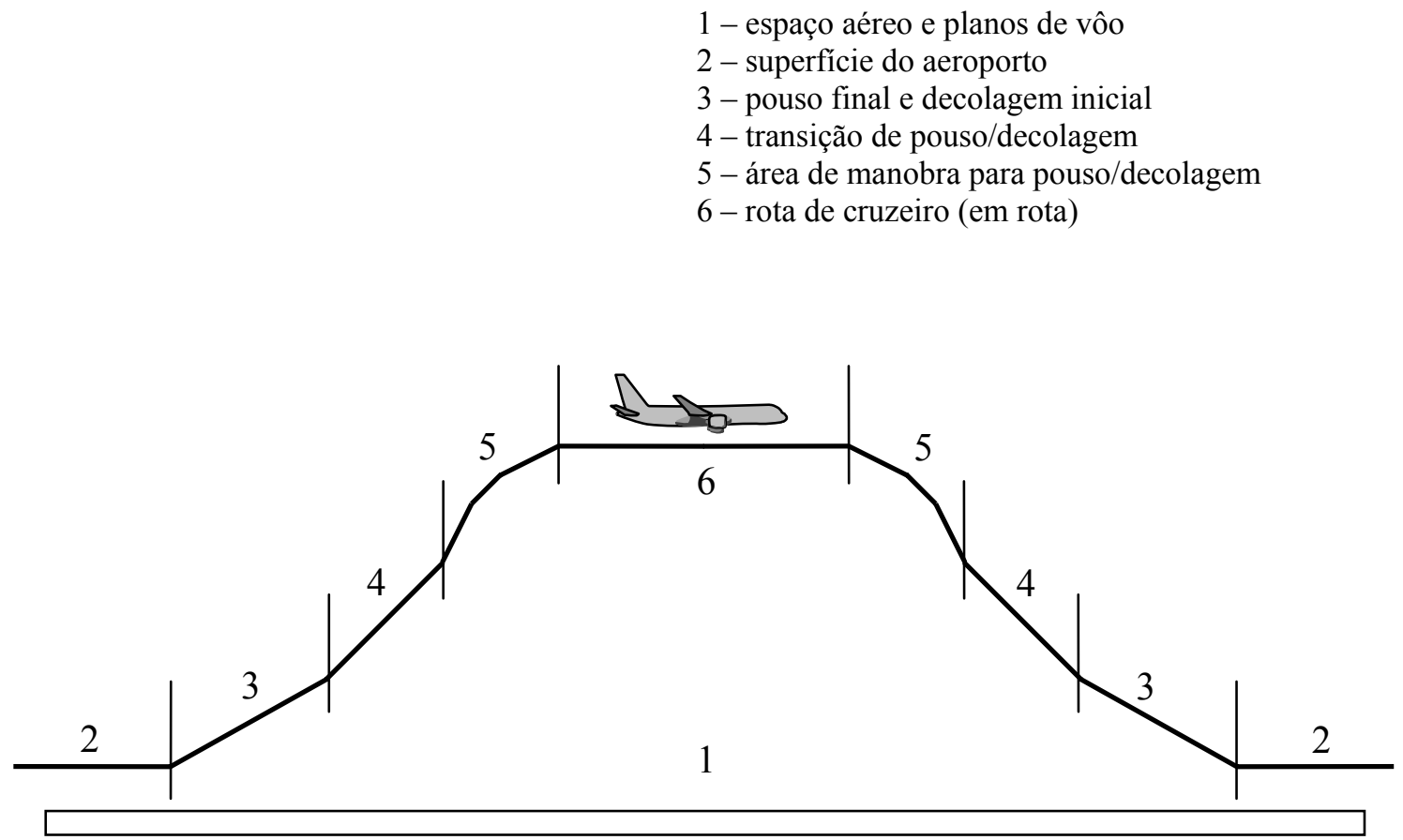

Figura 5: Fases de operação no espaço aéreo (OGATA, 2003).

A fase 1 abrange o espaço aéreo e o plano de vôo, contemplando também as outras cinco fases. Em um cenário gate-to-gate, a vigilância começa nas operações de solo, incluindo sincronização do tráfego e gerenciamento de conflitos, o que corresponde à fase 2 da Figura 5 . Ao ocorrer a decolagem (fase 3), o sistema ADS-B passa a controlar a aeronave dentro da área terminal (fase 4). O controle continua nas áreas de manobra (fase 5) e também no espaço aéreo em rota (fase 6), onde existe uma menor densidade de tráfego e finalmente, a aeronave passa ao processo de aproximação, percorrendo as fases de forma inversa, até voltar a operar em uma área terminal. Com a existência da vigilância por ADS-B, obstáculos tais como edifícios e montanhas também são identificados. Uma descrição mais detalhada de um vôo completo, dentro do conceito gate-to-gate, encontra-se em (ICAO, 2003a) e outras informações podem ser encontradas em (ICAO, 2003b).

É importante notar que o ADS-B é complementar aos outros sistemas de vigilâncias, como SSR e ADS-C. A Figura 6 ilustra o funcionamento do ADS-B. A figura se divide em duas partes: ar e solo, sendo que a utilização do ADS-B abrange as duas regiões. No ar, cada 
aeronave transmite suas informações de vigilância via broadcast, de forma que estas informações possam ser captadas por outras aeronaves ou pelos sistemas ADS de solo, desde que uma infra-estrutura apropriada esteja disponível no solo. Os dados podem ser provenientes dos satélites ou também dos radares tradicionais (EUROCONTROL, 2001).

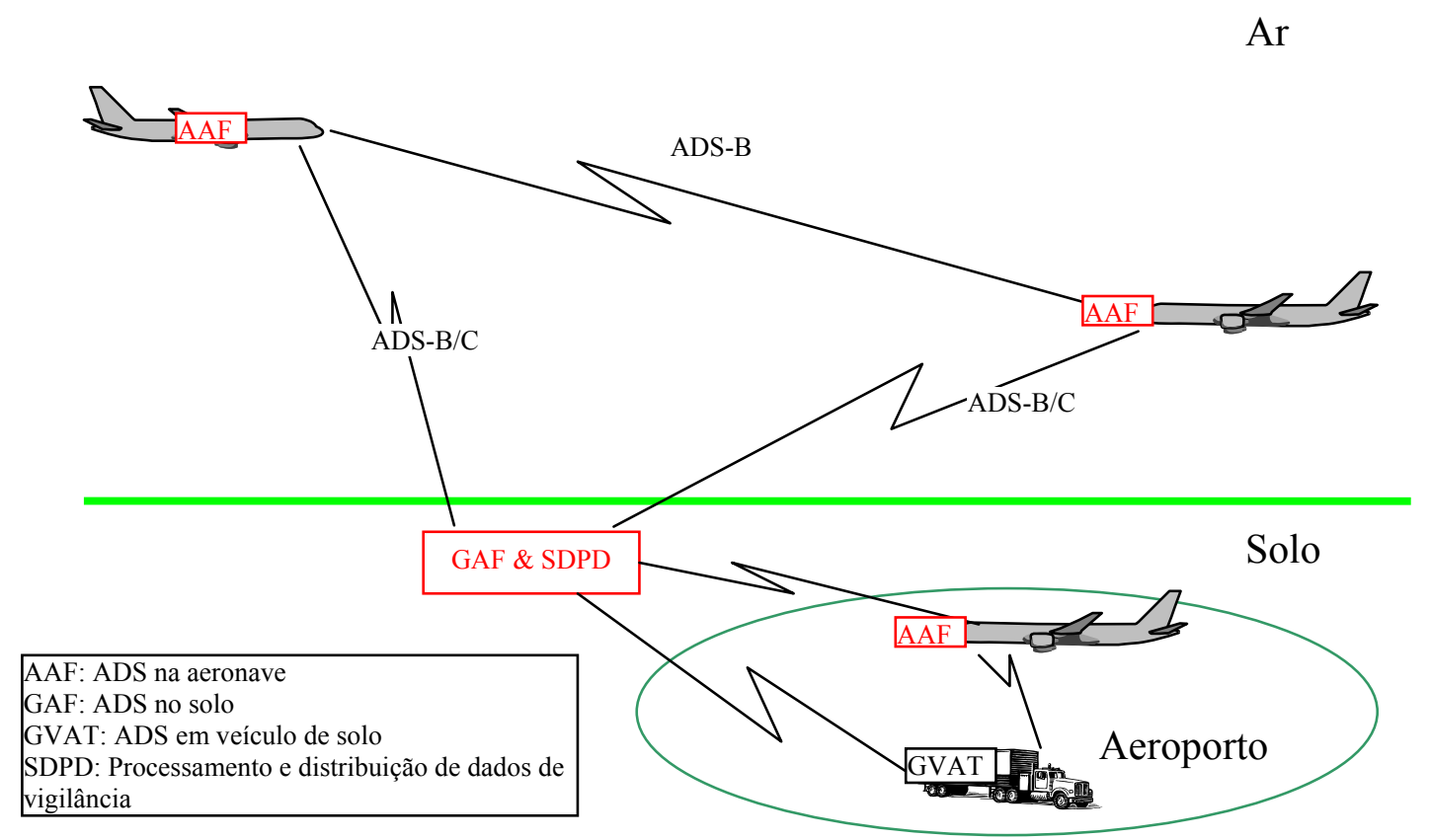

Figura 6: Ilustração do funcionamento do ADS-B (EUROCONTROL, 2001).

Os dados transmitidos pelo ADS são agrupados em três categorias: basic surveillance, enhanced surveillance, intent surveillance. A seguir descrevem-se quais informações são trocadas em cada uma dessas categorias. Maiores detalhes sobre as informações trocadas no ADS podem ser encontrados em (ICAO, 1999; EUROCONTROL, 2002; ICAO, 1996).

\section{Basic Surveillance}

As informações existentes na categoria basic surveillance correspondem ao que os sistemas de vigilância em uso atualmente já trazem, sobretudo o SSR Modo-S, que são:

- Identificação - corresponde ao número de registro da aeronave, conforme arquivado no plano de vôo;

- Posição em 3 dimensões - latitude, longitude e altitude da aeronave;

- Tempo - corresponde ao horário do relatório do sistema de vigilância;

- Incerteza da Posição - indicação da acurácia de uma informação sobre a posição. Corresponde ao Figure of Merit (FOM);

- Vetor de Solo (opcional) - velocidade em relação ao solo; e 
- Incerteza da Velocidade (opcional) - Informação indicativa da incerteza relacionada à velocidade da aeronave.

\section{Enhanced Surveillance}

As informações trazidas pela enhanced surveillance são conhecidas como state vector e são as seguintes:

- Vetor de solo - velocidade em relação ao solo;

- Altitude selecionada - nível de altitude selecionado para o vôo; e

- Meteorológicas - informação de velocidade do vento, direção do vento, temperatura, turbulência.

\section{Intent Surveillance}

Os dados trazidos pelo intent surveillance correspondem ao foco principal deste trabalho de pesquisa. As informações relacionadas a previsão de posição fazem parte do relatório do intent surveillance:

- Projected Profile - informações sobre a localização dos próximos fixos e os respectivos instantes de chegada da aeronave nesses fixos; e

- Previsão de curto prazo - latitude, longitude e altitude da posição prevista, bem como o instante de chegada da aeronave nessa posição.

Um estudo feito no Alaska mostra a evolução na quantidade de acidentes envolvendo aviação comercial, comparando o período antes e pós implantação do ADS-B. Considerando o período de 2000-2001, cerca de $45 \%$ da frota estava equipada com os sistema ADS-B, sendo que $50 \%$ do total dos vôos foram realizados pelas aeronaves já equipadas. Mesmo com esse equilíbrio entre as aeronaves equipadas com o ADS-B e aquelas não equipadas, $63 \%$ dos acidentes ocorreram com as aeronaves ainda não utilizavam o ADS-B, o que mostra os benefícios trazidos com as novas tecnologias (KIRKMAN, 2003).

\subsection{ATM}

Air Traffic Management (ATM) ou Gestão do Tráfego Aéreo pode ser considerado um conjunto de regras e procedimentos utilizados em aviação. As melhorias dentro de ATM são a grande finalidade a ser alcançada pelos avanços nos sistemas CNS. Portanto, os sistemas CNS são as ferramentas que permitirão as melhorias e proporcionarão maior eficiência no ATM. 
Quando se fala em ATM, a sigla não inclui apenas o controle do tráfego aéreo (ATC), mas também estão incluídos: Air Traffic Services (ATS), Air Traffic Flow Management (ATFM) e Airspace Management (ASM). Como todos esses conceitos envolvem elementos comuns, em alguns momentos, eles acabam se confundindo, ficando difícil fazer a distinção exata entre eles.

Entre os objetivos a serem alcançados com os avanços em ATM, destacam-se:

- A possibilidade de acomodar o crescimento esperado do tráfego aéreo;

- A obtenção de economia por parte das empresas;

- Uma padronização geral para todo o planeta, em termos de equipamentos e procedimentos;

- Melhorias na utilização simultânea dos recursos disponíveis;

- Aumento da flexibilidade das rotas;

- Operações gate-to-gate; e

- Aumento dos níveis de segurança, de forma a pelo menos manter os níveis absolutos das taxas de acidentes.

Atingir esses objetivos exigirá uma grande automação dos sistemas, incluindo controle de solo, que deverão assistir principalmente em situações de detecção e resolução de conflitos. A ICAO, através de seus painéis e reuniões, está constantemente trabalhando para estabelecer critérios que garantam o cumprimento dos objetivos traçados.

\subsection{Considerações Finais do Capítulo}

Neste capítulo foram apresentados os principais conceitos envolvidos no CNS/ATM. Trata-se de uma proposta para melhoria e automação nos sistemas de controle e gestão do tráfego aéreo. Os avanços necessários em comunicação, navegação e vigilância foram descritos, juntamente com os benefícios esperados para a gestão de tráfego aéreo. A tecnologia de satélites possibilitará que os objetivos desejados sejam atingidos.

Uma maior ênfase foi dada aos sistemas de vigilância, sobretudo ao ADS, o qual permite a transmissão de relatórios entre as aeronaves e estações de solo, fazendo parte desses relatórios um conjunto de informações que se chama intent surveillance. Dentro desse conjunto, uma das informações refere-se à previsão de posição futura de aeronaves, que corresponde ao foco desta pesquisa. Considerando os benefícios esperados para o ATM, é possível observar que muitos desses benefícios dependem de informações relacionadas a previsão de posição futura de aeronaves, justificando a importância deste estudo. 


\section{A PREVISÃO DA POSIÇÃO FUTURA DE AERONAVES DENTRO DOS SISTEMAS DE NAVEGAÇÃO}

Neste capítulo, é possível observar como a previsão da posição futura de uma aeronave é inserida dentro dos sistemas propostos pelo CNS/ATM. Inicialmente, há um destaque para os problemas gerados, quando a incerteza associada às previsões é muito alta. Posteriormente, é mostrado como o aumento da qualidade das previsões pode trazer benefícios para a Gestão de Tráfego Aéreo. Os principais sistemas de apoio a decisão, relacionados a detecção e resolução de conflitos, bem como os sistemas de auxílio aos pilotos e controladores de vôo também são brevemente citados.

Finalmente, são destacadas informações gerais sobre síntese de trajetórias de aeronaves, seus requisitos, principais conceitos envolvidos, bem como o inter-relacionamento da previsão com outras ferramentas e conceitos do CNS/ATM.

Um aspecto de destaque é definir o que é previsão de posição de médio prazo, considerando que para alguns estudos uma previsão de médio prazo corresponde a 20 minutos (PRANDINI; LYGEROS; SASTRY, 2000), enquanto outros autores citam que esse prazo corresponde a algo entre 10 a 30 minutos (WARREN, 2000), o que pode ser entendido como "cerca de 20 minutos".

\subsection{Motivações para o Estudo da Previsão de Posição Futura de Aeronaves}

Para facilitar o crescimento contínuo do tráfego aéreo e a demanda por maior flexibilidade na gestão desse tráfego, os controladores de vôo, pilotos e aeronaves necessitam do auxílio de alguns sistemas informatizados. Em grande parte, são sistemas que garantem uma separação segura entre as aeronaves de forma a prevenir colisões, com o mínimo de intervenção do controlador de tráfego aéreo. A natureza desses sistemas os leva a serem classificados como sistemas de apoio a decisão (Decision Support Systems). A correta detecção de conflito e a garantia de separação segura entre as aeronaves, ou seja, o correto funcionamento dos sistemas de apoio a decisão, dependem de informações sobre estimativas de posições futuras das aeronaves (SCHILD; KUCHAR, 2000; YANG; KUCHAR, 1998; MONDOLONI; PAGLIONE; GREEN, 2002). 
A acurácia na previsão de trajetórias influencia diretamente a eficiência e eficácia dos sistemas utilizados para a melhor gestão do tráfego aéreo. A melhoria na acurácia beneficia o sistema, reduzindo incertezas na previsão de conflitos e, conseqüentemente, reduzindo a necessidade de separação excessiva entre as aeronaves. Além disso, situações em que restrições devem ser impostas no espaço aéreo podem ser afetadas dependendo de como ocorrem as previsões de posição futura das aeronaves (FALKER; KUCHAR, 2001).

A obtenção das previsões é ainda mais difícil nos momentos de transição, quando uma aeronave entra ou sai de uma área terminal (fase 4 do vôo, visualizada na Figura 5). Essas transições envolvem mudanças significativas e mais constantes de direção, altitude e velocidade da aeronave, o que torna a previsão mais difícil que em situações onde a altitude e direção são constantes (GRACE; GREEN; WILLIAMS, 2000; MCNALLY; ERZBERGER; BACH, 1999).

Além disso, o conceito de Free Flight exige ainda mais flexibilidade para mudanças no cenário do espaço aéreo e, ao mesmo tempo, é necessário manter altos níveis de segurança. Por esse motivo, as ferramentas de apoio a decisão tornam-se essenciais para viabilizar o Free Flight. Assim, prever a posição das aeronaves e também antecipar-se sobre a ocupação do espaço aéreo aparecem como fatores de sucesso ou fracasso do Free Flight (KIRK; BOLCZAK, 2003). Considerando a utilização de Free Flight nas situações em rota, deve-se ter uma boa informação tática sobre o vôo para um período de até 10 minutos além do momento atual, incluindo-se as informações referentes a trajetórias previstas para as aeronaves (FERRO, 2000; YANG; KUCHAR, 1997).

Outro aspecto que merece destaque refere-se aos impactos das novas tecnologias nos fatores humanos, visto que a melhoria dos sistemas não pode acarretar aumento da carga de trabalho (workload) dos profissionais da aviação. É provável que a maior flexibilidade nos vôos traga um aumento considerável na quantidade de potenciais conflitos. Assim, para que a sobrecarga pela resolução de conflitos não fique totalmente sobre o controlador de tráfego aéreo, esta resolução deverá ter auxílios de sistemas automatizados. Para viabilizar as ferramentas traçadas, os elementos do CNS/ATM terão papel fundamental, sobretudo o ADSB, o qual proporcionará as informações necessários à vigilância (FERRO, 2000).

Algumas das principais aplicações beneficiadas por uma melhor previsão de posição futura de aeronaves são:

- Seqüenciamento de aeronaves;

- Redução da separação mínima das aeronaves;

- Detecção e resolução de conflitos; 
- Operações simultâneas em pistas paralelas (OGATA, 2003);

- Sistemas de apoio a decisão;

- RNP - Required Navigation Performance e, conseqüentemente, redução da separação vertical mínima; e

- Operações gate-to-gate.

Com relação às ferramentas de auxílio à detecção e resolução de conflitos, elas podem ser automáticas ou semi-automáticas. Entre as ferramentas automáticas destaca-se o ASAS (Airborne Separation Assistance System), que pode ser definido como: "Um sistema da aeronave baseado em dados de vigilância que proporciona auxílio à tripulação, permitindo a separação entre uma aeronave e outra" (ICAO, 2003d). Entre as ferramentas semiautomáticas, fazem parte dessa categoria o CTAS (Center TRACON Automation System) e o URET (User Request Evaluation Tool). Por se tratarem de ferramentas semi-automáticas, elas apenas proporcionam um auxílio aos controladores, os quais devem tomar as decisões sobre modificações de rotas ou planos de vôos. Maiores detalhes sobre essas ferramentas são descritos em seguida, na seção 3.2.

Finalmente, é importante destacar estudos que mostram a necessidade de melhorar as previsões de posição. Erros em previsões obtidas por extrapolação constituem um fator chave para riscos de colisão na dimensão longitudinal. O ADS foi implantado na região do Pacífico Norte e foi realizado um estudo para analisar os erros associados às previsões de posição obtidas por extrapolação (KODO; NAKAOKA; AMAI, 2002). A proposta dessa pesquisa é iniciar uma avaliação do comportamento das previsões por extrapolação dentro do espaço aéreo brasileiro.

\subsection{Sistemas de Apoio à Decisão para Detecção e Resolução de Conflitos}

Conforme foi destacado, um dos principais motivos de se estudar a previsão de trajetórias é a melhoria no processo de resolução e detecção de conflitos (CD\&R - Conflict Detection and Resolution). O principal objetivo de um sistema CD\&R é prever que um conflito poderá ocorrer no futuro, comunicar o conflito detectado aos controladores de tráfego aéreo e auxiliar na resolução da situação de conflito. Todo esse processo é mostrado resumidamente na Figura 7 (KUCHAR; YANG, 2000). 


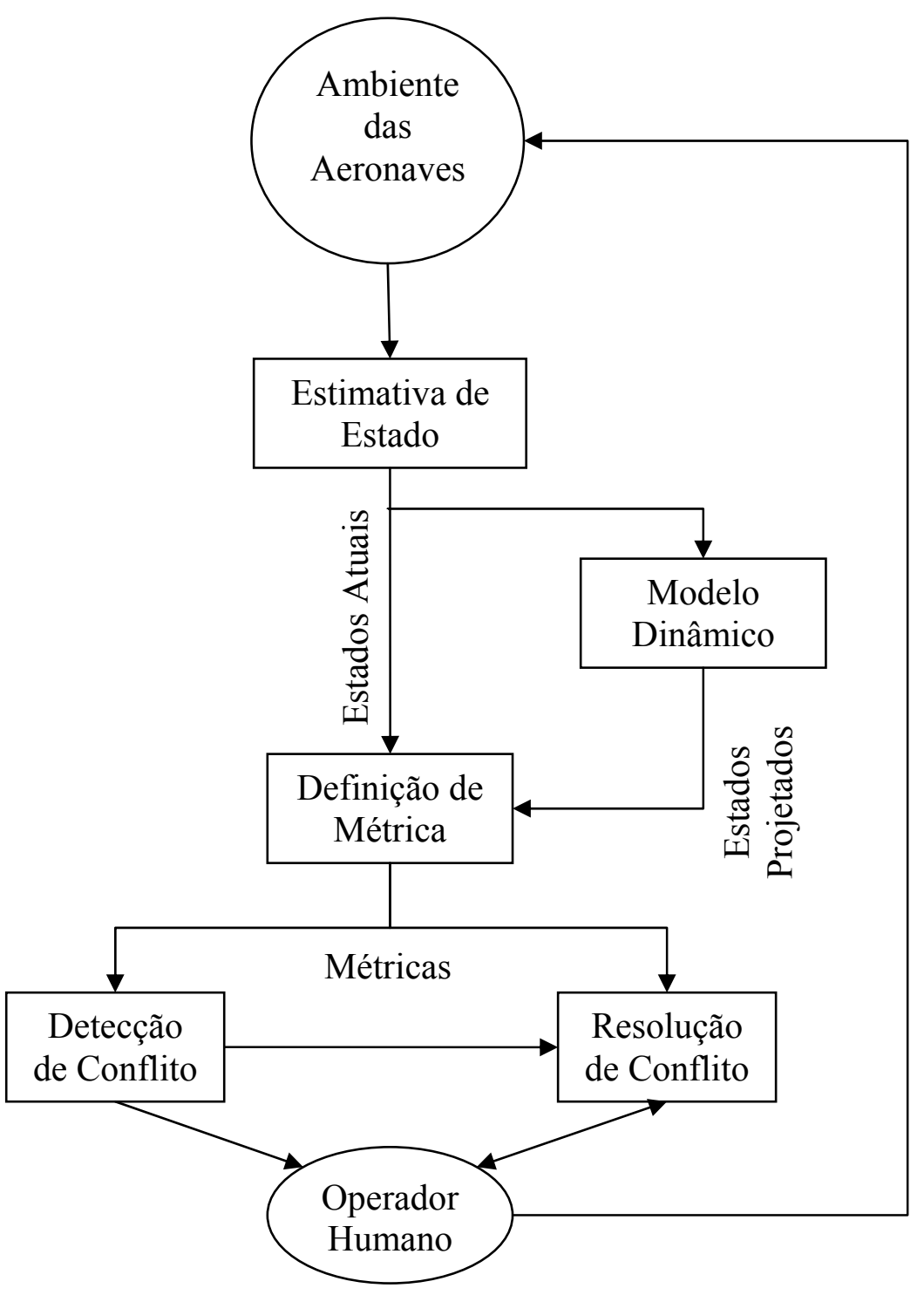

Figura 7: Processo de deteç̧ão e resolução de conflitos (KUCHAR; YANG, 2000). 
De acordo com a figura, o tráfego aéreo deve ser monitorado considerando-se o ambiente em que as aeronaves se encontram. As informações obtidas das aeronaves permitem estimar os estados gerais das aeronaves, que incluem informações sobre o espaço aéreo, tráfego existente, posição, velocidade, rotas, origem e destino das aeronaves. Um modelo dinâmico das trajetórias é utilizado para se prever os estados futuros das aeronaves. Esta previsão, no que diz respeito à posição futura das aeronaves, pode ser baseada em uma simples extrapolação baseada nas posições e velocidades conhecidas, ou pode se basear em um modelo mais complexo, o qual inclui outras variáveis e outros fatores de incerteza, tais como fatores climáticos. Combinando-se as informações atuais e as informações projetadas para os estados futuros, são definidas algumas métricas, como o valor da separação mínima necessária entre as aeronaves. Então, baseado nas métricas definidas, é detectado se há ou não um potencial conflito no futuro. Em situações de conflito, o sistema pode gerar uma notificação para que um operador humano determine a resolução deste conflito ou, então, o próprio sistema pode sugerir uma forma de resolver o conflito detectado.

O processo descrito na Figura 7 mostra, de uma forma genérica, como funciona a detecção e resolução de conflitos. A seguir, são descritos os principais sistemas relacionados ao CD\&R em uso atualmente.

\subsubsection{CTAS}

O Center TRACON ${ }^{8}$ Automation System (CTAS) é uma ferramenta semi-automatizada para auxiliar os operadores do gerenciamento de tráfego, utilizada por diversos órgãos de controle de tráfego aéreo dos EUA. Por se tratar de uma ferramenta semi-automatizada, ela consiste em um meio básico de gerenciamento de tráfego aéreo e não uma solução para resolver, automaticamente, as situações de conflito. O seu princípio geral de funcionamento é o mesmo aplicado a outros sistemas de detecção e resolução de conflitos, conforme descrito anteriormente (GRACE; GREEN; WILLIAMS, 2000; ERZBERGER et al., 1997; PALMER et al., 1997).

Para realizar a detecção de conflito de forma correta, o CTAS é altamente dependente de previsões de posição futura de aeronaves que apresentem alta acurácia (COPPENBARGER; KANNING, 2001). É importante ressaltar que a forma como esse sistema realiza as previsões de posição não são divulgadas, tornando difícil uma comparação entre os resultados obtidos neste trabalho de pesquisa com outros trabalhos semelhantes.

\footnotetext{
${ }^{8}$ TRACON: Terminal Radar Approach Control.
} 


\subsubsection{URET}

O User Request Evaluation Tool (URET) é parte do CTAS, dedicado ao controle em $\mathrm{ACCs}^{9}$ - Area Control Center. É importante destacar que os ACCs controlam o tráfego aéreo em regiões onde as aeronaves estão em rota, correspondendo a uma situação em que as aeronaves sofrem poucas modificações de velocidade ou direção. A dinâmica de um vôo em rota é diferente da dinâmica existente nas áreas terminais e, por essa razão, é necessária uma ferramenta própria para esse cenário. Na proposta de resolução do conflito apresentada pelo sistema, é oferecido um auxílio para a redefinição dinâmica das rotas (KIRK; BOLCZAK, 2003).

\subsubsection{ACAS / TCAS}

O ACAS (Airborne Collision Avoidance System) é um sistema existente na maioria das aeronaves comerciais e que, baseando-se em informações da própria aeronave e também das demais aeronaves dentro de um determinado raio de distância, emite alertas sobre possíveis situações de conflito. Esse sistema também é conhecido como TCAS (Traffic Collision Avoidance System). Para maiores detalhes, consultar (YANG; KUCHAR, 1998; KUCHAR; YANG, 2000; OLIVEIRA; 2003).

\subsubsection{CE-6 - Negociação de Trajetória Em Rota}

Dentro do projeto Advanced Air Traffic Technologies (AATT), a NASA (National Aeronautics and Space Administration) selecionou um grupo de Elementos Conceituais ou Concept Elements (CEs), de forma a explorar e organizar atividades de pesquisa. Dentro desses elementos está o CE-6, que envolve negociação de trajetória, e está diretamente ligado ao problema de previsão de posição futura de uma aeronave (COULURIS, 2000).

\subsection{Aspectos Conceituais da Previsão de Posição Futura de Aeronaves}

Inicialmente, é importante apresentar os principais aspectos conceituais referentes à previsão de posição futura de aeronaves, incluindo os possíveis enfoques que o problema pode ter e também destacando os conceitos de RSP (Required Surveillance Performance) e RNP (Required Navigation Performance).

\subsubsection{Possíveis Enfoques}

Considerando o problema da previsão de conflitos, a previsão de trajetórias pode seguir três enfoques diferentes, conforme destacados em (YANG; KUCHAR, 1998; KUCHAR; YANG, 2000):

\footnotetext{
${ }^{9}$ ACC: Area Control Center / Centro de Controle de Área: órgão responsável por controlar e monitorar aeronaves em âmbito regional (OLIVEIRA, 2003).
} 
- Propagação nominal;

- Propagação no pior caso; e

- Propagação Probabilística

Esses diferentes enfoques são ilustrados na Figura 8.

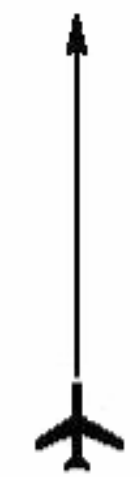

Nominal

(a)

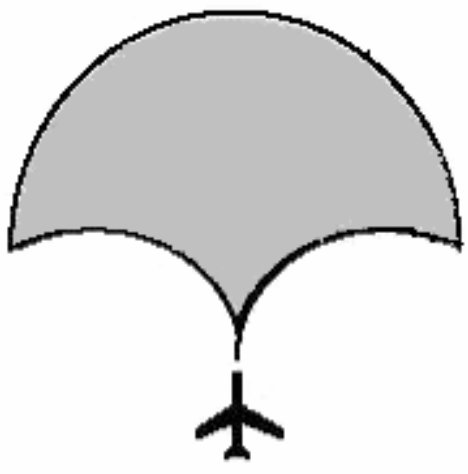

Pior Caso

(b)

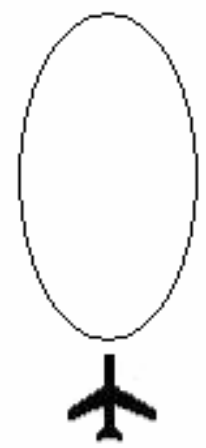

Probabilistico

(c)

Figura 8: Enfoques para a propagação de erro (KUCHAR; YANG, 2000).

$\mathrm{Na}$ trajetória com enfoque em propagação nominal, as incertezas são desconsideradas, sendo realizada uma simples extrapolação baseada na posição atual da aeronave e no vetor da velocidade. A projeção nominal é facilmente calculada e pode ser útil em situações em que a trajetória é bastante previsível, tais como projetar a posição da aeronave poucos segundos no futuro (curto prazo). Por não considerar comportamentos inesperados, a trajetória nominal não pode ser utilizada para situações de médio (5 a 20 minutos) e longo prazo (acima de 20 minutos).

Outro extremo é modelar o comportamento da aeronave com um enfoque de projeção no pior caso. Este enfoque considera que a aeronave pode realizar uma grande série de manobras a partir de sua posição inicial. Se a situação do tráfego não for propensa a uma série grande de manobras, essa abordagem não deverá ser utilizada, pois muitos alarmes falsos serão gerados em sistema de detecção de conflitos, tornando o seu uso pouco eficiente.

No meio termo está o enfoque de propagação probabilístico. Em sistema como URET e CTAS, um erro de posição é adicionado à trajetória nominal. Outra possibilidade é gerar um conjunto completo de possíveis trajetórias futuras, atribuindo uma função densidade de probabilidade para cada uma dessas possíveis trajetórias e, com isso, obter a região mais provável em que a aeronave se encontrará. Trata-se de um enfoque que apresenta equilíbrio entre as duas abordagens anteriores. Em termos de previsão de conflitos e estudos de segurança em tráfego aéreo, esta é a abordagem mais adequada e por meio dela é possível 
estabelecer requisitos quantitativos para medir a segurança dos sistemas (YANG; KUCHAR, 1998).

Sempre que eventos futuros, tais como mudanças de direção, altitude ou velocidade forem conhecidos, essas informações podem ser utilizadas para melhorar a previsão de posição. Um desses eventos ocorre quando o próximo fixo conhecido pelo sistema de previsão de posição futura é alterado, já que esta informação indica uma mudança de direção conhecida.

\subsection{Requisitos da Previsão de Trajetória}

Os estudos do CNS/ATM levaram à especificação de padrões desejados para um bom desempenho dos sistemas de controle e gestão do tráfego aéreo, abrangendo os sistemas de ar e de solo, possibilitando o estabelecimento de métricas gerais para a gestão do tráfego aéreo.

A especificação chamada de Required Navigation Performance (RNP) é uma das mais conhecidas e abrange padrões a serem utilizados nos sistemas de navegação aérea. De forma simplificada, o RNP corresponde a métricas de desempenho relacionadas à acurácia, integridade, disponibilidade e continuidade dos serviços e sistemas de navegação. O sucesso dessa metodologia em definir requisitos comuns para diferentes tecnologias de navegação levou a se buscar esforços similares para se especificar métricas similares a vigilância, criando uma especificação dos requisitos chamada Required Surveillance Performance (RSP) (WARREN, 2000).

Em seguida, são descritas as métricas em termos de previsão de trajetórias, correspondendo aos conceitos básicos envolvendo RSP. A especificação dessas métricas é necessária para garantir que os sistemas de previsão de posição futura atinjam a confiabilidade necessária. Qualquer problema relacionado a esses requisitos, ou seja, se algum deles não for

respeitado, pode forçar a métodos procedurais de vôo, conforme descrito no capítulo 2. Como os métodos procedurais envolvem pouca ou nenhuma automação, uma conseqüência direta é a necessidade de aumento das distâncias (separação) entre as aeronaves, de forma a se manter os níveis de segurança desejados (WARREN, 2000).

\subsubsection{Acurácia}

A acurácia de uma posição futura prevista para uma aeronave é uma medida da incerteza lateral, longitudinal e vertical referente à respectiva posição. Essa incerteza costuma ser medida como uma elipse de forma que existe uma probabilidade de $95 \%$ de que a verdadeira posição da aeronave esteja dentro dessa elipse (WARREN, 2000). 
O modelo proposto neste trabalho de pesquisa trata apenas das incertezas laterais e longitudinais da aeronave, considerando altitude constante. Em geral, a previsão da incerteza vertical é mais difícil de ser calculada, pois são muitos os fatores de incerteza atuando na aeronave, levando a um controle por métodos procedurais, o que corresponde a impor restrições em relação à separação vertical.

$\mathrm{Na}$ Figura 9, está ilustrado como ocorre o crescimento das incertezas lateral e longitudinal da aeronave ao longo do tempo, considerando-se que $t_{l}$ é o instante presente, enquanto $t_{2}$ e $t_{3}$ são instantes futuros para os quais ocorreu uma previsão da posição da aeronave. A partir do formato da elipse, percebe-se que a incerteza longitudinal cresce muito mais que a incerteza lateral. Isso ocorre porque, em geral, desvios laterais são corrigidos pelos equipamentos de controle de vôo. Já os desvios longitudinais têm um alto custo para serem corrigidos, pois exigem acelerações e desacelerações constantes da aeronave, implicando em um aumento no consumo de combustível, o que não é desejável. No capítulo 5, há explicações mais detalhadas sobre esse assunto, incluindo explicações sobre como as distribuições dos erros lateral e longitudinal são calculadas.

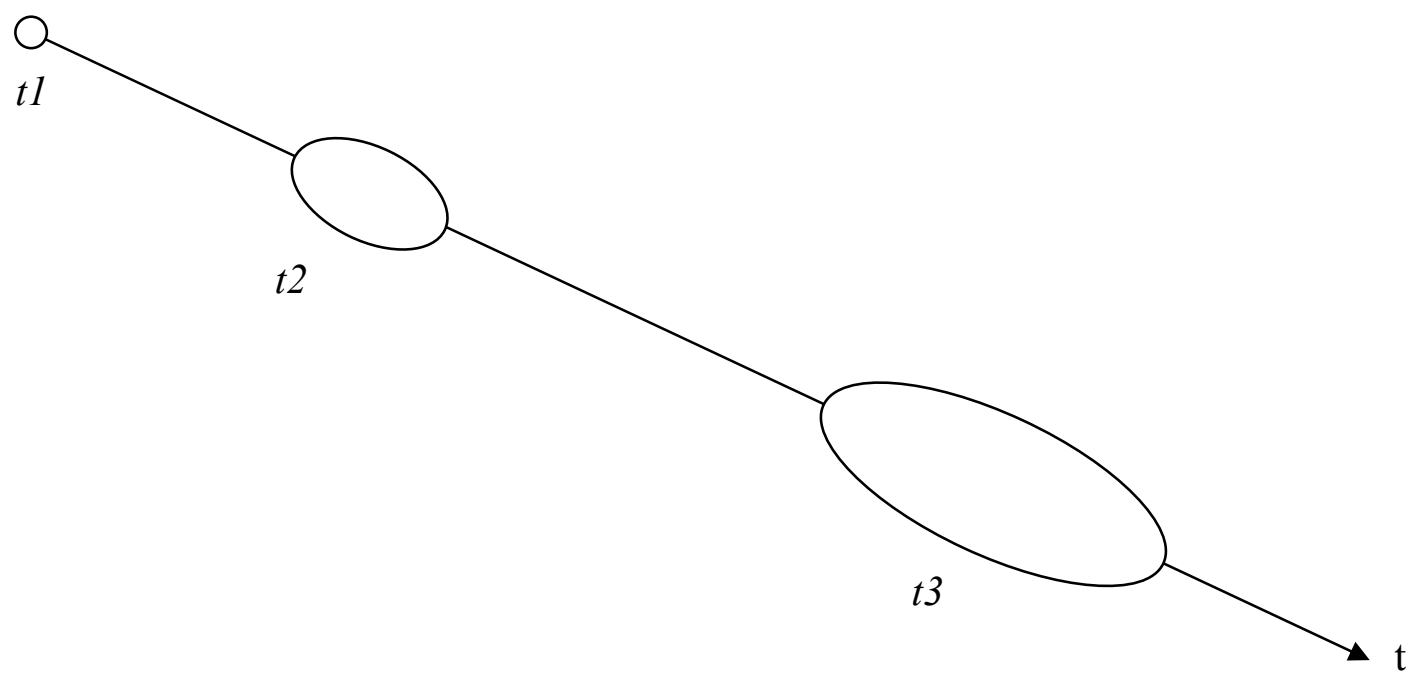

Figura 9: Propagação da incerteza ao longo do tempo.

O escopo desse trabalho se concentra em avaliar a acurácia ao se prever uma posição futura de uma aeronave aplicando-se o princípio de extrapolação baseada em posições conhecidas da aeronave. 
As principais falhas que impedem a obtenção da acurácia esperada estão relacionadas a mudanças não previstas na direção de vôo. Outra causa de falhas ocorre quando há mudanças de direção da própria aeronave. Mudanças de direção ocorrem sempre que um fixo é atingido dentro do plano de vôo, em situações de conflito, ou quando há a necessidade de alterar o plano de vôo. As manobras utilizadas em uma mudança de direção inserem uma grande incerteza na trajetória, mesmo quando são mudanças previstas, impactando a acurácia de uma previsão de posição. Também é importante destacar como a acurácia se comporta no conceito de Free Flight. Com a flexibilidade trazida pelo Free Flight em termos de possibilidades de escolha de rotas a serem seguidas, a acurácia pode ficar mais baixa, em razão de aumentar a quantidade de mudanças na direção das aeronaves e dos seus respectivos planos de vôo. Vôos realizados nessas condições requerem um tratamento especial (YANG; KUCHAR; 1997).

\subsubsection{Integridade}

A integridade da previsão de posição de uma aeronave é uma medida da probabilidade de que uma posição prevista esteja fora da região esperada e sem que exista um alerta para o problema. De forma mais simplificada, é a probabilidade do sistema fornecer informações erradas sem avisar.

Uma falha na integridade não implica, necessariamente, em uma falha no sistema. Mas fica o risco de se operar diante de um erro de previsão. Os níveis aceitáveis para a falta da integridade dependem das possíveis conseqüências da perda da integridade em termos de segurança.

Há dois níveis de integridade considerados nos sistemas de apoio a decisão:

- Não Essencial - em aplicações como gerenciamento de carga do tráfego, o nível de integridade pode ser baixo, já que as conseqüências de sua falha são pequenas; e

- Essencial - as aplicações como gerenciamento de chegadas requerem maior nível de integridade, já que as conseqüências podem ser mais perigosas, causando sobrecarga para pilotos e controladores. As falhas, ou seja, a quantidade de vezes que a integridade pode falhar, devem ter uma probabilidade de ocorrência da ordem de $10^{-5}$ falhas/hora.

Aplicações que necessitem de níveis de integridade ainda melhores ainda são pouco prováveis (WARREN, 2000).

A maior parte dos métodos de previsão de trajetórias existentes hoje não são capazes de garantir um bom nível de integridade. Uma das principais causas são os grandes erros existentes na previsão dos ventos. Para melhorar a integridade é necessário incluir fontes redundantes de informações. Com isso, é possível realizar correções de dados vindos de 
fontes com baixa confiabilidade, sobretudo previsões incorretas sobre ventos. Quando não for possível realizar as correções, resta aumentar a incerteza na previsão ou indicar que naquele momento a previsão está indisponível.

\subsubsection{Disponibilidade}

A disponibilidade assintótica ${ }^{10}$ do fornecimento da posição de uma aeronave é uma medida da porcentagem do tempo que o sistema de previsão de posição está disponível e fornecendo resultados satisfatórios. As principais causas para a não disponibilidade do sistema são:

- Não disponibilidade das informações básicas das trajetórias.

- Mudanças bruscas nas condições meteorológicas ou condições meteorológicas adversas.

Em relação à primeira causa, há centenas de tipos de aeronaves em operação, o que pode tornar difícil manter informações confiáveis sobre os dados das trajetórias para todos os tipos de aeronave. Pelo menos os espaços aéreos mais importantes e as aeronaves que mais voam nesses espaços aéreos têm as informações atualizadas.

Mudanças nas condições climáticas, sobretudo os ventos, constituem uma grande causa da indisponibilidade de previsões de posição. Os sistemas atuais de previsão do tempo nem sempre conseguem prever todas as mudanças que ocorrem, o que pode acarretar previsões de posição incorretas.

\subsection{Fontes de Dados e Fatores de Incerteza}

Nesta seção, são apresentadas as principais fontes de erro e incerteza associados à previsão de posição futura de uma aeronave. Há cinco potenciais fatores que causam erros na previsão, sobretudo em situações de mudanças de altitude, conforme lista seguinte (WARREN, 2000):

- Erros de rota e de pontos de referência (Path routing \& intent errors) - são erros ligados à falta de algumas informações que deveriam estar presentes nos planos de vôo, sobretudo informações que permitam prever os perfis de subida e descida (mudanças de altitude) da aeronave;

\footnotetext{
${ }^{10}$ A disponibilidade de um sistema, expressa por $A(t)$, é uma função do tempo definida como a probabilidade de que o sistema estará funcionando corretamente e estará disponível para executar suas funções no instante de tempo $t$. A função $A(t)$ costuma ser uma curva que começa com valores próximos a 1 e tende a um certo valor, assintoticamente. Este valor para o qual $A(t)$ tende é chamado de disponibilidade assintótica.
} 
- Erros na previsão meteorológica (YANG; KUCHAR, 1998) - nesse caso há dificuldade em se prever corretamente o comportamento dos ventos, principalmente prever mudanças na direção dos ventos;

- Erros de vigilância acerca da posição e velocidade da aeronave em um determinado instante no tempo - alguns sistemas de vigilância não fornecem, de forma correta, algumas informações, principalmente as componentes de velocidade da aeronave;

- Erros de modelagem de desempenho e perfil de vôo de aeronaves (Aircraft performance and profile modeling errors) - esta fonte de erros está associada à complexidade da dinâmica associada à mudanças de altitude, sendo que o comportamento da aeronave varia de um vôo para outro; e

- Erro técnico no controle do caminho de vôo (Flight Technical Error (FTE) in trajectory path control) - erros técnicos que podem impedir o correto monitoramento do caminho sendo percorrido.

Os três primeiros tipos de erro tendem a dominar em fase de cruzeiro, que corresponde ao foco de investigação deste trabalho. Para melhorar as previsões nessas situações, surgem as necessidades de:

- Enhanced Surveillance - permite trazer informações mais corretas sobre as componentes de velocidade da aeronave e nível de altitude do vôo;

- Atualização constante sobre a previsão dos ventos - a atualização constante na previsão dos ventos, associado ao uso de sistemas redundantes para realizar estas previsões auxiliam na diminuição desse que é um dos principais fatores de incerteza; e

- Atualização do caminho pretendido a ser seguido no vôo - a constante verificação se o caminho percorrido está em conformidade com o plano de vôo, associada a uma atualização do plano sempre que necessário, auxilia na diminuição das incertezas nas previsões.

Conforme destacado anteriormente, as mudanças de altitude tornam a previsão de posição mais difícil. Para facilitar, existem métodos simplificados para previsão de trajetórias em situações de subida e descida que utilizam informações do comportamento padrão de um determinado tipo de aeronave em situações de mudanças de altitude. No entanto, por não considerarem muitos dos fatores de incerteza associados a mudanças de altitude, acarretam erros com um grau de magnitude muito alto, o que limita o seu uso. O correto é utilizar 
algumas técnicas mais avançadas, descritas em (COPPENBARGER, 1999), para garantir uma previsão mais segura em situações de mudanças de altitude.

O foco de estudos mais recentes é manter o máximo de controle nas incertezas da velocidade causadas por fontes de informações como vigilância e previsão de vento. Dentre os fatores de erros citados e considerando as propostas para melhorias nas previsões de posição futura, existem três categorias de fontes de dados que merecem um destaque:

- Plano de vôo;

- Dados de vigilância relacionados à aeronave e condições climáticas; e

- Dados de desempenho da aeronave.

A Tabela 1 mostra um resumo dos dados que estão relacionados a essas fontes (WARREN, 2000), juntamente com a informação sobre cada fonte, se ela já pode ser utilizada no presente ou se é uma fonte para o futuro.

Tabela 1: Fontes de dados para melhoria nas previsões de posição futura (WARREN, 2000).

\begin{tabular}{|l|l|}
\hline Fonte de Dados & Status \\
\hline Plano de vôo & \\
\hline Plano de vôo como uma seqüência de fixos & Presente \\
\hline Velocidade do ar & Futuro \\
\hline Perfil de subida e descida & Futuro \\
\hline Dados de vigilância relacionados à aeronave e condições & \\
\hline Previsão de temperatura longitudinal & \\
\hline Previsões de ventos laterais e longitudinais & Presente \\
\hline Dados de vigilância do radar ou ADS-B & Presente \\
\hline Posição horizontal e altitude Modo C / S & Presente \\
\hline Previsão do tempo de chegada ao próximo fixo & Futuro \\
\hline Base de dados de desempenho da aeronave & Presente \\
\hline Perfis de empuxo e arrasto / Coeficientes BADA ${ }^{11}$ & Futuro \\
\hline Parâmetros do vôo, ex.: Transição CAS / Mach & \\
\hline Estimativa da massa da aeronave & Presente \\
\hline
\end{tabular}

\footnotetext{
${ }^{11}$ BADA: Base of Aircraft Data: Base de dados contendo informações utilizadas para se calcular diversos parâmetros para um vôo, tais como empuxo, arrasto, consumo de combustível e velocidades nominais de cruzeiro, subida e descida. Essa base fornece, atualmente, informações para 295 diferentes tipos de aeronaves (EUROCONTROL, 2004).

${ }^{12}$ Mach: é um número obtido pela razão Velocidade da Aeronave/Velocidade do Som.
} 
Convém destacar novamente os erros associados aos sistemas de vigilância, os quais apresentam pouca acurácia na estimativa dos componentes da velocidade, principalmente em manobras verticais ou manobras de curvas (mudanças de direção). Isso também reflete na magnitude da incerteza longitudinal.

\subsubsection{Roteamento e Intenção de Trajetória (Trajectory Routing and Intent)}

As informações sobre trajetória são obtidas, inicialmente, a partir do plano de vôo. No entanto, o tipo da aeronave e as condições do espaço aéreo influenciam fortemente a trajetória que a aeronave seguirá. Maiores informações sobre planos de vôo e construção de trajetórias podem ser obtidas no capítulo 5. O importante é destacar que não basta apenas a aeronave seguir o plano de vôo. Algumas outras opções podem ser utilizadas para que se obtenha uma vigilância mais avançada e, conseqüentemente, se melhorem as previsões:

- Atualização dinâmica do plano de vôo - foi detectada a necessidade de se alterar a interface onde o controlador de tráfego aéreo insere e altera as informações sobre plano de vôo. Desta maneira, torna-se mais fácil manter o plano de vôo atualizado sempre que houver modificações no mesmo;

- Broadcast dos fixos - uma outra possibilidade é obter a atualização dos fixos de forma automática por meio de um broadcast feito pela aeronave utilizando o ADS-B. Com isso, é possível verificar se o plano de vôo está sendo seguido, possibilitando atualizações; e

- Monitoramento do caminho seguido - um método de manter atualizada a rota seguida pela aeronave é monitorar se o caminho sendo seguido está em conformidade com o plano de vôo. No entanto, isso não é suficiente para se atualizar automaticamente o plano de vôo, mas pode ser possível estimar quais são os possíveis candidatos a novos fixos e, com isso, obter uma previsão de qual pode ser o caminho mais provável a ser seguido pela aeronave.

\subsubsection{Incertezas do Vetor do Vento e da Velocidade da Aeronave em Relação ao Ar}

Para o cálculo da posição futura, é necessário obter a velocidade da aeronave em relação ao solo $\left(\mathrm{V}_{\mathrm{g}}\right.$ - ground velocity). Geralmente esta velocidade é calculada compondo o vetor da velocidade em relação ao ar $\left(\mathrm{V}_{\mathrm{a}}\right.$ - airspeed $)$ com o vetor do vento $\left(\mathrm{V}_{\mathrm{w}}\right.$ - windspeed $)$, conforme a Figura 10. 


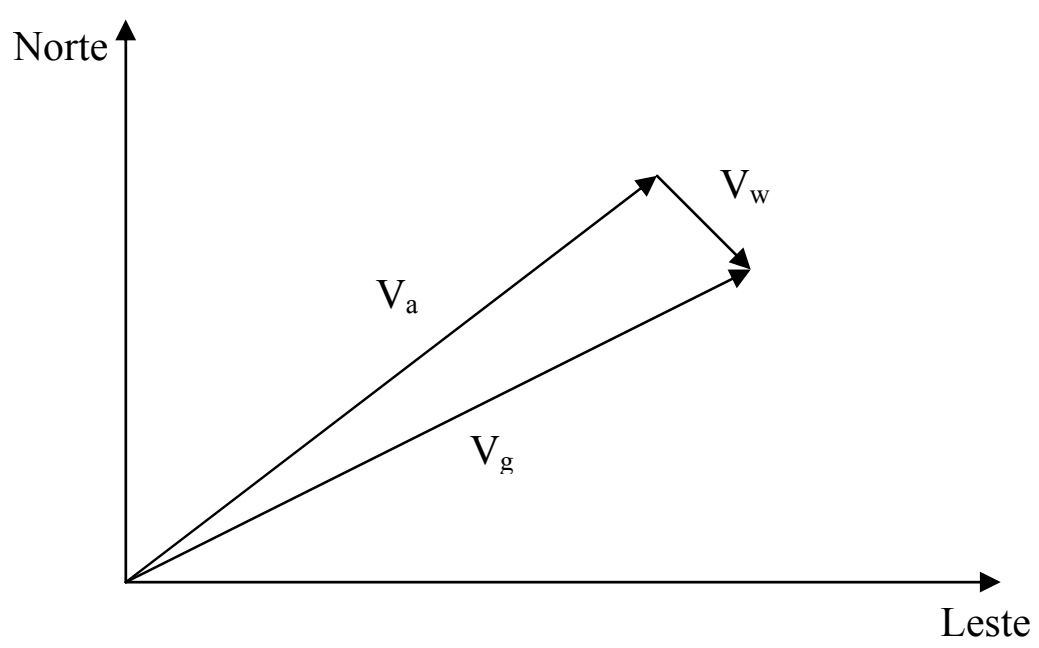

Figura 10: Cálculo da velocidade vetorial da aeronave em relação ao solo $\left(V_{\mathrm{g}}\right)$.

Um problema desse enfoque é que os vetores $V_{w}$ e $V_{a}$, utilizados para se obter a velocidade da aeronave $\left(\mathrm{V}_{\mathrm{g}}\right)$ têm uma grande imprecisão. Uma outra possibilidade é utilizar a velocidade $\left(\mathrm{V}_{\mathrm{g}}\right)$ obtida pelos radares. No entanto, esta velocidade também apresenta uma imprecisão maior que o desejado. A verificação da velocidade utilizando as duas abordagens simultaneamente é uma maneira de melhorar a integridade. Para maiores detalhes sobre a modelagem do vento, consultar (MONDOLONI, 2000).

Outro fator que merece um destaque especial corresponde às mudanças de direção da aeronave (MONDOLONI; PAGLIONE; GREEN, 2002). Em geral, as mudanças de direção são modeladas como mudanças instantâneas (descontínuas), como se a curva fosse feita de forma imediata. A inclusão da dinâmica de mudança de direção pode melhorar significativamente o modelo, sobretudo para situações de previsão de longo prazo (acima de 20 minutos). Quando a previsão é obtida para um trecho sem que a aeronave passe por um fixo, é possível considerar mudanças instantâneas de direção, sem comprometer a qualidade da posição prevista.

\subsection{Considerações Finais do Capítulo}

Neste capítulo, foi destacado como a previsão de posição futura de aeronaves se insere dentro do contexto do controle de tráfego aéreo. A principal utilização ocorre dentro de sistemas de apoio a decisão, principalmente sistemas para detecção e resolução de conflitos (CD\&R), os quais necessitam de previsões geradas para o curto (poucos segundos) e médio (até 20 minutos) prazos. Então, alguns dos principais sistemas CD\&R foram descritos. Destacam-se também os sistemas responsáveis pelo dimensionamento do espaço aéreo, com a verificação da densidade do tráfego, interessando para esses sistemas as informações de previsão de posição de longo prazo (acima de 20 minutos). 
Posteriormente, foram apresentados os aspectos principais da previsão de posição futura das aeronaves, destacando detalhes mais específicos sobre os requisitos exigidos na previsão de posição. Os possíveis enfoques do problema foram mostrados, com especial destaque para o enfoque probabilístico. Em seguida, foram descritos os requisitos envolvidos na determinação das trajetórias, atribuindo-se maior ênfase no requisito da acurácia. Foi mostrado como os erros de previsão se comportam ao longo do tempo, visto que o conhecimento desta propagação é fundamental para se saber que tipo de informação pode ser utilizado dentro dos sistemas de apoio a decisão.

Finalmente, foram destacadas as fontes de informações e os respectivos fatores de incerteza. De forma geral, as informações sobre posição, desempenho da aeronave e velocidade são utilizadas para se calcular a posição prevista. O principal fator de incerteza é o vento, já que não existe um controle sobre ele, além de ele ter um comportamento bastante aleatório. 


\section{MÉTODOS ESTATÍSTICOS E REGRESSÃO LINEAR}

Este capítulo apresenta a fundamentação matemática utilizada nos métodos propostos neste trabalho de pesquisa. Inicialmente, são mostrados alguns conceitos elementares sobre descrição de dados de uma amostra, medidas de suas probabilidades, e como isso tudo pode representar os dados de uma população. Em seguida, as principais distribuições de probabilidade são apresentadas, com destaque para a distribuição normal e suas propriedades. A distribuição normal é a base para todo o estudo e análise de erros realizadas neste trabalho. Por fim, são mostradas as principais formas de se construir modelos que permitam obter a correlação entre variáveis existentes em um problema. A maior ênfase é dada para a análise de regressão linear, utilizada na extrapolação dos dados para determinar o comportamento da variação de posição das aeronaves ao longo do tempo.

O objetivo deste capítulo não é fornecer uma visão detalhada desses tópicos, mas apenas familiarizar o leitor com os principais conceitos e notações utilizadas neste trabalho de pesquisa, de forma a facilitar a leitura dos capítulos seguintes.

\subsection{Descrição de Dados}

Nesta seção, são apresentadas maneiras de se medir posição e variabilidade para um conjunto de valores. Essas medidas são importantes para se saber, mais detalhadamente, como os dados de uma população se comportam. As principais medidas utilizadas são: média e variância (KAZMIER, 1982).

\subsubsection{Medidas de Posição}

Uma medida de posição é um valor calculado para um grupo de dados e usado, de alguma forma, para descrevê-los. Tipicamente, trata-se de um valor que seja representativo de todos os valores do grupo. Do ponto de vista estatístico, é uma medida de tendência central para uma série de valores.

A média aritmética $\mu$ é a medida mais comum para determinar essa tendência central para uma série de valores. Para um conjunto de valores $X=\left\{X_{1}, X_{2}, \ldots, X_{N}\right\}$, a média pode ser obtida pela expressão:

$$
\mu=\frac{\sum_{i=1}^{N} X_{i}}{N}
$$

A mediana de um grupo de itens é o valor do item médio quando todos os itens do grupo forem dispostos em ordem crescente ou decrescente. 
Para os estudos realizados nesta pesquisa, apenas interessará utilizar a média como medida de posição, já que ela permite uma maior quantidade de análises.

\subsubsection{Medidas de Variabilidade}

As medidas de tendência central, como a média, são úteis para identificar um valor típico em um grupo de valores. Por outro lado, as medidas de variabilidade dizem respeito à descrição de um grupo de valores em termos da variabilidade existente entre os itens incluídos dentro do grupo. Há várias técnicas disponíveis para a mensuração da variabilidade, tais como:

\section{Amplitude Total}

A amplitude total é a diferença entre o maior e o menor valor dentro dos itens existentes em um grupo de valores de uma amostra.

\section{Amplitude Modificada}

Uma amplitude modificada é aquela em que se eliminou uma certa porcentagem de valores em cada um dos extremos da distribuição. As amplitudes modificadas típicas são dos elementos $50 \%$ centrais, dos elementos $80 \%$ centrais ou dos elementos $90 \%$ centrais.

\section{Desvio Médio}

O desvio médio $D M$ é baseado na diferença entre cada valor do conjunto de dados $X$ e a média $\mu$ do grupo. Em notação matemática, tem-se:

$$
D M=\frac{\sum_{i=1}^{N}\left|X_{i}-\mu\right|}{N}
$$

\section{Variância e Desvio Padrão}

A variância $\sigma^{2}$ é similar ao desvio médio no sentido de que também é baseada nas diferenças entre cada valor do conjunto de dados $X$ e a média aritmética $\mu$ do grupo. No entanto, na variância essas diferenças são elevadas ao quadrado. Para o seu cálculo, utiliza-se a fórmula:

$$
\sigma^{2}=\frac{\sum_{i=1}^{N}\left(X_{i}-\mu\right)^{2}}{N}
$$


A Equação (3) apenas é válida para o cálculo da variância de uma população inteira. Por exemplo, para analisar a variância dos erros de posição de uma aeronave, essa fórmula apenas pode ser utilizada se forem considerados todos os vôos de uma determinada aeronave. Naturalmente, esta situação é muito difícil de ser obtida, já que dificilmente consegue-se calcular os erros de posição para todos os vôos de uma aeronave. Assim, é necessário calcular a variância para uma amostra e, então, utilizar este valor para estimar o valor da variância para toda a população. Isso corresponde a se obter a variância considerando apenas alguns vôos de uma aeronave. No entanto, para o cálculo da variância de uma amostra, a expressão muda um pouco, ficando da seguinte forma:

$$
\sigma^{2}=\frac{\sum_{i=1}^{N}\left(X_{i}-\mu\right)^{2}}{N-1}
$$

Esta diferença no denominador corresponde a um fator de correção da fórmula, de maneira que a variância da amostra seja um estimador não tendencioso ${ }^{13}$ da variância da população; para maiores detalhes consultar (KAZMIER, 1982).

Baseado no cálculo da variância, é obtido o desvio padrão $\sigma$ dos dados, por meio da raiz quadrada do valor da variância. Assim, para uma amostra de dados, que é a realidade deste estudo, o desvio padrão $\sigma$ pode ser expresso por:

$$
\sigma=\sqrt{\frac{\sum_{i=1}^{N}\left(X_{i}-\mu\right)^{2}}{N-1}}
$$

O desvio padrão é a mais importante medida de dispersão. Maiores detalhes do seu uso são apresentados na descrição de distribuição normal de probabilidade.

\subsection{Distribuições de Probabilidade}

Aqui são apresentadas as principais distribuições de probabilidade existentes. As propriedades mais importantes de interesse para esse trabalho estão descritas, assim como as aplicações práticas de cada distribuição. Maiores detalhes são encontrados em (BUSSAB; MORETIN, 1994).

Antes de descrever as distribuições de probabilidade, é importante introduzir o conceito de variável aleatória discreta e variável aleatória contínua.

\footnotetext{
${ }^{13}$ Um estimador não tendencioso é uma estatística amostral cujo valor esperado é igual ao parâmetro que está sendo utilizado. Em outras palavras, a variância da amostra é uma boa medida para se estimar a variância da população. (KAZMIER, 1982).
} 


\section{Variável Aleatória Discreta:}

Definição: Seja a função $X: \Omega \rightarrow E$, tal que $\Omega$ é um espaço amostral e $E \subset \Re$ é um conjunto enumerável de valores reais. A probabilidade que $X$ assuma o valor $x_{i}$ é $P\left(X=x_{i}\right)=P(A)$, onde:

$A \subset \Omega$ é um sub-conjunto do espaço amostral, tal que:

$$
\begin{aligned}
& X\left(\omega_{i}\right)=x_{i}, \text { se } \omega_{i} \in A \text { e } \\
& X\left(\omega_{i}\right) \neq x_{i}, \text { se } \omega_{i} \notin A
\end{aligned}
$$

A função $X$, conforme definida é chamada de variável aleatória discreta. A Figura 11 ilustra a situação descrita na definição de uma variável aleatória discreta.

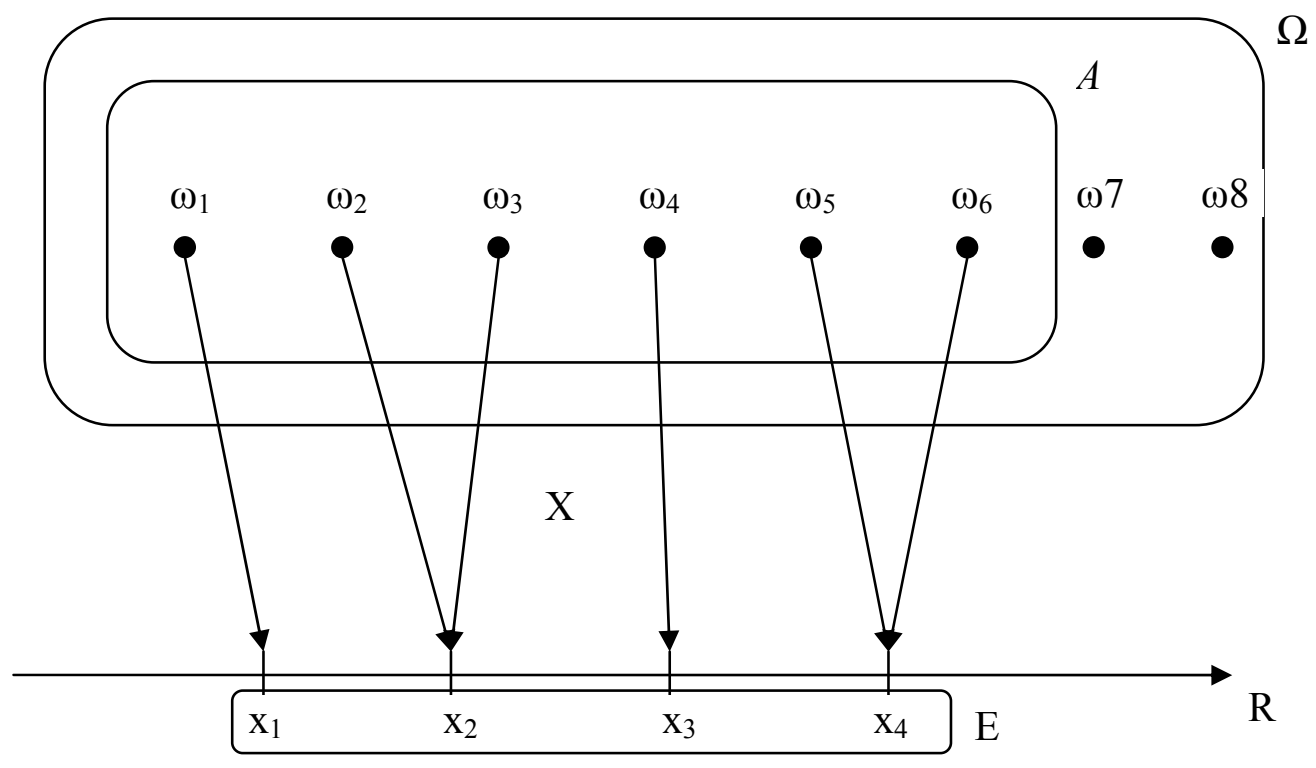

Figura 11: Ilustração da definição de uma variável aleatória discreta.

Definição: Seja a função $p: E \rightarrow[0,1]$, tal que $p\left(x_{i}\right)=P\left(X=x_{i}\right)=p_{i}$ é a probabilidade de que $X$ assuma o valor $x_{i}$, ou seja, $\sum_{x_{i} \in E} p\left(x_{i}\right)=1$. A função $p$, conforme definida, é chamada de função de probabilidade da variável aleatória discreta $X$.

Existem diversos problemas cujas modelagens levam à obtenção de uma função de probabilidade de uma variável aleatória. O exemplo mais conhecido é a distribuição de Poisson, utilizada para modelar eventos raros que ocorrem em um certo intervalo de tempo, tais como: número de chamadas telefônicas recebidas por um PABX, número de falhas de um computador em um dia de operação, número de relatórios de acidentes enviados a uma companhia de seguros em uma semana, etc.

Outros exemplos de utilização de variáveis aleatórias discretas estão disponíveis em (BUSSAB; MORETIN, 1994). 


\section{Variável Aleatória Contínua:}

Definição: Seja a função $f: \mathfrak{R} \rightarrow \mathfrak{R}^{+}$tal que $\int_{-\infty}^{\infty} f(x) d x=1$. Esta função é chamada de função densidade de probabilidade e define uma variável aleatória contínua $X$, de forma que $\forall a, b \in \mathfrak{R}, a<b, P(a \leq X<b)=\int_{a}^{b} f(x) d x$.

Este capítulo traz alguns exemplos de distribuições de probabilidade que seguem uma variável aleatória contínua. A Figura 12 mostra um exemplo de função densidade de probabilidade de forma que a área sob o gráfico, entre os pontos $a$ e $b$ corresponde à probabilidade de que a variável $X$ assuma valores entre $a$ e $b$, ou seja, $P(a \leq X<b)$.

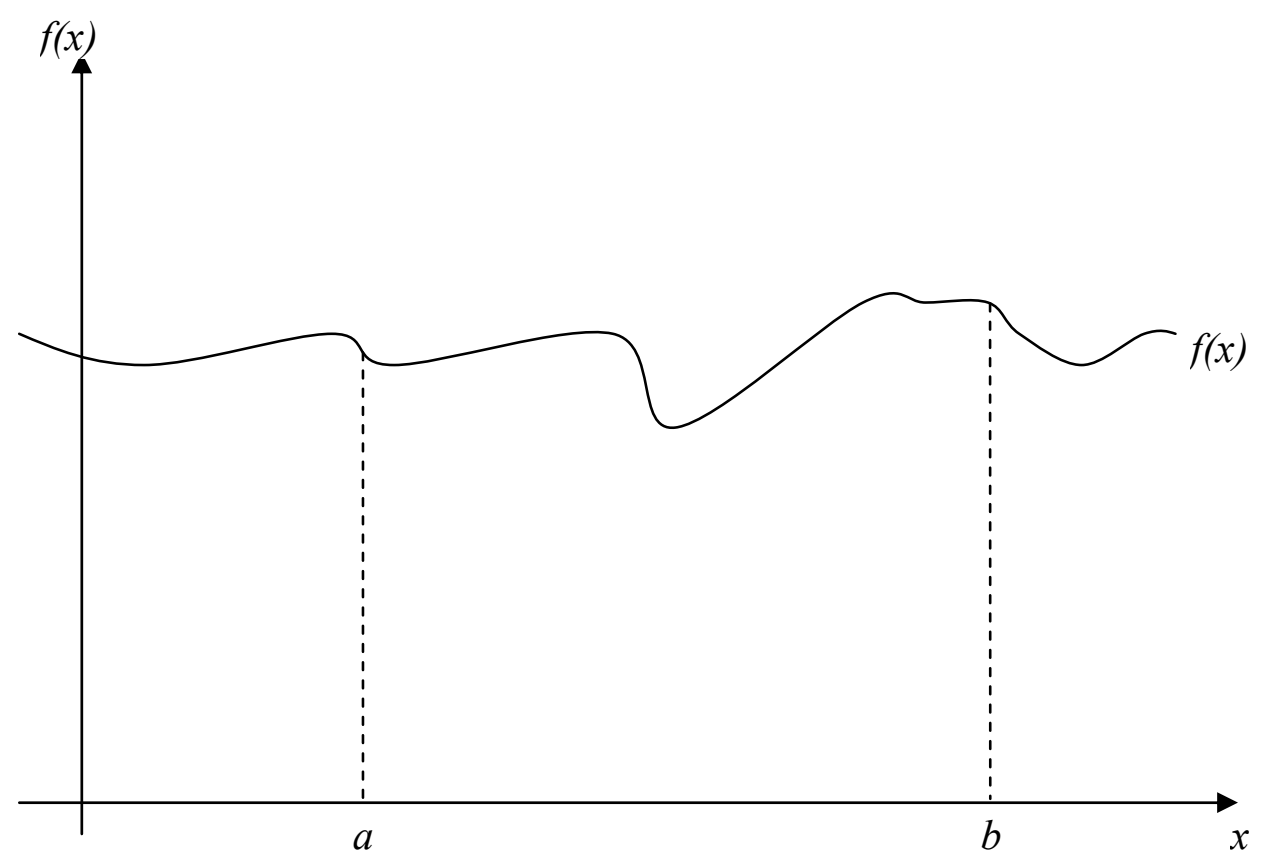

Figura 12: Exemplo de função densidade de probabilidade

\section{Exemplos de Variáveis e Distribuições:}

Considere um conjunto $X$, que contém diversos valores, que podem ser contínuos $\left(X_{I}\right)$ ou discretos $\left(X_{2}\right)$, como por exemplo:

$$
\begin{aligned}
& X_{1}=\{1,2,3,4,5\} \\
& X_{2}=[-5, \pi]
\end{aligned}
$$


Quando são atribuídos valores de probabilidade a todos os possíveis valores de $X$, está-se inserindo o conceito de variável aleatória, conforme já definido anteriormente. Para toda variável aleatória, duas medidas são importantes: o valor esperado ou média, representado por $E(X)$, e a variância, representada por $\operatorname{Var}(X)$. A forma como são obtidos o valor esperado e a variância podem ser vistos em (BUSSAB; MORETIN, 1994). Algumas das principais distribuições probabilísticas, modeladas como variáveis aleatórias contínuas, são descritas a seguir.

\subsubsection{Distribuição Uniforme}

Uma variável aleatória $X$ tem distribuição uniforme de probabilidade se a sua função distribuição de probabilidade é dada por:

$\left\{\begin{array}{l}f(x)=\frac{1}{\beta-\alpha}, \text { se } \alpha \leq x \leq \beta \\ f(x)=0, \text { nos demais pontos }\end{array}\right.$

A representação gráfica da distribuição uniforme está ilustrada na Figura 13.

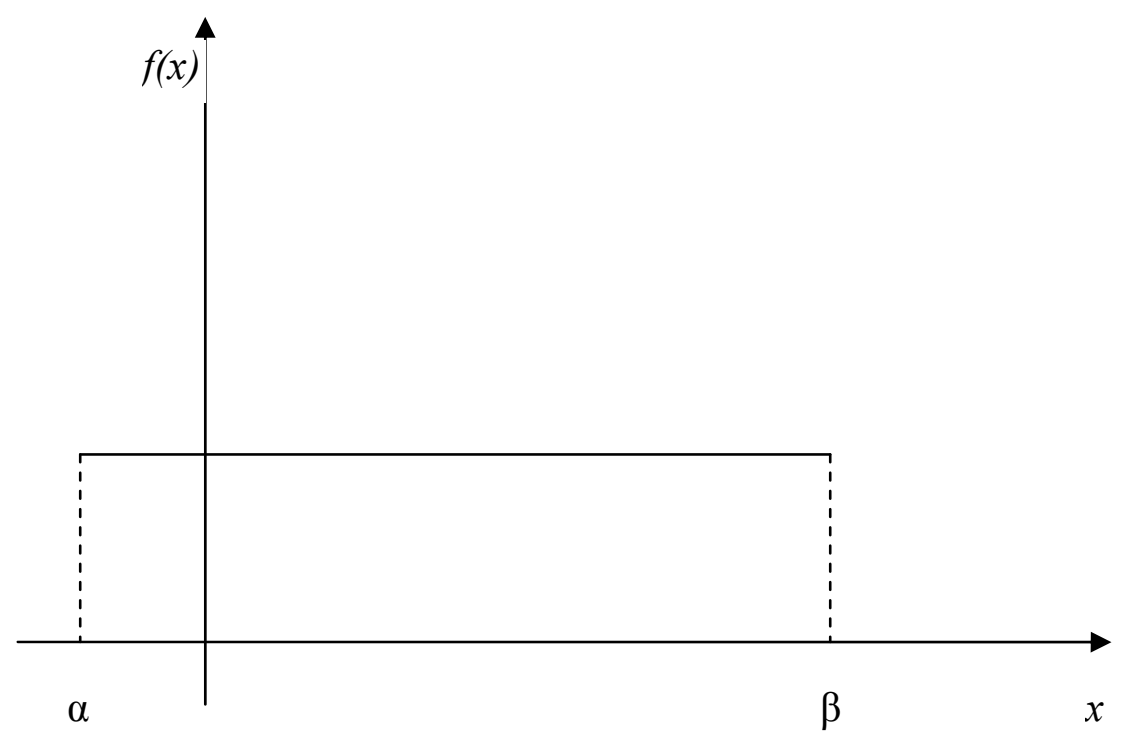

Figura 13: Distribuição uniforme de probabilidade.

Para a distribuição uniforme, tem-se (BUSSAB; MORETIN, 1994):

$$
\begin{aligned}
& E(X)=\frac{\alpha+\beta}{2} \\
& \operatorname{Var}(X)=\frac{(\beta-\alpha)^{2}}{12}
\end{aligned}
$$




\subsubsection{Distribuição Exponencial}

Uma variável aleatória $\mathrm{X}$ tem distribuição exponencial de probabilidade, com parâmetro $\beta>0$, se a sua função distribuição de probabilidade é dada por:

$$
\left\{\begin{array}{l}
\mathrm{f}(\mathrm{x})=\frac{1}{\beta} e^{-x / \beta}, \text { se } \mathrm{x} \geq 0 \\
\mathrm{f}(\mathrm{x})=0, \text { se } \mathrm{x}<0
\end{array}\right.
$$

O gráfico da distribuição exponencial de probabilidade está representado na Figura 14.

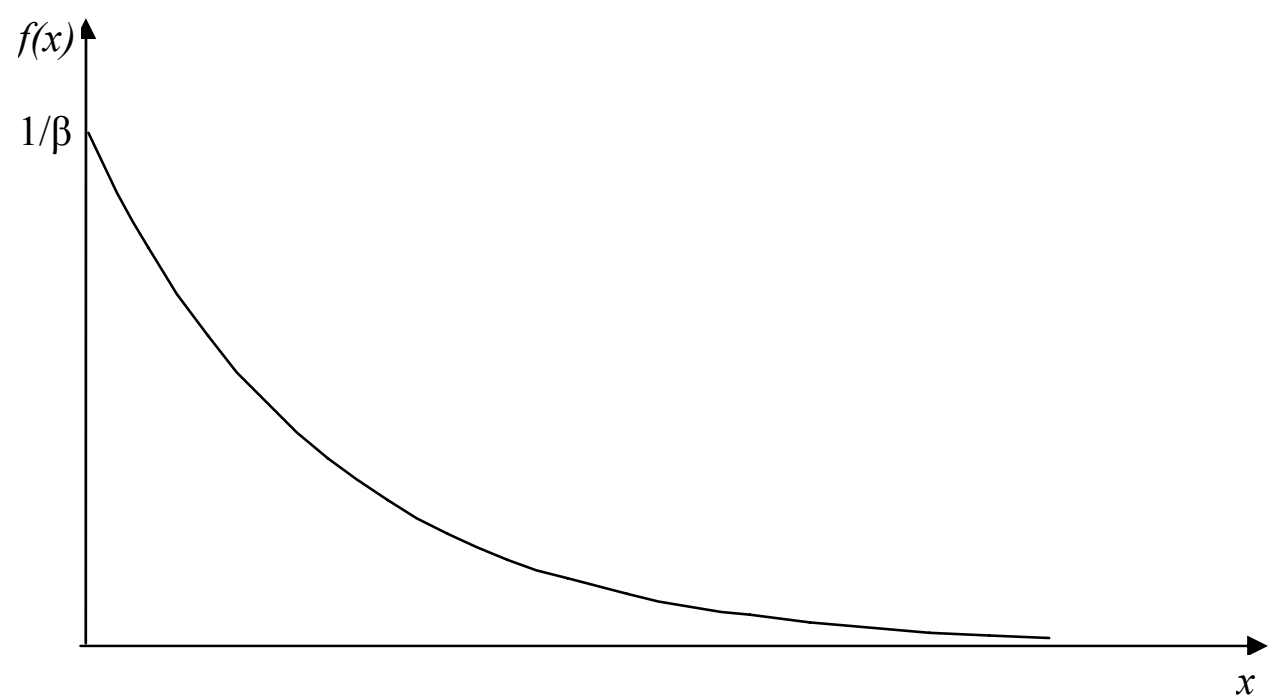

Figura 14: Distribuição exponencial de probabilidade.

Para a distribuição exponencial, tem-se (BUSSAB; MORETIN, 1994):

$$
\begin{aligned}
& E(X)=\beta \\
& \operatorname{Var}(X)=\beta^{2}
\end{aligned}
$$

A distribuição exponencial é utilizada para modelar problemas como o tempo de vida de equipamentos.

\subsubsection{Distribuição Normal}

Uma variável aleatória $X$ tem distribuição normal com parâmetros $\mu$ e $\sigma^{2},-\infty<\sigma^{2}<+\infty$, se sua função distribuição de probabilidade é dada por:

$$
f(x)=\frac{1}{\sigma \sqrt{2 \pi}} e^{-(x-\mu)^{2 / 2 \sigma^{2}}}, \text { para }-\infty<x<+\infty
$$

O gráfico para a distribuição normal tem a forma de um "sino", conforme pode ser visto na Figura 15. 


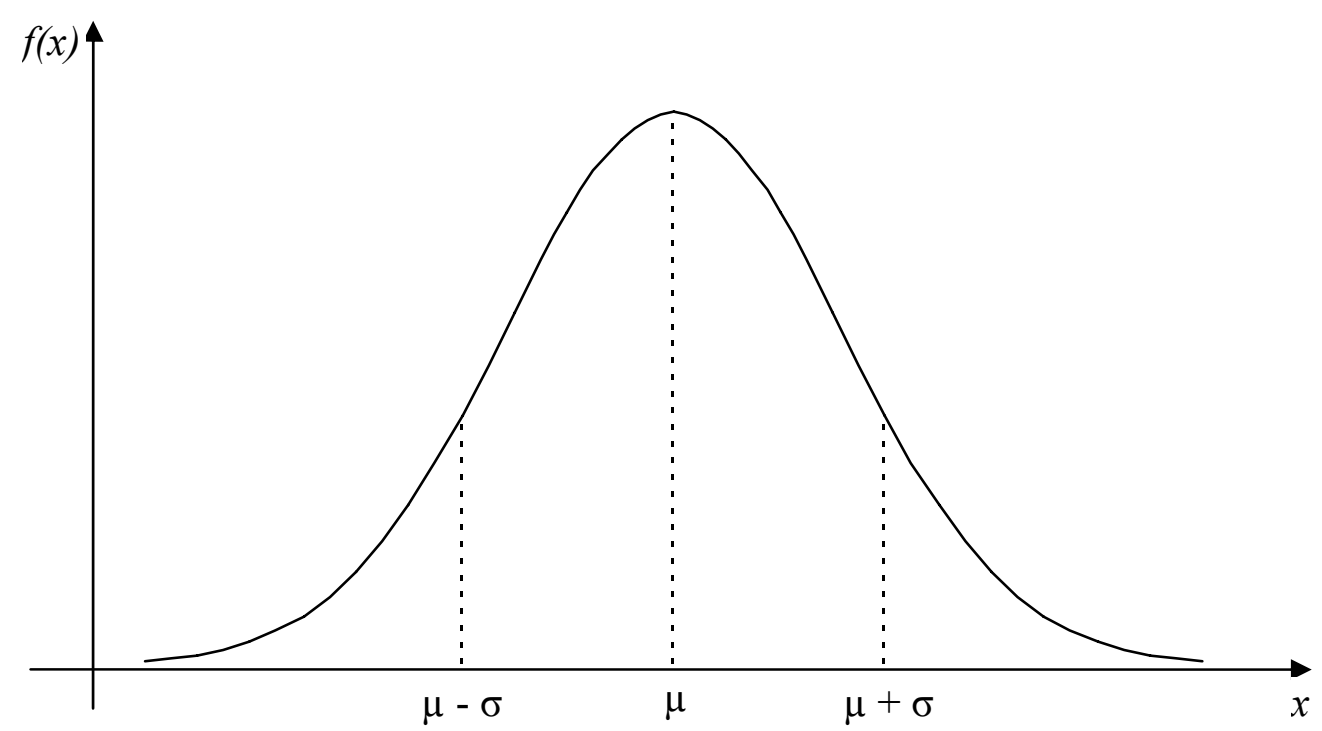

Figura 15: Distribuição normal de probabilidade.

Para uma distribuição normal, tem-se (BUSSAB; MORETIN, 1994):

$$
\begin{aligned}
& E(X)=\mu \\
& \operatorname{Var}(X)=\sigma^{2}
\end{aligned}
$$

A distribuição normal é simétrica no eixo definido pelo parâmetro $\mu$. Quando $X$ tiver distribuição normal com média 0 e variância 1 , obtêm-se uma distribuição normal padrão ou reduzida.

Este é o tipo mais importante de distribuição a ser utilizado nesta pesquisa. A medida de diversos processos aleatórios segue esta distribuição, assim como as distribuições de estatísticas de amostras diversas de uma população. Conforme será mais detalhado posteriormente, os erros laterais e longitudinais de previsões de posições de aeronaves têm distribuição normal com média 0 .

\subsection{Amostragens e Intervalos de Confiança}

Esta seção não tem por objetivo formalizar os conceitos de amostragem e intervalo de confiança, já que se trata de um assunto complexo e que foge do escopo deste trabalho de pesquisa. Apenas são destacados alguns aspectos gerais, suficientes para o entendimento das simulações realizadas para este trabalho.

Para estudar o comportamento dos erros laterais e longitudinais de uma aeronave, é praticamente inviável analisar todas as medidas relacionadas com as posições daquela aeronave. Assim, a análise deve ser baseada em amostragem. Conforme será detalhado posteriormente, os erros laterais e longitudinais seguem uma distribuição normal com média 0 . 
Baseado em uma amostra qualquer com dados de vôos, pode ser encontrada a trajetória mais provável da aeronave, conforme será explicado na próxima seção. Com isso, podem ser encontrados os erros laterais e longitudinais para um conjunto de previsões de posição. Este conjunto de previsões é a amostra a ser analisada para se estudar o comportamento dos erros. Uma forma comum na construção dos intervalos de confiança é descartar dados discrepantes. Assim, são considerados apenas os dados referentes à região hachurada, mostrada na Figura 16.

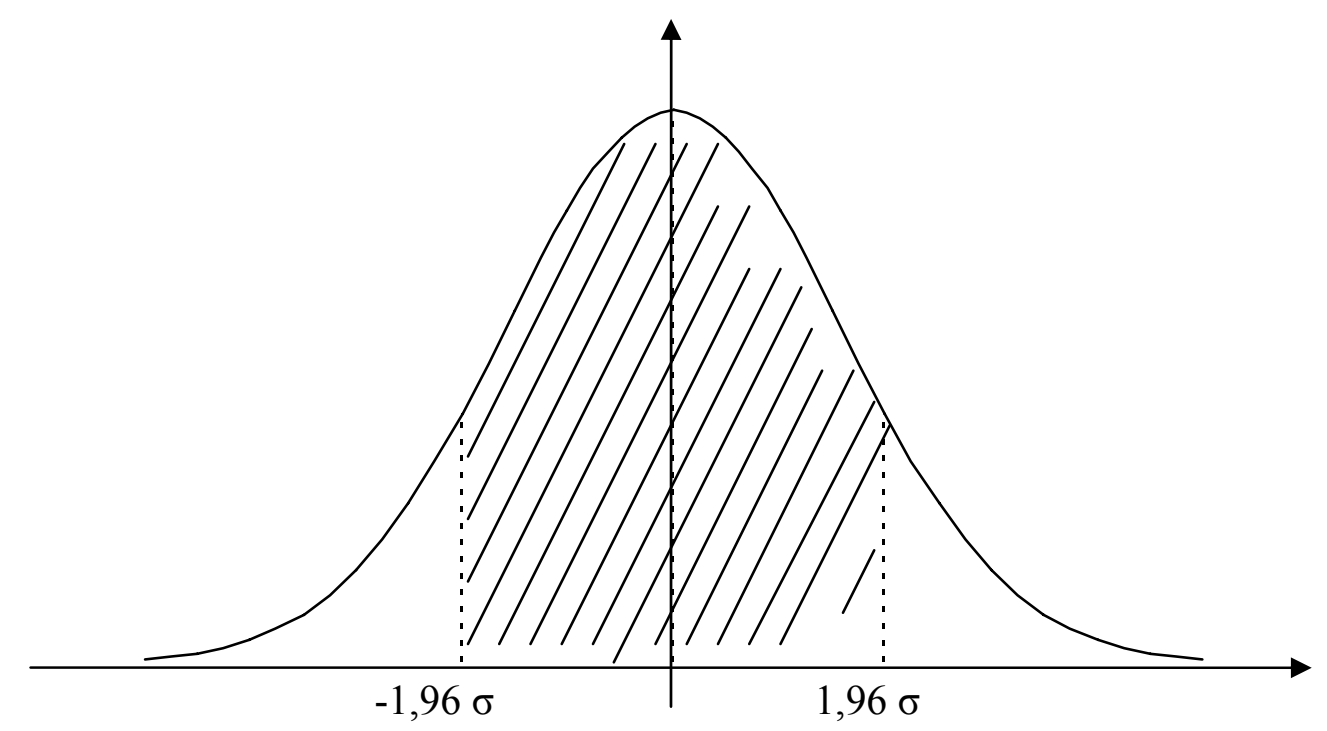

Figura 16: Intervalos de confiança em distribuição normal.

Esta região hachurada compreende $95 \%$ dos dados, cujos valores estão no intervalo $-1,96 \sigma \leq X \leq 1,96 \sigma$. Valores fora desse intervalo são considerados discrepantes e podem “contaminar" a amostra. Por este motivo, eles costumam ser excluídos.

\subsection{Análise de Regressão Linear e de Correlação}

O principal objetivo da regressão linear é predizer o valor de uma variável, chamada variável dependente, considerando que seja conhecido o valor de uma outra variável associada. A análise de regressão simples indica que a predição da variável dependente é feita com base em apenas uma variável independente. Na análise de regressão múltipla a predição da variável dependente é feita com base em duas ou mais variáveis independentes. 


\section{Exemplo (KAZMIER, 1982):}

Suponha que um analista tome uma amostra aleatória de 10 carregamentos recentes feitos por um caminhão de uma companhia e anota a distância percorrida, em quilômetros, e o tempo de entrega, em dias, para cada carregamento. Essas amostras estão resumidas na Tabela 2.

Tabela 2: Amostras para carregamentos de caminhões.

\begin{tabular}{|c|c|c|c|c|c|c|c|c|c|c|}
\hline Carregamento & 1 & 2 & 3 & 4 & 5 & 6 & 7 & 8 & 9 & 10 \\
\hline $\begin{array}{c}\text { Distância } \\
(\mathbf{K m})\end{array}$ & 825 & 215 & 1070 & 550 & 480 & 920 & 1350 & 325 & 670 & 1215 \\
\hline $\begin{array}{c}\text { Tempo de } \\
\text { entrega (dias) }\end{array}$ & 3,5 & 1,0 & 4,0 & 2,0 & 1,0 & 3,0 & 4,5 & 1,5 & 3,0 & 5,0 \\
\hline
\end{tabular}

Neste exemplo, a distância é considerada a variável independente, enquanto o tempo de entrega é a variável dependente, pois alguém poderia estimar o tempo de entrega de mercadorias de acordo com a distância a ser percorrida. Por exemplo, qual é o tempo esperado de entrega para distâncias de $1000 \mathrm{~km}$ ?

A Figura 17 mostra, em formato gráfico, os pontos obtidos nas amostras dos carregamentos dos caminhões. Conforme será explicado na próxima seção, uma forma de se estimar o tempo de entrega para distâncias de $1000 \mathrm{~km}$ é encontrar uma curva que melhor se ajuste aos pontos da amostra. Na mesma Figura 17, pode ser visualizada uma reta ajustada aos pontos. Utilizando essa reta, estima-se um tempo de entrega de 3,71 dias para distâncias de $1000 \mathrm{~km}$.

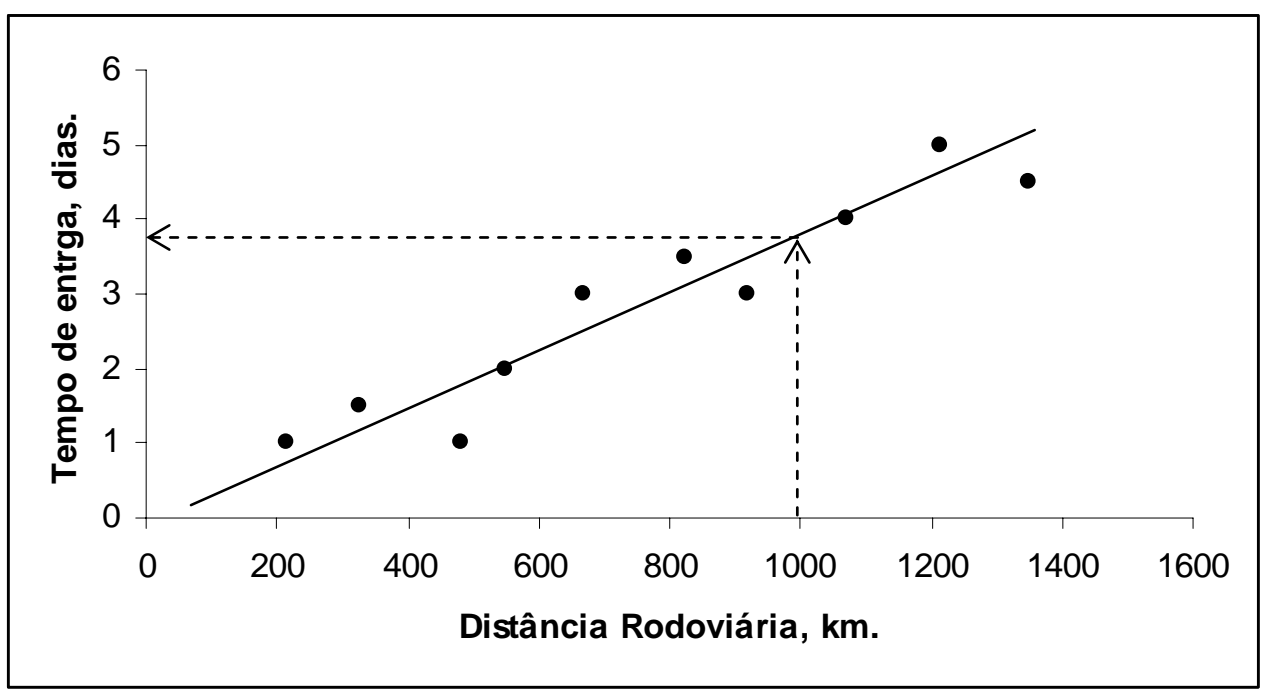

Figura 17: Pontos da amostra dos carregamentos de caminhão. 
A seguir é apresentado um método para se realizar este tipo de estimativa.

\subsection{Método dos Mínimos Quadrados}

Dado um conjunto de valores conhecidos, como no exemplo da Tabela 2, é necessário encontrar uma curva que melhor ajuste os pontos existentes. Em primeiro lugar é importante visualizar como os dados se comportam, utilizando um diagrama de dispersão. Na Figura 18 há um exemplo de relação linear direta entre a variável independente, no eixo $x$, e a variável dependente, no eixo $y$. Nota-se uma tendência de crescimento da variável dependente $Y$ linearmente proporcional ao crescimento da variável independente $X$.

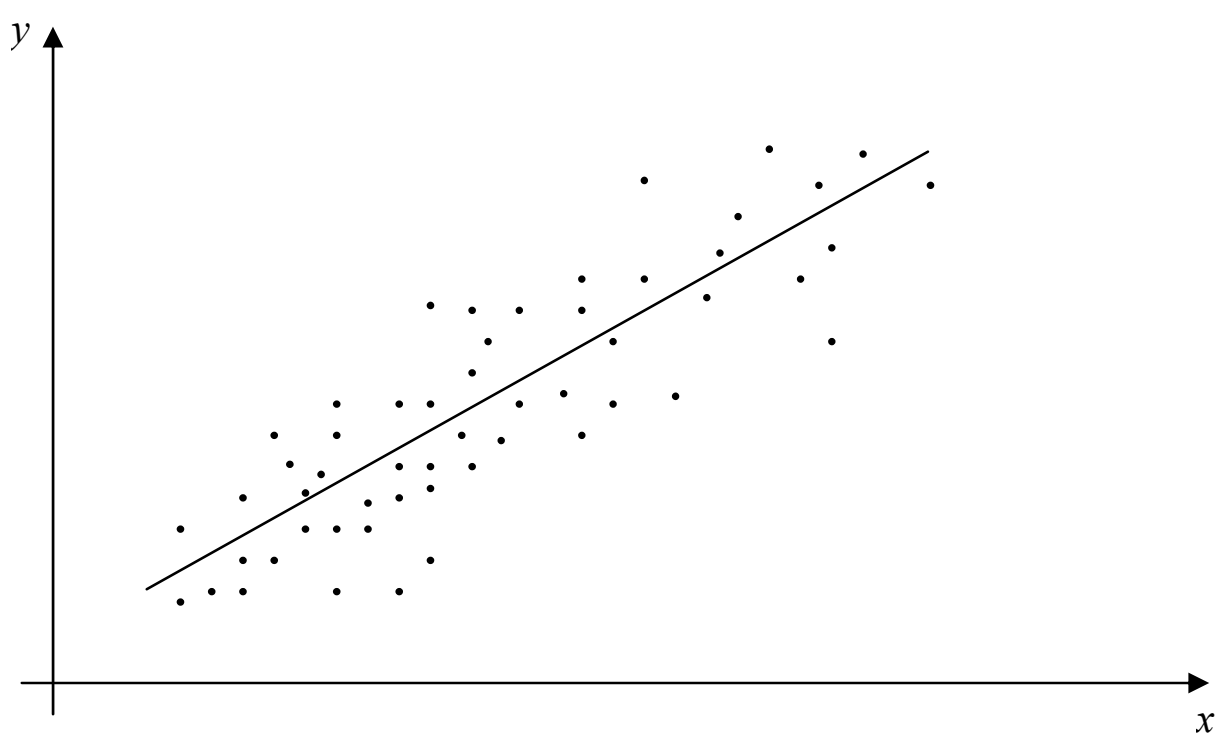

Figura 18: Relação linear direta entre variáveis.

Podem surgir situações em que o relacionamento entre as variáveis não seja linear, mas sim curvilínio, conforme visualizado na Figura 19, que mostra um exemplo de relação exponencial entre as variáveis. Há situações em que esta relação pode ser logarítmica, polinomial, etc. 


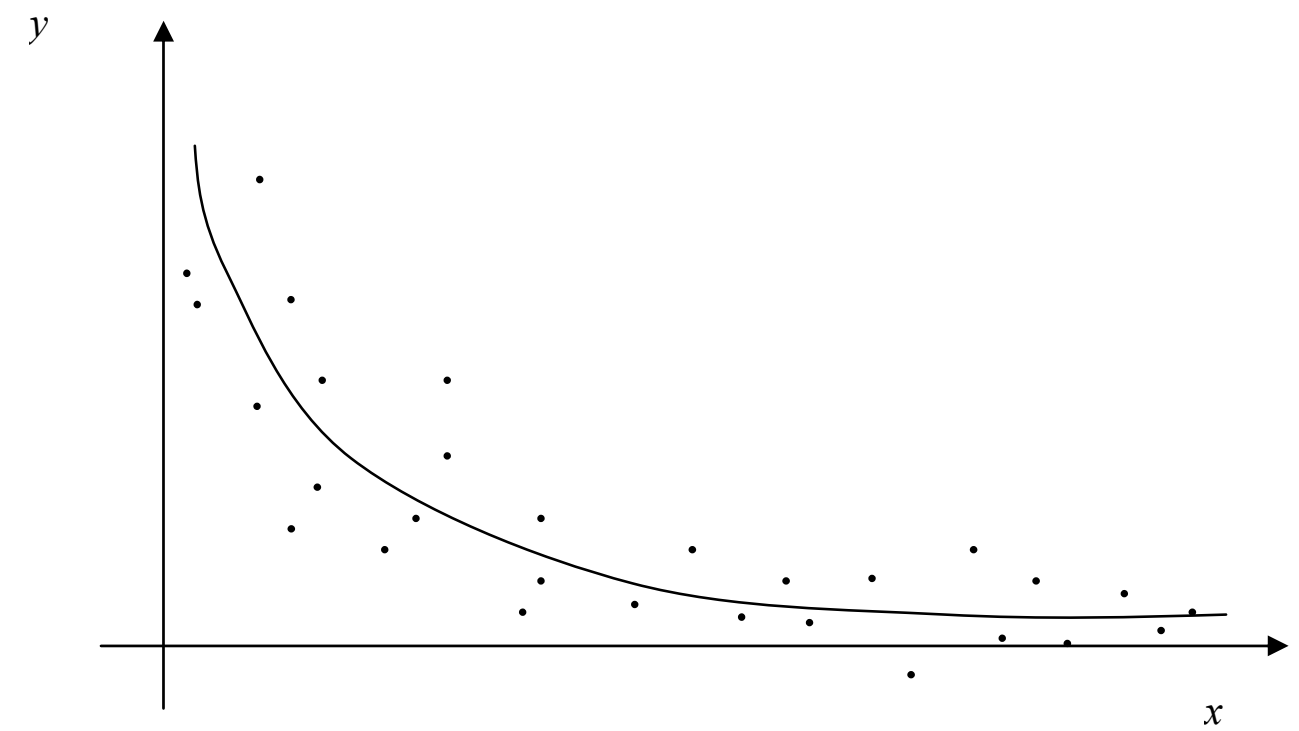

Figura 19: Função exponencial de relação curvilínea entre variáveis.

Considerando uma curva polinomial, a função que permite o melhor ajuste tem a forma: $f(x)=a_{0}+a_{1} x+a_{2} x^{2}+\ldots+a_{n} x^{n}$

Nessa situação, dado um conjunto de valores $\left.X Y=\left\{\left(x_{1}, y_{1}\right),\left(x_{2}, y_{2}\right), \ldots, x_{m}, y_{m}\right)\right\}$, obtido experimentalmente, é necessário estimar os parâmetros $a_{0}, a_{1}, a_{2}, \ldots, a_{n}$ que permitam o melhor ajuste da função $\mathrm{f}$ aos pontos de $X Y$.

Seja $\left(x_{i}, y_{i}\right) \in X Y$ um valor experimental obtido. Nessa situação,

$$
e_{i}=f\left(x_{i}\right)-y_{i}
$$

é a medida do erro cometido entre o valor obtido experimentalmente e o valor obtido por uma função que se ajusta ao conjunto de pontos. Alguns critérios de ajuste possíveis seriam:

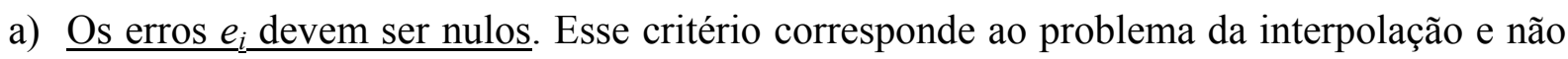
leva em conta os erros nos dados. A função $f$ obtida passa por todos os pontos de $X Y$. No entanto, o grau do polinômio gerado depende da quantidade de pontos existentes em $X Y$. Genericamente, o grau do polinômio tem o mesmo valor da quantidade de pontos existentes. Para o problema de se obter a trajetória mais provável de uma aeronave, o resultado seria uma curva polinomial que passa por todos os pontos já percorridos pela aeronave, e não uma reta correspondente à trajetória mais provável (BARROS, 1972). 
b) A soma dos erros $e_{i}$ deve ser mínima, ou seja, $\sum_{i=1}^{m} e_{i}$ deve ser mínimo. Esse critério compensa os erros positivos e negativos e pode produzir ajustes nulos, como mostrado no exemplo da Figura 20, onde os pontos poderiam ser aproximados por uma reta. No entanto, a curva obtida no exemplo segue o critério de minimizar a soma dos erros mas, neste caso, não é uma boa função de aproximação, pois a amplitude da curva minimiza a soma dos erros mas traz uma curva que não se aproxima dos valores experimentais.

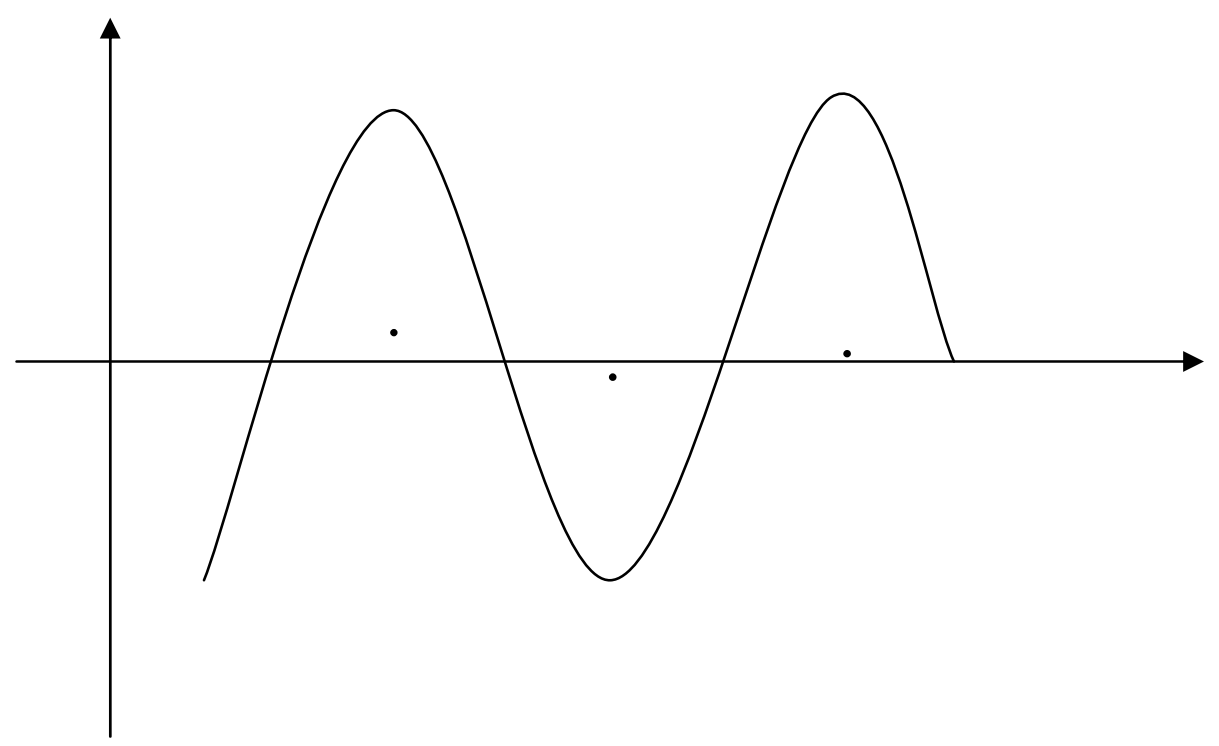

Figura 20: Exemplo de aproximação não adequada por curva de soma de erro mínima.

c) A soma dos valores absolutos dos erros deve ser mínima, ou seja, $\sum_{i=1}^{m}\left|e_{i}\right|$ é mínimo. Esse critério resulta em uma função modular, a qual não é diferenciável, impossibilitando a utilização de cálculo diferencial e integral para a obtenção dos parâmetros do polinômio. Portanto, não será considerado.

d) A soma dos quadrados dos erros deve ser mínima, ou seja, $\sum_{i=1}^{m} e_{i}^{2}$ é mínimo. Esse critério traz vantagens sobre todos os anteriores. Não compensa os erros positivos e negativos como o critério b) e traz a vantagem sobre o critério c), por ser diferenciável.

O critério d) é conhecido como Método dos Mínimos Quadrados. Por esse método, a curva que melhor se ajusta aos dados é aquela para a qual é mínima a soma dos quadrados da diferença entre os valores observados e os valores ajustados pela função. A formalização desses conceitos é apresentada a seguir. 


\subsubsection{Método dos Mínimos Quadrados para Retas em Duas Dimensões}

No início dessa seção, foi colocado o problema de se estimar uma curva polinomial para ajustar um conjunto de pontos. Para o estudo de trajetórias de aeronaves em rota interessa apenas ajustes de pontos por retas, já que nessa fase de vôo a aeronave segue uma trajetória aproximadamente retilínea. No entanto, o método dos mínimos quadrados pode ser generalizado para funções polinomiais de grau $\mathrm{n}$, ou pode também ser generalizado para qualquer tipo de função (BARROS, 1972). O próximo passo é conhecer como os parâmetros que melhor ajustam uma reta são obtidos.

Seja $f: \mathfrak{R} \rightarrow \mathfrak{R}$ uma função tal que $f(x)=a x+b$. Para ajustar $f$ a um conjunto de pontos pelo método dos mínimos quadrados, é necessário encontrar os parâmetros $a$ e $b$ que minimizem a soma do quadrado da distância entre os pontos obtidos experimentalmente e a função $f$. Dado o conjunto de pontos da amostra $\left.X Y=\left\{\left(x_{1}, y_{1}\right),\left(x_{2}, y_{2}\right), \ldots, x_{m}, y_{m}\right)\right\}$, para cada ponto $\left(x_{i}, y_{i}\right)$, o erro é:

$$
e_{i}=f\left(x_{i}\right)-y_{i}=a x_{i}+b-y_{i}
$$

O resíduo total do erro é dados por:

$$
E=\sum_{i=1}^{m} e_{i}^{2}=\sum_{i=1}^{m}\left(a x_{i}+b-y_{i}\right)^{2}
$$

Portanto, basta obter os valores de $a$ e $b$ que minimizem a função $E$. No ponto de mínimo, tem-se:

$$
\frac{\partial E}{\partial a}=\frac{\partial E}{\partial b}=0
$$

Desenvolvendo a expressão (18) obtém-se:

$$
\begin{aligned}
& \frac{\partial E}{\partial a}=\sum_{i=1}^{m} 2 \cdot\left(a x_{i}+b-y_{i}\right) \cdot x_{i}=0 \\
& \frac{\partial E}{\partial b}=\sum_{i=1}^{m} 2 \cdot\left(a x_{i}+b-y_{i}\right) \cdot 1=0
\end{aligned}
$$

Isolando $a$ e $b$ obtém-se:

$$
\begin{aligned}
& a \sum_{i=1}^{m} x_{i}^{2}+b \sum_{i=1}^{m} x_{i}=\sum_{i=1}^{m} x_{i} y_{i} \\
& a \sum_{i=1}^{m} x_{i}+b \sum_{i=1}^{m} 1=\sum_{i=1}^{m} y_{i}
\end{aligned}
$$

As expressões (21) e (22) podem ser escritas na forma de um sistema linear: 


$$
\left[\begin{array}{cc}
\sum_{i=1}^{m} x_{i}^{2} & \sum_{i=1}^{m} x_{i} \\
\sum_{i=1}^{m} x_{i} & m
\end{array}\right]\left[\begin{array}{l}
a \\
b
\end{array}\right]=\left\{\begin{array}{c}
\sum_{i=1}^{m} x_{i} y_{i} \\
\sum_{i=1}^{m} y_{i}
\end{array}\right\}
$$

A solução do sistema (23) produz:

$$
\begin{array}{r}
a=\frac{m \sum_{i=1}^{m} x_{i} y_{i}-\sum_{i=1}^{m} x_{i} \sum_{i=1}^{m} y_{i}}{m \sum_{i=1}^{m} x_{i}^{2}-\left(\sum_{i=1}^{m} x_{i}\right)^{2}} \\
b=\frac{\sum_{i=1}^{m} x_{i}^{2} \sum_{i=1}^{m} y_{i}-\sum_{i=1}^{m} x_{i} \sum_{i=1}^{m} x_{i} y_{i}}{m \sum_{i=1}^{m} x_{i}^{2}-\left(\sum_{i=1}^{m} x_{i}\right)^{2}}
\end{array}
$$

Aplicando o método dos mínimos quadrados ao problema dos carregamentos de caminhão, obtém-se:

$$
\begin{aligned}
& a=0,11 \\
& b=0,0036
\end{aligned}
$$

Ou seja, a equação que indica o tempo $t$ esperado de entrega de acordo com a distância $d$ de viagem é:

$$
t=0,11+0,0036 \cdot d
$$

Logo, para $d=1.000 \mathrm{~km}, t=3,71$ dias.

Uma pergunta importante que surge é se esta equação de regressão poderia ser utilizada para estimar o tempo de entrega para um carregamento de 2.500 quilômetros. A resposta a essa questão é que não é apropriado utilizar a mesma equação para uma viagem de 2.500 quilômetros, porque os dados da amostra que geraram esta equação de regressão linear incluem viagens de até 1.350 quilômetros, somente. Essa amostra não explica como é o comportamento do problema para distâncias acima de 1.350 quilômetros, o que poderia gerar erros nas estimativas. 
No entanto, será notado nos próximos capítulos que o problema de previsão de posição futura de aeronaves exigirá que sejam feitas estimativas para instantes de tempo que estão fora da amostra. Isso pode ser feito por causa de algumas premissas existentes para o problema. Foi delimitado que as previsões apenas considerarão vôos em rota, ou seja, onde não há variações significativas de velocidade e direção. Assim, a aeronave deve manter o mesmo comportamento também para os instantes de tempo desconhecidos e que estão fora de uma amostra conhecida, pelo menos até atingir o próximo fixo.

\subsubsection{Método dos Mínimos Quadrados para Retas em Três Dimensões}

Para o caso particular do estudo de trajetórias, a função a ser ajustada será um pouco diferente. A amostra de pontos conhecida terá o formato:

$$
P=\left\{\left(x_{1}, y_{1}, t_{1}\right),\left(x_{2}, y_{2}, t_{2}\right), \ldots,\left(x_{n}, y_{n}, t_{n}\right)\right\}
$$

Isso porque, para cada instante de tempo $t_{i}$, haverá uma posição $\left(x_{i}, y_{i}\right)$ correspondente da aeronave, desconsiderando a sua altitude. Assim, para encontrar uma função que permita estimar a trajetória mais provável da aeronave e extrapolar suas posições futuras, deve-se encontrar uma função $f$, tal que:

$f: \mathfrak{R} \rightarrow \mathfrak{R}^{2}$, sendo $f(t)=(x, y)$, de forma que:

$$
\begin{aligned}
& x=\alpha_{1} t+\beta_{1} \\
& y=\alpha_{2} t+\beta_{2}
\end{aligned}
$$

A função $f$ definida anteriormente corresponde à equação de uma reta no espaço. Utilizando novamente o método dos mínimos quadrados, é necessário minimizar a soma do quadrado das distâncias entre os pontos conhecidos e a função $f$. Para cada ponto experimental $\left(x_{i}, y_{i}\right)$, o erro é calculado pela expressão que indica a distância entre o ponto experimental e a função obtida:

$$
e_{i}=\sqrt{\left(x\left(t_{i}\right)-x_{i}\right)^{2}+\left(y\left(t_{i}\right)-y_{i}\right)^{2}}
$$

Nessa situação, o resíduo total $E$ do erro é dado por:

$$
\begin{aligned}
& E=\sum_{i=1}^{m} e_{i}^{2}=\sum_{i=1}^{m}\left(\left(x\left(t_{i}\right)-x_{i}\right)^{2}+\left(y\left(t_{i}\right)-y_{i}\right)^{2}\right)= \\
& =\sum_{i=1}^{m}\left(\left(\alpha_{1} t_{i}+\beta_{1}-x_{i}\right)^{2}+\left(\alpha_{2} t_{i}+\beta_{2}-y_{i}\right)^{2}\right)
\end{aligned}
$$

Portanto, basta obter os valores de $\alpha_{1}, \beta_{1}, \alpha_{2}$ e $\beta_{2}$ que minimizem a função $E$. No ponto de mínimo, tem-se: 


$$
\frac{\partial E}{\partial \alpha_{1}}=\frac{\partial E}{\partial \beta_{1}}=\frac{\partial E}{\partial \alpha_{2}}=\frac{\partial E}{\partial \beta_{2}}=0
$$

Desenvolvendo essas derivadas parciais, tem-se:

$$
\begin{aligned}
& \frac{\partial E}{\partial \alpha_{1}}=\sum_{i=1}^{m} 2 \cdot\left(\alpha_{1}+\beta_{1} \cdot t-x_{i}\right) \cdot t=0 \\
& \frac{\partial E}{\partial \beta_{1}}=\sum_{i=1}^{m} 2 \cdot\left(\alpha_{1}+\beta_{1} \cdot t-x_{i}\right) \cdot 1=0 \\
& \frac{\partial E}{\partial \alpha_{2}}=\sum_{i=1}^{m} 2 \cdot\left(\alpha_{2}+\beta_{2} \cdot t-y_{i}\right) \cdot t=0 \\
& \frac{\partial E}{\partial \beta_{2}}=\sum_{i=1}^{m} 2 \cdot\left(\alpha_{2}+\beta_{2} \cdot t-y_{i}\right) \cdot 1=0
\end{aligned}
$$

Comparando-se a obtenção dos parâmetros para as retas em duas e em três dimensões, verifica-se que o cálculo das derivadas parciais reduz o problema do mínimo quadrado para retas em três dimensões como um problema de decompor a reta nas componentes $X$ e $Y$. Portanto, basta aplicar o método separadamente para as componentes $x=\alpha_{1} t+\beta_{1} \mathrm{e}$ $y=\alpha_{2} t+\beta_{2}$.

Caso o problema de previsão de posição futuras de aeronaves seja estudado considerando-se também a altitude, surge uma terceira componente, dada por $z=\alpha_{3} t+\beta_{3}$.

\subsubsection{Noções sobre Erros de Estimação}

O erro padrão de estimação, em termos conceituais, é um desvio padrão condicional, na medida que indica o desvio padrão da variável dependente $Y$, dado um valor específico da variável independente $X$. Esse erro de estimação pode ser usado para estabelecer um intervalo de predição para a variável dependente (KAZMIER, 1982).

$\mathrm{O}$ estudo de trajetórias de aeronaves utiliza algumas formas diferentes para cálculo das incertezas. Torna-se necessário decompor as incertezas nas componentes lateral e longitudinal. O capítulo 5 e 6 trazem maiores detalhes de como ocorre o estudo das incertezas. 


\subsection{Considerações Finais do Capítulo}

O conteúdo deste capítulo fornece a base matemática necessária para entender o restante do estudo. Os aspectos mais importantes estão relacionados aos conceitos de variável aleatória, distribuições de probabilidade e, sobretudo, a descrição da distribuição normal. É extremamente importante entender o comportamento desse tipo de distribuição, já que servirá para modelar o comportamento das incertezas de posicionamento das aeronaves.

Outro aspecto importante do capítulo é o estudo de regressão linear. A regressão será utilizada para analisar o comportamento da aeronave em situações conhecidas. Com isso, ocorrerá a tentativa de extrapolar o comportamento da aeronave para situações não conhecidas. Utilizando posições conhecidas pelas quais uma aeronave passou, podem ser estimadas suas posições futuras. É importante destacar que, via de regra, a análise de regressão não poderia ser utilizada desta maneira, já que o fato de se conhecer o comportamento da aeronave para alguns instantes entre $t_{1}$ e $t_{2}$ nos permitiria apenas estimar a posição da aeronave para um instante não conhecido entre $t_{1}$ e $t_{2}$. No entanto, parte-se do pressuposto de que a aeronave está em um vôo em rota, ou seja, não há variações significativas de sua velocidade e direção. Por este motivo, a análise de regressão pode ser utilizada para extrapolação.

Os dois próximos capítulos tratam de aspectos mais específicos sobre o modelo utilizado para estimar a posição de uma aeronave, mostrando como esse modelo podem ser aplicado, e fazem grande uso da base matemática contida neste capítulo. 


\section{MODELO PARA PREVISÃO DE POSIÇÃO FUTURA DE AERONAVES}

Neste capítulo, é apresentado um modelo para a previsão de posição futura de aeronaves, com enfoque principal em aeronaves voando em rota. Inicialmente, um modelo de construção de trajetórias é descrito, incluindo a formalização do conceito de plano de vôo. Em seguida, o problema da previsão de posição futura de aeronaves é delimitado para o escopo do estudo, sendo apresentado um modelo que utiliza regressão linear e extrapolação como uma forma de se prever as posições futuras de uma aeronave. Nesse modelo são consideradas as incertezas relacionadas com as posições conhecidas da aeronave e também é realizado um estudo de como se comporta a variação das incertezas laterais e longitudinais em relação à trajetória ao longo do tempo.

\subsection{Construção de Trajetórias de Aeronaves}

Dentro do contexto da previsão de posição futura de uma aeronave, surge inicialmente um problema maior, que corresponde à necessidade de se prever a trajetória que a aeronave irá percorrer. Esse problema é chamado de construção de trajetória (trajectory synthesis). De forma resumida, três fatores são considerados para se construir um modelo de construção de trajetórias: plano de vôo, dados de desempenho da aeronave e condições do espaço aéreo. As informações específicas da aeronave podem ser obtidas, dentre diversas fontes, por meio de uma base de dados de aeronaves denominada BADA (Base of Aircraft Data) (EUROCONTROL, 2004). Com base nessas informações, a trajetória da aeronave pode ser modelada, de acordo com o modelo descrito na Figura 21. Maiores detalhes sobre modelagem de trajetórias são encontrados em (ERZBERGER et al., 1997). 


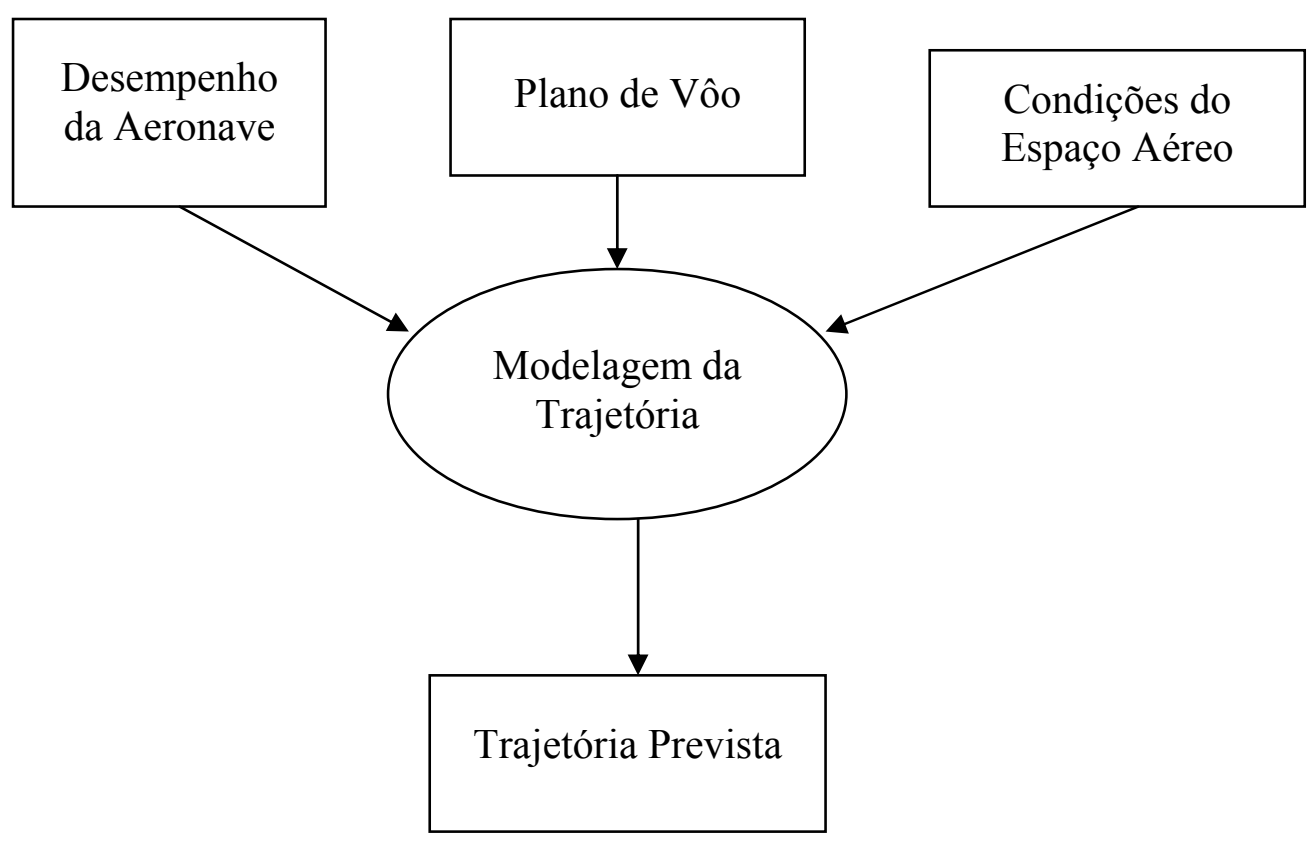

Figura 21: Modelo de construção de trajetórias de aeronaves.

Para que o modelo de construção de trajetórias fique mais claro, inicialmente é descrito como pode ser modelado um plano de vôo. É importante também explicar como ocorre a reconstrução de trajetórias cada vez que um novo fixo é atingido.

\subsubsection{Plano de Vôo}

Considere-se uma seqüência de $n$ pontos denominados fixos, tais que:

$$
\left\{P_{j}\right\}_{j=0, \ldots, n}, P_{j} \in \mathfrak{R}^{3}
$$

Esses são alguns pontos no espaço pelos quais a aeronave deverá passar ao longo do seu caminho. Por simplificação, serão considerados pontos $P_{j} \in \mathfrak{R}^{2}$, ou seja, apenas a movimentação da aeronave no plano, supondo-se uma altitude constante.

Considere-se, também, uma seqüência de velocidades:

$$
\left\{v_{j}\right\}_{j=1, \ldots, n}, v_{j} \in \mathfrak{R}_{+}
$$

Cada valor $v_{j}$ corresponde ao valor da velocidade da aeronave no caminho entre os pontos $P_{j-1}$ e $P_{j}$. Estas duas seqüências, de pontos e velocidades, constituem o plano de vôo (PRANDINI; LYGEROS; SASTRY, 2000), conforme ilustrado na Figura 22, para $n=5$. 


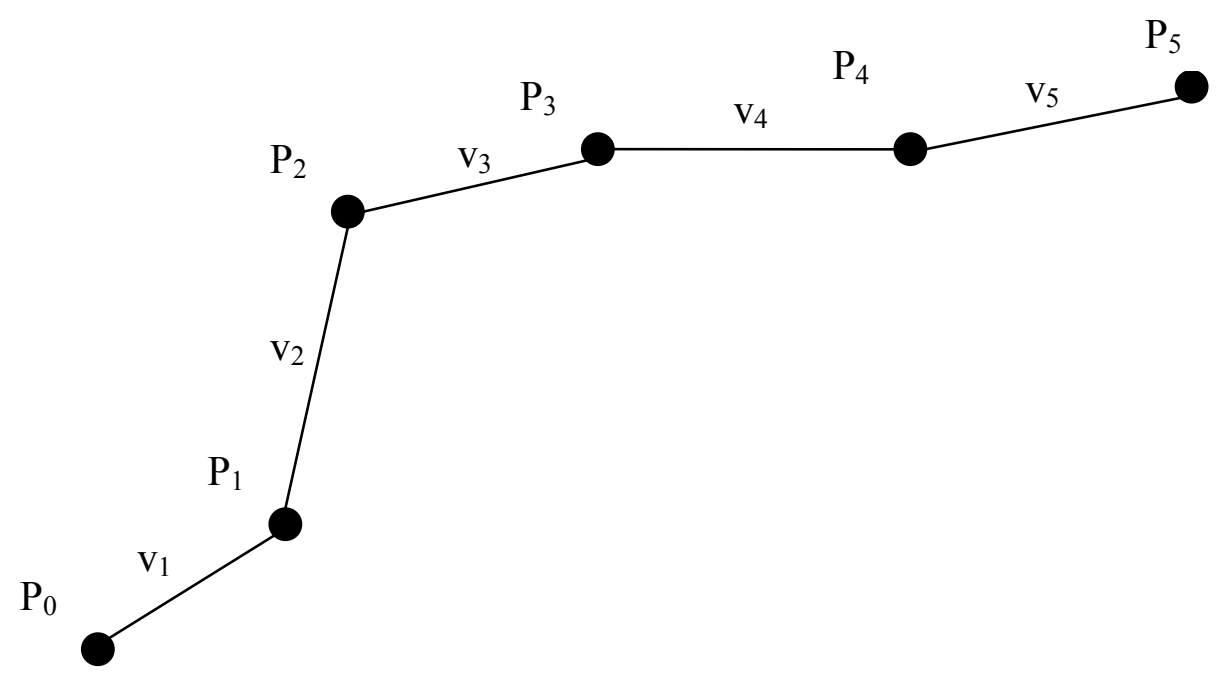

Figura 22: Exemplo de plano de vôo.

\subsubsection{Previsão de Chegada aos Fixos}

Com base no plano de vôo, é necessário calcular também os valores dos tempos de chegada $\left\{T_{j}\right\}_{j=1, \ldots, n}$ da aeronave em cada um dos $n$ fixos. De forma simplificada, é possível calcular cada valor do tempo recursivamente, conforme indicado na Equação (31):

$$
T_{j}=\frac{\left\|P_{j}-P_{j-1}\right\|}{v_{j}}+T_{j-1}
$$

O cálculo inicia-se com $T_{0}=0$ e $p\left(T_{0}\right)=P_{0}$, ou seja, a posição inicial da aeronave. A partir dos valores dos tempos de chegada em cada fixo é possível calcular a posição esperada da aeronave em um certo instante $t$. Considere-se $t \epsilon\left(T_{j-1}, T_{j}\right]$. É possível calcular a posição $p(t)$ da aeronave no instante $t$ a partir da expressão (PRANDINI; LYGEROS; SASTRY, 2000):

$$
p(t)=p\left(T_{j-1}\right)+v_{j} \cdot\left(t-T_{j-1}\right) \frac{P_{j}-p\left(T_{j-1}\right)}{\left\|P_{j}-p\left(T_{j-1}\right)\right\|}
$$

No entanto, a movimentação da aeronave é afetada por fatores de desempenho da aeronave, sendo que alguns desses fatores, relacionados a empuxo, arrasto, massa, velocidade permitida, coeficientes aerodinâmicos, etc., são obtidos por meio de consulta ao BADA. Outros fatores, que podem trazer incertezas para a construção de trajetórias são: situação do tráfego, condições meteorológicas, etc., e dependem das condições do espaço aéreo. A forma como as incertezas influenciam a construção de trajetórias pode ser visualizada no capítulo 3, onde são discutidos os conceitos de acurácia, sendo que as elipses associadas a cada posição prevista da aeronave correspondem ao grau de incerteza lateral e longitudinal da previsão. 
Para efeito de construção de trajetórias, cada vez que um fixo é atingido, o conjunto $\left\{P_{j}\right\}$ é re-calculado, de forma que $P_{0}$ passa a ser o fixo atingido. Assim, todos os tempos $T_{j}$ também são re-calculados. Na proposta apresentada na próxima seção, esses fatores de incerteza serão incorporados ao modelo proposto. Há outras explicações interessantes sobre construção de trajetórias em (GREEN; GOKA; WILLIAMS, 1997).

\subsection{Modelo para Extrapolação de Posição}

Nesta seção é apresentado um modelo de extrapolação que pode ser utilizado para prever a posição futura de uma aeronave. Conforme a redução de escopo já apresentada, está contemplada uma situação em que a aeronave está voando entre dois fixos. Este tipo de enfoque é comum e, portanto, aceito para verificação de diversas situações, tais como detecção de conflitos (KUCHAR; YANG, 2000).

Considere-se um trecho sendo percorrido pela aeronave entre os fixos $P_{0}$ e $P_{1}$, com uma velocidade $v_{l}$, de forma que se deseje calcular a previsão de posição futura da aeronave para um determinado instante entre os fixos. Nesta situação, uma forma de se prever a posição da aeronave é por meio da extrapolação dos dados de posições conhecidas, pois é uma abordagem que pode ser utilizada em situações em rota. O modelo proposto visa prever, não apenas a posição futura, mas também os valores de incertezas lateral e longitudinal associados à previsão.

Conforme já destacado anteriormente, as previsões de posição considerarão apenas as movimentações da aeronave no plano. Assim, o domínio utilizado para cada posição da aeronave será o $\mathfrak{R}^{2}$.

Considere-se a função:

$$
R(t): \mathfrak{R} \rightarrow\left(\mathfrak{R}^{2}, N\right)
$$

Essa função traz a posição real $(x, y)$ da aeronave em um instante $t$, e também o valor $f$ de FOM (Figure of Merit). Os valores de FOM variam de 0 a 7 , sendo que para cada valor há uma medida de acurácia correspondente, conforme mostra a Tabela 3 (KODO; NAGAOKA; AMAI, 2002). O erro associado ao FOM é decorrente de incertezas associadas aos dados medidos pelos radares. 
Tabela 3: Valores de FOM (Figure of Merit) (KODO; NAGAOKA; AMAI, 2002).

\begin{tabular}{|c|c|}
\hline Valor de FOM & Acurácia da medida (95 \%) \\
\hline 0 & $\geq 30 \mathrm{NM}^{14}$ \\
\hline 1 & $<30 \mathrm{NM}$ \\
\hline 2 & $<15 \mathrm{NM}$ \\
\hline 3 & $<8 \mathrm{NM}$ \\
\hline 4 & $<4 \mathrm{NM}$ \\
\hline 5 & $<1 \mathrm{NM}$ \\
\hline 6 & $<0,25 \mathrm{NM}$ \\
\hline 7 & $<0,05 \mathrm{NM}$ \\
\hline
\end{tabular}

Isso significa que a aeronave provavelmente estará dentro de um círculo delimitado por uma circunferência cujo raio tem o valor da acurácia da medida, conforme ilustrado na Figura 23. O intervalo de confiança garante uma probabilidade de $95 \%$ de que a aeronave esteja dentro do círculo correspondente ao valor de FOM considerado.

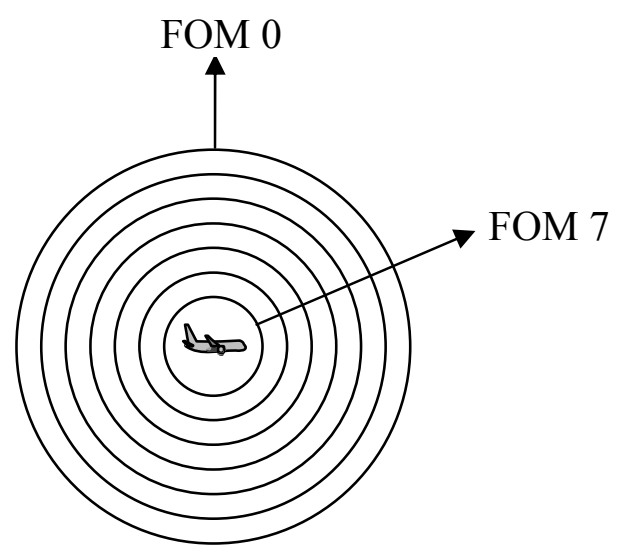

Figura 23: Ilustração do significado dos valores do FOM.

Seja também a função:

$$
P(t, \Delta t): \mathfrak{R}^{2} \rightarrow \mathfrak{R}^{2}
$$

Esta função traz a posição prevista da aeronave, em $\mathfrak{R}^{2}$, para um instante de tempo $t+\Delta t$, sabendo-se que o momento presente é $t$. O principal objetivo do método de regressão linear com extrapolação é encontrar a função $P$. Esta função pode trazer também os valores de incerteza lateral e longitudinal da previsão.

\subsubsection{Modelagem da Função $P$}

Considere-se o conjunto de pontos correspondentes a $n-1$ posições conhecidas de uma aeronave:

\footnotetext{
${ }^{14}$ NM: Nautical Mile ou Milha Náutica, corresponde a 1.852 metros ou 1,1508 milhas terrestres (MITE).
} 


$$
\text { Pos }=\left\{\left(x_{1}, y_{1}\right),\left(x_{2}, y_{2}\right), \ldots,\left(x_{n-1}, y_{n-1}\right)\right\}, \text { onde }\left(x_{i}, y_{i}\right) \in R^{2}, \text { para } 1 \leq i<n
$$

Conforme a função $R$ definida em (33), tem-se que:

$$
R\left(t_{i}\right)=\left(x_{i}, y_{i}, f_{i}\right) \text {, para } t_{i}=t_{1}, t_{2}, \ldots, t_{n-1}, \operatorname{com} t_{1}<t_{2}<\ldots<t_{n-1}
$$

A posição correspondente a $\left(x_{n-1}, y_{n-1}\right)$ é a última posição conhecida para a aeronave, sendo que a Figura 24 ilustra este conjunto de pontos considerando um vôo em duas dimensões espaciais. Com base nos $n-1$ pontos conhecidos, é possível efetuar uma regressão linear, a fim de se descobrir a trajetória mais provável que a aeronave está seguindo. Primeiramente, considere-se o conjunto:

$$
\operatorname{Pos} T=\left\{\left(x_{1}, y_{1}, t_{1}\right),\left(x_{2}, y_{2}, t_{2}\right), \ldots,\left(x_{n-1}, y_{n-1}, t_{n-1}\right)\right\}
$$

Este conjunto é obtido por meio dos pontos do conjunto Pos e da função $R$, definidos nas Equações (35) e (36), respectivamente. Utilizando regressão linear, é obtida uma reta $r$ no espaço, conforme apresentado na Figura 24. É importante notar que esta reta não corresponde à trajetória provável da aeronave. Trata-se apenas de uma função que traz uma possível previsão de posição da aeronave para um certo instante $t$, considerando sua movimentação no plano $X Y$. Formalmente, tem-se:

$$
r: \mathfrak{R} \rightarrow \mathfrak{R}^{2}, r(t)=(x, y)
$$

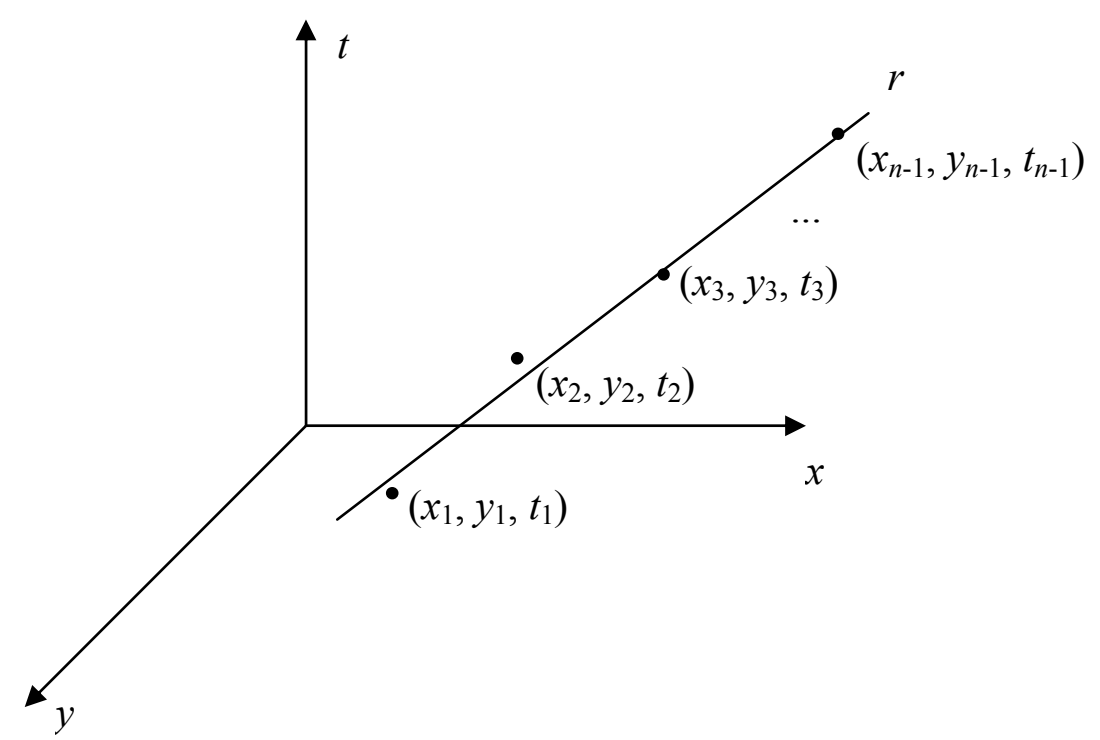

Figura 24: Função posição da aeronave ao longo do tempo.

A projeção linear da reta $r$ no plano $X Y$ corresponde à trajetória percorrida pela aeronave no plano, que pode ser representada pela reta $T$, que é apresentada na Figura 25 . A equação da reta $T$ será:

$$
T: y=A x+B
$$




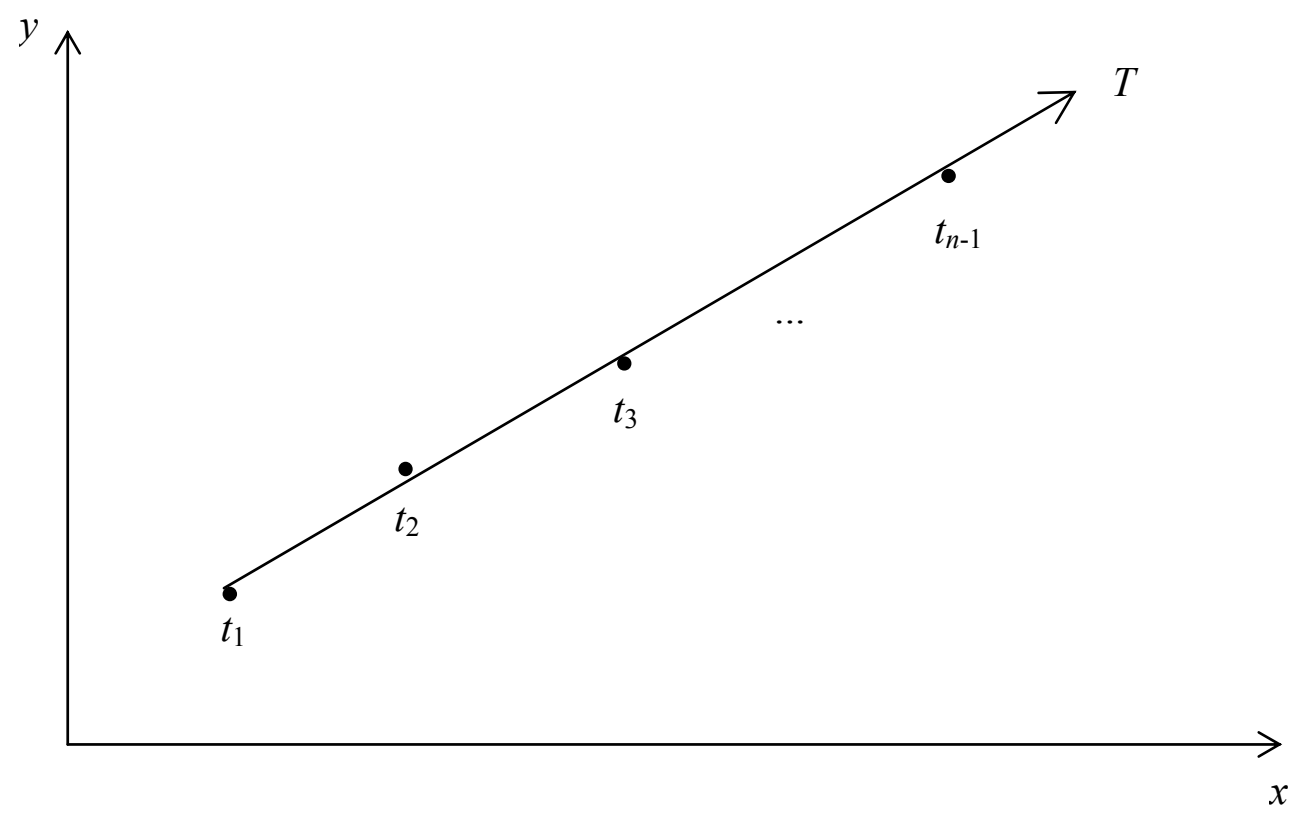

Figura 25: Trajetória provável da aeronave no plano.

O enfoque utilizado pode ser justificado pelas restrições consideradas na definição do problema, dentre as quais o fato de que esse estudo fornece a previsão de posição futura de aeronaves para a fase de vôo em rota. Nessa fase de vôo, a aeronave segue, predominantemente, trajetórias com longos trechos retilíneos. Claro que pode haver mudanças de direção não previstas, o que aumenta a imprecisão do modelo apresentado.

Associado a uma posição da aeronave, existe um valor da Figure of Merit (FOM), que corresponde à acurácia da medida da posição. O nível de acurácia da posição da aeronave é representado por uma região dentro da qual existe uma probabilidade de $95 \%$ de que a aeronave se encontre. Nesse estudo, a região considerada é um círculo, conforme descrito anteriormente.

Para cada ponto $\left(x_{i}, y_{i}\right)$, existe um valor $r_{i}$ que corresponde ao raio da circunferência $C_{i}$ dentro da qual a aeronave provavelmente se encontra no instante $t_{i}$. Então, para cada circunferência $C_{i}$ calculam-se os pontos $P_{\text {imax }}=\left(x_{\text {imax }}, y_{\text {imax }}\right)$ e $P_{\text {imin }}=\left(x_{\text {imin }}, y_{\text {imin }}\right)$, tais que:

- $P_{\text {imax }}, P_{\text {imin }} \in C_{i}$,

- $\mathrm{O}$ vetor $p=\left(P_{\text {imax }}-P_{\text {imin }}\right)$ é perpendicular à reta $T$, de forma que $\left(y_{\text {imax }}-y_{\text {imin }}\right) \geq 0$ e a reta $\left(P_{\text {imax }}+\alpha p\right)$ passa pelo centro de $C_{i}$.

A Figura 26 ilustra esta situação. 


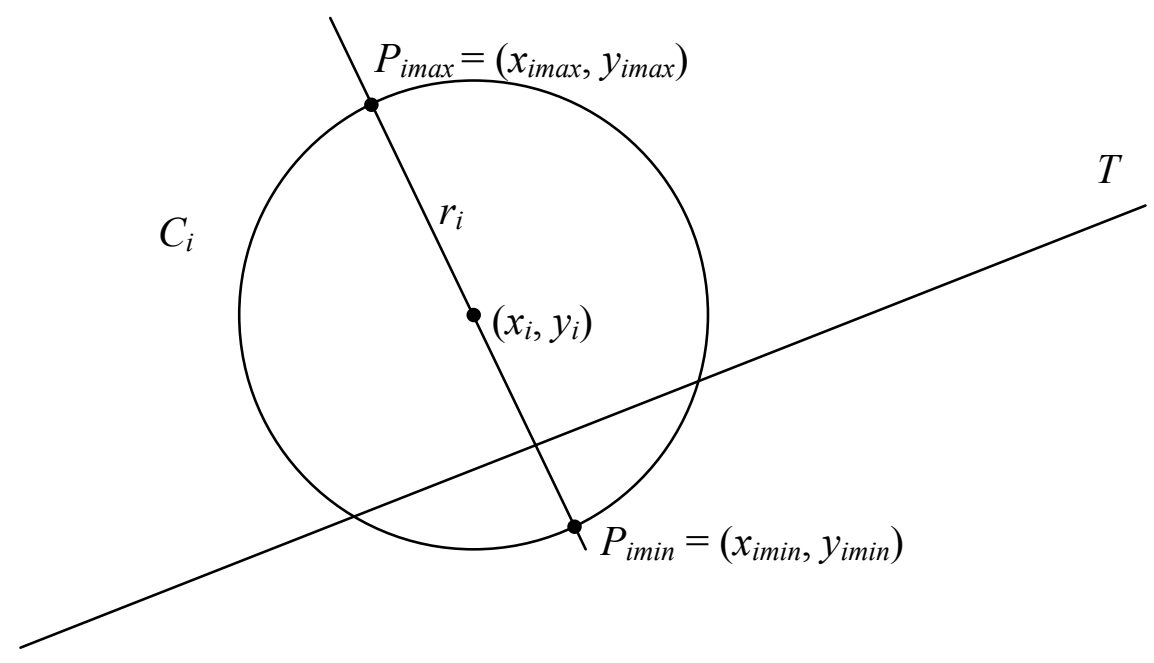

Figura 26: Incerteza da posição da aeronave para um determinado instante $\boldsymbol{t}_{\boldsymbol{i}}$.

\subsubsection{Incertezas Laterais da Posição}

De acordo com (PRANDINI et al., 2000), os erros laterais para a previsão de posição futura das aeronaves seguem uma distribuição Gaussiana com média zero. A variância $\sigma^{2}(t)$ do erro lateral no instante $t$ cresce de forma quadrática em função da distância viajada $s(t)$, saturando em um certo valor $\sigma_{c}^{2}$. Isso pode ser formalizado pela expressão:

$$
\sigma^{2}(t) \sim r^{2} s^{2}(t), \operatorname{sat}\left\{\sigma^{2}(t)\right\}=\sigma_{c}^{2}
$$

Alguns estudos sobre conflitos em condições de Free Flight apresentam propostas de modelos probabilísticos nos quais as incertezas da trajetória não precisam seguir uma distribuição Gaussiana (YANG; KUCHAR, 1997). No entanto, o estudo realizado neste trabalho não abrangeu vôos em condições de Free Flight, o que leva a se utilizar a variância definida na expressão (40). A função $s(t)$ traz a distância viajada pela aeronave entre um intervalo de tempo $t$ definido como $t_{n}-t_{n-1}$, conforme mostra a Figura 27. 


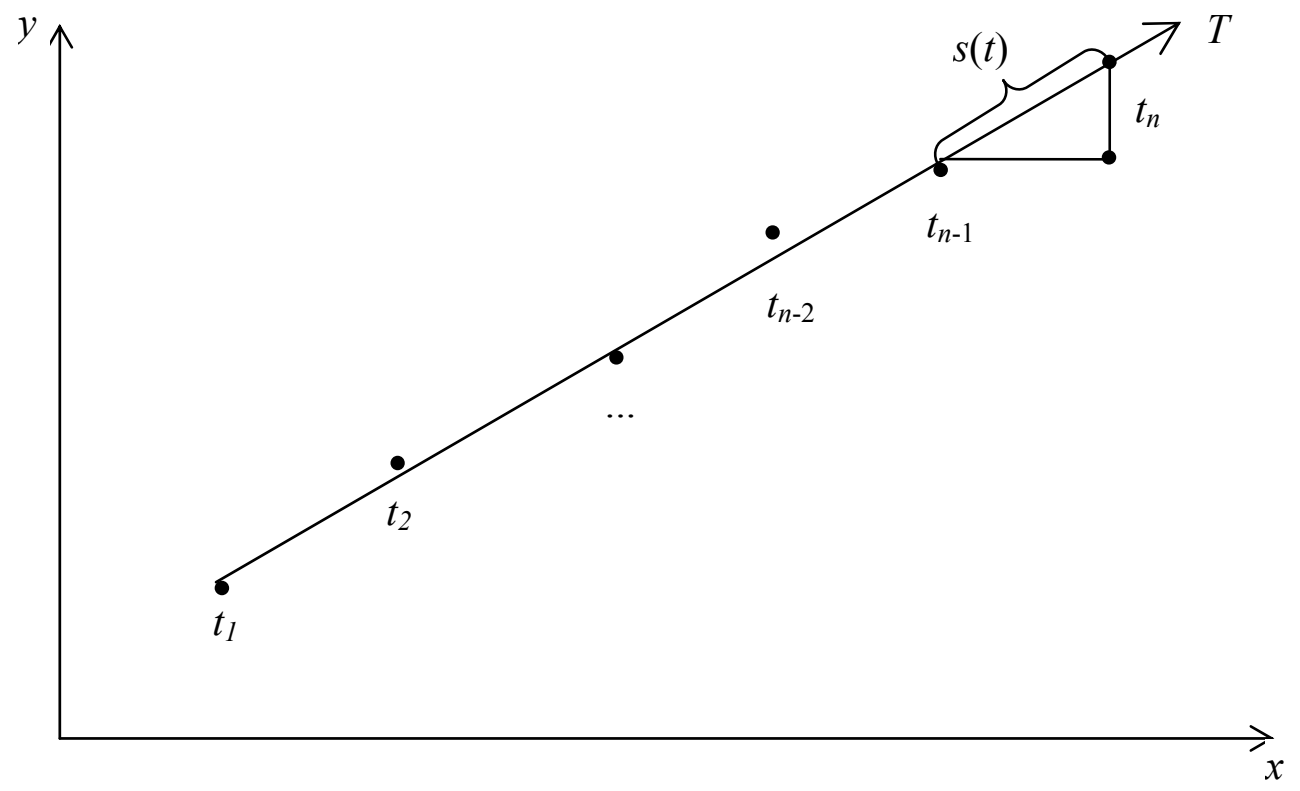

Figura 27: Cálculo da distância percorrida pela aeronave.

Em termos matemáticos, tem-se a expressão:

$$
s(t): \mathfrak{R}_{+} \rightarrow \mathfrak{R} \text {, tal que, } s(t)=\sqrt{\left(x_{n}-x_{n}-1\right)^{2}+\left(y_{n}-y_{n}-1\right)^{2}}
$$

Os valores de $r^{2}$, que modela a função da variância $\sigma^{2}(t)$, e o ponto de saturação da variância $\sigma_{c}^{2}$ são obtidos experimentalmente. Em seguida, há uma proposta para se calcular esses valores.

Baseado na proposta que foi explicada sobre o comportamento do erro lateral (vide Equação (40)), o gráfico da Figura 28 ilustra o comportamento da variância ao longo da distância percorrida. $\mathrm{O}$ eixo horizontal apresenta os valores da distância viajada $d$, enquanto o eixo vertical apresenta os valores da variância do erro lateral $\sigma^{2}(t)$. O ponto de inflexão I indica a distância a partir da qual o aumento da variância começa a ocorrer em uma menor velocidade, de forma que o seu valor começa a tender a $\sigma_{c}^{2}$. O gráfico corresponde a uma variação quadrática até o ponto de inflexão $I$ e depois, torna-se uma função que converge para um determinado valor $\sigma_{c}^{2}$. 


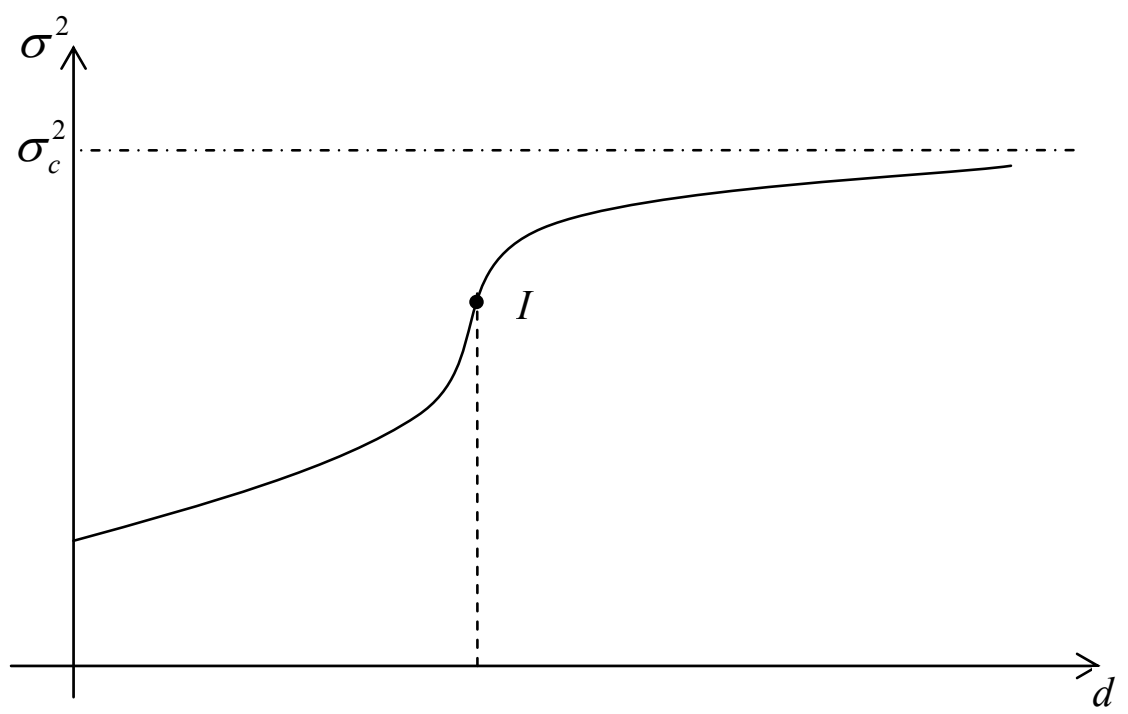

Figura 28: Comportamento da incerteza lateral de posição da aeronave.

\subsubsection{Obtenção Empírica de $r^{2}$ e $\sigma_{c}^{2}$}

Agora, considerem-se os conjuntos de pontos:

$$
\begin{aligned}
& P_{\text {os }} \text { Max } \\
& =\left\{P_{1 \max }, P_{2 \max }, \ldots, P_{n-1 \max }\right\} \\
& \text { Pos }_{\text {Min }}=\left\{P_{1 \min }, P_{2 \min }, \ldots, P_{n-1 \min }\right\}
\end{aligned}
$$

Esses conjuntos são compostos pelos pontos definidos na Figura 26. Baseado nesses conjuntos é possível calcular a variação da incerteza lateral para as previsões de posição. Para cada um dos conjuntos de pontos $\operatorname{Pos}_{\operatorname{Max}}$ e $\operatorname{Pos}_{\mathrm{Min}}$, é realizada uma regressão linear, encontrando-se as retas $T_{M a x}$ e $T_{M i n}$, ilustradas na Figura 29.

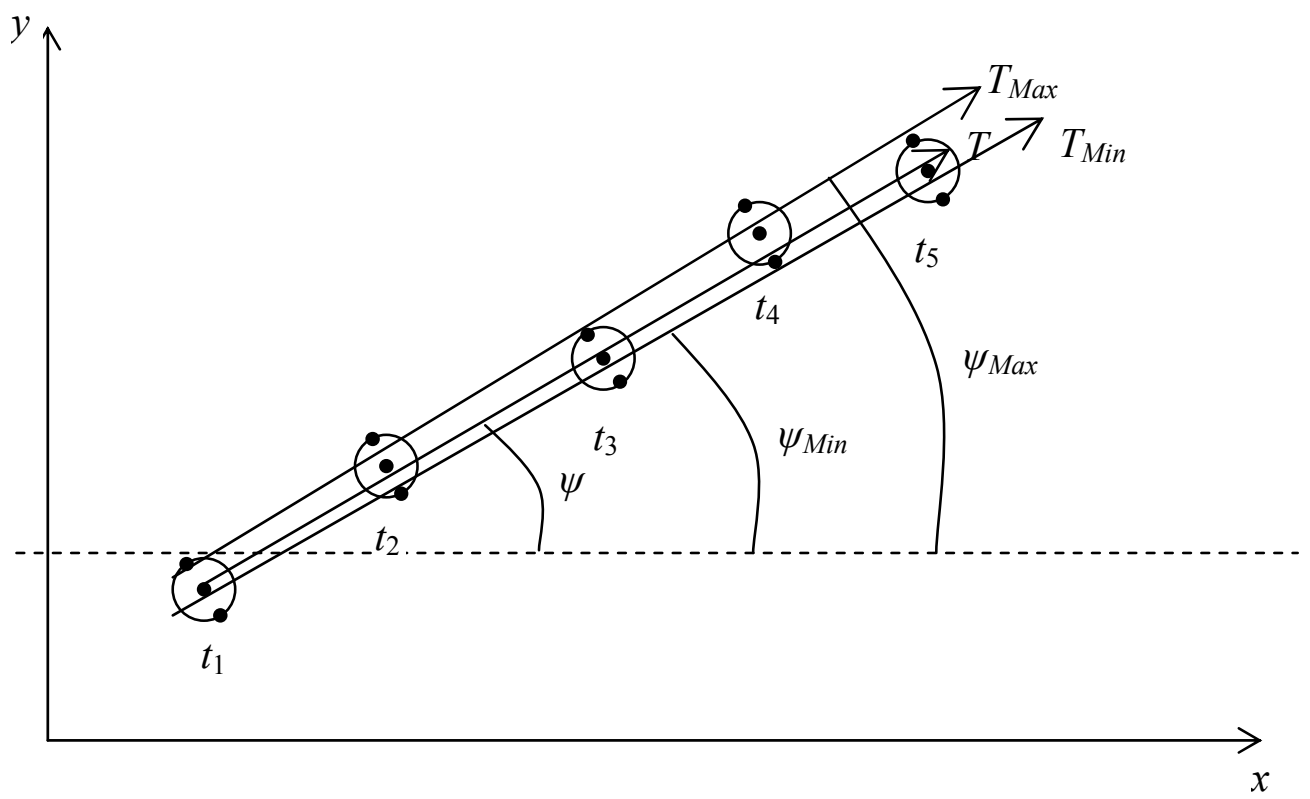

Figura 29: Propagação das incertezas. 
Em particular, as situações em que os valores de FOM são os mesmos em todas as posições conhecidas da aeronave levam as retas $T_{M a x}$ e $T_{M i n}$ a serem paralelas em relação a reta $T$. De acordo com as probabilidades, considerando-se o vôo em rota, a aeronave deverá permanecer dentro do espaço delimitado pelas retas durante todo o trajeto, e isso valerá apenas até que ela atinja o fixo seguinte, quando ocorrerá uma mudança de direção. Considerando-se esse fato sobre a incerteza, a distância entre as retas $T_{\text {Max }}$ e $T_{\text {Min }}$ deve ser considerada na obtenção do valor de saturação $\sigma_{c}^{2}$.

Considere-se $d$ a distância entre as retas $T_{M a x}$ e $T_{\text {Min }}$ e suponha-se que em $95 \%$ das vezes a aeronave deverá permanecer dentro do espaço delimitado pelas retas. Conforme descrito no capítulo 4 , se há a probabilidade de $95 \%$ de a aeronave estar neste espaço, então:

$$
-1,96 . \sigma \leq X \leq 1,96 . \sigma
$$

onde $X$ é o erro lateral da previsão. Na situação descrita, $X$ corresponde à distância $d$, de forma que $-1,96 . \sigma \leq d \leq 1,96 . \sigma$. Assim, tem-se que no pior caso:

$$
d^{2}=(1,96)^{2} \cdot \sigma^{2} \Rightarrow \sigma^{2}=\frac{d^{2}}{3,8416}
$$

Dessa maneira, o ponto de saturação da variância pode ser estimado por:

$$
\sigma_{c}^{2}=\frac{d^{2}}{3,8416}
$$

Pode haver situações em que as retas $T_{M a x}$ e $T_{M i n}$ não sejam paralelas. Nesse caso, haverá um ângulo de abertura entre elas, como ilustra a Figura 29. Quando isso ocorrer, $d$ será a distância entre as retas no instante $t_{n-1}$.

As equações das retas $T_{M a x}$ e $T_{M i n}$ são, respectivamente:

$$
\begin{aligned}
& y=A_{\text {Max }} x+B_{\text {Max }} \\
& y=A_{\text {Min }} x+B_{\text {Min }}
\end{aligned}
$$

Os ângulos de inclinação das retas $T, T_{M a x}, T_{\text {Min }}$ (heading angle) são, respectivamente, $\psi$, $\psi_{\text {Max }}, \psi_{\text {Min }}$, tais que:

$$
\begin{aligned}
& \psi=\operatorname{arctg}(A) \\
& \psi_{\text {Max }}=\operatorname{arctg}\left(A_{\text {Max }}\right) \\
& \psi_{\text {Min }}=\operatorname{arctg}\left(A_{\text {Min }}\right)
\end{aligned}
$$

A diferença de inclinação entre as retas acarreta que $\psi_{\text {Min }}<\psi<\psi_{\text {Max }}$. Isso significa que a aeronave está voando em uma direção tal que $\psi \epsilon\left[\psi_{\text {Min }}, \psi_{M a x}\right]$.

Com base na variação do heading angle (entre $\psi_{\text {Min }}$ e $\psi_{\text {Max }}$ ), pode ser encontrada uma função que determine o erro lateral da previsão ao longo do tempo. Uma outra forma para se 
estudar e obter o comportamento das incertezas laterais encontra-se no capítulo 6. Trata-se de um método mais específico para a situação em rota utilizado nesta pesquisa.

Para se estimar $r^{2}$ é necessário estudar o comportamento do erro lateral ao longo da distância viajada. Por meio da reta $r$, definida na Equação (38) pode ser estimada uma posição em que a aeronave estará em um instante futuro dentro de um intervalo de tempo $\Delta t_{j}$, tal que $\Delta t_{j}=t_{n+j}-t_{n-1}, 0 \leq j \leq k$, considerando que a última posição conhecida da aeronave foi obtida no instante $t_{n-1}$.

Então, para qualquer intervalo $\Delta t_{j}$ é calculada a posição prevista $P_{j}$, conforme ilustrado na Figura 30. Na mesma figura, a posição real da aeronave após o intervalo $\Delta t_{j}$ é representada pelo ponto $R_{j}$, de forma que a projeção da posição real da aeronave na reta da trajetória provável $T$ é o ponto $\operatorname{Proj}_{j}$. Desta maneira, a diferença $E_{j}=R_{j}-\operatorname{Proj}_{j}$ representa o erro lateral da posição prevista.

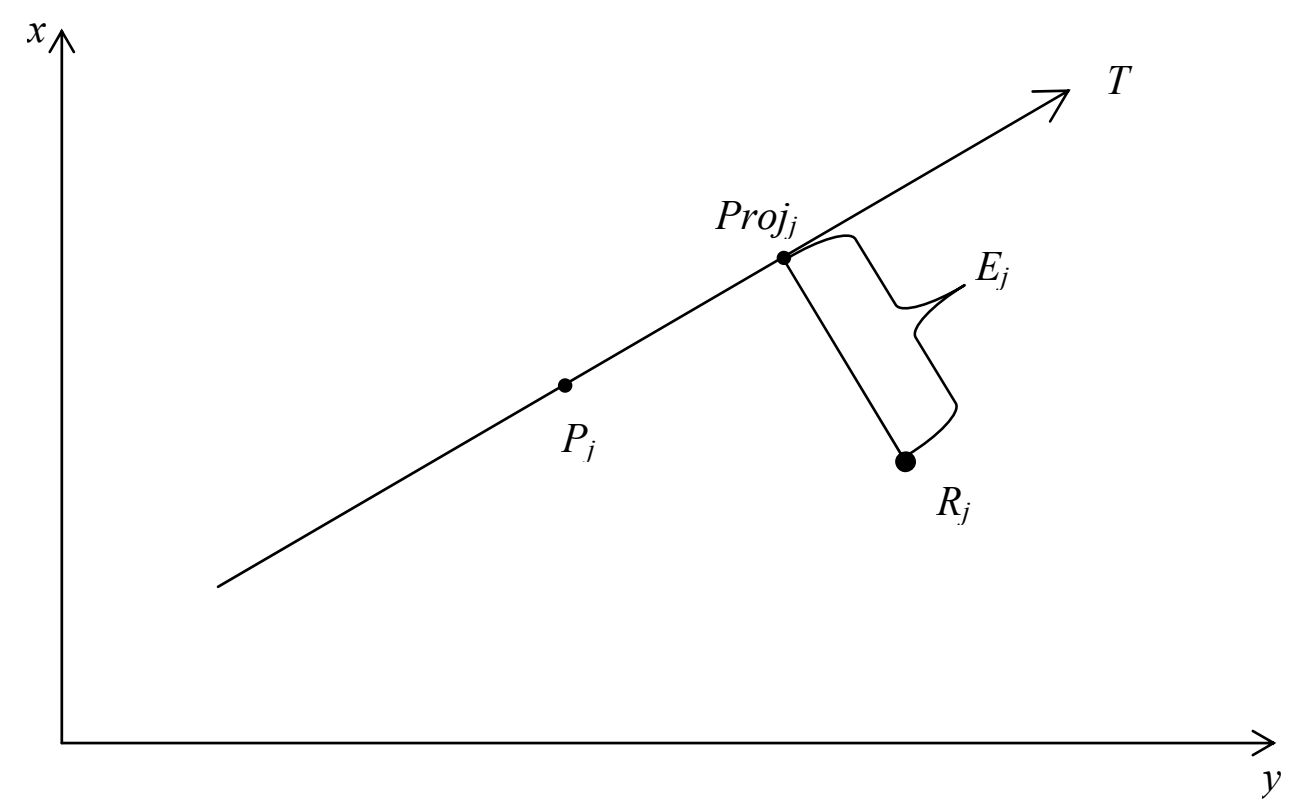

Figura 30: Cálculo do erro lateral para a previsão da posição futura de uma aeronave.

Então, dentro de um trecho de vôo, visualizado na Figura 31, são obtidas diversas previsões de posição futura (as previsões podem ser realizadas a cada minuto). Em cada previsão são estimadas as posições para todos os intervalos $\Delta t_{j}, 0 \leq j \leq k$. Assim, para cada um desses intervalos de tempo $\Delta t_{j}$, são obtidas diversas previsões de posição, e considerando todos os erros laterais $\left(E_{j}\right)$ das posições previstas para $\Delta t_{j}$, é calculada a variância do erro lateral, $\sigma^{2}\left(s\left(\Delta t_{j}\right)\right)$, sendo $s$ a função que traz a distância viajada, conforme definida na Equação (41) para previsões de posições dentro de um intervalo $\Delta t_{j}$. Desta forma, é obtido o seguinte conjunto de variâncias: 


$$
\sigma^{2}=\left\{\sigma^{2}\left(s\left(\Delta t_{1}\right)\right), \sigma^{2}\left(s\left(\Delta t_{2}\right)\right), \ldots, \sigma^{2}\left(s\left(\Delta t_{k}\right)\right)\right\}
$$

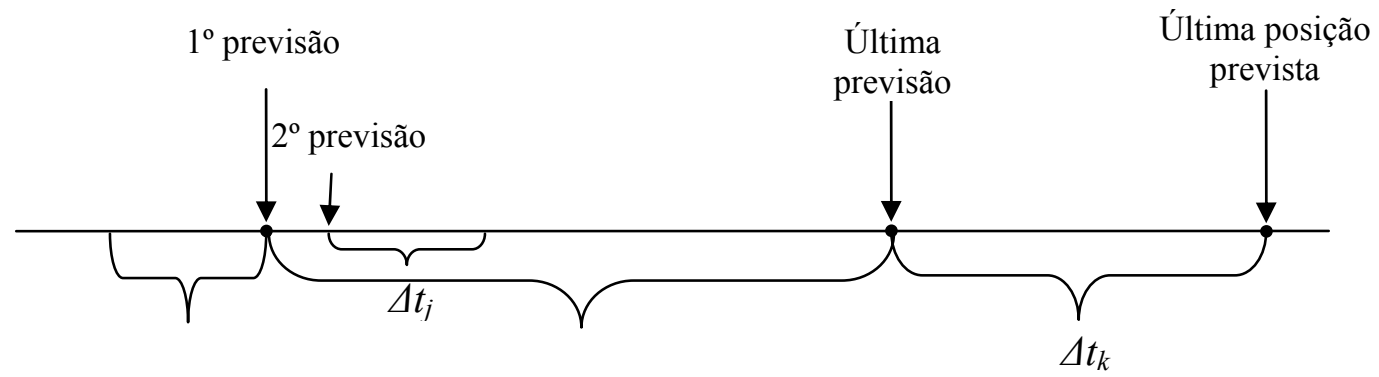

Figura 31: Previsões de posição futura para um trecho de vôo.

Baseado nos valores contidos no conjunto (47), e utilizando regressão linear para funções polinomiais de segundo grau, pois a variância cresce de forma quadrática em função do tempo conforme equação (40), é obtida a função que traz a variância do erro lateral em função da distância percorrida:

$$
\sigma^{2}: \mathfrak{R} \rightarrow \mathfrak{R}, \sigma^{2}(s(t))=a \cdot s(t)^{2}+b \cdot s(t)+c
$$

A Figura 32 ilustra o crescimento da variância do erro lateral, de forma quadrática, em função da distância percorrida.

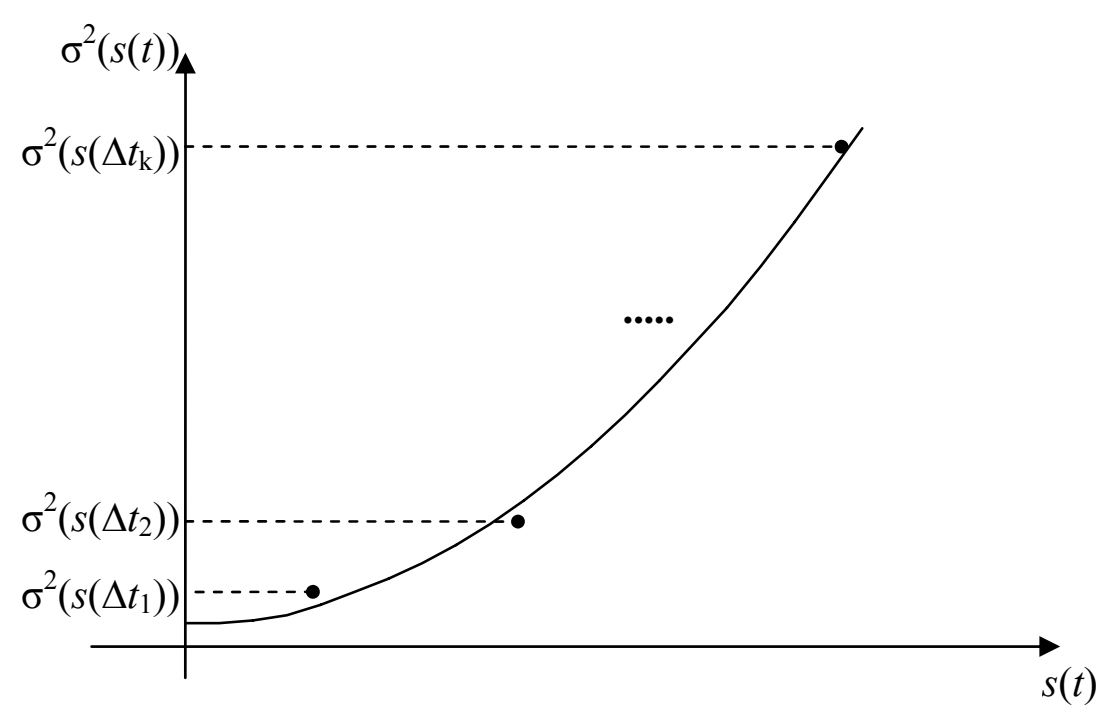

Figura 32: Crescimento da variância do erro lateral de forma quadrática.

As variâncias existentes no conjunto (47) podem ter seus valores atualizados constantemente, baseado nas informações provenientes dos vôos.

Existem alguns estudos interessantes que mostram como melhorar a previsão de posição lateral (SCHLEICHER; JONES; DOW, 2002). 


\subsubsection{Incertezas Longitudinais}

As incertezas longitudinais (along-track error) têm um comportamento diferente da incerteza lateral. Enquanto os equipamentos de controle do vôo têm condições de corrigir eventuais variações laterais, limitando o tamanho do erro, a incerteza longitudinal é mais complexa e os equipamentos de controle de vôo têm uma possibilidade de atuação mais limitada. A seção anterior mostrou esse fato, enfatizando que a variância do erro lateral tende a um valor de saturação. O mesmo não ocorre com o erro longitudinal porque, para manter-se com um erro de posição longitudinal pequeno, a aeronave teria que acelerar e desacelerar quase que continuamente, o que traria um gasto excessivo de combustível.

Os erros na previsão da posição longitudinal também têm uma distribuição Gaussiana (PRANDINI et al., 2000). No entanto, nesse caso, a média é zero e a variância $\sigma^{2}(t)$ cresce de forma quadrática ao longo do tempo e não ocorre saturação no crescimento da variância. $\mathrm{O}$ crescimento da variância do erro longitudinal pode ser expresso por:

$$
\sigma^{2}(t) \sim r_{a}^{2} t^{2}
$$

De forma geral, estudar a incerteza longitudinal requer que sejam estimados os valores da variância do erro longitudinal e seja modelado o seu crescimento ao longo do tempo. Isso significa modelar a variância $\sigma^{2}(t)$, definida na Equação (49), e que cresce de forma quadrática em função do tempo de previsão.

Considere-se uma aeronave voando em um determinado espaço aéreo. Conforme definido na Equação (39), a trajetória mais provável da aeronave é representada pela reta $T$, a qual é obtida por meio de regressão linear sobre o conjunto de pontos $\operatorname{Pos} T$, definido em (37). A reta $r$, definida em (38) pode ser utilizada para se estimar uma posição em que a aeronave estará em um instante futuro dentro de um intervalo $\Delta t_{j}$, tal que $\Delta t_{j}=t_{n+j}-t_{n-1}, 0 \leq j \leq k$, considerando que a última posição conhecida da aeronave foi obtida no instante $t_{n-1}$.

Então, para qualquer intervalo $\Delta t_{j}$ é calculada a posição prevista $P_{j}$, conforme ilustrado na Figura 33. Na mesma figura, a posição real da aeronave após o intervalo $\Delta t_{j}$ é representada pelo ponto $R_{j}$, de forma que a projeção da posição real da aeronave na reta da trajetória provável $T$ é o ponto $\operatorname{Proj}_{j}$. Desta maneira, a diferença $E_{j}=P_{j}-\operatorname{Proj}_{j}$ representa o erro longitudinal da posição prevista. 


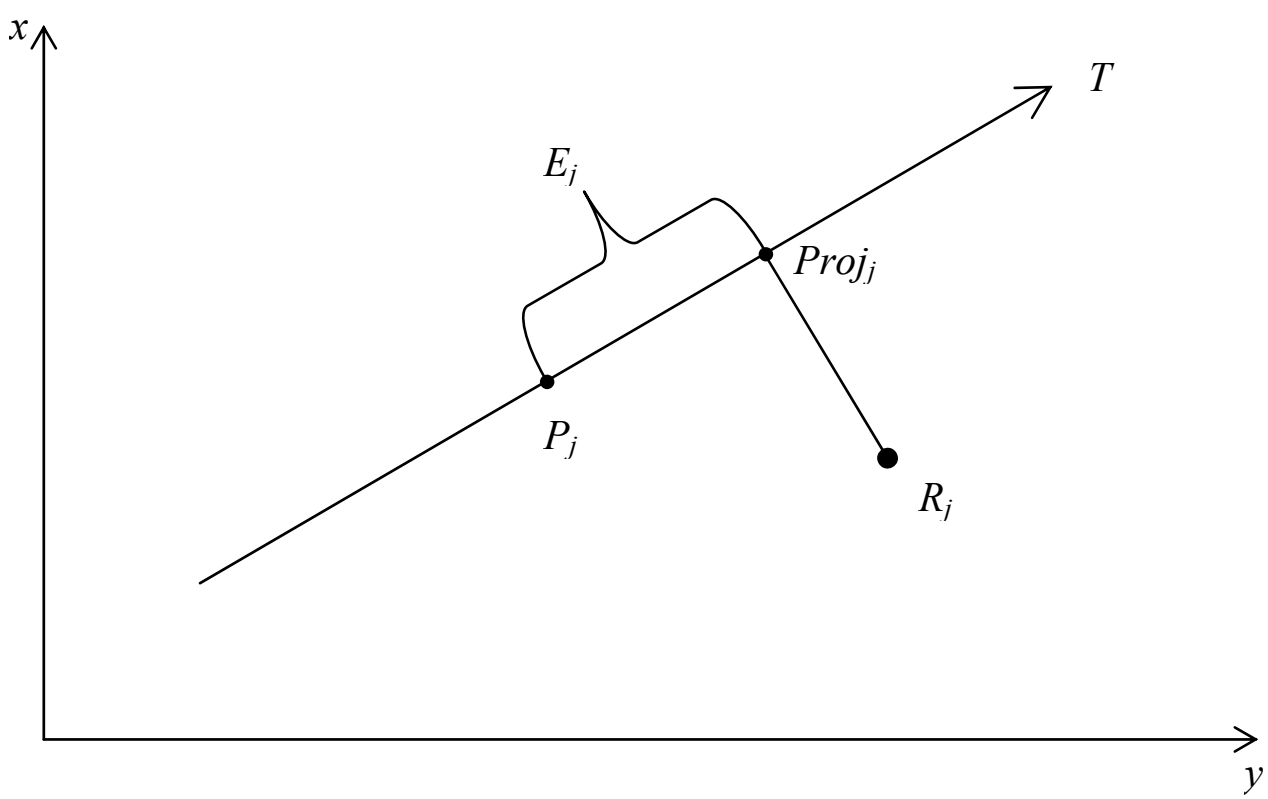

Figura 33: Cálculo do erro longitudinal para a previsão da posição futura de uma aeronave.

Então, dentro de um trecho de vôo, visualizado na Figura 31, são obtidas diversas previsões de posição futura (as previsões podem ser realizadas a cada minuto). Em cada previsão são estimadas as posições para todos os intervalos $\Delta t_{j}, 0 \leq j \leq k$. Assim, para cada um desses intervalos de tempo $\Delta t_{j}$, são obtidas diversas previsões de posição, e considerando todos os erros longitudinais $\left(E_{j}\right)$ das posições previstas para $\Delta t_{j}$, é calculada a variância do erro longitudinal, $\sigma^{2}\left(\Delta t_{j}\right)$, para previsões de posições dentro de um intervalo $\Delta t_{j}$. Desta forma, é obtido o seguinte conjunto de variâncias:

$$
\sigma^{2}=\left\{\sigma^{2}\left(\Delta t_{1}\right), \sigma^{2}\left(\Delta t_{2}\right), \ldots, \sigma^{2}\left(\Delta t_{k}\right)\right\}
$$

Baseado nos valores contidos no conjunto (50) e utilizando regressão linear para funções polinomiais de segundo grau, pois a variância cresce de forma quadrática em função do tempo, conforme ilustra a Equação (49), é obtida a função que traz a variância do erro longitudinal em função do tempo da previsão:

$$
\sigma^{2}: \mathfrak{R} \rightarrow \mathfrak{R}, \sigma^{2}(t)=a \cdot t^{2}+b \cdot t+c
$$

A Figura 34 ilustra o crescimento da variância do erro longitudinal, de forma quadrática, em função do tempo de viagem. 


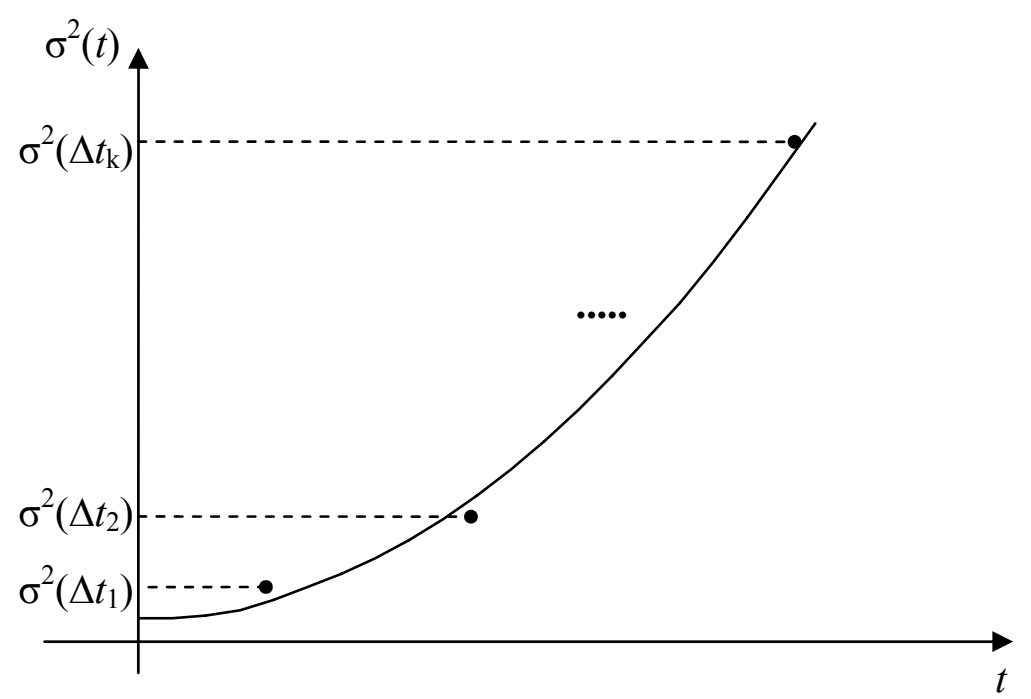

Figura 34: Crescimento da variância do erro longitudinal de forma quadrática.

As variâncias existentes no conjunto (50) podem ter seus valores atualizados constantemente, baseado nas informações provenientes dos vôos.

\subsection{Tópicos Adicionais}

Sabe-se que o modelo de previsão parte da premissa que a aeronave está na fase de vôo em rota. Assim, a aeronave está realizando um percurso entre dois fixos $W P_{j-1}$ e $W P_{j}$, com uma velocidade $v_{j}$. É possível comparar a reta $T$ com a reta determinada pelos pontos $W P_{j-1}$ e $W P_{j}$, ou seja, determinada pelo plano de vôo. Isso permite verificar se a aeronave está seguindo a rota traçada, possibilitando que sejam efetuadas correções no plano de vôo.

Alguns fatores de incerteza adicionais podem ser incluídos no modelo de previsão de posição de aeronaves, como: desempenho da aeronave, características do espaço aéreo e comportamento do vento (MONDOLONI, 2000).

\subsection{Considerações Finais do Capítulo}

Neste capítulo foi apresentado o modelo proposto para a previsão de posição futuras das aeronaves. Primeiramente foi mostrado um modelo geral utilizado na construção de trajetórias. Com base neste modelo, foi proposto um modelo para ser utilizado em situações de vôo entre dois fixos, sendo este cenário o foco da investigação nesta pesquisa.

Então, a seção seguinte destacou o método de extrapolação utilizado, que consiste em utilizar informações passadas conhecidas sobre as posições da aeronave para extrapolar e prever uma posição futura. Além disso, foi agregado ao modelo um estudo para calcular a propagação das incertezas laterais e longitudinais ao longo da trajetória. As incertezas dos radares, utilizados para calcular as posições das aeronaves, não foram consideradas neste 
estudo, mas podem ser incorporadas em futuras investigações já que estas incertezas impactam a extrapolação para a previsão de posições futuras de aeronaves. 


\section{ESTUDO DE CASO}

Neste capítulo é apresentado o estudo de caso utilizado para analisar e verificar a aplicabilidade do modelo proposto para previsão de posições futuras de aeronaves. Há informações a respeito dos dados obtidos para as simulações, tipo de espaço aéreo considerado e modelos de aeronaves.

O processo de simulação utilizado foi descrito de forma mais detalhada, trazendo como exemplos estudos para dois vôos. Em seguida os resultados são apresentados, contendo uma breve análise e interpretação dos valores obtidos.

\subsection{Cenário de Estudo}

No contexto deste trabalho, considerando o tema da aviação dentro do espaço aéreo brasileiro, é importante destacar que o espaço aéreo é dividido em regiões chamadas de Flight Information Regions (FIRs). No território brasileiro, existem quatro FIRs: Brasília, Curitiba, Recife e Amazônica. Dentre essas, a FIR Brasília é a mais movimentada e, por essa razão, foi a escolhida para o estudo de caso deste trabalho de pesquisa.

Com os dados de vôos obtidos na FIR Brasília é possível verificar posições conhecidas de uma aeronave, efetuar a extrapolação da sua trajetória percorrida, conforme descrito no capítulo anterior e, então, comparar a posição prevista com a informação da posição real da aeronave. Nas simulações realizadas, não estão sendo considerados fatores como plano de vôo, condições meteorológicas. No capítulo 7, há sugestões de fatores que podem ser utilizados para a continuidade deste estudo.

\subsection{Processo da Simulação}

Inicialmente, um esquema que ilustra as nove etapas do processo de simulação é apresentado na Figura 35, para a determinação de posições futuras de uma aeronave. As primeiras quatro etapas do processo são importantes para agrupar apenas as informações necessárias para o cálculo das previsões. Nas cinco etapas seguintes, realmente ocorre todo o cálculo que gera as previsões futuras de aeronaves, e correspondem à principal contribuição deste trabalho de pesquisa. 


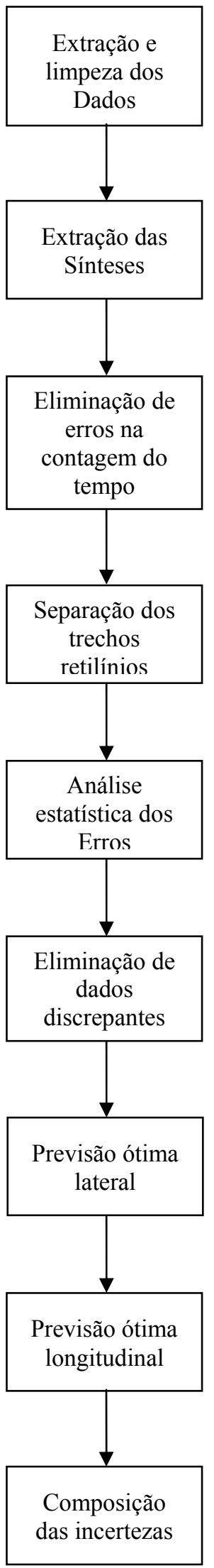

Figura 35: Etapas do processo de simulação para determinação de posição futura de uma aeronave. 
Cada uma das etapas do processo da Figura 35 está resumidamente descrita a seguir:

1. Extração e limpeza dos dados - Nos arquivos que guardam as informações do vôo, há vários dados que não interessam para a previsão de posição, como por exemplo número da pista, código SSR radar, tipo do código SSR, etc. Assim, são extraídos apenas os dados necessários para a simulação;

2. Extração das sínteses - Cada posição da aeronave contida no arquivo dos vôos é determinada por 1 a 4 radares. Há também uma posição síntese, que corresponde a uma composição das posições medidas pelos radares. Neste trabalho, apenas a posição síntese é extraída para a análise dos dados;

3. Eliminação de erros na contagem do tempo - Os dados referentes às posições percorridas pela aeronave trazem a informação do instante do tempo da posição, cuja contagem ocorre de 10 em 10 segundos. No entanto, há situações em que a contagem do tempo apresenta erros, como valor do tempo zerado, ou inconsistências, como valores inválidos para o instante de tempo;

4. Separação dos trechos retilíneos - Alguns vôos apresentam variações de direção ao longo do tempo, de acordo com o plano de vôo. Cada trecho retilíneo é separado para ser analisado individualmente;

5. Análise estatística dos erros - É efetuada uma análise estatística do comportamento das incertezas laterais e longitudinais, para cada trecho retilíneo de um vôo, encontrando-se as médias e variâncias dos erros lateral e longitudinal;

6. Eliminação de dados discrepantes - Tendo conhecimento da distribuição dos erros das posições extrapoladas, ocorre a eliminação de dados discrepantes, os quais podem contaminar a análise;

7. Previsão ótima lateral - De posse das informações de média e variância ajustadas do erro lateral, é encontrada a situação que permite a extrapolação com menor taxa de erro lateral;

8. Previsão ótima longitudinal - Da mesma forma como é feito para a previsão lateral, é encontrada a situação em que a extrapolação traz a menor taxa de erro longitudinal; e

9. Composição das incertezas - Finalmente, as posições lateral e longitudinal previstas são compostas para se obter uma única previsão, juntamente com as suas incertezas laterais e longitudinais.

As próximas seções (6.2.1 a 6.2.9) trazem mais detalhes de cada uma destas etapas que foram brevemente descritas, considerando os dados referentes ao vôo BRB9983, do dia 25/04/2005, e servem para ilustrar melhor o procedimento adotado. Para outros vôos serão exibidos apenas os resultados consolidados. 


\subsubsection{Extração e Limpeza dos Dados}

Os dados obtidos correspondem a relatórios de vôos, os quais contêm informações gerais das condições de vôo e também detalhes sobre a rota e os trechos percorridos pela aeronave. Além disso, há um relatório que mostra o acompanhamento e a evolução das posições da aeronave ao longo do tempo, utilizando dados medidos por radar, obtidos em intervalos de 10 em 10 segundos. Nas simulações foram considerados os seguintes dados dos vôos:

- Tempo (TIME) - instante da mensagem, medido em segundos;

- Posição X (XPOS) - componente X da posição relativa da aeronave, medido em milhas náuticas $(\mathrm{NM})$; e

- Posição Y (YPOS) - componente Y da posição relativa da aeronave, medido em milhas náuticas $(\mathrm{NM})$.

Além das informações sobre instante da mensagem e posição da aeronave, algumas outras informações importantes também são obtidas por meio dos relatórios, como:

- RAD - indica o nome do radar considerado;

- TD - traz informações sobre a origem da detecção dos dados, por exemplo TD = C é origem secundária e $\mathrm{TD}=2 \mathrm{D}$ é origem primária $2 \mathrm{D}$;

- QF - traz uma medida do fator de qualidade da pista (não se trata de acurácia da medida);

- VELC - indica a velocidade da aeronave em nós (knot); e

- PLN - traz o número do plano de vôo.

Essas quatro últimas medidas não são relevantes para o algoritmo proposto nesta pesquisa, e foram mantidas apenas para ilustrar os dados trazidos. Na Tabela 4, há exemplos onde o formato desses dados podem ser visualizados. Conforme está explicado nas seções seguintes, outros dados podem ser considerados para aumentar a acurácia do algoritmo de extrapolação, como detecção de variação da velocidade e detecção de variação na direção da aeronave. Sempre que se souber que houve uma grande variação na velocidade ou direção, esta informação deve ser considerada na extrapolação, já que isso interfere diretamente no resultado obtido para a previsão de posição.

Tabela 4: Exemplo de formato dos dados.

\begin{tabular}{|l|l|l|l|l|l|l|l|}
\hline RAD & TIME (s) & XPOS (NM) & YPOS (NM) & TD & QF & VELC & PLN \\
\hline SINT & 745,04 & $-136,03$ & 173,19 & C & 7 & 435 & 742 \\
\hline GAMA & 745,04 & $-136,03$ & 173,19 & C & 7 & 435 & 0 \\
\hline TRM & 745,04 & $-136,22$ & 170,47 & C & 5 & 455 & 0 \\
\hline
\end{tabular}


Os arquivos utilizados vieram em formato texto e incluem uma série de informações não relevantes para este trabalho. Por este motivo, foi necessário efetuar uma limpeza e filtrar apenas os dados a serem utilizados nas simulações. Para automatizar este processo, foi construído um script utilizando a linguagem Perl, para permitir uma rápida limpeza e filtragem dos dados, sempre que novos arquivos devam ser analisados. O apêndice A contém o código do script gerado. Com a filtragem, foi gerado um arquivo contendo apenas os dados ilustrados na Tabela 4.

\subsubsection{Extração das Sínteses}

É importante considerar a forma como as informações são obtidas com o uso dos radares existentes na FIR Brasília, dentro da qual há dezessete radares. Há várias situações em que as regiões de cobertura dos radares se sobrepõem, causando a detecção da posição da aeronave por dois ou mais radares. A Figura 36 ilustra uma situação considerando dois radares se sobrepondo, de forma que a região cinza corresponde a uma área onde dois radares atuam ao mesmo tempo. Nessas situações, uma única posição, chamada de síntese, é composta por meio das posições medidas pelos radares. Para as simulações, pode ser interessante utilizar as posições medidas por todos os radares, já que isso constitui uma forma de medir a imprecisão do valor conhecido. No entanto, optou-se por se utilizar apenas as informações sintetizadas, já que são as informações utilizadas por pilotos e controladores, além de que a síntese já elimina automaticamente eventuais medidas discrepantes.

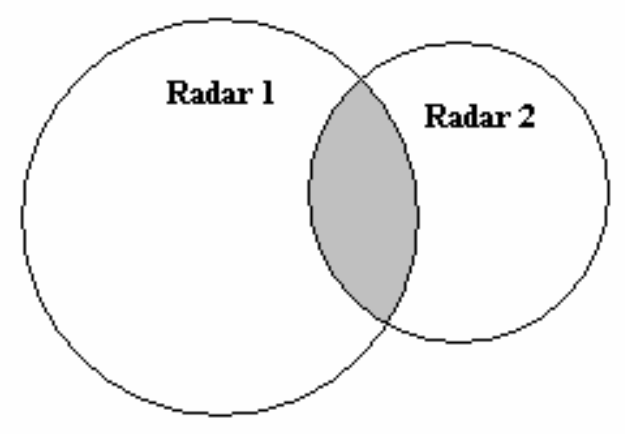

Figura 36: Exemplo de sobreposição de radares.

Dentro dos arquivos, uma situação como a ilustrada na Figura 36 aparece na Tabela 4. A segunda linha da tabela contém os dados da aeronave medidos pelo radar denominado GAMA. A terceira linha da tabela contém os dados do radar denominado TRM. Já a primeira linha traz os dados sintetizados (SINT), que são compostos pelos dois radares que cobrem a região onde a aeronave se encontra. 


\subsubsection{Extração de Erros na Contagem do Tempo}

Foi detectada a necessidade de uma nova filtragem dos dados, pois em razão da natureza dos sistemas que controlam a contagem do tempo, existem ciclos de medidas e a contagem do tempo é zerada a cada novo ciclo. Um exemplo disso está nos dados da Tabela 5, onde a primeira linha traz uma medida para o instante $1284,42 \mathrm{~s}$ e esta contagem é crescente até a terceira linha, ocorrendo de 10 em 10 segundos. Considerando a periodicidade da contagem do tempo, a quarta linha deveria ter o valor 1314,42 segundos. Entretanto, em virtude de um novo ciclo ter sido iniciado em algum instante entre a terceira e quarta posição, a contagem do tempo trouxe o valor 3,7 segundos. A eliminação dos erros na contagem do tempo foi feita com auxílio da ferramenta Matlab, de onde os dados foram importados.

Tabela 5: Exemplo de ciclo de tempo.

\begin{tabular}{|c|c|c|c|c|c|c|c|}
\hline RAD & TIME (s) & XPOS (NM) & YPOS (NM) & TD & QF & VELC & PLN \\
\hline SINT & $1.284,42$ & $-58,88$ & $-51,59$ & $3 C$ & 7 & 461 & 742 \\
\hline SINT & $1.294,42$ & $-58,44$ & $-52,81$ & $3 \mathrm{C}$ & 7 & 461 & 742 \\
\hline SINT & $1.304,42$ & $-57,94$ & $-54,06$ & $3 \mathrm{C}$ & 7 & 461 & 742 \\
\hline SINT & 3,70 & $-57,50$ & $-55,22$ & $3 \mathrm{C}$ & 7 & 460 & 742 \\
\hline SINT & 13,70 & $-56,19$ & $-56,38$ & $3 \mathrm{C}$ & 7 & 452 & 742 \\
\hline SINT & 23,70 & $-55,78$ & $-57,69$ & $3 \mathrm{C}$ & 7 & 453 & 742 \\
\hline
\end{tabular}

Pode-se notar que, após o instante 1.304,42 s, a contagem do tempo volta para 3,70 s. Para viabilizar as simulações, foi necessário redefinir a contagem do tempo, tornando-a seqüencial. Então, para o exemplo mostrado na Tabela 5, a contagem do tempo é modificada, conforme exibido na Tabela 6.

Tabela 6: Contagem do tempo ajustada para as simulações.

\begin{tabular}{|l|c|c|c|c|c|c|c|}
\hline RAD & TIME (s) & XPOS (NM) & YPOS (NM) & TD & QF & VELC & PLN \\
\hline SINT & $1.284,42$ & $-58,88$ & $-51,59$ & $3 \mathrm{C}$ & 7 & 461 & 742 \\
\hline SINT & $1.294,42$ & $-58,44$ & $-52,81$ & $3 \mathrm{C}$ & 7 & 461 & 742 \\
\hline SINT & $1.304,42$ & $-57,94$ & $-54,06$ & $3 \mathrm{C}$ & 7 & 461 & 742 \\
\hline SINT & $1.314,42$ & $-57,50$ & $-55,22$ & $3 \mathrm{C}$ & 7 & 460 & 742 \\
\hline SINT & $1.324,42$ & $-56,19$ & $-56,38$ & $3 \mathrm{C}$ & 7 & 452 & 742 \\
\hline SINT & $1.334,42$ & $-55,78$ & $-57,69$ & $3 \mathrm{C}$ & 7 & 453 & 742 \\
\hline
\end{tabular}

Há também situações de erros na contagem do tempo, tais como valores zerados do tempo, ou situações em que ocorre decréscimo no tempo, conforme pode ser visualizado nas 
linhas 2 e 3 da Tabela 7. Todas essas situações foram desconsideradas pelo algoritmo descrito no apêndice A.

Tabela 7: Exemplos de erros na contagem do tempo.

\begin{tabular}{|l|l|l|l|l|l|l|l|}
\hline RAD & TIME (s) & XPOS (NM) & YPOS (NM) & TD & QF & VELC & PLN \\
\hline SINT & $1.284,42$ & $-58,88$ & $-51,59$ & $3 \mathrm{C}$ & 7 & 461 & 742 \\
\hline SINT & 0 & $-58,44$ & $-52,81$ & $3 \mathrm{C}$ & 7 & 461 & 742 \\
\hline SINT & $1.304,42$ & $-57,94$ & $-54,06$ & $3 \mathrm{C}$ & 7 & 461 & 742 \\
\hline SINT & $1.302,35$ & $-57,50$ & $-55,22$ & $3 \mathrm{C}$ & 7 & 460 & 742 \\
\hline SINT & $1.324,42$ & $-56,19$ & $-56,38$ & $3 \mathrm{C}$ & 7 & 452 & 742 \\
\hline SINT & $1.334,42$ & $-55,78$ & $-57,69$ & $3 \mathrm{C}$ & 7 & 453 & 742 \\
\hline
\end{tabular}

\subsubsection{Separação dos Trechos Retilíneos}

Conforme ilustrado na definição de plano de vôo, a aeronave muda a direção de vôo a cada fixo atingido, podendo também ocorrer mudanças de direção em algumas outras situações. Como o foco deste estudo é para os trechos em rota, a análise é feita apenas para os trechos de vôo retilíneos. Por isso, é necessário separar cada trecho retilíneo existente dentro de um vôo. Maiores detalhes a respeito estão apresentados no estudo caso de 2 para o vôo TAM8096 (seção 6.3.2).

\subsubsection{Análise Estatística dos Erros}

Os passos descritos agora, de forma mais detalhada, são baseados nos dados do vôo BRB9983, realizado no dia 25/04/2005. A função de extrapolação foi construída utilizando o método dos mínimos quadrados, descrito no capítulo 4. Além disso, foram calculados alguns valores que indicam a variabilidade dos dados, como a média e o desvio padrão. Estas medidas ocorreram, separando-se as componentes lateral e longitudinal da trajetória e são utilizadas nos passos seguintes para concluir a construção do modelo, possibilitando a obtenção das incertezas lateral e longitudinal, a serem incluídas junto com a posição prevista. A Figura 37 mostra um exemplo de extrapolação. Os pontos destacados no canto superior esquerdo correspondem a posições conhecidas da aeronave durante um minuto de vôo, com destaque para a posição atual. Com essas informações, foi construída a trajetória mais provável da aeronave, que corresponde ao segmento de reta existente na figura. $\mathrm{O}$ asterisco existente sobre a reta correspondente à posição prevista da aeronave para um instante dentro de cinco minutos está colocado na reta da trajetória provável. O outro asterisco correspondente à posição real para o instante dentro de 5 minutos também pode ser visualizado. 


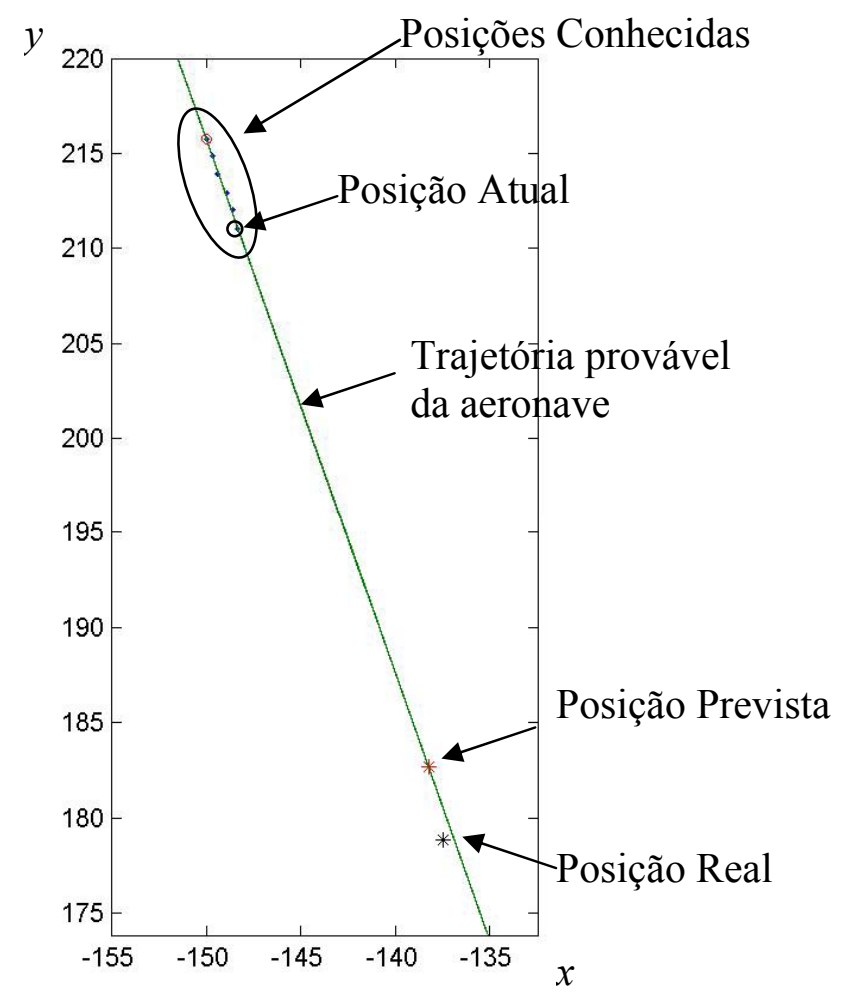

Figura 37: Trajetória provável e posição extrapolada.

Neste exemplo, foram consideradas as 6 posições conhecidas anteriores ao instante atual para a aeronave, o que corresponde ao caminho da aeronave no último minuto. Entretanto, há a possibilidade de se considerar uma quantidade diferente de pontos. Para isso, foi feito uma investigação a fim de se encontrar a quantidade de pontos que permita obter a melhor previsão. Foram consideradas algumas situações, listadas na Tabela 8.

Tabela 8: Quantidades de posições conhecidas consideradas nas simulações.

\begin{tabular}{|c|c|}
\hline Quantidade de Pontos & $\begin{array}{c}\text { Tempo Transcorrido } \\
\text { (minutos) }\end{array}$ \\
\hline 6 & 1 \\
\hline 12 & 2 \\
\hline 18 & 3 \\
\hline 24 & 4 \\
\hline 30 & 5 \\
\hline
\end{tabular}


As trajetórias em rota analisadas contêm vôos com duração média de 40 minutos entre dois fixos. Em geral, as previsões de posição futura ocorrem para um período máximo de 20 minutos. Ao se aplicarem as regressões lineares, foram consideradas posições conhecidas da aeronave desde 1 minuto até 5 minutos. Não foi utilizado um valor maior, pois nesses casos, dentro de um vôo de 40 minutos, haveria poucas previsões a serem realizadas, limitando a análise do modelo. A Tabela 8 mostra a quantidade de pontos utilizada, múltiplos de 6 , e o respectivo tempo transcorrido entre as posições conhecidas, em minutos, a serem considerados na regressão.

Para cada uma das quantidades de pontos descrita, foi realizada a regressão. Em todas as situações, a posição mais recente utilizada foi a mesma, modificando-se apenas a quantidade de posições anteriores consideradas. Então, ocorreu a extrapolação da posição para instantes futuros entre 5 e 20 minutos. Como resultado, foi gerado um arquivo em que cada linha contém as seguintes informações:

- Time - Instante do tempo futuro previsto;

- Pts_Pas - Quantidade de pontos passados considerados;

- Pts_Fut - Quantidade de pontos futuros considerados;

- Dist - Distância percorrida desde o instante inicial até o instante previsto;

- Std_Lat - Desvio padrão da componente lateral dos erros, considerando a quantidade de pontos passados extrapolados e a quantidade de pontos futuros da previsão;

- Std_Lon - Desvio padrão da componente longitudinal dos erros, considerando a quantidade de pontos passados extrapolados e a quantidade de pontos futuros da previsão;

- Erro_Lat - Erro lateral da previsão;

- Erro_Lon - Erro longitudinal da previsão; e

- Erro_Abs - Erro absoluto da previsão.

Para os dados do vôo BRB9983 foi considerado um trecho retilíneo de 67 minutos. Então, a primeira previsão ocorreu no instante 5 minutos, de forma a permitir realizar a regressão desde 1 até 5 minutos. A última previsão $\left(42^{\mathrm{a}}\right)$ ocorreu no instante 47 do trecho, permitindo que a última posição prevista fosse referente ao minuto 67 do trecho. Portanto, as extrapolações, realizadas de minuto a minuto, contemplaram um trecho de vôo com duração de 42 minutos, ou seja, a previsão foi realizada para 42 instantes de tempo. Para cada um desses instantes foram realizadas 5 regressões lineares, considerando posições passadas conhecidas com duração total do intervalo, variando de 1 a 5 minutos, ou seja, um total de 
210 regressões. Finalmente, para cada uma das 210 regressões foram realizadas 20 previsões (20 intervalos $\Delta t, 0 \leq j \leq k$, com $k=19$, conforme definido em 5.2.3 e 5.2.4) entre 1 e 20 minutos $\left(\Delta t_{0}=1, \Delta t_{1}=2, \ldots, \Delta t_{19}=20\right)$, gerando um total de 4200 previsões. Todas essas 4200 previsões, seguindo o formato descrito, foram utilizadas para analisar o comportamento dos erros laterais e longitudinais, com o auxílio da ferramenta MS-Excel. A visualização do trecho retilíneo inteiro é encontrada na Figura 38.

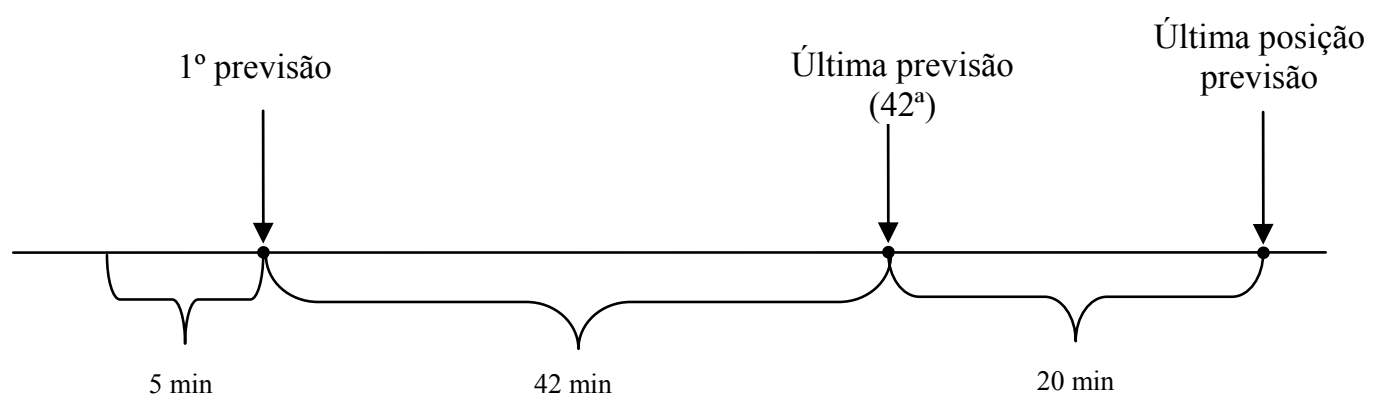

Figura 38: Previsões de posição baseadas em um trecho retilíneo de vôo.

\subsubsection{Eliminação de Dados Discrepantes}

Conforme destacado no capítulo anterior, os erros laterais e longitudinais seguem uma distribuição normal com média 0 . Foi obtida a variância para cada combinação (quantidade de pontos da regressão, variando de 1 a 5 minutos versus instante de tempo futuro, variando de 1 a 20 minutos). Em seguida, os valores discrepantes dos dados foram eliminados. A Figura 39 mostra a curva de distribuição dos erros das previsões, sendo que a região hachurada contempla $95 \%$ dos dados existentes, pois para cada ponto dessa região, tem-se:

$-1,96 . \sigma \leq$ Erro $\leq 1,96 . \sigma$

Portanto, foram descartados os dados cujos erros sejam maiores que $1,96 . \sigma$ ou menores que $-1,96 . \sigma$. Os dados que estão fora desta região apresentam valores discrepantes, que podem contaminar as situações mais comuns para o comportamento dos erros lateral e longitudinal. Com os dados que foram efetivamente considerados, novos valores foram obtidos para as variâncias dos erros. 


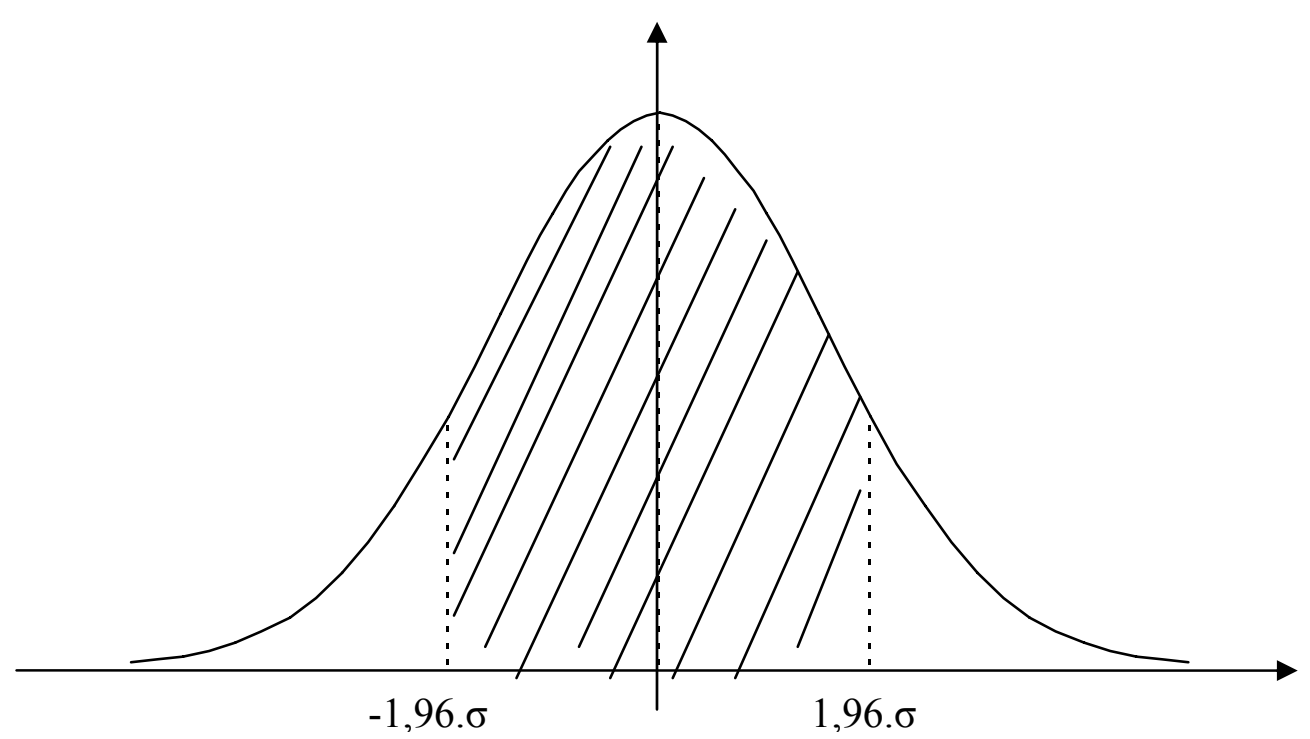

Figura 39: Ilustração dos dados considerados na análise.

\subsubsection{Eliminação de Dados Discrepantes nos Erros Laterais}

Para a eliminação dos dados discrepantes relativos aos erros laterais, primeiramente é necessário determinar qual a situação que minimiza a incerteza dos erros laterais. Então, todas as informações sobre os erros são determinadas por meio da comparação dos valores extrapolados com os valores reais. Os dados estão colocados na Tabela 9, apresentada na forma de matriz. Cada célula dessa matriz corresponde ao cruzamento de um Instante da Previsão, medido em minutos, com a quantidade de pontos passados considerados na extrapolação. Então, cada célula traz a média do erro lateral e a variância do erro lateral, calculados conforme expressões contidas no capítulo 4, bem como a média da distância percorrida. Pela análise das variâncias, é detectado que a melhor situação para diminuir a incerteza do erro lateral ocorre quando 30 pontos são considerados na regressão, ou seja, são consideradas posições conhecidas dos últimos 5 minutos. Já foi destacado que não ocorreram regressões para mais de 5 minutos porque isso limitaria a quantidade de previsões a serem realizadas, o que poderia comprometer a viabilidade da aplicação prática do trabalho, já que sobraria uma amostra pequena de previsões para serem analisadas. 
Tabela 9: Média e variância do erro lateral e distância média percorrida.

\begin{tabular}{|c|c|c|c|c|c|c|c|}
\hline & & \multicolumn{5}{|c|}{ Pontos Passados Considerados } & \multirow[b]{2}{*}{ Média geral } \\
\hline Instante da Previsão (min.) & Dados (NM) & 6 & 12 & 18 & 24 & 30 & \\
\hline \multirow[t]{3}{*}{ ( } & Média do erro lateral & $-0,03$ & 0,05 & 0,06 & 0,07 & 0,09 & 0,05 \\
\hline & Variância do erro lateral & 1,15 & 0,32 & 0,31 & 0,30 & 0,29 & 0,47 \\
\hline & Média da distância percorrida & 7,47 & 7,40 & 7,37 & 7,33 & 7,27 & 7,37 \\
\hline \multirow{3}{*}{2} & Média do erro lateral & $-0,08$ & 0,03 & 0,06 & 0,07 & 0,10 & 0,04 \\
\hline & Variância do erro lateral & 2,47 & 0,67 & 0,59 & 0,50 & 0,43 & 0,92 \\
\hline & Média da distância percorrida & 14,88 & 14,75 & 14,70 & 14,64 & 14,55 & 14,71 \\
\hline \multirow{3}{*}{3} & Média do erro lateral & $-0,17$ & 0,02 & 0,05 & 0,07 & 0,11 & 0,02 \\
\hline & Variância do erro lateral & 4,71 & 1,09 & 0,87 & 0,68 & 0,56 & 1,56 \\
\hline & Média da distância percorrida & 22,27 & 22,10 & 22,04 & 21,96 & 21,84 & 22,04 \\
\hline \multirow{3}{*}{4} & Média do erro lateral & $-0,20$ & 0,01 & 0,05 & 0,08 & 0,12 & 0,01 \\
\hline & Variância do erro lateral & 6,94 & 1,49 & 1,11 & 0,88 & 0,71 & 2,20 \\
\hline & Média da distância percorrida & 29,70 & 29,46 & 29,37 & 29,27 & 29,13 & 29,39 \\
\hline \multirow{3}{*}{5} & Média do erro lateral & $-0,25$ & 0,01 & 0,05 & 0,09 & 0,13 & 0,01 \\
\hline & Variância do erro lateral & 9,99 & 1,87 & 1,48 & 1,14 & 0,91 & 3,04 \\
\hline & Média da distância percorrida & 40,26 & 39,92 & 39,81 & 39,69 & 39,51 & 39,84 \\
\hline \multirow{3}{*}{6} & Média do erro lateral & $-0,35$ & $-0,04$ & 0,02 & 0,05 & 0,10 & $-0,04$ \\
\hline & Variância do erro lateral & 13,16 & 2,62 & 1,97 & 1,52 & 1,25 & 4,05 \\
\hline & Média da distância percorrida & 47,58 & 47,20 & 47,07 & 46,93 & 46,73 & 47,10 \\
\hline \multirow{3}{*}{7} & Média do erro lateral & $-0,48$ & $-0,13$ & $-0,06$ & $-0,02$ & 0,04 & $-0,13$ \\
\hline & Variância do erro lateral & 18,07 & 3,14 & 2,24 & 1,69 & 1,27 & 5,21 \\
\hline & Média da distância percorrida & 54,91 & 54,47 & 54,31 & 54,16 & 53,93 & 54,36 \\
\hline \multirow{3}{*}{8} & Média do erro lateral & $-0,57$ & $-0,17$ & $-0,10$ & $-0,05$ & 0,01 & $-0,17$ \\
\hline & Variância do erro lateral & 23,49 & 4,20 & 3,07 & 2,24 & 1,70 & 6,85 \\
\hline & Média da distância percorrida & 62,21 & 61,70 & 61,53 & 61,36 & 61,10 & 61,58 \\
\hline \multirow{3}{*}{9} & Média do erro lateral & $-0,67$ & $-0,23$ & $-0,15$ & $-0,09$ & $-0,03$ & $-0,23$ \\
\hline & Variância do erro lateral & 29,34 & 5,22 & 3,70 & 2,73 & 2,17 & 8,52 \\
\hline & Média da distância percorrida & 69,50 & 68,94 & 68,76 & 68,57 & 68,29 & 68,81 \\
\hline \multirow{3}{*}{10} & Média do erro lateral & $-0,79$ & $-0,30$ & $-0,21$ & $-0,15$ & $-0,08$ & $-0,31$ \\
\hline & Variância do erro lateral & 34,23 & 5,89 & 4,31 & 3,37 & 2,69 & 9,97 \\
\hline & Média da distância percorrida & 76,78 & 76,16 & 75,95 & 75,74 & 75,44 & 76,02 \\
\hline \multirow{3}{*}{11} & Média do erro lateral & $-0,93$ & $-0,39$ & $-0,29$ & $-0,23$ & $-0,15$ & $-0,40$ \\
\hline & Variância do erro lateral & 42,19 & 7,22 & 5,46 & 4,16 & 3,30 & 12,30 \\
\hline & Média da distância percorrida & 84,07 & 83,40 & 83,17 & 82,94 & 82,61 & 83,24 \\
\hline & Média do erro lateral & $-1,07$ & $-0,48$ & $-0,38$ & $-0,31$ & $-0,23$ & $-0,49$ \\
\hline 12 & Variância do erro lateral & 48,99 & 8,86 & 6,52 & 4,97 & 3,93 & 14,46 \\
\hline & Média da distância percorrida & 91,37 & 90,63 & 90,39 & 90,14 & 89,78 & 90,46 \\
\hline & Média do erro lateral & $-1,26$ & $-0,61$ & $-0,50$ & $-0,43$ & $-0,34$ & $-0,63$ \\
\hline 13 & Variância do erro lateral & 57,93 & 9,97 & 7,42 & 5,70 & 4,50 & 16,88 \\
\hline & Média da distância percorrida & 98,66 & 97,87 & 97,61 & 97,34 & 96,96 & 97,69 \\
\hline & Média do erro lateral & $-1,44$ & $-0,75$ & $-0,63$ & $-0,55$ & $-0,46$ & $-0,76$ \\
\hline 14 & Variância do erro lateral & 65,71 & 11,62 & 8,69 & 6,71 & 5,27 & 19,35 \\
\hline & Média da distância percorrida & 105,98 & 105,14 & 104,86 & 104,57 & 104,16 & 104,94 \\
\hline & Média do erro lateral & $-1,63$ & $-0,88$ & $-0,75$ & $-0,67$ & $-0,57$ & $-0,90$ \\
\hline 15 & Variância do erro lateral & 77,80 & 13,73 & 10,24 & 7,80 & 6,07 & 22,83 \\
\hline & Média da distância percorrida & 113,31 & 112,41 & 112,11 & 111,80 & 111,36 & 112,20 \\
\hline & Média do erro lateral & $-1,83$ & $-1,04$ & $-0,90$ & $-0,81$ & $-0,71$ & $-1,06$ \\
\hline 16 & Variância do erro lateral & 85,67 & 15,39 & 11,51 & 8,84 & 6,94 & 25,34 \\
\hline & Média da distância percorrida & 120,65 & 119,68 & 119,36 & 119,03 & 118,57 & 119,46 \\
\hline & Média do erro lateral & $-2,09$ & $-1,25$ & $-1,10$ & $-1,01$ & $-0,90$ & $-1,27$ \\
\hline 17 & Variância do erro lateral & 97,11 & 17,79 & 13,44 & 10,61 & 8,58 & 29,12 \\
\hline & Média da distância percorrida & 128,00 & 126,97 & 126,63 & 126,29 & 125,79 & 126,73 \\
\hline & Média do erro lateral & $-2,38$ & $-1,50$ & $-1,34$ & $-1,25$ & $-1,14$ & $-1,52$ \\
\hline 18 & Variância do erro lateral & 109,17 & 21,33 & 16,75 & 13,85 & 11,43 & 34,05 \\
\hline & Média da distância percorrida & 135,34 & 134,26 & 133,90 & 133,54 & 133,02 & 134,01 \\
\hline & Média do erro lateral & $-2,76$ & $-1,83$ & $-1,67$ & $-1,57$ & $-1,45$ & $-1,86$ \\
\hline 19 & Variância do erro lateral & 124,60 & 27,03 & 22,18 & 18,75 & 15,80 & 41,10 \\
\hline & Média da distância percorrida & 142,71 & 141,56 & 141,18 & 140,79 & 140,24 & 141,29 \\
\hline & Média do erro lateral & $-3,20$ & $-2,22$ & $-2,05$ & $-1,95$ & $-1,83$ & $-2,25$ \\
\hline 20 & Variância do erro lateral & 139,74 & 34,33 & 28,61 & 24,54 & 20,81 & 48,90 \\
\hline & Média da distância percorrida & 150,07 & 148,85 & 148,45 & 148,04 & 147,47 & 148,57 \\
\hline Média geral do erro lateral & & $-1,11$ & $-0,58$ & $-0,49$ & $-0,43$ & $-0,36$ & $-0,60$ \\
\hline $\begin{array}{c}\text { Variância geral do erro } \\
\text { lateral }\end{array}$ & & 49,34 & 9,90 & 7,73 & 6,26 & 5,13 & 15,73 \\
\hline $\begin{array}{c}\text { Média da distância } \\
\text { percorrida }\end{array}$ & & 79,79 & 79,15 & 78,93 & 78,71 & 78,39 & 78,99 \\
\hline
\end{tabular}


Após a eliminação dos dados discrepantes, explicado em 6.2.6, são encontrados os novos valores para a variância, cuja distribuição de valores encontra-se na Tabela 10. Esta tabela segue o mesmo formato da tabela anterior, porém considerando apenas as regressões que utilizaram 30 pontos ( 5 minutos), já que essas regressões apresentaram a menor variância das incertezas laterais.

Tabela 10: Média e variância do erro lateral e distância média percorrida, após eliminação dos dados discrepantes, considerando 30 pontos passados (5 minutos).

\begin{tabular}{|c|c|c|c|}
\hline $\begin{array}{c}\text { Instante da } \\
\text { Previsão (min.) }\end{array}$ & $\begin{array}{c}\text { Média do erro } \\
\text { lateral }\end{array}$ & $\begin{array}{c}\text { Variância do erro } \\
\text { lateral }\end{array}$ & $\begin{array}{c}\text { Média da distância } \\
\text { percorrida }\end{array}$ \\
\hline 1 & 0,0432 & 0,2082 & 7,2745 \\
\hline 2 & 0,0127 & 0,2852 & 14,5471 \\
\hline 3 & 0,0621 & 0,4928 & 21,7940 \\
\hline 4 & 0,0320 & 0,5834 & 29,2159 \\
\hline 5 & 0,0128 & 0,4953 & 39,8718 \\
\hline 6 & 0,0057 & 0,8578 & 46,9777 \\
\hline 7 & $-0,0174$ & 0,9233 & 54,2124 \\
\hline 8 & 0,0076 & 1,3903 & 61,4405 \\
\hline 9 & $-0,1037$ & 1,5627 & 68,5614 \\
\hline 10 & $-0,0946$ & 2,1495 & 75,8671 \\
\hline 11 & $-0,0699$ & 2,4389 & 83,0815 \\
\hline 12 & $-0,2464$ & 3,0640 & 90,2820 \\
\hline 13 & $-0,2219$ & 3,0576 & 97,5093 \\
\hline 14 & $-0,2161$ & 4,2540 & 104,0955 \\
\hline 15 & $-0,3026$ & 4,8442 & 111,2950 \\
\hline 16 & $-0,4205$ & 5,4596 & 118,4554 \\
\hline 17 & $-0,5543$ & 6,2492 & 125,6700 \\
\hline 18 & $-0,6866$ & 7,4283 & 132,8715 \\
\hline 19 & $-0,8756$ & 9,0431 & 140,0733 \\
\hline 20 & $-1,1207$ & 10,8760 & 147,2758 \\
\hline Geral & $-0,2380$ & $\mathbf{3 , 3 1 4 8}$ & 78,4288 \\
\hline
\end{tabular}

Nota-se que a variância sofreu uma redução considerável com a eliminação dos dados discrepantes. O valor geral original era de 5,13 NM (Tabela 9) e passou a ser de 3,31 NM (Tabela 10). 


\subsubsection{Eliminação de Dados Discrepantes nos Erros Longitudinais}

O mesmo método descrito para os erros laterais foi realizado para os erros longitudinais.

A Tabela 11 traz as informações sobre o comportamento dos erros longitudinais, de acordo com a quantidade de pontos considerados na regressão e de acordo com o instante futuro da previsão. Pela análise das variâncias, é detectado que a melhor situação para diminuir a incerteza do erro longitudinal ocorreu quando 18 pontos são considerados na extrapolação. Provavelmente esta aeronave sofreu alterações de velocidade ao longo do tempo, de forma que em um período maior de tempo estas alterações causam maior variância no erro longitudinal.

Tabela 11: Média e variância do erro longitudinal.

\begin{tabular}{|c|c|c|c|c|c|c|c|}
\hline \multirow[b]{2}{*}{ Instante da Previsão (min.) } & \multirow[b]{2}{*}{ Dados (NM) } & \multicolumn{5}{|c|}{ Pontos Passados Considerados } & \multirow[b]{2}{*}{ Média geral } \\
\hline & & 6 & 12 & 18 & 24 & 30 & \\
\hline \multirow{2}{*}{1} & Média do erro longitudinal & $\begin{array}{l}-0,09 \\
\end{array}$ & 0,03 & 0,04 & 0,08 & 0,14 & 0,04 \\
\hline & Variância do erro longitudinal & 1,21 & 0,63 & 0,46 & 0,46 & 0,50 & 0,64 \\
\hline \multirow{2}{*}{2} & Média do erro longitudinal & $-0,10$ & 0,08 & 0,12 & 0,22 & 0,29 & 0,12 \\
\hline & Variância do erro longitudinal & 2,62 & 0,82 & 0,64 & 0,67 & 0,85 & 1,12 \\
\hline \multirow{2}{*}{3} & Média do erro longitudinal & $-0,09$ & 0,19 & 0,26 & 0,29 & 0,43 & 0,22 \\
\hline & Variância do erro longitudinal & 5,29 & 1,64 & 1,17 & 1,27 & 1,65 & 2,19 \\
\hline \multirow{2}{*}{4} & Média do erro longitudinal & $-0,02$ & 0,25 & 0,31 & 0,39 & 0,62 & 0,31 \\
\hline & Variância do erro longitudinal & 7,96 & 2,32 & 1,80 & 2,16 & 2,74 & 3,37 \\
\hline \multirow{2}{*}{5} & Média do erro longitudinal & $-0,08$ & 0,34 & 0,42 & 0,55 & 0,74 & 0,40 \\
\hline & Variância do erro longitudinal & 11,75 & 3,52 & 3,06 & 3,59 & 4,73 & 5,30 \\
\hline \multirow{2}{*}{6} & Média do erro longitudinal & $-0,08$ & 0,40 & 0,50 & 0,64 & 0,83 & 0,46 \\
\hline & Variância do erro longitudinal & 17,32 & 5,43 & 4,66 & 5,36 & 6,68 & 7,83 \\
\hline \multirow{2}{*}{7} & Média do erro longitudinal & $-0,13$ & 0,42 & 0,55 & 0,73 & 0,94 & 0,51 \\
\hline & Variância do erro longitudinal & 23,94 & 8,28 & 7,39 & 8,22 & 10,23 & 11,52 \\
\hline \multirow{2}{*}{8} & Média do erro longitudinal & $-0,22$ & 0,38 & 0,60 & 0,79 & 1,03 & 0,52 \\
\hline & Variância do erro longitudinal & 31,37 & 10,71 & 9,41 & 10,40 & 12,78 & 14,83 \\
\hline \multirow{2}{*}{9} & Média do erro longitudinal & $-0,26$ & 0,39 & 0,58 & 0,73 & 1,03 & 0,50 \\
\hline & Variância do erro longitudinal & 38,09 & 13,52 & 11,97 & 13,24 & 16,14 & 18,42 \\
\hline \multirow{2}{*}{10} & Média do erro longitudinal & $\begin{array}{c}-0,38 \\
\end{array}$ & 0,27 & 0,49 & 0,67 & 1,03 & 0,42 \\
\hline & Variância do erro longitudinal & 48,78 & 17,24 & 15,13 & 16,64 & 19,72 & 23,28 \\
\hline \multirow{2}{*}{11} & Média do erro longitudinal & $-0,49$ & 0,16 & 0,46 & 0,55 & 0,88 & 0,31 \\
\hline & Variância do erro longitudinal & 60,44 & 21,89 & 19,48 & 21,12 & 25,02 & 29,24 \\
\hline \multirow{2}{*}{12} & Média do erro longitudinal & $-0,68$ & $-0,02$ & 0,20 & 0,50 & 0,83 & 0,17 \\
\hline & Variância do erro longitudinal & 74,57 & 27,94 & 24,50 & 26,36 & 31,17 & 36,46 \\
\hline \multirow{2}{*}{13} & Média do erro longitudinal & $-1,17$ & $-0,24$ & 0,03 & 0,29 & 0,72 & $-0,08$ \\
\hline & Variância do erro longitudinal & 90,70 & 34,32 & 30,94 & 33,65 & 38,98 & 45,25 \\
\hline \multirow{2}{*}{14} & Média do erro longitudinal & $-1,55$ & $-0,58$ & $-0,22$ & 0,05 & 0,50 & $-0,36$ \\
\hline & Variância do erro longitudinal & 106,76 & 44,18 & 40,83 & 43,78 & 50,00 & 56,50 \\
\hline \multirow{2}{*}{15} & Média do erro longitudinal & $-2,02$ & $-0,82$ & $-0,59$ & $-0,35$ & 0,30 & $-0,70$ \\
\hline & Variância do erro longitudinal & 132,47 & 58,54 & 53,61 & 57,12 & 64,34 & 72,39 \\
\hline \multirow{2}{*}{16} & Média do erro longitudinal & $-2,52$ & $-1,28$ & $-0,98$ & $-0,71$ & $-0,07$ & $-1,11$ \\
\hline & Variância do erro longitudinal & 160,68 & 74,48 & 69,61 & 73,74 & 82,33 & 91,06 \\
\hline \multirow{2}{*}{17} & Média do erro longitudinal & $-3,13$ & $-1,80$ & $-1,49$ & $-1,18$ & $-0,60$ & $-1,64$ \\
\hline & Variância do erro longitudinal & 193,86 & 95,20 & 89,60 & 94,62 & 104,40 & 114,04 \\
\hline \multirow{2}{*}{18} & Média do erro longitudinal & $-3,84$ & $-2,43$ & $-2,12$ & $-1,82$ & $-1,21$ & $-2,29$ \\
\hline & Variância do erro longitudinal & 228,71 & 121,71 & 116,11 & 122,07 & 133,61 & 142,45 \\
\hline \multirow{2}{*}{19} & Média do erro longitudinal & $-4,77$ & $-3,37$ & $-2,95$ & $-2,58$ & $-1,87$ & $-3,11$ \\
\hline & Variância do erro longitudinal & 282,47 & 160,51 & 155,19 & 163,13 & 176,15 & 184,84 \\
\hline 2 & Média do erro longitudinal & $-5,86$ & $-4,30$ & $-3,95$ & $-3,54$ & $-2,79$ & $-4,09$ \\
\hline 20 & Variância do erro longitudinal & 347,43 & 214,00 & 209,16 & 218,05 & 232,63 & 240,62 \\
\hline Média geral do erro longitudinal & & $-1,37$ & $-0,60$ & $-0,39$ & $-0,18$ & 0,19 & $-0,47$ \\
\hline Var. geral do erro longitudinal & & 94,16 & 46,59 & 43,83 & 46,13 & 50,62 & 56,48 \\
\hline
\end{tabular}


Após a eliminação dos dados discrepantes, são encontrados os novos valores para a variância. A distribuição desses valores encontra-se na Tabela 12. Esta tabela segue o mesmo formato da tabela anterior, sendo que apenas foram consideradas regressões que utilizaram 18 pontos, já que essas regressões apresentaram a menor variância das incertezas longitudinais.

Tabela 12: Média e variância do erro longitudinal, após eliminação dos dados discrepantes, considerando 18 posições passadas ( 3 minutos).

\begin{tabular}{|c|c|c|}
\hline $\begin{array}{c}\text { Instante da } \\
\text { Previsão (min.) }\end{array}$ & $\begin{array}{c}\text { Média do erro } \\
\text { longitudinal }\end{array}$ & $\begin{array}{c}\text { Variância do erro } \\
\text { longitudinal }\end{array}$ \\
\hline 1 & 0,0458 & 0,2356 \\
\hline 2 & $-0,0193$ & 0,4152 \\
\hline 3 & $-0,0096$ & 0,4457 \\
\hline 4 & $-0,0270$ & 0,6109 \\
\hline 5 & 0,0384 & 1,1338 \\
\hline 6 & 0,0345 & 1,6997 \\
\hline 7 & $-0,0733$ & 2,2600 \\
\hline 8 & $-0,0981$ & 3,0891 \\
\hline 9 & $-0,2000$ & 4,0298 \\
\hline 10 & $-0,3833$ & 5,3600 \\
\hline 11 & $-0,2623$ & 5,5377 \\
\hline 12 & $-0,3177$ & 5,5092 \\
\hline 13 & $-0,4547$ & 7,0475 \\
\hline 14 & $-0,6956$ & 9,8082 \\
\hline 15 & $-1,0642$ & 13,9213 \\
\hline 16 & $-0,9640$ & 26,4711 \\
\hline 17 & $-0,9113$ & 27,6886 \\
\hline 18 & $-1,3472$ & 37,0171 \\
\hline 19 & $-1,2136$ & 66,8410 \\
\hline 20 & $-1,0836$ & 104,2722 \\
\hline Geral & $-0,4445$ & $\mathbf{1 5 , 9 4 9 0}$ \\
\hline
\end{tabular}

Nota-se que a variância sofreu uma redução significativa com a eliminação dos dados discrepantes. O valor geral original era de 43,83 NM (Tabela 11) e passou a ser de 15,95 NM (Tabela 12).

\subsubsection{Previsão Ótima Lateral}

As informações sobre o comportamento da variância lateral são inseridas no modelo de previsão, de forma a se obter não apenas a previsão de posição, mas também a previsão do seu erro lateral. Conforme foi destacado na expressão (40) no capítulo 5, o erro lateral segue uma distribuição normal, com variância crescendo de forma quadrática com a distância percorrida, estabilizando em um determinado valor $\sigma_{c}^{2}$. Segue a expressão novamente: 


$$
\sigma^{2}(\mathrm{t}) \sim r^{2} s^{2}(t), \operatorname{sat}\left\{\sigma^{2}(t)\right\}=\sigma_{c}^{2}
$$

Desta forma, resta obter os valores dos parâmetros $r^{2}$ e $\sigma_{c}^{2}$. No entanto, a distribuição da variância lateral não apresentou uma estabilização no exemplo do vôo BRB9983, mantendose apenas crescente. De acordo com (PRANDINI, LYGEROS, SASTRY, 2000), é possível que a estabilidade realmente ocorra, mas com um valor de distância acima das consideradas neste trabalho. Para a investigação dos erros laterais dentro do contexto desta pesquisa, não é relevante determinar o ponto de saturação, já que é possível modelar o crescimento do erro lateral sem considerar que existe um ponto de saturação.

Os dados da Tabela 10 podem ser utilizados para se verificar o crescimento da variância do erro lateral ao longo da distância percorrida $d$. Anteriormente foi destacado que a variância do erro cresce de forma quadrática; assim, essa variância é determinada pela função:

VarLat: $\mathfrak{R} \rightarrow \mathfrak{R}$, tal que

$\operatorname{VarLat}(d)=a \cdot d^{2}+b \cdot d+c$

As previsões utilizadas para determinar o erro lateral consideram 30 pontos passados para a regressão (melhor situação), no caso do vôo BRB9983. Para cada previsão realizada, por meio de regressão linear, utiliza-se a função VarLat para se determinar a incerteza lateral da previsão. Como a função VarLat foi obtida considerando-se a variância do erro lateral, é necessário extrair a raiz quadrada do resultado para se chegar ao valor do desvio padrão da incerteza. No entanto, há um fato importante a ser considerado. A média do erro lateral é próxima a zero, mas tem um valor significativo que pode influir na incerteza lateral, o que leva a se considerar o valor da média no cálculo da incerteza lateral. Além disso, foi observado que a média do erro lateral também cresce de forma quadrática com a distância percorrida $d$ e, por essa razão, a média do erro lateral é obtida com o uso de uma função quadrática da forma:

MediaErroLateral: $\mathfrak{R} \rightarrow \mathfrak{R}$, tal que

MediaErroLateral $(d)=a \cdot d^{2}+b \cdot d+c$

Assim, o desvio padrão não pode ser a única medida utilizada para estimar o erro lateral, e por esta razão, o módulo da média do erro lateral foi acrescentado no cálculo, resultando em uma expressão da forma:

$$
\operatorname{IncertezaLat}(d)=\sqrt{\operatorname{VarLat}(d)}+|\operatorname{MediaErroLat}(d)|
$$




\subsubsection{Previsão Ótima Longitudinal}

As informações sobre o comportamento da variância longitudinal são inseridas no algoritmo de previsão, de forma que o mesmo possa fornecer não apenas a previsão de posição, mas também o erro longitudinal. Conforme foi destacado no capítulo 5 , na expressão (49), o erro longitudinal segue uma distribuição normal, com variância crescendo de forma quadrática com o tempo transcorrido $t$. Segue a expressão novamente:

$$
\sigma^{2}(t) \sim r_{a}^{2} t^{2}
$$

Resta obter o valor do parâmetro $r_{a}^{2}$. Os dados da Tabela 12, referentes ao crescimento da variância do erro longitudinal ao longo do tempo, podem ser utilizados para determinar uma função quadrática da forma:

VarLon: $\mathfrak{R} \rightarrow \mathfrak{R}$, tal que

$$
\operatorname{VarLon}(t)=a \cdot t^{2}+b \cdot t+c
$$

As previsões que servem para determinar o erro longitudinal mínimo consideram 18 pontos passados para a regressão (melhor situação), no caso do vôo BRB9983. Então, a cada previsão realizada, utiliza-se a função VarLon para se determinar a incerteza longitudinal da previsão. Como a função VarLon foi obtida considerando-se a variância do erro longitudinal, é necessário extrair a raiz quadrada do resultado para se chegar ao valor do desvio padrão da incerteza. No entanto, há um fato importante a ser considerado. A média do erro longitudinal é próxima a zero, mas tem um valor significativo que pode influir na incerteza longitudinal e, por isso, o valor da média foi levado em conta no cálculo da incerteza longitudinal. Foi observado que a média do erro longitudinal também cresce de forma quadrática com o tempo transcorrido $t$ e, portanto, a média do erro longitudinal é obtida com uso de uma função quadrática da forma:

MediaErroLongitudinal: $\mathfrak{R} \rightarrow \mathfrak{R}$, tal que

MediaErroLongitudinal $(t)=a \cdot t^{2}+b \cdot t+c$

Assim, a incerteza longitudinal é calculada da seguinte forma:

$$
\operatorname{IncertezaLon}(t)=\sqrt{\operatorname{VarLon}(t)}+|\operatorname{MediaErroLon}(t)|
$$

\subsubsection{Composição das Incertezas}

As duas previsões efetuadas em um certo instante do tempo, considerando o menor erro lateral e longitudinal, são compostas para se obter uma única previsão, que minimize tanto o erro lateral quanto o longitudinal. 
Primeiramente é encontrada a previsão que minimiza o erro lateral, ilustrado na Figura 40 pelo ponto $P_{L a}$. Como esta previsão considera a situação que minimiza o erro lateral, este ponto está sobre a reta $r$, a qual indica a direção mais provável da trajetória da aeronave. Em seguida, é encontrada a posição prevista que minimiza o erro longitudinal, ilustrado pelo ponto $P_{L o}$. Como a reta $r$, encontrada na previsão lateral, corresponde à trajetória mais provável da aeronave, e minimiza o erro lateral, o ponto $P_{L o}$, obtido na última previsão, é projetado na reta $r$. Com isso, o ponto obtido $P_{P r e}$ corresponde à previsão que minimiza tanto o erro lateral quanto o longitudinal. A situação descrita tem o ponto $P_{\text {Real }}$ como a posição real da aeronave.

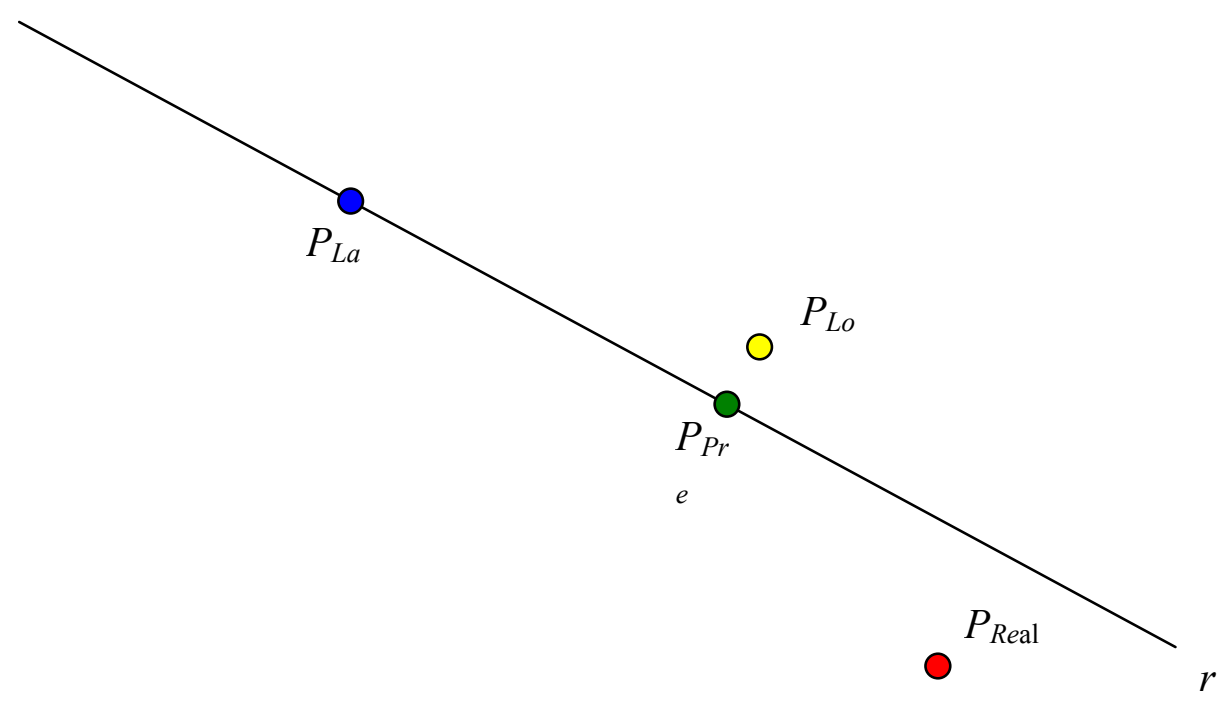

Figura 40: Ilustração da composição das incertezas para a determinação da posição futura de uma aeronave.

\subsection{Resultados Obtidos}

O processo de simulação descrito foi aplicado em 2 estudos de caso, para os vôos BRB9983 e TAM8096, e os respectivos resultados são apresentados na seqüência.

\subsubsection{Estudo de Caso 1: BRB9983}

Conforme explicado anteriormente e ilustrado no capítulo 4, a variância das incertezas lateral e longitudinal cresce com a distância viajada ou ao longo do tempo. Para mostrar como isso se reflete ao se prever a posição de uma aeronave, inicialmente será apresentado o resultado da taxa de acerto das previsões considerando a variância e média constantes. Logo depois, os mesmos resultados são mostrados, porém considerando a variância crescente. 
Para o vôo BRB9983, foi aplicado todo o processo descrito anteriormente e, então, o algoritmo de previsão foi executado para diversos instantes do vôo. Considerando as incertezas constantes, foram contabilizadas as taxas de acerto da posição prevista, separando as componentes lateral e longitudinal. As taxas de acerto para a previsão lateral (considera-se um acerto quando o erro da posição prevista em relação à posição real é menor ou igual à incerteza), assim como as incertezas, podem ser visualizadas na Tabela 13 e na Figura 41. A incerteza lateral foi calculada utilizando-se a Equação (55), considerando VarLat e MediaErroLateral como a variância e média gerais, obtidas da Tabela 10, ou seja:

$$
\text { IncertezaLat }=\sqrt{\text { VarLat }}+\mid \text { MediaErroLat }|=\sqrt{3,3148}+|-0,2380 \mid=2,0586
$$

Como era esperado e ilustrado anteriormente, pelo fato de a incerteza ser considerada constante, a taxa de acerto cai quanto mais no futuro é a previsão.

Tabela 13: Taxa de acerto para as previsões laterais, considerando incertezas constantes.

\begin{tabular}{|c|c|c|}
\hline $\begin{array}{c}\text { Instante de } \\
\text { Previsão(min) }\end{array}$ & $\begin{array}{c}\text { Taxa de } \\
\text { Acerto }\end{array}$ & $\begin{array}{c}\text { Incerteza } \\
\text { Lateral (NM) }\end{array}$ \\
\hline 1 & $100,00 \%$ & 2,0586 \\
2 & $99,58 \%$ & 2,0586 \\
3 & $100,00 \%$ & 2,0586 \\
4 & $99,58 \%$ & 2,0586 \\
5 & $98,73 \%$ & 2,0586 \\
6 & $97,05 \%$ & 2,0586 \\
7 & $92,41 \%$ & 2,0586 \\
8 & $89,03 \%$ & 2,0586 \\
9 & $86,92 \%$ & 2,0586 \\
10 & $83,54 \%$ & 2,0586 \\
11 & $79,32 \%$ & 2,0586 \\
12 & $75,53 \%$ & 2,0586 \\
13 & $70,04 \%$ & 2,0586 \\
14 & $65,40 \%$ & 2,0586 \\
15 & $61,60 \%$ & 2,0586 \\
16 & $58,23 \%$ & 2,0586 \\
17 & $55,70 \%$ & 2,0586 \\
18 & $51,48 \%$ & 2,0586 \\
19 & $44,30 \%$ & 2,0586 \\
20 & $42,19 \%$ & 2,0586 \\
\hline Total geral & $77,53 \%$ & 2,0586 \\
\hline
\end{tabular}




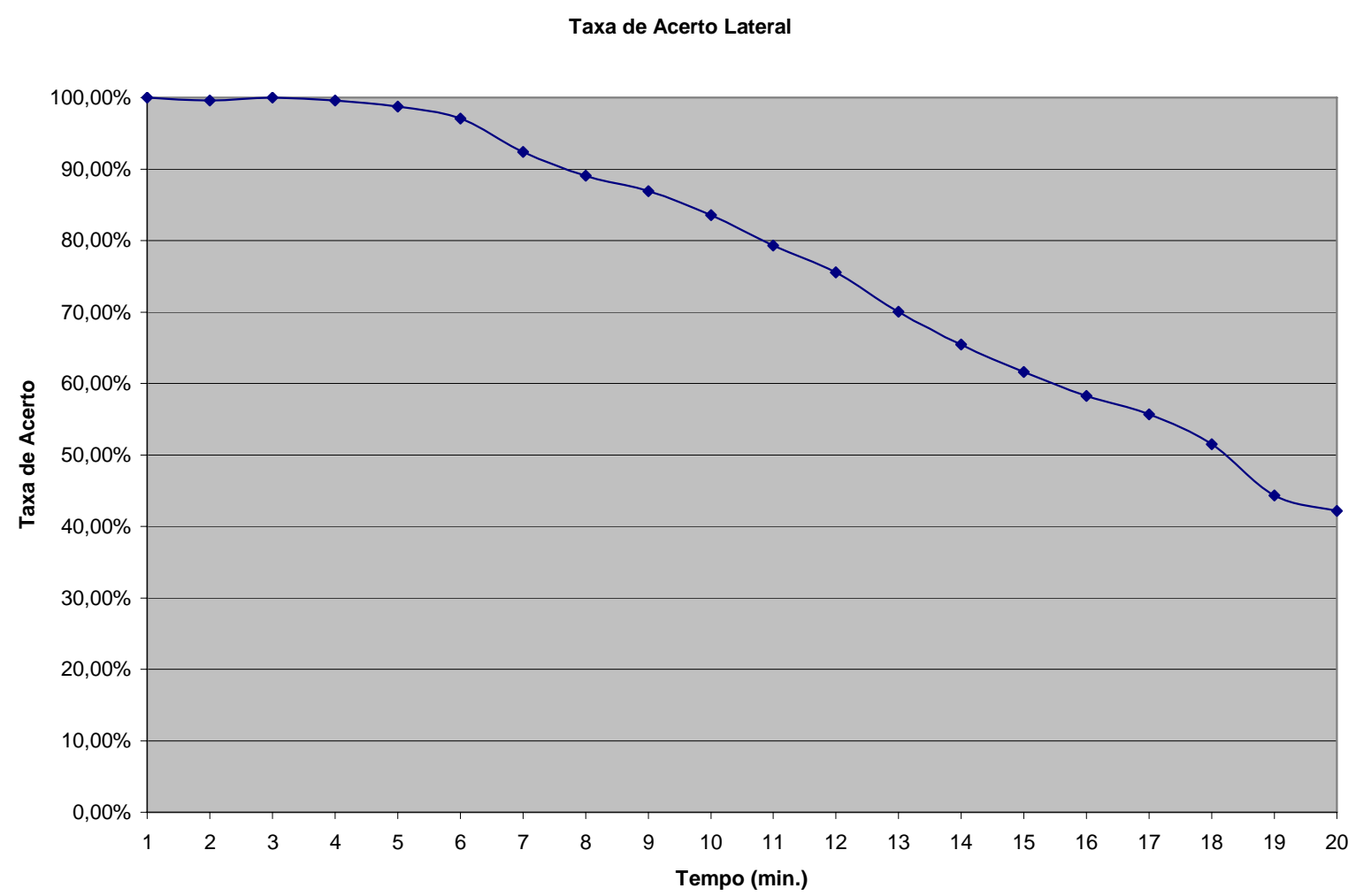

Figura 41: Taxa de acerto para as previsões laterais, considerando incertezas constantes.

Agora, são exibidas as informações referentes às taxas de acerto para a previsão longitudinal, assim como as suas respectivas incertezas. $\mathrm{O}$ valor da incerteza foi calculado pela Expressão (59), considerando a variância e média gerais, obtidas da Tabela 12, ou seja:

$$
\text { IncertezaLon }=\sqrt{\text { VarLon }}+\mid \text { MediaErroLon }|=\sqrt{15,9490}+| 0,4445 \mid=4,4382
$$

Os dados sobre os acertos das previsões podem ser visualizadas na Tabela 14 e na Figura 42. Assim como na análise lateral, as taxas de acerto para as previsões longitudinais também caem ao longo do tempo, já que foi considerada a incerteza constante, o que não está de acordo com a realidade, conforme já descrito anteriormente. 
Tabela 14: Taxa de acerto para as previsões longitudinais, considerando incertezas constantes.

\begin{tabular}{|c|c|c|}
\hline $\begin{array}{c}\text { Instante da previsão } \\
\text { (min) }\end{array}$ & $\begin{array}{c}\text { Taxa de } \\
\text { acerto }\end{array}$ & $\begin{array}{c}\text { Incerteza } \\
\text { longitudinal (NM) }\end{array}$ \\
\hline 1 & $100,00 \%$ & 4,4382 \\
2 & $100,00 \%$ & 4,4382 \\
3 & $100,00 \%$ & 4,4382 \\
4 & $97,47 \%$ & 4,4382 \\
5 & $95,78 \%$ & 4,4382 \\
6 & $95,36 \%$ & 4,4382 \\
7 & $94,94 \%$ & 4,4382 \\
8 & $93,25 \%$ & 4,4382 \\
9 & $91,98 \%$ & 4,4382 \\
10 & $91,98 \%$ & 4,4382 \\
11 & $90,72 \%$ & 4,4382 \\
12 & $89,03 \%$ & 4,4382 \\
13 & $84,81 \%$ & 4,4382 \\
14 & $79,75 \%$ & 4,4382 \\
15 & $74,26 \%$ & 4,4382 \\
16 & $69,62 \%$ & 4,4382 \\
17 & $60,76 \%$ & 4,4382 \\
18 & $58,23 \%$ & 4,4382 \\
19 & $55,70 \%$ & 4,4382 \\
20 & $47,68 \%$ & 4,4382 \\
\hline Total geral & $83,57 \%$ & 4,4382 \\
\hline
\end{tabular}

Taxa de Acerto Longitudinal

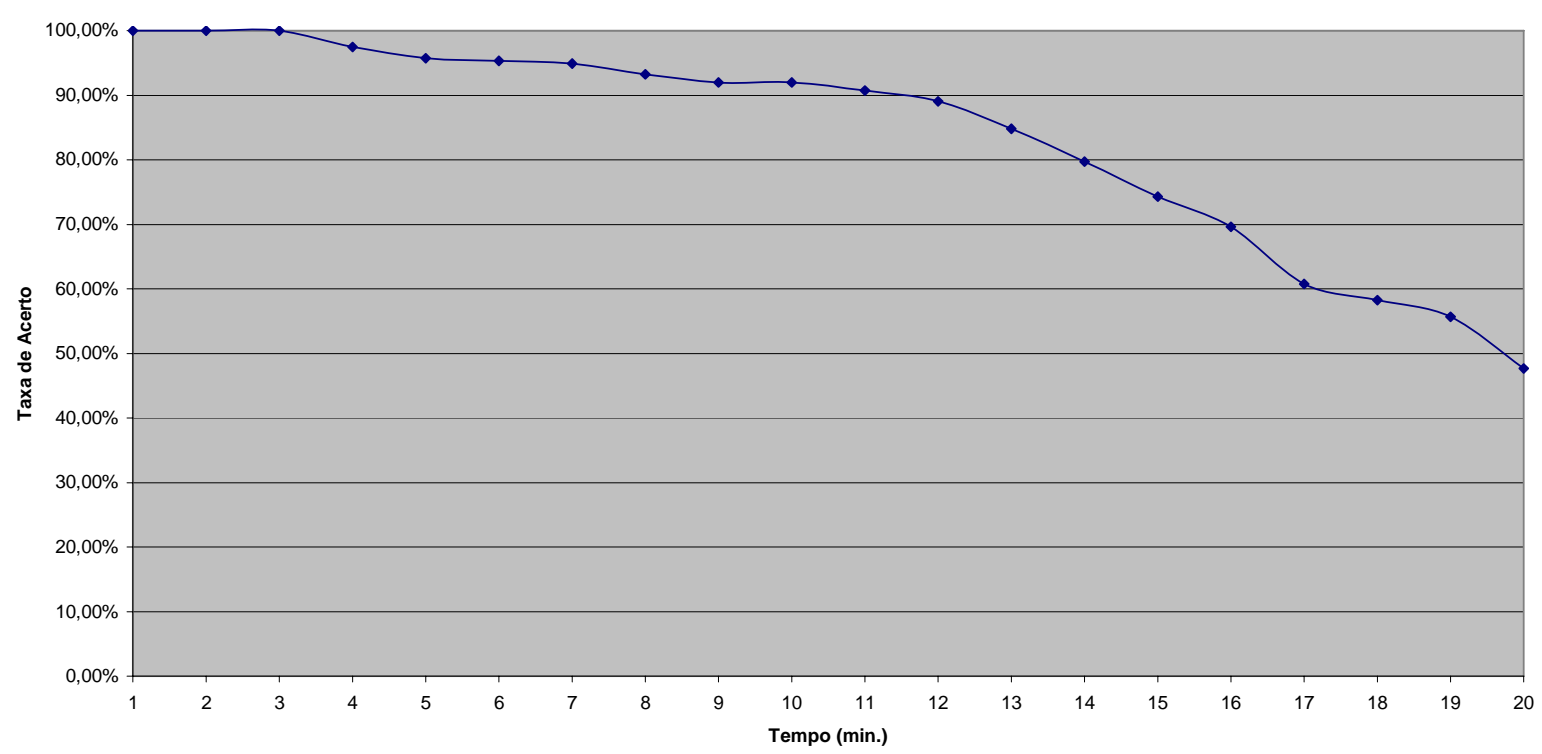

Figura 42: Taxa de acerto para as previsões longitudinais, considerando incertezas constantes.

A composição das taxas de acerto das previsões lateral e longitudinal gera a taxa de acerto geral da previsão, que podem ser observadas na Tabela 15 e Figura 43. A mesma tendência, de queda na taxa de acerto ao longo do tempo, também é notada neste caso. 
Tabela 15: Taxa de acerto geral para as previsões, considerando incertezas constantes.

\begin{tabular}{|c|c|}
\hline $\begin{array}{c}\text { Instante da previsão } \\
\text { (min) }\end{array}$ & $\begin{array}{c}\text { Taxa de } \\
\text { Acerto }\end{array}$ \\
\hline 1 & $100,00 \%$ \\
2 & $99,58 \%$ \\
3 & $100,00 \%$ \\
4 & $97,05 \%$ \\
5 & $94,94 \%$ \\
6 & $92,41 \%$ \\
7 & $87,34 \%$ \\
8 & $82,28 \%$ \\
9 & $78,90 \%$ \\
10 & $75,53 \%$ \\
11 & $71,31 \%$ \\
12 & $66,24 \%$ \\
13 & $58,23 \%$ \\
14 & $50,63 \%$ \\
15 & $44,30 \%$ \\
16 & $40,08 \%$ \\
17 & $35,02 \%$ \\
18 & $32,07 \%$ \\
19 & $29,54 \%$ \\
20 & $24,05 \%$ \\
\hline Total geral & $67,97 \%$ \\
\hline
\end{tabular}

Taxa de Acerto

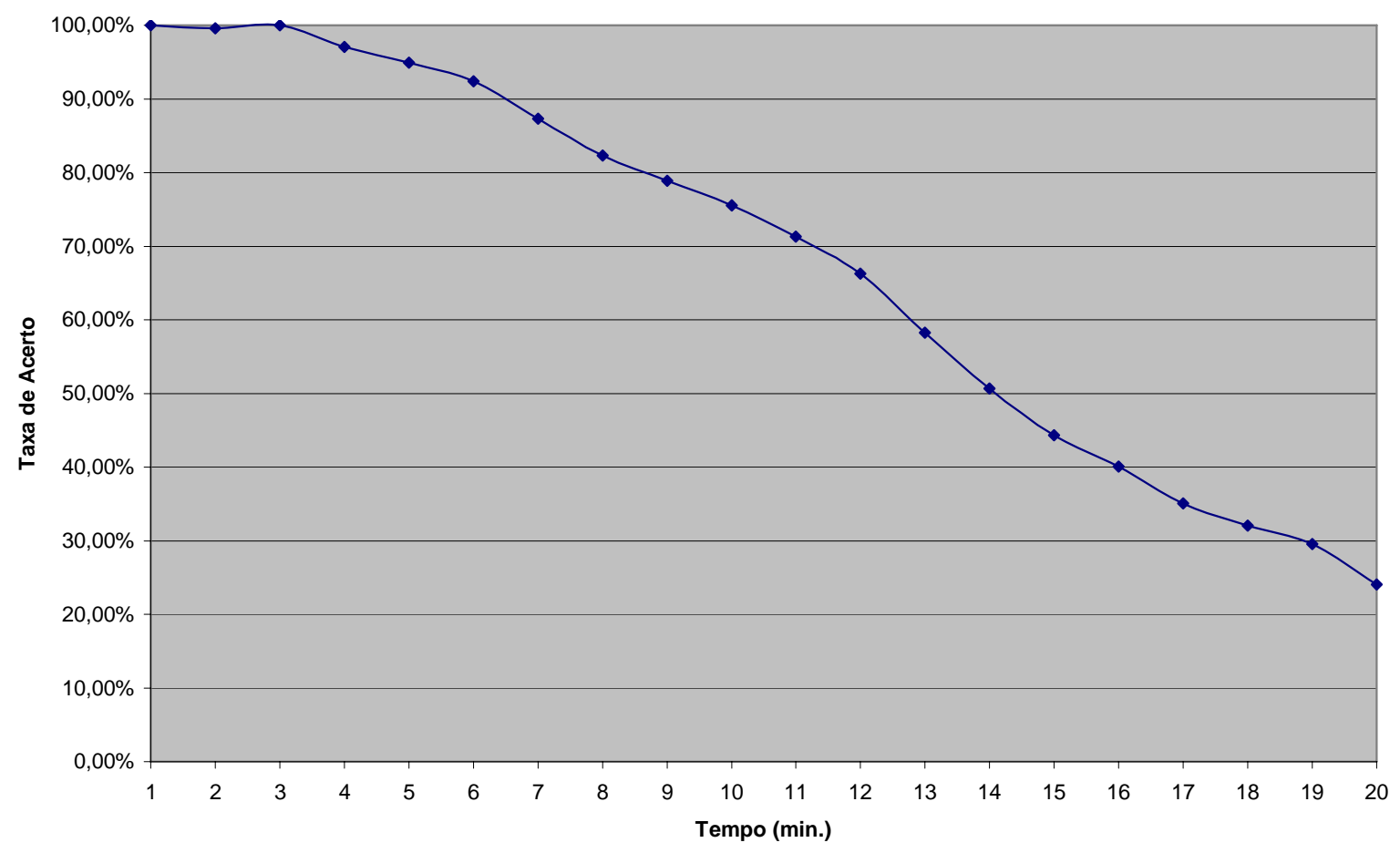

Figura 43: Taxa de acerto geral para as previsões, considerando incertezas constantes.

A tendência de queda na taxa de acerto quando as incertezas são constantes justifica a utilização de incertezas crescentes, conforme sugere a literatura (WARREN, 2000; 
PRANDINI; LYGEROS; SASTRY, 2000). Para as incertezas laterais, os dados de variância e distância, da Tabela 10, são utilizados para se modelar a função VarLat, expressa em (53). Os dados de média e distância, da mesma tabela, são utilizados para se modelar a função MediaLateral, expressa em (54). Com isso, a cada previsão, a incerteza é obtida na expressão (55). Utilizando este enfoque, tem-se as taxas de acerto visualizadas na Tabela 16 e Figura 44.

Tabela 16: Taxa de acerto para as previsões laterais, considerando as incertezas crescentes.

\begin{tabular}{|c|c|c|}
\hline $\begin{array}{c}\text { Instante de previsão } \\
\text { (min) }\end{array}$ & Taxa de Acerto & $\begin{array}{c}\text { Incerteza } \\
\text { Lateral (NM) }\end{array}$ \\
\hline 1 & $95,78 \%$ & 0,9305 \\
2 & $78,90 \%$ & 0,7636 \\
3 & $67,51 \%$ & 0,6458 \\
4 & $63,29 \%$ & 0,5972 \\
5 & $67,51 \%$ & 0,6473 \\
6 & $70,46 \%$ & 0,7412 \\
7 & $66,67 \%$ & 0,8598 \\
8 & $64,14 \%$ & 0,9902 \\
9 & $64,98 \%$ & 1,1588 \\
10 & $65,82 \%$ & 1,3602 \\
11 & $64,98 \%$ & 1,5787 \\
12 & $71,73 \%$ & 1,8110 \\
13 & $70,89 \%$ & 2,0574 \\
14 & $71,31 \%$ & 2,3166 \\
15 & $71,73 \%$ & 2,5881 \\
16 & $75,95 \%$ & 2,8717 \\
17 & $76,37 \%$ & 3,1668 \\
18 & $76,37 \%$ & 3,4734 \\
19 & $77,22 \%$ & 3,7910 \\
20 & $75,95 \%$ & 4,1195 \\
\hline Total geral & $71,88 \%$ & 1,8234 \\
\hline
\end{tabular}

Taxa de Acerto Lateral

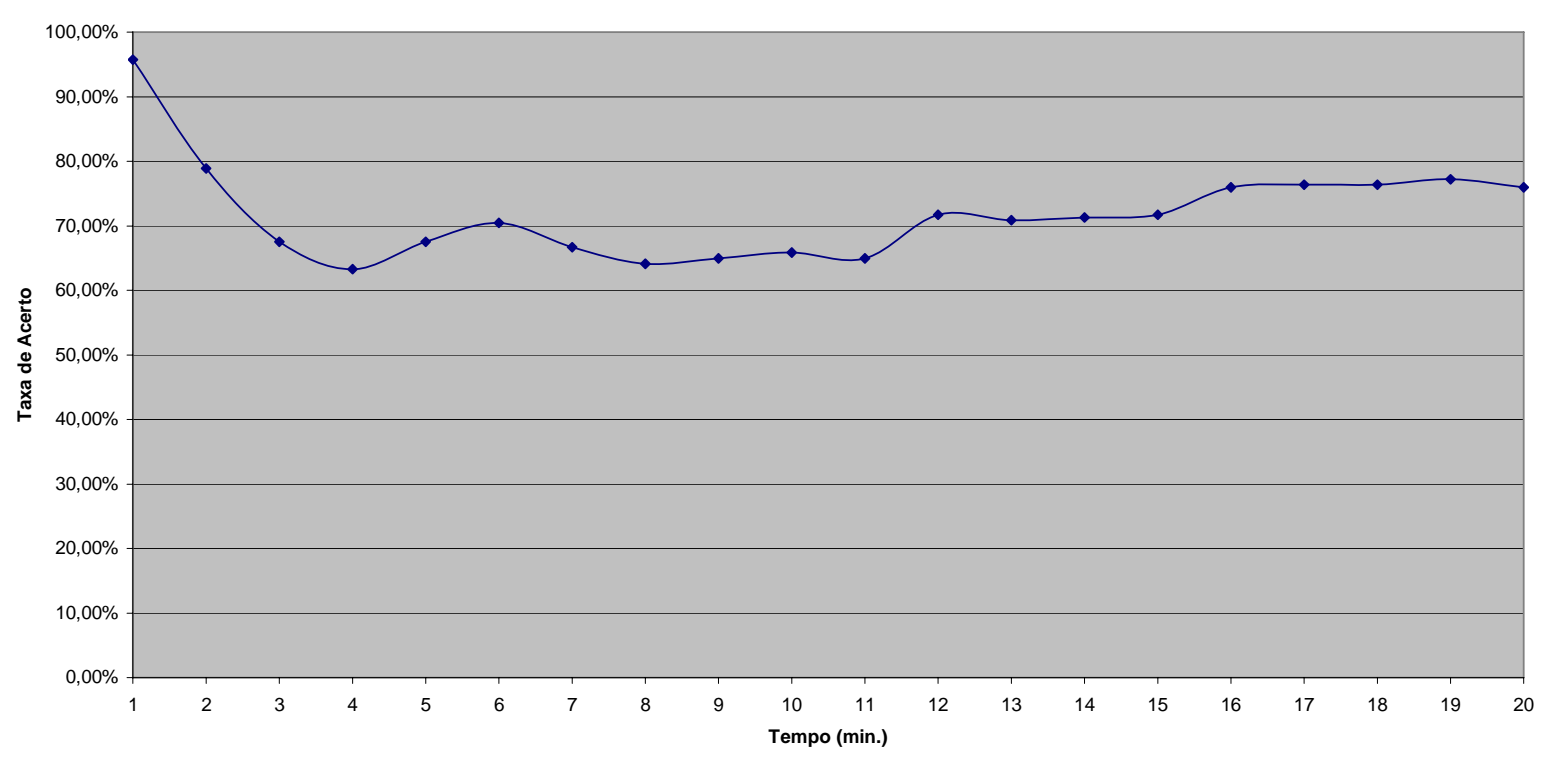

Figura 44: Taxa de acerto para as previsões laterais, considerando as incertezas crescentes. 
Nota-se que a taxa de acertos na previsão está abaixo dos valores desejados, que era de 95 \% de acerto. Em geral, o valor oscilou entre 60 e 80 \%. É importante notar que o algoritmo de previsão não considerou variações laterais (mudanças de direção) conhecidas da aeronave dentre os pontos utilizados na regressão. Essas variações podem impactar a qualidade das posições previstas.

De qualquer forma, é interessante notar que a utilização de incerteza crescente levou a uma taxa de acerto quase constante. Essa taxa foi bastante alta para previsões de 1 e 2 minutos, e depois teve valores relativamente estáveis.

O mesmo tipo de análise realizada para as incertezas laterais é utilizado para se compor incertezas longitudinais crescentes. São considerados os dados de variância e média da Tabela 12, utilizando-se as expressão (57) e (58), para se obter a incerteza longitudinal, que é calculada utilizando-se a Equação (59). O resultado das taxas de acerto são exibidos na Tabela 17 e na Figura 45.

Tabela 17: Taxa de acerto para as previsões longitudinais, considerando as incertezas crescentes.

\begin{tabular}{|c|c|c|}
\hline Instante de previsão (min) & $\begin{array}{c}\text { Taxa de } \\
\text { acerto }\end{array}$ & $\begin{array}{c}\text { Incerteza } \\
\text { Longitudinal } \\
\text { (NM) }\end{array}$ \\
\hline 1 & $100,00 \%$ & 3,3810 \\
2 & $98,31 \%$ & 2,4712 \\
3 & $92,41 \%$ & 1,4436 \\
4 & $62,03 \%$ & 0,7987 \\
5 & $69,20 \%$ & 1,1081 \\
6 & $70,04 \%$ & 1,3795 \\
7 & $69,62 \%$ & 1,6189 \\
8 & $73,84 \%$ & 1,9199 \\
9 & $76,79 \%$ & 2,2233 \\
10 & $79,75 \%$ & 2,5919 \\
11 & $76,37 \%$ & 2,6977 \\
12 & $73,84 \%$ & 2,7789 \\
13 & $77,64 \%$ & 3,5554 \\
14 & $78,90 \%$ & 4,4406 \\
15 & $80,17 \%$ & 5,2905 \\
16 & $77,64 \%$ & 6,1248 \\
17 & $77,22 \%$ & 6,9502 \\
18 & $74,68 \%$ & 7,7718 \\
19 & $73,84 \%$ & 9,3160 \\
20 & $72,57 \%$ & 11,4833 \\
\hline Total geral & $77,74 \%$ & 3,9673 \\
\hline
\end{tabular}

Nota-se que a taxa de acertos na previsão está abaixo dos valores desejados, que era de 95 $\%$ de acerto. Em geral, o valor oscilou entre 70 e $80 \%$, com média próxima de $77 \%$. Um ponto a destacar é a taxa de acertos para previsões de curto prazo; para previsões de 1 a 3 
minutos, a taxa de acerto foi mais alta (acima de $90 \%$ ). É importante notar que o algoritmo de previsão não considerou variações de velocidade que podem ter ocorrido ao longo do tempo. Essas variações podem impactar a qualidade das posições previstas.

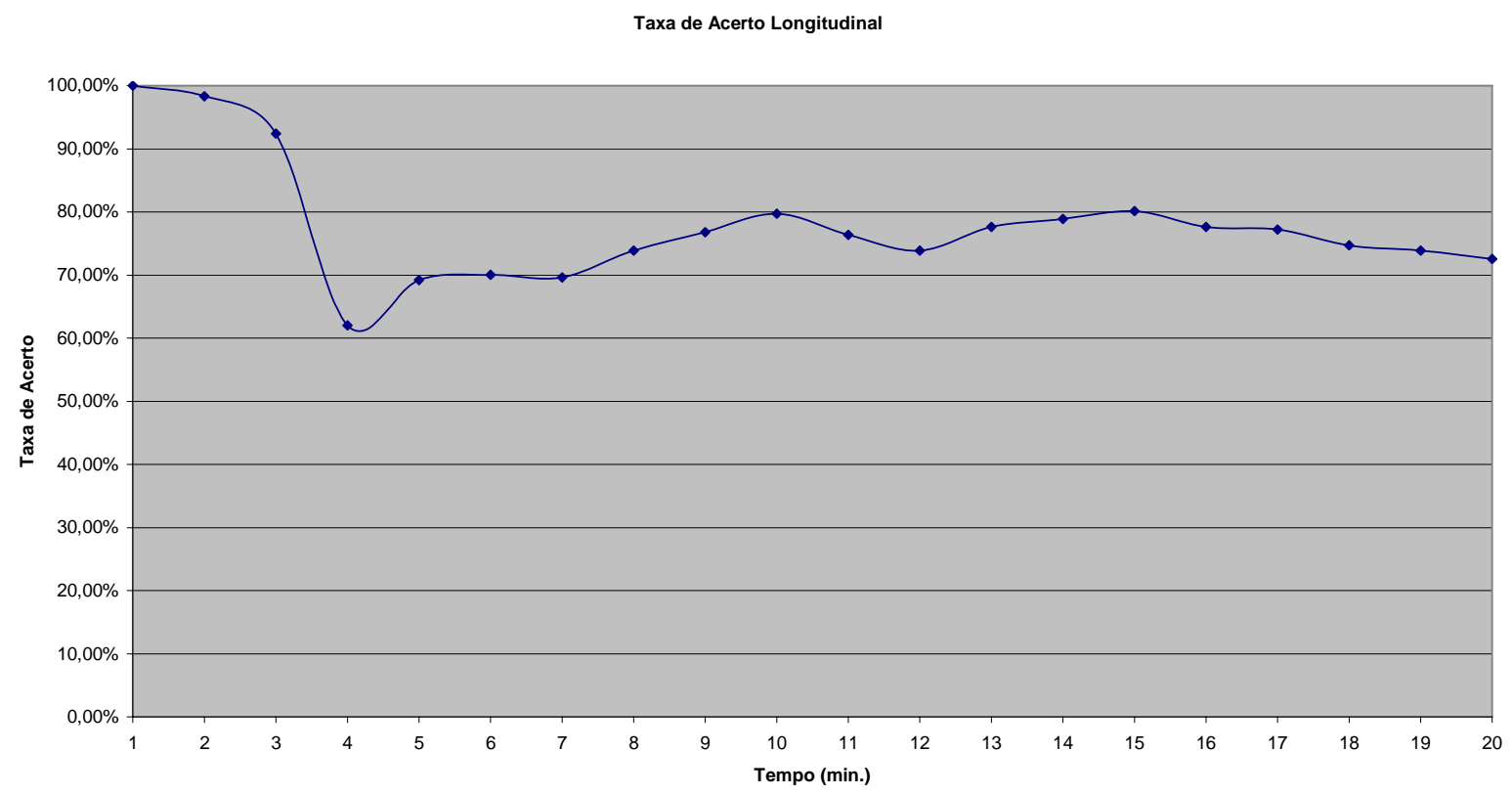

Figura 45: Taxa de acerto para as previsões longitudinais, considerando as incertezas crescentes.

Finalmente, são contabilizadas as situações em que há acerto tanto na previsão lateral quanto na previsão longitudinal, gerando os valores tabulados na Tabela 18 e ilustrados na Figura 46.

A composição das previsões lateral e longitudinal produziu um resultado não muito satisfatório, já que o ideal seria uma taxa de acerto de $95 \%$. Para as previsões de curto prazo, 1 a 2 minutos, a previsão é razoável (acima de $75 \%$ ). Depois, os valores oscilam entre 40 e $60 \%$ na taxa de acerto, com uma leve tendência de alta para previsões a partir de 11 minutos. 
Tabela 18: Taxa de acerto geral para as previsões, considerando as incertezas crescentes.

\begin{tabular}{|c|c|}
\hline $\begin{array}{c}\text { Instante de } \\
\text { previsão (min) }\end{array}$ & $\begin{array}{c}\text { Taxa de } \\
\text { acerto }\end{array}$ \\
\hline 1 & $95,78 \%$ \\
2 & $77,22 \%$ \\
3 & $60,34 \%$ \\
4 & $41,77 \%$ \\
5 & $45,57 \%$ \\
6 & $47,26 \%$ \\
7 & $45,57 \%$ \\
8 & $44,73 \%$ \\
9 & $47,68 \%$ \\
10 & $51,90 \%$ \\
11 & $48,95 \%$ \\
12 & $51,90 \%$ \\
13 & $52,74 \%$ \\
14 & $53,59 \%$ \\
15 & $55,70 \%$ \\
16 & $58,65 \%$ \\
17 & $59,07 \%$ \\
18 & $58,23 \%$ \\
19 & $59,92 \%$ \\
20 & $62,03 \%$ \\
\hline Total geral & $55,93 \%$ \\
\hline
\end{tabular}

Taxa de Acerto

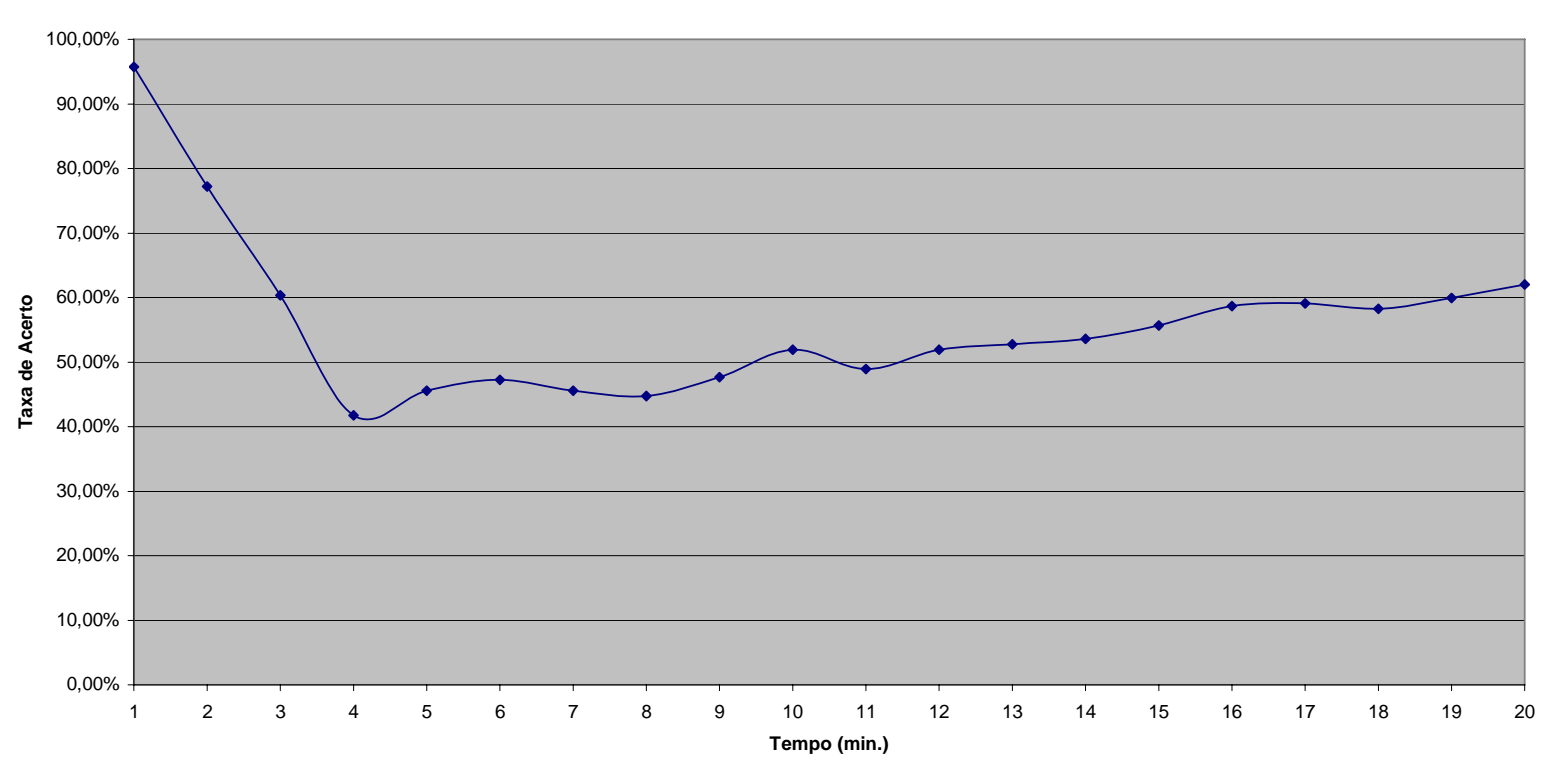

Figura 46: Taxa de acerto geral para as previsões, considerando as incertezas crescentes. 


\subsection{2. $\quad$ Estudo de Caso 2: TAM8096}

Os resultados apresentados para este vôo seguem formato semelhante ao apresentado anteriormente, diferenciando apenas pela unificação dos resultados em uma única tabela e em um único gráfico. Por esse motivo, muitas das explicações do significado dos gráficos foram omitidas.

Em primeiro lugar, é importante colocar que o vôo TAM8096 apresentou uma particularidade. Enquanto a trajetória do vôo BRB9983 era praticamente uma linha reta, sem grandes oscilações, o vôo TAM8096 tinha muitas mudanças grandes de direção ao longo do caminho. Essas mudanças foram descobertas ao se utilizar as posições conhecidas para se plotar o caminho percorrido pela aeronave. Portanto, a análise foi dividida em três grandes trechos, que podem ser visualizados na Figura 47.

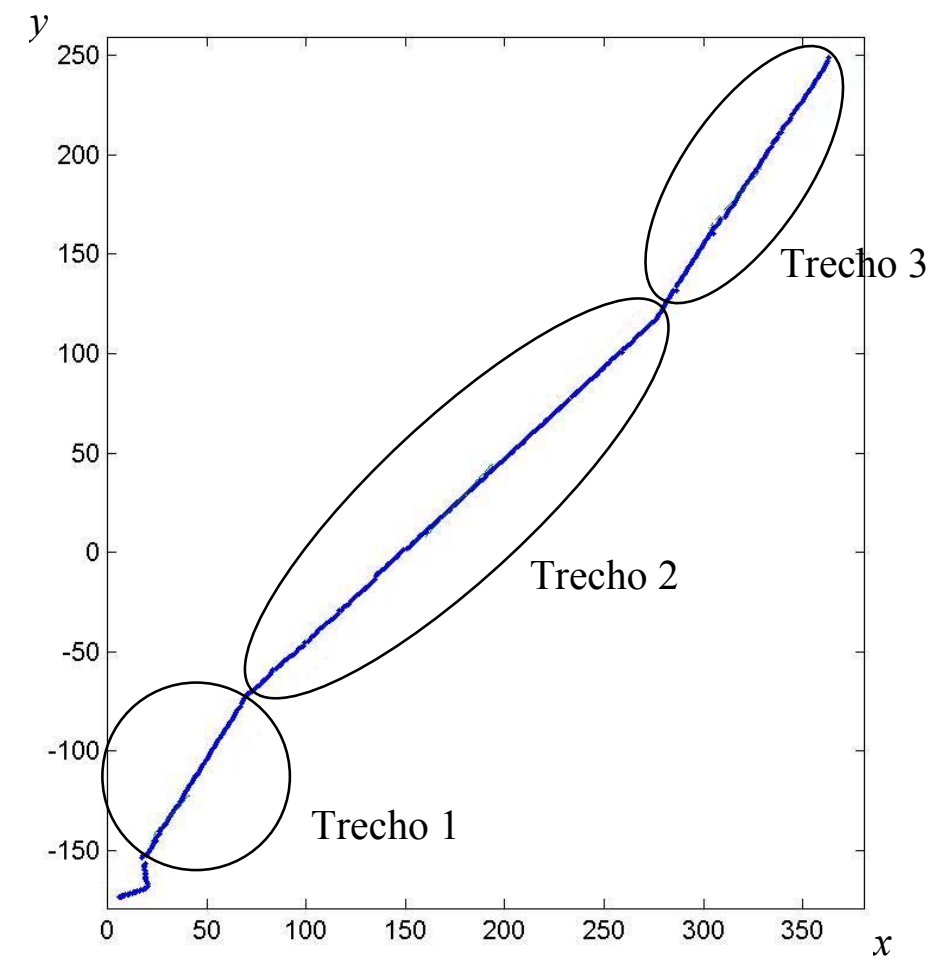

Figura 47: Trechos retilínios para a análise das previsões do vôo TAM8096.

Foi feita análise apenas do trecho 2, já que os outros trechos são muito curtos, não permitindo uma análise satisfatória.

Realizando todo o processo descrito neste capítulo, foi detectada a variância lateral mínima quando 30 posições passadas são consideradas na previsão (5 minutos) e a variância longitudinal mínima também ocorreu quando 30 posições passadas são consideradas na 
previsão (5 minutos). A Tabela 19 e a Figura 48 mostram as taxas de acerto das previsões lateral, longitudinal e geral, considerando a incerteza média e constante.

Tabela 19: Taxas de acerto para as previsões do vôo TAM8096, considerando incertezas constantes.

\begin{tabular}{|c|c|c|c|c|c|}
\hline $\begin{array}{c}\text { Instante de } \\
\text { previsão (min) }\end{array}$ & $\begin{array}{c}\text { Taxa de acerto } \\
\text { lateral }\end{array}$ & $\begin{array}{c}\text { Incerteza } \\
\text { Lateral (NM) }\end{array}$ & $\begin{array}{c}\text { Taxa de acerto } \\
\text { longitudinal }\end{array}$ & $\begin{array}{c}\text { Incerteza } \\
\text { Longitudinal (NM) }\end{array}$ & $\begin{array}{c}\text { Taxa de } \\
\text { acerto geral }\end{array}$ \\
\hline 1 & $100,00 \%$ & 1,5599 & $100,00 \%$ & 1,8771 & $100,00 \%$ \\
2 & $100,00 \%$ & 1,5599 & $100,00 \%$ & 1,8771 & $100,00 \%$ \\
4 & $100,00 \%$ & 1,5599 & $100,00 \%$ & 1,8771 & $100,00 \%$ \\
5 & $100,00 \%$ & 1,5599 & $100,00 \%$ & 1,8771 & $100,00 \%$ \\
6 & $100,00 \%$ & 1,5599 & $100,00 \%$ & 1,8771 & $100,00 \%$ \\
7 & $100,00 \%$ & 1,5599 & $100,00 \%$ & 1,8771 & $100,00 \%$ \\
8 & $100,00 \%$ & 1,5599 & $100,00 \%$ & 1,8771 & $100,00 \%$ \\
9 & $100,00 \%$ & 1,5599 & $100,00 \%$ & 1,8771 & $100,00 \%$ \\
10 & $100,00 \%$ & 1,5599 & $96,77 \%$ & 1,8771 & $96,77 \%$ \\
11 & $100,00 \%$ & 1,5599 & $93,55 \%$ & 1,8771 & $93,55 \%$ \\
12 & $96,77 \%$ & 1,5599 & $87,10 \%$ & 1,8771 & $83,87 \%$ \\
13 & $96,77 \%$ & 1,5599 & $83,87 \%$ & 1,8771 & $83,87 \%$ \\
14 & $87,10 \%$ & 1,5599 & $64,52 \%$ & 1,8771 & $54,84 \%$ \\
15 & $87,10 \%$ & 1,5599 & $58,06 \%$ & 1,8771 & $51,61 \%$ \\
16 & $83,87 \%$ & 1,5599 & $35,48 \%$ & 1,8771 & $32,26 \%$ \\
17 & $77,42 \%$ & 1,5599 & $16,13 \%$ & 1,8771 & $12,90 \%$ \\
18 & $77,42 \%$ & 1,5599 & $3,23 \%$ & 1,8771 & $3,23 \%$ \\
19 & $77,42 \%$ & 1,5599 & $0,00 \%$ & 1,8771 & $0,00 \%$ \\
20 & $74,19 \%$ & 1,5599 & $3,23 \%$ & 1,8771 & $0,00 \%$ \\
Total geral & $\mathbf{9 1 , 4 5 \%}$ & $\mathbf{1 , 5 5 9 9}$ & $\mathbf{6 7 , 1 0 \%}$ & 1,8771 & $0,00 \%$ \\
\hline & & & & $\mathbf{1 , 8 7 7 1}$ & $\mathbf{6 5 , 6 5 \%}$ \\
\hline
\end{tabular}

Taxas de Acerto

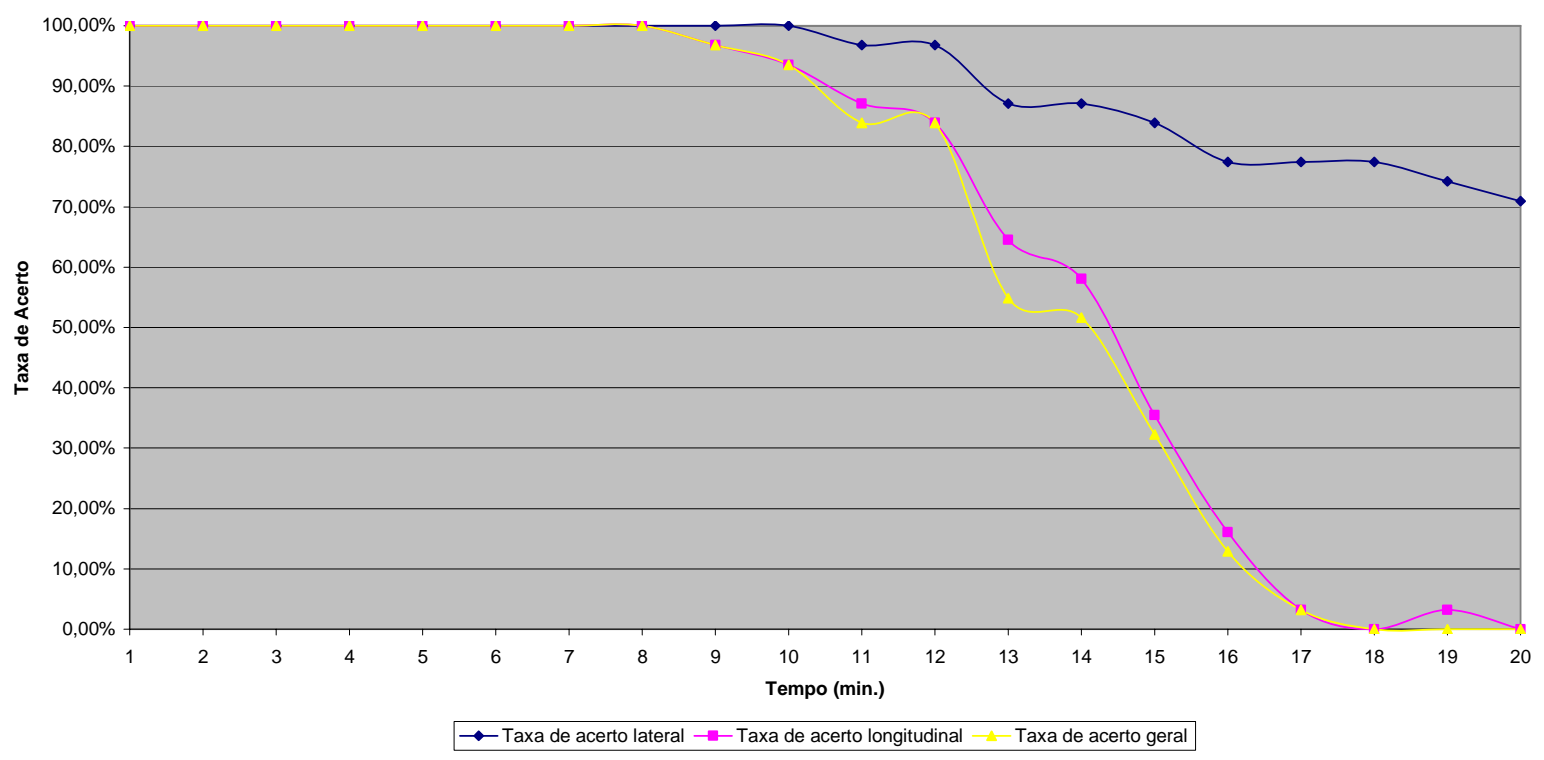

Figura 48: Taxas de acerto para as previsões do vôo TAM8096, considerando incertezas constantes. 
A análise foi repetida, considerando as incertezas crescentes. A Tabela 20 e a Figura 49 mostram as taxas de acerto das previsões lateral, longitudinal e geral, considerando as incertezas crescentes.

Tabela 20: Taxas de acerto para as previsões do vôo TAM8096, considerando incertezas crescentes.

\begin{tabular}{|c|c|c|c|c|c|}
\hline $\begin{array}{c}\text { Instante de } \\
\text { previsão (min) }\end{array}$ & $\begin{array}{c}\text { Taxa de acerto } \\
\text { lateral }\end{array}$ & $\begin{array}{c}\text { Incerteza } \\
\text { lateral (NM) }\end{array}$ & $\begin{array}{c}\text { Taxa de acerto } \\
\text { longitudinal }\end{array}$ & $\begin{array}{c}\text { Incerteza } \\
\text { longitudinal (NM) }\end{array}$ & $\begin{array}{c}\text { Taxa de } \\
\text { acerto geral }\end{array}$ \\
\hline 1 & $77,42 \%$ & 0,9076 & $61,29 \%$ & 0,2073 & $61,29 \%$ \\
\hline 2 & $70,97 \%$ & 0,947 & $45,16 \%$ & 0,1835 & $35,48 \%$ \\
\hline 3 & $70,97 \%$ & 0,9939 & $58,06 \%$ & 0,3345 & $38,71 \%$ \\
\hline 4 & $67,74 \%$ & 1,0479 & $64,52 \%$ & 0,3893 & $35,48 \%$ \\
\hline 5 & $77,42 \%$ & 1,1085 & $90,32 \%$ & 0,5715 & $67,74 \%$ \\
\hline 6 & $96,77 \%$ & 1,1767 & $93,55 \%$ & 0,7472 & $90,32 \%$ \\
\hline 7 & $96,77 \%$ & 1,2493 & $90,32 \%$ & 0,9214 & $87,10 \%$ \\
\hline 8 & $96,77 \%$ & 1,3246 & $87,10 \%$ & 1,0978 & $83,87 \%$ \\
\hline 9 & $100,00 \%$ & 1,4031 & $87,10 \%$ & 1,2815 & $87,10 \%$ \\
\hline 10 & $93,55 \%$ & 1,4838 & $90,32 \%$ & 1,5456 & $87,10 \%$ \\
\hline 11 & $87,10 \%$ & 1,5663 & $87,10 \%$ & 1,885 & $77,42 \%$ \\
\hline 12 & $96,77 \%$ & 1,651 & $96,77 \%$ & 2,0639 & $96,77 \%$ \\
\hline 13 & $90,32 \%$ & 1,738 & $93,55 \%$ & 2,3808 & $87,10 \%$ \\
\hline 14 & $87,10 \%$ & 1,8255 & $93,55 \%$ & 2,5998 & $83,87 \%$ \\
\hline 15 & $93,55 \%$ & 1,913 & $96,77 \%$ & 2,9812 & $90,32 \%$ \\
\hline 16 & $90,32 \%$ & 2,0003 & $93,55 \%$ & 3,2277 & $87,10 \%$ \\
\hline 17 & $87,10 \%$ & 2,0871 & $93,55 \%$ & 3,5057 & $83,87 \%$ \\
\hline 18 & $87,10 \%$ & 2,1732 & $90,32 \%$ & 3,6551 & $80,65 \%$ \\
\hline 19 & $83,87 \%$ & 2,2586 & $83,87 \%$ & 3,7613 & $70,97 \%$ \\
\hline 20 & $87,10 \%$ & 2,343 & $87,10 \%$ & 4,2227 & $77,42 \%$ \\
\hline Total geral & $\mathbf{8 6 , 9 4 \%}$ & $\mathbf{1 , 5 5 9 9}$ & $\mathbf{8 4 , 1 9 \%}$ & $\mathbf{1 , 8 7 8 1}$ & $\mathbf{7 5 , 4 8 \%}$ \\
\hline
\end{tabular}

Taxas de Acerto

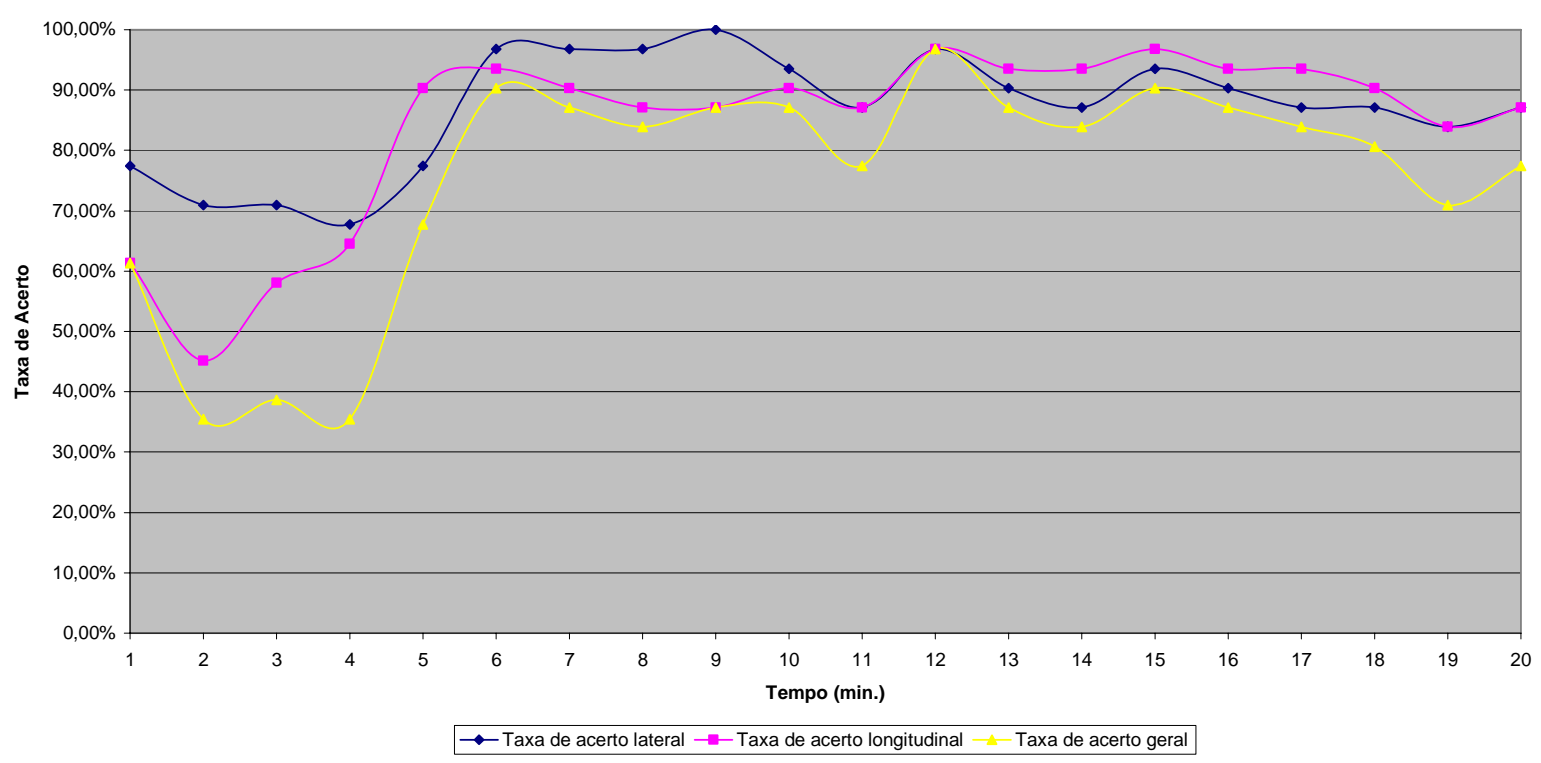

Figura 49: Taxas de acerto para as previsões do vôo TAM8096, considerando incertezas crescentes. 
O resultado obtido para este vôo apresentou taxas de acerto melhores do que as obtidas para o vôo BRB9983. Para as previsões de mais curto prazo (1 a 4 minutos) as taxas de acerto foram baixas, em geral próximas a $35 \%$. A partir das previsões de 5 minutos o resultado foi consideravelmente satisfatório, com taxas de acerto oscilando entre 80 e $90 \%$. É possível verificar que os maiores problemas que resultaram em baixa taxa de acerto no curto prazo se devem a erros na previsão longitudinal, provavelmente causados por pequenas oscilações na velocidade.

\subsection{Considerações Finais do Capítulo}

Neste capítulo, foi apresentada toda a descrição do processo de simulação, assim como os resultados alcançados. Como é esperado, para se manter a taxa de acerto das previsões, as incertezas das previsões tendem a ficar maiores ao longo do tempo e da distância viajada. Por isso, é necessário considerar incertezas crescentes, de forma a garantir uma taxa de acerto mais estável, ou seja, garantir a acurácia da previsão. Foi possível verificar que a taxa de acerto cai bastante ao longo do tempo, quando se considera a incerteza constante. Ao se considerar as incertezas crescentes, a taxa de acerto traz valores melhores.

Os resultados das previsões de posição futura de aeronaves podem ser trazidos pelos sistemas de vigilância (SSR ou ADS), conforme destacado no capítulo 2. Então essas informações podem ser utilizadas por sistemas de apoio a decisão, principalmente sistemas de detecção e resolução de conflitos.

Uma análise mais criteriosa dos resultados obtidos e formas de aplicação prática do trabalho encontra-se no próximo capítulo, no qual são apresentadas considerações sobre continuidades que podem ser dadas a este trabalho. 


\section{CONSIDERAÇÕES FINAIS}

Neste capítulo, são apresentadas as conclusões referentes aos resultados desta pesquisa e destacadas algumas aplicações práticas em que o modelo proposto pode ser inserido. Além disso, são mostradas também algumas possíveis linhas de pesquisa visando a dar continuidade a este trabalho.

\subsection{Análise dos Resultados}

O principal objetivo desta pesquisa foi investigar o problema das previsões de posições futuras de aeronaves dentro do espaço aéreo brasileiro, para vôos em rota. O resultado dos dois vôos analisados encontram-se sintetizados na Tabela 21.

Tabela 21: Resultados sintetizados das previsões de posições.

\begin{tabular}{|c|c|c|c|}
\hline Vôo & $\begin{array}{c}\text { Taxa de } \\
\text { Acerto } \\
\text { Lateral }\end{array}$ & $\begin{array}{c}\text { Taxa de } \\
\text { Acerto } \\
\text { Longitudinal }\end{array}$ & $\begin{array}{c}\text { Taxa de } \\
\text { Acerto Geral }\end{array}$ \\
\hline BRB9983 & $71,88 \%$ & $77,74 \%$ & $55,93 \%$ \\
\hline TAM8096 & $86,94 \%$ & $84,19 \%$ & $75,48 \%$ \\
\hline
\end{tabular}

Os sistemas de controle de tráfego aéreo, sobretudo para detecção e resolução de conflitos, requerem uma acurácia das posições previstas que garantam uma probabilidade de $95 \%$ de que a posição prevista esteja correta, conforme destacado no capítulo 3. Essa taxa de acerto permite que as situações de conflito sejam verificadas, garantindo a segurança necessária para o controle do tráfego aéreo.

A utilização do modelo apresentado neste trabalho de pesquisa, da forma como ele foi proposto, trouxe resultados inferiores aos $95 \%$ de taxa acerto. No entanto, esse resultado não inviabiliza a utilização deste modelo, já que nesse trabalho foram realizadas algumas reduções de escopo do problema, pois o objetivo consistiu em analisar a possibilidade de se utilizar as informações existentes sobre posições passadas para extrapolar as posições futuras de uma aeronave. O estudo mostra que o modelo é viável de ser implementado, o que resultaria em um custo aceitável, permitindo sua utilização.

Para que isso se torne possível, algumas das simplificações colocadas no modelo de forma a viabilizar essa investigação inicial, devem ser tratadas. Dentre essas simplificações, destacam-se a não consideração das incertezas meteorológicas e eventuais alterações de direção e velocidade da aeronave. A inclusão desses fatores no modelo o tornarão viável, do ponto de vista da segurança necessária para os sistemas de controle de tráfego aéreo e, ao 
mesmo tempo, permanece válido o equacionamento elaborado para solucionar o problema de previsão de posição futura de aeronaves. Ainda considerando apenas os aspectos de segurança, aumentos nos valores das incertezas laterais e longitudinais, sem alteração no modelo, trarão uma maior taxa de acerto das previsões, possibilitando o uso do modelo para a construção de softwares embarcados nos sistemas de controle do tráfego aéreo. No entanto, a primeira alternativa, inclusão de outros fatores, tende a aumentar as taxas de acerto das previsões, sem que com isso ocorra um grande aumento nas incertezas associadas.

Convém também destacar a importância de um sistema com nível de integridade satisfatória, pois ele proporciona a emissão de alertas quando a previsão de posição fornecida não estiver correta, garantindo a segurança do sistema.

\subsection{Aplicações Práticas Relacionadas à Pesquisa}

O crescimento do uso de aeronaves como meio de transporte é constante e vem se mostrando contínuo, com expectativa de que continue crescendo nos próximos anos. A garantia da segurança é fundamental para que a sociedade mantenha a confiança no transporte aeronáutico. Com isso, os sistemas de gestão de tráfego aéreo tornam-se, cada vez mais, ferramentas fundamentais no auxílio a pilotos e controladores de vôo. Neste trabalho, foi exibida uma pesquisa a respeito da previsão de posição futura de aeronaves utilizando regressão linear das posições conhecidas da aeronave e extrapolação das posições futuras, agregada de uma informação adicional, que é o valor da incerteza associada à previsão.

Desta forma, a pesquisa realizada tem aplicações práticas relacionadas diretamente aos sistemas de controle de tráfego. Como exemplo, destacam-se os sistemas de vigilância (SSR ou ADS), os quais podem incluir o modelo de previsão apresentado, possibilitando disponibilizar as informações de posição futura das aeronaves juntamente com as respectivas incertezas associadas às previsões. Como os dados de vôos necessários para a implantação do modelo proposto podem ser obtidos para diversas aeronaves e em diversas rotas, é viável utilizar esses dados para se calcular as previsões.

O grande objetivo para uma aplicação prática é a construção de softwares embarcados nos sistemas de controle do tráfego que possam utilizar um algoritmo baseado no modelo proposto neste trabalho de pesquisa. Desta maneira, os sistemas de apoio a decisão poderão utilizar as informações geradas por meio desse software. Para se chegar a esse software, alguns passos anteriores tornam-se necessários, conforme descrito a seguir.

Em primeiro lugar, é necessário obter uma amostra maior de dados sobre vôos, permitindo analisar melhor os resultados para diversas situações, contemplando diferentes 
modelo de aeronaves e diferentes rotas seguidas. Em segundo lugar, alguns fatores de incertezas devem ser investigados, de forma a se descobrir suas relevâncias para o resultado das previsões, como por exemplo, as incertezas meteorológicas. Sabendo-se quais fatores de incerteza apresentam relevância, eles devem ser incorporados ao modelo. Então, uma nova análise é necessária, para se verificar se os resultados obtidos continuam satisfatórios. Com isso, outros ajustes devem ser feitos até que os níveis de incerteza e as taxas de acerto fiquem adequados. Em um passo seguinte, uma base de dados deve ser construída, armazenando informações do comportamento dos vôos, levando-se em conta diversos tipos de aeronaves e as respectivas rotas em que essas aeronaves voam. As informações existentes nessa base de dados são utilizadas, então, para a obtenção das previsões de posição futuras das aeronaves. Assim, um software de previsão pode ser construído e incorporado aos sistemas de controle do tráfego.

O software implementado pode ser utilizado para detecção e resolução de conflitos e também em sistemas que controlam a densidade e ocupação do tráfego aéreo, para períodos de longo prazo. Essa última utilização permite uma antecipação diante de eventuais ocupações desordenadas do espaço aéreo.

Uma outra contribuição importante da previsão de posição futura relaciona-se com a utilização de VANTs (Veículos Aéreos Não Tripulados). Esses veículos, que poderão, no futuro, ser até mesmo aeronaves, devem ser comandados por um piloto que esteja em solo. A interface que o piloto necessita deve permitir que o veículo seja comandado como se o piloto estive a bordo. Para que esses veículos sejam utilizados com um nível de segurança compatível ao das aeronaves existentes hoje, os softwares que controlam esses veículos devem ser altamente tolerantes a falhas. Assim, a detecção e resolução de conflitos também deverá estar neles implementadas, o que exigirá previsões de posição futura com boa acurácia e precisão.

\subsection{Futuras Linhas de Pesquisa}

Algumas linhas de pesquisa podem surgir como continuidade do trabalho iniciado nesta pesquisa. As próximas seções trazem uma breve explicação sobre algumas possíveis linhas de pesquisa sugeridas. 


\subsubsection{Análise da Magnitude do Erro Associado a uma Previsão}

O trabalho apresentado exibiu as taxas de acerto para as previsões de posição lateral e longitudinal. No entanto, nas situações em que a previsão da posição foi incorreta, ou seja, a aeronave não estava dentro da região prevista, não se sabe qual foi a magnitude do erro. Encontrar essa magnitude permitiria saber, para as situações em que houve erro, o quanto se errou, ou seja, a magnitude do erro.

Baseado na magnitude do erro da previsão, é possível estimar o quanto é necessário aumentar os valores de incerteza lateral e longitudinal das previsões de forma a manter as taxas de acerto nos níveis desejados, por exemplo, acima de $95 \%$. Se a manutenção dessas taxas exigir que as incertezas aumentem muito, a previsão podia ser pouco eficiente, já que quanto maior a incerteza, maior a área onde a aeronave possivelmente se encontra, acarretando baixa acurácia. Com isso, seria necessário aumentar as distâncias entre as aeronaves para manter os níveis de segurança, o que podia impedir um dos principais ganhos esperados, que é o aumento da capacidade de utilização do espaço aéreo.

\subsubsection{Sistema Inteligente para Melhorar os Níveis de Acerto}

No capítulo 6 foram mostradas nove etapas sugeridas no modelo proposto para a previsão de posição futura das aeronaves. As primeiras seis etapas são utilizadas para se estimar a variabilidade do erro lateral e longitudinal que a aeronave apresenta quando é utilizada uma regressão linear das posições passadas, seguida de uma extrapolação das posições futuras. As principais etapas envolvidas para se estimar a variabilidade são as etapas 5 (análise estatística dos erros) e 6 (eliminação dos dados discrepantes) e os dados utilizados nessas etapas são obtidos a partir dos vôos de um certo tipo de aeronave voando dentro de uma determinada rota.

Um sistema inteligente pode continuamente atualizar a análise de variabilidade, utilizando os dados de diversos vôos. Uma outra opção é realizar a análise de variabilidade de acordo com as condições gerais do vôo. Por exemplo, para situações climáticas adversas, podem ser obtidos os fatores de incerteza que se verificam nessas situações. Em situações de congestionamento do espaço aéreo, os fatores também podem ser calculados separadamente. O ganho esperado é a obtenção de fatores de incerteza característicos para uma determinada situação do espaço aéreo, permitindo maiores taxas de acerto sem aumentar indiscriminadamente os fatores de incerteza. Assim, as incertezas podem aumentar ou diminuir, dentro de uma margem de segurança aceitável, assegurando taxas de acerto próximas de $95 \%$. 


\subsubsection{Análises Utilizando Amostras Maiores}

Conforme descrito nos passos necessários para se implementar um software que utiliza o modelo proposto nesse trabalho, é importante realizar outras análises com amostras maiores, contendo informações a respeito de outros vôos, bem como contemplando diversos tipos de aeronaves e diversas rotas. Então, a mesma análise realizada neste trabalho deverá ser feita, o que permitirá uma verificação mais abrangente do modelo proposto. Com base nas conclusões desta nova investigação, eventuais ajustes podem se mostrar necessários para permitir a sua utilização como software embarcado.

\subsubsection{Consideração das Incertezas Associadas às Medidas dos Radares ou Satélites}

A análise realizada neste trabalho não considerou os fatores de incerteza (FOM) associados às medidas de posição realizadas pelos radares ou satélites. O capítulo 6 mostra um modelo que utiliza essas informações (medidas das posições de aeronaves e as suas respectivas incertezas dessas medidas) como variáveis de entrada para cálculo da previsão de posição futura de uma aeronave. A utilização dessas informações pode ser utilizada sobretudo na melhoria da previsão da incerteza lateral, conforme descrito. Com isso, espera-se que a acurácia geral da previsão possa ser melhorada com a utilização do FOM.

\subsubsection{Detecção Automática de Problemas de Integridade}

O modelo proposto considerou a realização de uma regressão linear, utilizando posições conhecidas da aeronave, para então extrapolar as posições futuras da aeronave. Essa análise funciona para situações em rota, considerando que a aeronave sofre poucas mudanças de direção e velocidade. A solução proposta neste trabalho pode não se adequar a situações onde ocorra alguma modificação na direção ou velocidade da aeronave, já que isso aumenta a possibilidade de erro na previsão.

A abordagem utilizada não considera problemas de integridade, pois em situações como essa, em que a previsão de posição é incorreta, não há uma detecção prévia do problema. Uma forma de se resolver esse problema é inserir no sistema a possibilidade de se detectar uma modificação na direção ou velocidade da aeronave. Quando essa modificação for detectada, pode ser emitido um alerta automático de que a posição prevista anteriormente não está correta, garantindo assim a integridade do sistema. Para melhorar ainda mais o funcionamento, no momento em que ocorrer essa situação, uma nova previsão de posição pode ser realizada, considerando a nova realidade.

É importante ressaltar que o modelo utilizado nesse trabalho não considerou modificações de velocidade. Mudanças de direção apenas foram consideradas quando um fixo 
foi atingido. A desconsideração desses fatores pode levar a problemas tanto de acurácia quanto de integridade.

\subsubsection{Inclusão de Outras Variáveis de Incerteza}

Uma série de variáveis e fatores de incerteza influenciam o comportamento da aeronave durante um vôo. A inclusão dessas variáveis dentro do algoritmo de previsão de posição futura pode aumentar a qualidade dessa previsão, sobretudo em termos de acurácia e integridade. O comportamento dos ventos é um fator importante, pois pode alterar significativamente o comportamento da aeronave. No entanto, modelar corretamente os fatores meteorológicos é uma tarefa complexa, o que levou a reduções de escopo na modelagem proposta. Outros estudos mostram mais detalhadamente como inserir o comportamento dos ventos dentro do problema de previsão de posição de aeronave (KIRK; BOLCZAK, 2003; MONDOLONI; LIANG, 2003; COLE et al., 2000).

A própria condição de ocupação do espaço aéreo influencia na previsão de posição futura. Quando a aeronave está voando em um espaço aéreo congestionado, a probabilidade de se realizarem manobras aumenta, podendo diminuir a acurácia das previsões. O contrário ocorre quando o espaço aéreo não está congestionado. As condições da aeronave, tais como massa, empuxo, arrasto, também influenciam diretamente nas previsões de posição futura. Tais variáveis podem ser inseridas no algoritmo de previsão. Alguns sistemas de detecção e resolução de conflitos, como o CTAS, modelam a previsão de posição futura de uma maneira bastante completa (COPPENBARGER; KANNING, 2001).

As previsões de trajetórias também podem ser melhoradas com atualizações dinâmicas de planos de vôo. Nem sempre que um plano de vôo é alterado, suas informações são corretamente atualizadas no sistema de controle de tráfego aéreo, o que pode causar problemas relacionados a construção de trajetórias. Maiores detalhes sobre atualização dinâmica de plano de vôo podem ser obtidos em (GRACE; GREEN; WILLIAMS, 2000).

\subsubsection{Análise do Impacto da Utilização de Previsão de Posições Futuras de Aeronaves no Risco Geral do Controle do Tráfego Aéreo}

Um passo muito importante para que um software embarcado que realize a previsão de posição futura de uma aeronave seja incorporado aos sistemas de controle do tráfego aéreo, é analisar o impacto que ele causa no risco geral do controle do tráfego aéreo. Portanto, uma análise desse impacto torna-se necessária, para garantir a segurança global do sistema. $\mathrm{O}$ resultado esperado é que essa segurança global aumente com a utilização de um novo software de previsão de posição futura de aeronaves. 


\subsubsection{Previsões de Posição Considerando Variação de Altitude}

Em muitas situações de um vôo, principalmente aquelas referentes a pousos e decolagens, as aeronaves têm variação de altitude. Nesse trabalho, este fator não foi considerado, pois toda a investigação realizada tratou de vôos em rota. Pesquisas podem ser realizadas para considerar a variação de altitude das aeronaves, existente principalmente em outras fases de vôo.

\subsubsection{Outras Possibilidade de Simulações}

Há três possíveis condições em que as simulações podem ocorrer:

1. Simulação com posições síntese - simulações em que apenas são consideradas as medidas de posição síntese dos radares. Assim, quando mais de um radar medir a posição da aeronave, essas informações particulares de cada radar não serão consideradas;

2. Simulação com todas as medidas - simulações considerando todas as medidas de posição existentes, incluindo as medidas individuais de cada radar; e

3. Simulação com posições síntese acrescida da FOM - simulações semelhantes ao primeiro grupo, acrescentando a imprecisão do radar em cada posição medida.

Nesta pesquisa foi utilizada a primeira opção, pois esta utiliza as informações sínteses de cada posição da aeronave, que é a medida de posição comumente utilizada por controladores de vôo e pilotos. Simulações utilizando as duas outras abordagens podem ser efetuadas, a fim de se comparar os resultados obtidos.

\subsection{Conclusões}

Neste capítulo, foram apresentados os resultados sintetizados referentes às simulações realizadas para previsão de posição futura de aeronaves. As conclusões obtidas permitem apontar para possíveis aplicações práticas deste trabalho e permitem também a proposta de linhas de pesquisa visando a continuidade da investigação realizada. O trabalho mostra a importância que existe em se realizar a previsão de posição futura para aeronaves e como utilizar as previsões para se manter a segurança da ocupação do espaço aéreo, especialmente em regiões onde a cobertura por radar é insuficiente ou inexistente. As informações sobre previsão de posição futura podem ser trazidas pelos sistemas de vigilância (SSR ou ADS). Considerando o crescimento do uso de aeronaves como meio de transporte, é fundamental que existam novos trabalhos de pesquisa nesta área, visando a obter um crescimento contínuo e seguro do transporte aéreo. 
O principal objetivo deste trabalho de pesquisa, o de propor um modelo para previsão de posição futura de aeronaves, foi alcançado. O modelo apresentado mostrou-se viável, tanto do ponto de vista computacional, já que os cálculos envolvidos puderam ser implementados, como do ponto de vista do resultado esperado para as previsões. Assim, espera-se que este trabalho sirva de inspiração para que novas pesquisas sejam realizadas, garantindo a sua continuidade, até que se obtenha um software que implemente o modelo proposto. Esse objetivo maior poderá trazer grandes ganhos para a aviação brasileira, já que a construção de sistemas próprios desta natureza não deixará o país totalmente dependente de tecnologia advinda de países desenvolvidos. 


\section{REFERÊNCIAS}

\section{Referências Citadas:}

ATKINS, S.; HANSMAN , R. J. Calculating Dependent Surveillance Update Rates by Modeling the Time-Dependence of Information Value. AIAA Guidance, Navigation, and Control Conference. Portland, October 1999.

BARROS, I. Q. Introdução ao Cálculo Numérico. Editora da USP, 1972.

BUSSAB, W. O.; MORETIN, P. A. Estatística Básica. Atual Editora Ltda., 1994.

CIEPLAK, J. J.; HAHN, E.; OLMOS, B. O. Safe Flight 21: The 1999 Operational Evaluation of ADS-B Applications. 3rd USA/Europe Air Traffic Management R\&D Seminar. Napoli, June 2000.

COLE, R. E.; GREEN, S.; JARDIN, M.; SCHWARTZ, B. E.; BENJAMIN, S. G. Wind Prediction Accuracy for Air Traffic Management Decision Support Tools. 3rd USA/Europe Air Traffic Management R\&D Seminar. Napoli, June 2000.

COPPENBARGER, R. A, KANNING, G. Real-Time Data Link of Aircraft Parameters to the Center-TRACON Automation System (CTAS). 4th USA/Europe Air Traffic Management R\&D Seminar. Santa Fe, December 2001.

COPPENBARGER, R. A. Climb Trajectory Prediction Enhancements Using Airline Flight-Planning Information. NASA Ames Research Center. 1999.

COULURIS, G. J. Detailed Description for CE6 En Route Trajectory Negotiation. Technical Research in Advanced Air Transportation Technologies. November 2000.

ERZBERGER, H.; PAIELLI, R. A.; ISSACSON, D. R.; ESHOW, M. M. Conflict Detection and Resolution In the Presence of Prediction Error. NASA Ames Research Center. 1997.

EUROCONTROL. ADS-B/TIS-B Functional Architeture. Eurocontrol ADS Programme. May 2003.

EUROCONTROL. Automatic Dependent Surveillance Concept. European Organisation for the Safety of Air Navigation. September 2001. 
EUROCONTROL. Automatic Dependent Surveillance Requirements. European Organisation for the Safety of Air Navigation. August 2002.

EUROCONTROL. User Manual for the Base of Aircraft Data (BADA). European Organisation for the Safety of Air Navigation. September 2004.

FALKER, J. M.; KUCHAR, J. K. Analytical and Empirical Analysis of the Impacts of Restricting Airspace. 4th USA/Europe Air Traffic Management R\&D Seminar. Santa Fe, December 2001.

FERRO, D. The impact of Human Factors on Airborne Separation Assurance Systems (ASAS). 3rd USA/Europe Air Traffic Management R\&D Seminar. Napoli, June 2000.

GALOTTI, V.INCENT P. JR. The Future Air Navigation System (FANS). Ashgate Publishing Company, 1998.

GRACE, M. P.; GREEN, S. M.; WILLIAMS, D. H. Flight Test Results: CTAS and FMS Cruise/Descent Trajectory Prediction Accuracy. $3^{\text {rd }}$ USA/Europe Air Traffic Management R\&D Seminar. Napoli, Italy, June 2000.

GREEN, S. M.; GOKA, T.; WILLIAMS, D. H. Enabling User Preferences through Data Exchange. NASA Research Center. 1997.

ICAO. ICAO Manual of Air Traffic Services (ATS) Data Link Applications. Automatic Dependent Surveillance Panel (ADSP) - Appendix B. September 1996.

ICAO. Aeronautical Telecommunication Network (ATN), Comprehensive ATN Manual (CAMAL). ATNP WORKING GROUPS, 1999.

ICAO. Automatic Dependent Surveillance - Broadcast (ADS-B) Concept of Use, 2003a.

ICAO. Automatic Dependent Surveillance Broadcast (ADS-B) for Air to Ground Surveillance. 30th Meeting of the APANPIRG ATS/AIS/SAR Sub-Group. Bangkok, Thailand, June 2003b.

ICAO. Conflict Management. 11th Air Navigation Conference. Montreal, SeptemberOctober 2003c. 
ICAO. ICAO Airborne Separation Assistance System (ASAS) Circular. Surveillance and Conflict Resolution Systems Panel. May 2003d.

ICAO. Report of the ADS-B Study and Implementation - Task Force Meeting. Brisbane, Australia, March 2003e.

JOHNSON, B.W. Evaluation Techniques. In: JOHNSON, B.W. Design and Analysis of Fault-Tolerant Digital Systems. Massachusetts. Addison Wesley Publishing Company, 1989. p. 169-262.

KAZMIER, L. J. Estatística Aplicada à Economia e Administração. McGraw Hill do Brasil, 1982.

KIRK, D. B.; BOLCZAK, R. Initial Evaluation of URET Enhancements to Support TFM Flow Initiatives, Severe Weather Avoidance and CPDLC. The MITRE Corporation, McLean, VA, 2003.

KIRKMAN, W. Commercial Aviation Accidents Before and During the Alaska Capstone Implementation of ADS-B, FIS-B, Terrain Situation Awareness, and Expanded IFR Infraestructure. MITRE Corporation Center for Advanced Systems Development. Virginia, 2003.

KODO, T; NAGAOKA, S.; AMAI, O. Analisys of Prediction Error of an ADS.First Meeting of the Working Group of the Whole. Separation and Airspace Safety Panel (SASP). Camberra, Australia, May 2002.

KUCHAR, J. K.; YANG, L. C. A Review of Conflict Detection and Resolution Modeling Methods. IEEE Transactions on Intelligent Transportation Systems. Vol. 1, no. 4, December 2000.

MCNAlly, D.; ERZBERGER, H.; BACH, R.. A Controller Tool for Transition Airspace. NASA Amer Research Center. 1999.

MONDOLONI, S. Wind Error Modeling - Impact on CD\&R. DAG Workshop NASA. Mae 2000. 
MONDOLONI, S.; LIANG, D. Improve Trajectory Forecasting through Adaptative Filtering Techniques. 5th USA/Europe Air Traffic Management R\&D Seminar. Budapest, June 2003.

MONDOLONI, S.; PAGLIONE, M.; GREEN, S. Trajectory Modeling Accuracy for Air Traffic Management Decision Support Tools. ICAO Congress. 2002.

OGATA, P. H. Avaliação do Perigo de Colisão entre Aeronaves em Operação de Aproximação em Pistas de Aterrisagem Paralelas. Dissertação de Mestrado. Escola Politécnica. Universidade de São Paulo. São Paulo. 2003.

OLIVEIRA, I. R. Verificação de Segurança em Confluência de Trajetórias de Aeronaves Utilizando Autômatos Híbridos. Dissertação de Mestrado. Escola Politécnica. Universidade de São Paulo. São Paulo. 2003.

PALMER, E.; CRANE, B.; JOHNSON, N.; FEARY, M. Field Evaluation of Flight Deck Procedures for Flying CTAS Descents. 1997.

PRANDINI, M.; HU, J.; LYGEROS, J.; SASTRY, S. A Probabilistic Approach to Aircraft Conflict Detection. 2000

SCHILD, R.; KUCHAR, J. K. Operational efficiency of maneuver coordination rules for an airborne separation assurance system. 3rd USA/Europe Air Traffic Management R\&D Seminar. Napoli, June 2000.

SCHLEICHER, D. R.; JONES, E.D; DOW, D. Improved Lateral Trajectory Prediction through En Route Air-Ground Data Exchange. AIAA's Aircraft Technology, Integration, and Operations (ATIO). Los Angeles, October 2002.

TANENBAUM, A. S. Computer Networks 4th Edition. Prentice Hall. 2003

TOMLIN, C.; PAPPAS, G. J.; SASTRY, S. Conflict Resolution for Air Traffic Management: A Study in Multiagent Hybrid Systems. IEEE Transactions on Automatic Control, Vol. 43, no. 4, April 1998.

TRIBBLE, A. C. Software Safety. IEEE Software, v. 19, n. 4, p. 84-5, 2002. 
WARREN, A. Trajectory Prediction Concepts for Next Generation

Air Traffic Management. 3rd USA/Europe Air Traffic Management R\&D Seminar. Napoli, June 2000.

YANG, L. C.; KUCHAR, J. K. Prototype Conflict Alerting System for Free Flight. Journal of Guidance, Control and Dynamics. vol. 20, no. 4, July-August 1997.

YANG, L. C.; KUCHAR, J. K. Using Intent Information in Probabilistic Conflict Analysis. AIAA-98-4237. American Institute of Aeronautics and Astronomics, Inc. 1998.

Outras Referências utilizadas:

DEPV. Regras do Ar e Serviço de Tráfego Aéreo (IMA100-12). Ministério da Aeronáutica - Departamento de Eletrônica e Proteção ao Vôo, 1999.

GREENWELL, W. S. Learning Lessons from Accidentes and Incidents Involving SafetyCritical Software Systems, 77 p. - Master Thesis. Faculty of the School of Engineering and Applied Science. University of Virginia, 2003.

MUELleR, E. R.; CHATTERJI, G. B. Analysis of Aircraft Arrival and Departure Delay Characteristics. AIAA's Aircraft Technology, Integration, and Operations (ATIO). Los Angeles, October 2002.

NASA. En Route Descent Advisor (EDA) Build 3 System Specification. System Resources Corporation. December 2000.

NASA. En Route Descent Advisor (EDA) General Description. Titan System Corporation - SRC Division. January 2002.

PEPPER, J. W.; MILLS, K. R.; WOJCIK, L. A. Predictability and Uncertainty in Air Traffic Flow Management. 5th USA/Europe Air Traffic Management R\&D Seminar. Budapest, June 2003.

WATKINS, O.; LYGEROS, J. Stochastic Reachability for Discrete Time Systems: An Application to Aircraft Collision Avoidance. European Commission. 
WEIDNER, T. J. Capacity-Related Benefits of Proposed CNS/ATM Technologies. 2nd USA/Europe Air Traffic Management R\&D Seminar. Orlando, December 1998.

ZEITLIN, A. D. Safety Assessments of ADS-B and ASAS. 4th USA/Europe Air Traffic Management R\&D Seminar. Santa Fe, December 2001.

ZEITLIN, A. D.; BONNEMAISON, B. Managing Criticality of ASAS Applications. 3rd USA/Europe Air Traffic Management R\&D Seminar. Napoli, June 2000. 


\section{APÊNDICE A}

\section{CÓDIGO GERADO PARA A LIMPEZA E FILTRAGEM DOS DADOS}

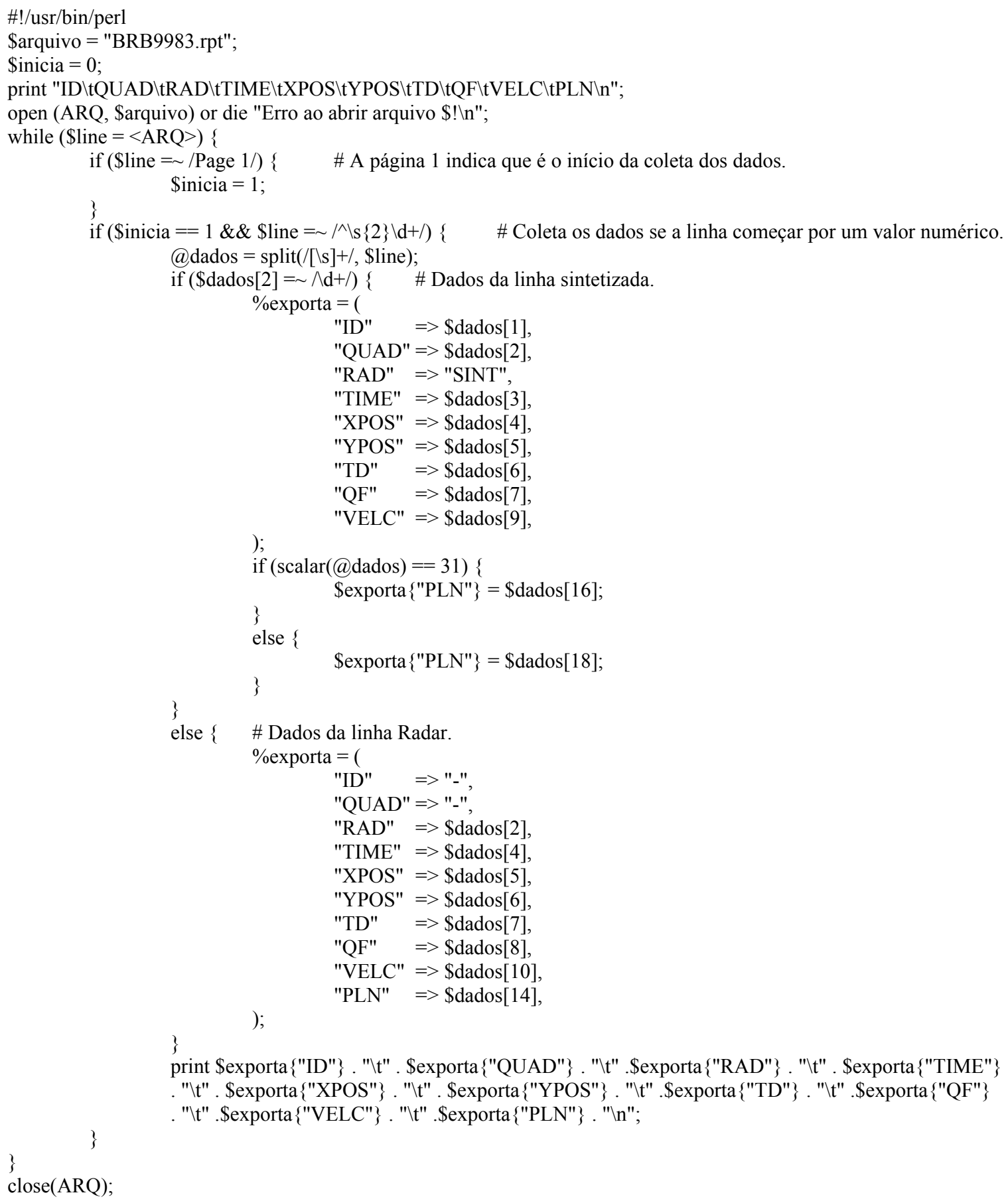




\section{APÊNDICE B}

\section{ALGORITMO DE PREVISÃo DE POSIÇÃO}

erro_longitudinal_min $=\min ($ vetor_erro_longitudinal);

$\%$ Calculo da distancia entre a posiçao real em t_pos e a posiçao projetada.

$\mathrm{i}=1$;

$\%$ Encontrando a posiçao real da aeronave para o instante previsto.

while $\mathrm{t} \_$todos $(\mathrm{i}) \sim=\mathrm{t} \_$pos

$$
\mathrm{i}=\mathrm{i}+1
$$

end;

xpos_real $=\operatorname{pos}(\mathrm{i}$, ind $\mathrm{x})$;

ypos_real $=$ pos $(\mathrm{i}$, ind_y $)$;

$\%$ Calculo do erro lateral, ou distancia entre a posiçao real e a reta que

$\%$ define a trajetoria extrapolada.

erro_lateral_real $=\left(\operatorname{trajetoria}(1) * x p o s \_r e a l-y p o s \_r e a l+\operatorname{trajetoria}(2)\right) / \operatorname{sqrt}\left(\operatorname{trajetoria}(1)^{\wedge} 2+1\right)$;

$\%$ Calculo do erro absoluto, ou distancia entre a posiçao prevista e a

$\%$ posiçao real.

erro_absoluto $=\operatorname{sqrt}\left((\text { xpos_real }- \text { xpos })^{\wedge} 2+(\text { ypos_real }- \text { ypos })^{\wedge} 2\right)$;

$\%$ Calculo do erro longitudinal.

erro_longitudinal $=\operatorname{sqrt}\left(\right.$ erro_absoluto ${ }^{\wedge} 2$ - erro_lateral_real $\left.{ }^{\wedge} 2\right)$;

$\%$ Preenchimento do vetor contendo as informaçoes relativas a posiçao

$\%$ prevista.

$\mathrm{v} \_$pos_prev $(1)=\mathrm{xpos}$;

v_pos_prev $(2)=$ ypos;

$\mathrm{v} \_$pos_prev $(3)=\mathrm{t} \_$pos;

v_pos_prev(4) = erro_lateral_real;

$\mathrm{v}$ _pos_prev $(5)=$ erro_longitudinal;

v_pos_prev(6) = erro_absoluto;

$\%$ Preenchimento do vetor contendo as informaçoes relativas aos erros

$\%$ laterais entre as posiçoes utilizadas na extrapolaçao e a funçao

$\%$ trajetoria projetada.

v_erro_lateral $(1)=$ erro_lateral_medio;

v_erro_lateral $(2)=$ erro_lateral_std;

v_erro_lateral $(3)=$ erro_lateral_max;

$\mathrm{v}$ - erro _lateral $(4)=$ erro lateral $\min$;

$\%$ Preenchimento do vetor contendo as informaçoes relativas aos erros $\%$ longitudinais entre as posiçoes utilizadas na extrapolaçao e a funçao $\%$ trajetoria projetada.

v_erro_longitudinal $(1)=$ erro_longitudinal_medio;

v_erro_longitudinal $(2)=$ erro_longitudinal_std;

v_erro_longitudinal $(3)=$ erro_longitudinal_max;

v_erro_longitudinal $(4)=$ erro_longitudinal_min;

$\%$ Preenchimento do vetor contendo as informaçoes relativas aos erros $\%$ absolutos entre as posiçoes utilizadas na extrapolaçao e a funçao

$\%$ trajetoria projetada.

V_erro_absoluto(1) = erro_absoluto_medio;

v_erro_absoluto(2) = erro_absoluto_std;

v_erro_absoluto (3) = erro_absoluto_max;

v_erro_absoluto(4) =erro_absoluto_min; 
$\%$ Grafico contendo os pontos conhecidos, a funçao trajetoria projetada e o

$\%$ ponto futuro projetado.

auxiliar(1) = floor $(\mathrm{x}(1))$;

$\operatorname{auxiliar}(2)=\operatorname{ceil}\left(\right.$ proj_x $\left(\mathrm{t} \_\right.$atual $+\mathrm{t}$ _futuro $\left.)\right)$;

auxiliar(3) $=$ xpos_real;

$\mathrm{xmin}=\min ($ auxiliar $)-5 ; \% \min \left(f \operatorname{loor}(\mathrm{x}(1))\right.$, ceil(proj_x(t_atual $+\mathrm{t} \_$futuro $\left.)\right), \mathrm{xpos}$ real $)-5$;

$\mathrm{xmax}=\max ($ auxiliar $)+5 ; \% \max \left(\right.$ floor $(\mathrm{x}(1))$, ceil $\left(\right.$ proj_x $\left(\mathrm{t} \_\right.$atual $+\mathrm{t} \_$futuro $\left.)\right), \mathrm{xpos}$-real $)+5$;

auxiliar $(1)=$ floor $(\mathrm{y}(1))$;

$\operatorname{auxiliar}(2)=\operatorname{ceil}\left(\right.$ proj_y $\left(\mathrm{t} \_\right.$atual $+\mathrm{t}$ _futuro $\left.)\right)$;

auxiliar(3) =ypos_real;

$\mathrm{ymin}=\min ($ auxiliar $)-5 ; \% \min \left(f l o o r(y(1)), \operatorname{ceil}\left(\operatorname{proj} \_\mathrm{y}\left(\mathrm{t} \_\right.\right.\right.$atual $+\mathrm{t} \_$futuro $\left.)\right), \mathrm{ypos}$ real $)-5$;

$\mathrm{ymax}=\max (\operatorname{auxiliar})+5 ; \% \max \left(\right.$ floor $(\mathrm{y}(1))$, ceil $\left(\right.$ proj_y(t_atual $+\overline{\mathrm{t}} \_$futuro $\left.\left.)\right), \mathrm{ypos}-\overline{r e a l}\right)+5$;

$\% \%$ subplot $(2,1,1)$, hist(erro_lateral, 25);

$\% \operatorname{subplot}(2,1,2)$, plot(x, y, '.', xpos, ypos, 'k*', xpos_real, ypos_real, 'r*', proj_x, proj_y, circx, circy), axis equal, axis $([\mathrm{xmin}$ xmax ymin ymax $])$;

$\% \%$ subplot $(2,1,2)$,

plot(x, y, '.', xpos_real, ypos_real, 'k*', xpos, ypos, 'r*', proj_x, proj_y, circx, circy), axis

equal, axis $([\mathrm{xmin} x \max y \min y \max ])$; 